\title{
THE BIOGEOCHEMISTRY OF MARINE PARTICULATE TRACE METALS
}

By

Daniel Chester Ohnemus

B.A., Williams College, 2004

Submitted in partial fulfillment of the requirements for the degree of

Doctor of Philosophy

at the

MASSACHUSETTS INSTITUTE OF TECHNOLOGY

and the

WOODS HOLE OCEANOGRAPHIC INSTITUTION

February 2014

(C) 2014 Daniel C. Ohnemus

All rights reserved.

The author hereby grants to MIT and WHOI permission to reproduce and to distribute publicly paper and electronic copies of this thesis document in whole or in part in any medium now known or hereafter created.

Signature of Author

Joint Program in Chemical Oceanography Massachusetts Institute of Technology and Woods Hole Oceanographic Institution

October 18, 2013

Certified by

Dr. Phoebe J. Lam

Thesis Supervisor

Accepted by

Dr. Elizabeth Kujawinski Chair, Joint Committee for Chemical Oceanography Massachusetts Institute of Technology/ Woods Hole Oceanographic Institution 


\title{
THE BIOGEOCHEMISTRY OF MARINE PARTICULATE TRACE METALS
}

By

\author{
Daniel Chester Ohnemus
}

Submitted to the MIT/WHOI Joint Program in Oceanography in partial fulfillment of the requirements for the degree of Doctor of Philosophy in the field of Chemical

Oceanography

\section{Thesis Abstract}

Marine particles include all living and non-living solid components of seawater, representing an extremely dynamic and chemically diverse mixture of phases. The distributions of these phases are poorly constrained and undersampled in the oceans, despite interactions between living organisms and non-living minerals having central roles within many globally relevant biogeochemical processes. Through a combination of method development, basin-scale particulate collection and analyses, modeling, and field experiments, this thesis examines both the distributions of marine particulate trace metals and the underlying processesinputs, scavenging, vertical and horizontal transport, and biotic uptake-in which marine particles participate.

I first present the results of an intercalibration exercise among several US laboratories that analyzed filtered particles on shared polyethersulfone filters. We use inter-lab and intra-lab total elemental recoveries of these particles to determine our state of our intercalibration $(\leq 21 \%$ one-sigma inter-lab uncertainty for most elements; $\leq 9 \%$ intra-lab) and to identify means of future improvement. We also present a new chemical method for complete dissolution of polyethersulfone filters and compare it to other total particle digestion procedures. I then present the marine particulate distributions of the lithogenic elements $\mathrm{Al}, \mathrm{Fe}$, and $\mathrm{Ti}$ in the North Atlantic GEOTRACES section. Inputs of lithogenic particles from African dust sources, hydrothermal systems, benthic nepheloid layers and laterally-sourced margin influences are observed and discussed. Lithogenic particle residence times, size-fractionation patterns, Ti-mineral speciation, and relationships to biological aggregation processes are calculated and described. A one-dimensional, sizefractionated, multi-box model that describes lithogenic particle distributions is also proposed and its parameter sensitivities and potential implications are discussed.

The thesis concludes with the presentation of results from a series of bottle incubations in naturally iron-limited waters using isotopically labeled Fe-minerals. We demonstrate both biotic and abiotic solubilization of the minerals ferrihydrite and fayalite via transfer of isotopic label into suspended particles. These results are the first of their kind to demonstrate that minerals can be a source of bioavailable iron to euphotic communities and that spatial and ecological variations in mineral Fe-bioavailability may exist.

Thesis supervisor: Phoebe J. Lam Title: Associate Scientist 


\section{Acknowledgements}

Although this thesis has my name on it, every page bears the watermark of my brilliant and ever thoughtful advisor, Phoebe (J.) Lam. Thank you so much for providing me with exciting projects, invigorating afternoon data conversations, prompt and thoughtful written feedback, and what I'm sure was a lifetime's worth of patience over the years. Together we've travelled to the bottom of the world, sampled oceans, and spent nights by the hum of a synchrotron; it's hard to imagine doing research without your insight.

Thanks also to my illustrious thesis committee: Ed Boyle, Colleen Hansel, Mak Saito, and Adam Kustka. Your advisorship and feedback were invaluable to keeping my goals in sight.

Woods Hole is an incredible place to live and WHOI is an amazing place to work. I thank every friend, colleague and institution employee who's helped guide my way and shaped my graduate school experiences. My good friends and roommates Abby Heithoff, Michael Toomey, and Liz Bonk made coming home from aborted cruises or long nights combating matrix effects in the Plasma Facility something extra special. I will always look fondly on my years sharing a home with you and my stupid cats. The nearly innumerable (but I'll try!) cast of friendcolleagues I was blessed to share my time here with: Meredith White, Abigail Noble, Jeff Kaeli, Erin Bertrand, Britta Voss, Carly Buchwald, Daniel Quinn, James Saenz, Stephanie Morris, Wilken von Appen, Whitney Bernstein, Julian Schanze, Jill McDermott, Ben Linhoff, Paul Morris, Elise Olson, Alison Laferriere, Tyler Goepfert, Kim Popendorf, Travis Meador, Alec Bogdanoff, Taylor Crockford, Ali Wing, Dan Chavas, Morgan O’Neill, Mike Sori, Neil Zimmerman, Malte Jansen, Rene Boiteau, Skylar Bayer, Maya Yamato, Ann Allen, Eoghan Reeves, Meagan Gonneea, Dreux Chappell, the GANG and the entire "Upper East Side" of Woods Hole. Thank you all so much just for being you. Kyle: MWAH.

Being a part of WHOI Chemistry teams over the years, both with Justin "Coachski" Ossolinski and Steve Pike at the helm, has been unbelievably rewarding for me. Phil Gschwend taught many MIT/WHOI students how hydrophobic organic molecules partition in sediments; he taught me to keep my rear foot planted while batting (and how to chat up an opponent). Thank you all for so many cherished memories. Nine year-old Dan 0. still can't believe I've managed to hit a grand slam. Against WHOI Biology. And now it's published forever.

Funding was provided by the Williams College Tyng Fellowship, the MIT/WHOI Academic Programs Office, the International and US GEOTRACES Offices, and U.S. National Science Foundation (NSF) \#0960880 and \#0963026 and PLR \#0838921 to P.J. Lam.

The captains, crews, and dock-side teams of all the research vessels and institutions involved in sample collection deserve special acknowledgement. I've been lucky enough to call the $R / V$ Revelle, $R / V$ Knorr, and RVIB Nathanial B. Palmer home for many weeks at a time and amidst demanding sampling schedules and conditions we always got our casts in. Those pumps certainly don't deploy and recover themselves! Thank you greatly for all your hard work. 
Maureen Auro: thank you so much for your friendship and help in both lab and life over the years; this would've been impossible without you. Scot

Birdwhistell: every number in this thesis is the direct result of your efforts; keep the torches burning, and thank you!

Finally, I thank my parents, my siblings, and my family. Your love and support mean the world to me. 
"This I do know beyond any reasonable doubt. Regardless of what you are doing, if you pump long enough, hard enough and enthusiastically enough, sooner or later the effort will bring forth the reward."

\section{-Zig Ziglar}




\section{TABLE OF CONTENTS}

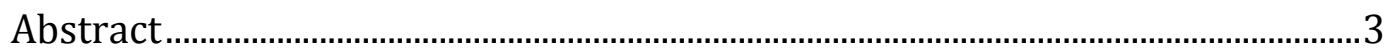

Acknowledgements........................................................................................................4

Table of Contents ............................................................................................................

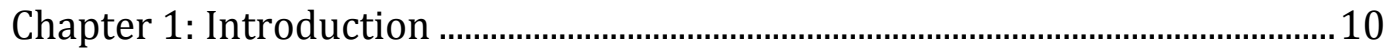

1.1 Preface .....................................................................................................

1.2 Marine Particles: What Are They and Why Examine Them .............10

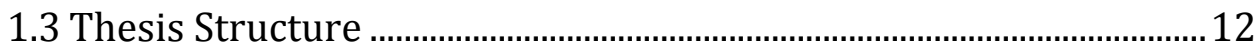

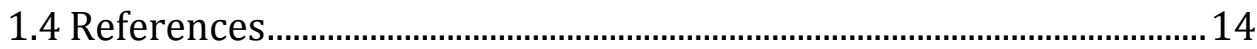

Chapter 2: Piranha: a chemical method for dissolution of polyethersulfone

filters and laboratory inter-comparison of marine particulate digests...........17

2.1 Acknowledgements....................................................................................18

2.2 Abstract....................................................................................................... 19

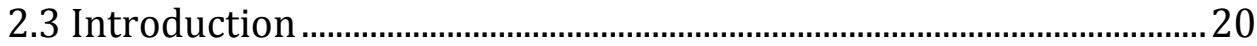

2.4 Materials and Procedures ...............................................................................2.

2.4.1 Reagents and equipment.......................................................21

2.4.2 Particulate samples used in intercomparison .....................22

2.4.3 Intercomparison sample distribution ....................................24

2.4.4 Procedures …………………………………………………..... 25

2.4.5 ICP-MS Analyses ........................................................................

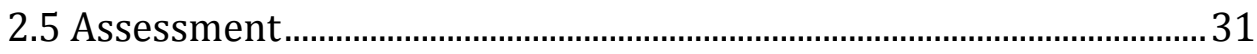

2.5.1 Certified reference materials ...................................................31

2.5.2 Subsample variability (intra-lab comparison) .....................32

2.5.3 Digest and filter blank intercomparison ................................33

2.5.4 Sample results and general trends .........................................34

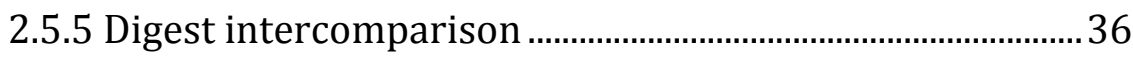

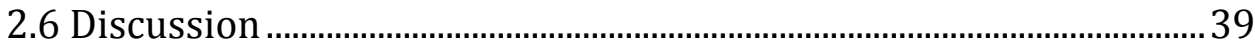

2.7 Comments and recommendations .......................................................... 40 
2.7.2 Variations on piranha .................................................................. 41

2.8 References .................................................................................................... 43

2.9 Figures and figure legends...................................................................... 44

2.10 Tables and table legends..................................................................... 53

Chapter 3: Cycling of Lithogenic Marine Particulates in the US GEOTRACES North Atlantic Zonal Transect.....................................................................................64

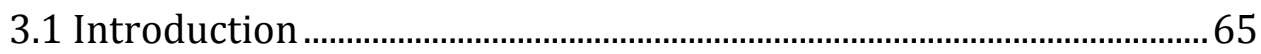

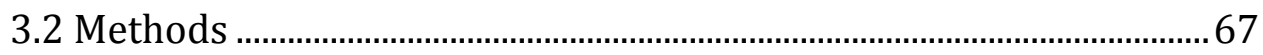

3.2.1 Study Region............................................................................ 67

3.2.2 Particulate Sampling ................................................................67

3.2.3 Analytical Techniques ............................................................... 69

3.2.4 Synchrotron X-ray Methods.....................................................69

3.2.4 A Note On Units and Plotting Conventions.............................70

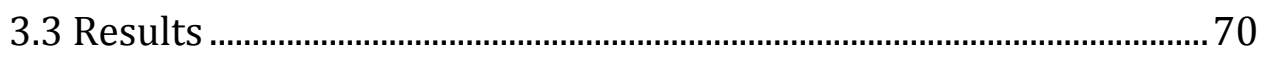

3.3.1 Dataset At A Glance: Elemental Correlations ........................70

3.3.2 General Oceanic Distribution of Lithogenic Particles.......72

3.4 Discussion ................................................................................................. 74

3.4.1 Bulk Input Composition Ratios ……………………………...... 74

3.4.2 Benthic Nepheloid Layers............................................................ 76

3.4.3 Unique Ti Mineralogy Near Cape Verde …………………......79

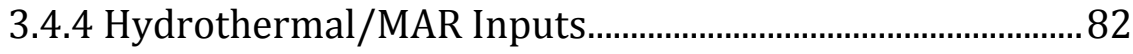

3.4.5 Evidence for Scavenging........................................................... 83

3.4.6 Lithogenic Normalization ........................................................ 83

3.4.7 Aeolian and Lateral Lithogenic Inputs ...................................84

3.4.8 Lithogenic Residence Times ........................................................ 86

3.4.9 Lithogenic Particle Cycling 1-D Model: Context.................89

3.4.10 Lithogenic Particle Cycling 1-D Model: Description.......92

3.4.11 Lithogenic Particle Cycling 1-D Model: Results................93

3.4.12 Applications of inter particle model to other particle 
types. 98

3.5 Conclusions 99

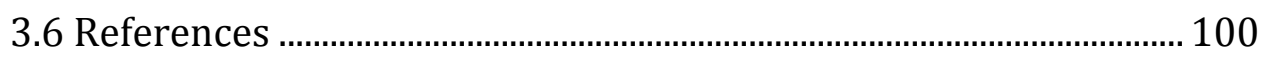

3.7 Figures and figure legends...................................................................... 106

3.8 Tables and table legends .................................................................. 127

Chapter 4: Bioavailability of Synthetic ${ }^{57} \mathrm{Fe}-$ Minerals to HNLC Surface Seawater

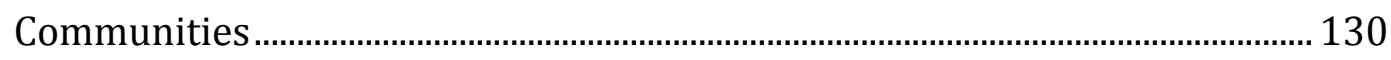

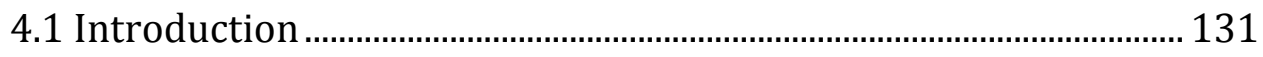

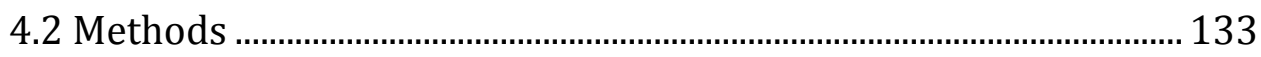

4.2.1 Mineral Synthesis ................................................................. 133

4.2.2 Slide Preparation ..................................................................... 135

4.2.3 Marine Particulate Sample Collection ................................... 136

4.2.4 Incubation Source Waters ..................................................... 137

4.2.5 Incubation Design .................................................................... 137

4.2.6 Nutrient and Chlorophyll Analyses ........................................ 139

4.2.7 Particulate Leaches, Digests, and Analyses........................ 139

4.3 Results ................................................................................................... 141

4.3.1 Water Column Particulates at Incubation Sites ............... 142

4.3.1.1 Particulate Fe Distributions ................................... 142

4.3.1.2 Particulate P Distributions...................................... 144

4.3.2 Time-Course Bottle Experiments ......................................... 144

4.3.3 Small Volume Incubation Results.......................................... 146

4.3.3.1 Abiotic ${ }^{57} \mathrm{Fe}-$ Transfer Experiments ...................... 146

4.3.3.2 Biotic Experimental Results .................................. 148

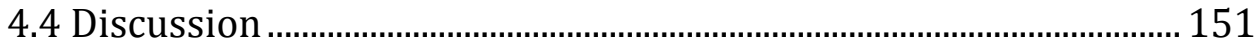

4.5 References ........................................................................................... 156

4.6 Figures and figure legends................................................................. 161

4.7 Tables and table legends ................................................................... 176

Chapter 5: Conclusions...................................................................................... 178 


\section{Chapter 1: Introduction}

\subsection{Preface}

From an analytical perspective, this thesis is centered around concentration measurements of filtered marine particulate matter in seawater: in short, how much of particulate element $\mathrm{X}$ is present in seawater at location and time $\mathrm{Y}$ or under condition Z? My three data chapters use these measurements to address, in order: 1) How well do we perform analytical particulate digests? 2) How are marine particulates distributed across and within the North Atlantic, and can we explain them? 3) Are mineral forms of particulate iron, an important micronutrient, at all accessible to biotic communities? But let's step back for a moment: why were these measurements performed in the first place, and why are oceanic particles the focus of scientific investigation at all?

\subsection{Marine Particles: What Are They and Why Examine Them?}

From a chemical perspective, the particles present in the ocean at any given time and location can be conceptually split into two pools: particles deriving from living (or recently living) organisms, and non-living or abiotic material. Each pool can be further sub-divided. Biotic particles can be separated via various chemical techniques into different major phases based on marine organisms' dominant compositions: those that form skeletons of biogenic silica (bSi) or calcium carbonate $\left(\mathrm{CaCO}_{3}\right.$ or particulate inorganic carbon: PIC), and soft-tissue organisms and biotic exudates (particulate organic carbon: POC) (Francois et al., 2002). The abiotic pool of particles can be subdivided into minerals of various size and origin, either sourced from entirely outside the ocean ("exogenous" lithogenic or crustallyderived dust and resuspended sedimentary particles) and minerals formed within seawater itself (in situ-formed authigenic minerals) (Chester, 2009 and refs. therein). These pools undergo constant interaction, both physically and chemically, to form and un-form small and large assemblages, marine snow aggregates, biofilms, fecal pellets, multicellular colonies, and innumerable other micro- and macroenvironments that are the habitats and environs of living things. 
Marine particulates thus include nearly all organisms (unicellular bacterial and eukaryotes, multicellular colonies and animals) that live, grow and die in the oceans, along with nearly all the non-living solid materials (dust, sediments, other minerals and aggregates) that naturally cycle through marine environments. These particulates influence and control global biogeochemical cycles through biological production, vertical export and in situ alteration processes. A pressing question facing oceanographers and earth scientists at the current time is understanding how carbon dioxide-a rapidly accumulating anthropogenic greenhouse gas-is removed by the planet's biosphere. As $40 \%$ of the planetary primary production is by the marine biosphere (Boyd et al., 2007; Martin et al., 1994), understanding the major controls over marine primary production, carbon export, and recycling-the ocean's biological pump-is an integral part in describing how the biosphere operates presently, how it has in the past (Sarmiento and Toggweiler, 1984), and how it will in the future (Bernstein et al., 2008).

One of the key controls of marine primary productivity is iron, which is a limiting micronutrient for phytoplankton growth in vast regions of the world oceans (Boyd et al., 2007; Jickells, 2005; Mahowald et al., 2009; Martin, 1988). Total iron in the ocean is often strongly partitioned to the particulate phase due to its poor solubility in seawater. Iron has been a central focus for marine biogeochemical studies since the 1980s. Measurements of dissolved iron (dFe) have been collected as parts of global ocean surveys (JGOFS, CLIVAR, and now GEOTRACES) and numerous regional (Blain et al., 2008; Planquette et al., 2007) and transect studies (de Jong et al., 2012; Fitzsimmons et al., 2013) for many years, and have informed our current scientific understanding of this element as an increasingly complex one controlled by variable inputs (Lam and Bishop, 2008; Mahowald et al., 2009), ligands (Buck, 2012), light effects (Strzepek et al., 2012) and organic/biotic interactions (Rose and Waite, 2003; Shaked and Kustka, 2005). Even so, recent compilations of dissolved Fe measurements (Moore and Braucher, 2007; Tagliabue et al., 2012) are quick to note the large spatial and temporal gaps in dissolved datasets and thus, perhaps also, our understanding of iron cycling itself. 
Particulate iron measurements are even more sparsely distributed-no global compilations are even available-despite growing evidence that aeolian (Achterberg et al., 2013; Mahowald et al., 2009), and lateral/benthic iron sources (Hatta et al., 2013; e.g. Lam and Bishop, 2008; Planquette et al., 2009) frequently invoked as controlling $\mathrm{dFe}$ distributions and driving regional primary productivity, are often also associated with strong or dominant particulate Fe signals as well. The US GEOTRACES program offered an opportunity to examine large-scale particulate distributions in a manner not probed since the GEOSECS program (Brewer et al., 1976) and particle-focused nepheloid layer programs of the 1970s and 1980s (Biscaye and Eittreim, 1977; Gardner et al., 1983). The method development and size-fractionated particle dataset that emerged from the US GEOTRACES N. Atlantic project are the focus of my first two data chapters and represent a significant expansion of available water column iron data, among other particulate elements. The bioavailability of mineral particulate Fe is examined using bottle incubations with synthetic Fe-minerals in my third data chapter.

\subsection{Thesis Structure}

The data chapters of this thesis examine a range of questions relevant to particulate metal analyses, distributions, and both biotic and abiotic marine processes. Chapter two, an intercalibration and methods paper prepared for submission to the journal Limnology and Oceanography Methods, quantifies how several US laboratories participating in the US GEOTRACES program, including our own, performed when analyzing the same set of filtered particulate samples. This paper also serves to introduce a filter digestion procedure I developed-the socalled "Piranha method" after the primary reagent used-that completely solubilizes the otherwise refractory filter membrane (polyethersulfone, PES; or Supor-brand) used for trace metal particle collection on the US GEOTRACES cruises.

Chapter three presents and models our particulate trace metal results from the US GEOTRACES North Atlantic Zonal Transect (GTNAZT) that were analyzed using the methodologies outlined in chapter two. The bulk of this chapter focuses on three of the eighteen elements collected: the particulate lithogenic tracer 
elements $\mathrm{Al}, \mathrm{Fe}$, and $\mathrm{Ti}$. This dataset is the first of its kind in that it presents full ocean depth trace metal particulate data for an entire ocean basin zonal transect at a depth and spatial resolution great enough to observe surface, lateral, hydrothermal, and benthic distributions of refractory lithogenic material simultaneously. Our examination of lithogenic elements (and their ratios) in an oceanographic section allows for determination of regions of various input dominance (African dust, hydrothermal particles, benthic nepheloid layers, and biogenic inputs), as well as lithogenic particulate residence times within several depth ranges, which we calculate using lithogenic inventories and external aeolian input fluxes in the open ocean. We use synchrotron-based x-ray fluorescence (XRF) mapping to visualize fine aeolian lithogenic particles within large $(>51 \mu \mathrm{m})$ biogenic aggregates to explore why the surface mixed layer, but not the deep chlorophyll max, has elevated lithogenic metal abundances. We also use synchrotron x-ray near-edge spectroscopy (XANES) to compare and contrast the mineral speciation of particulate titanium (pTi) in fine particles from aeolian dust, the African margin, and near Cape Verde.

Chapter three also exploits the observations that pTi is essentially inertespecially compared to bioactive elements (e.g. carbon) but even compared to lithogenic tracers $\mathrm{Al}$ and $\mathrm{Fe}$-and is entirely sourced from fine aeolian dust inputs into the surface ocean in regions away from lateral influence from the margin. The vertical profiles and size-fractionation of pTi in the open ocean should thus be explained by a) dust input variations and b) vertical particle sinking rates, which in turn are driven by c) depth-dependent biotic aggregation and disaggregation between small (slowly sinking) and large (fast-sinking) particle size fractions. I develop and explore a 1-D lithogenic particle model that demonstrates these results and explores sensitivities to various particulate parameters, furthermore suggesting that abiotic particles not only demonstrate the effects of lithogenic inputs and alteration processes, but may explain facets of biotically-driven processes as well.

Chapter four directly examines the bioavailability of mineral particulate iron to iron-limited biotic surface communities. We prepared synthetic minerals using a naturally minor and stable isotope of iron $\left({ }^{57} \mathrm{Fe}\right)$, immobilized them on acrylic slides, 
and incubated them in whole surface seawater from iron limited regions for 12-13d, looking for transfer of ${ }^{57} \mathrm{Fe}$ signal from the mineral phase into suspended (biotic and abiotic) particles. We examine the trends in ${ }^{57} \mathrm{Fe}$-transfer between a) the minerals ferrihydrite (an $\mathrm{Fe}^{3+}$-oxyhydroxide) and fayalite (an $\mathrm{Fe}^{2+}$-silicate); b) abiotic (Hgpoisoned) and live-incubation (whole seawater) bottles; and c) marine communities from a coastal (high Fe) and an open ocean (low Fe) environment. Our results suggest evidence for surprisingly similar magnitudes of abiotic, light-dependent Fetransfer from both minerals, despite differences in crystallinity; notable biotic chlorophyll responses to both minerals in the island-influenced incubation, but only ferrihydrite in the open ocean incubation); and physiologically relevant ${ }^{57} \mathrm{Fe}: \mathrm{P}$ uptake ratios in the island-influenced incubation. These results suggest a more direct biological role for refractory mineral pFe sources than traditionally considered.

\section{References}

Achterberg, E. P., Mark Moore, C., Henson, S. A., Steigenberger, S., Stohl, A., Eckhardt, S., Avendano, L. C., Cassidy, M., Hembury, D. and Klar, J. K.: Natural iron fertilization by the Eyjafjallajökull volcanic eruption, Geophysical Research Letters, doi:10.1002/grl.50221, 2013.

Bernstein, L., Bosch, P., Canziani, O., Chen, Z., Christ, R., Davidson, O., Hare, W., Huq, S., Karoly, D. and Kattsov, V.: Climate Change 2007: Synthesis Report: An Assessment of the Intergovernmental Panel on Climate Change,, 2008.

Biscaye, P. E. and Eittreim, S. L.: Suspended particulate loads and transports in the nepheloid layer of the abyssal Atlantic Ocean, Marine Geology, 23(1), 155-172, 1977.

Blain, S., Sarthou, G. and Laan, P.: Distribution of dissolved iron during the natural iron-fertilization experiment KEOPS (Kerguelen Plateau, Southern Ocean), Deep Sea Research Part II: Topical Studies in Oceanography, 55(5-7), 594-605, doi:10.1016/j.dsr2.2007.12.028, 2008.

Boyd, P. W., Jickells, T., Law, C. S., Blain, S., Boyle, E. A., Buesseler, K. O., Coale, K. H., Cullen, J. J., de Baar, H. J. W., Follows, M., Harvey, M., Lancelot, C., Levasseur, M., Owens, N. P. J., Pollard, R., Rivkin, R. B., Sarmiento, J., Schoemann, V., Smetacek, V., Takeda, S., Tsuda, A., Turner, S. and Watson, A. J.: Mesoscale Iron Enrichment Experiments 1993-2005: Synthesis and Future Directions, Science, 315(5812), 612617, doi:10.1126/science.1131669, 2007. 
Brewer, P. G., Spencer, D. W., Biscaye, P. E., Hanley, A., Sachs, P. L., Smith, C. L., Kadar, S. and Fredericks, J.: The distribution of particulate matter in the Atlantic Ocean, Earth and Planetary Science Letters, 32(2), 393-402, 1976.

Buck, M. G. A. K. N.: The organic complexation of iron in the marine environment: a review, 1-17, doi:10.3389/fmicb.2012.00069/abstract, 2012.

Chester, R.: Marine geochemistry. 2009.

de Jong, J., Schoemann, V., Lannuzel, D., Croot, P., de Baar, H. and Tison, J.-L.: Natural iron fertilization of the Atlantic sector of the Southern Ocean by continental shelf sources of the Antarctic Peninsula, J. Geophys. Res, 117(G1), doi:10.1029/2011JG001679, 2012.

Fitzsimmons, J. N., Zhang, R. and Boyle, E. A.: Marine Chemistry, Marine Chemistry, 154(C), 87-99, doi:10.1016/j.marchem.2013.05.009, 2013.

Francois, R., Honjo, S., Krishfield, R. and Manganini, S.: Factors controlling the flux of organic carbon to the bathypelagic zone of the ocean, Global Biogeochem. Cycles, 16(4), 34-1-34-20, doi:10.1029/2001GB001722, 2002.

Gardner, W. D., Richardson, M. J., Hinga, K. R. and Biscaye, P. E.: Resuspension measured with sediment traps in a high-energy environment, Earth and Planetary Science Letters, 66, 262-278, 1983.

Hatta, M., Measures, C. I., Selph, K. E., Zhou, M. and Hiscock, W. T.: Iron fluxes from the shelf regions near the South Shetland Islands in the Drake Passage during the austral-winter 2006, Deep-Sea Research Part II, 90(C), 89-101, doi:10.1016/j.dsr2.2012.11.003, 2013.

Jickells, T. D.: Global Iron Connections Between Desert Dust, Ocean Biogeochemistry, and Climate, Science, 308(5718), 67-71, doi:10.1126/science.1105959, 2005.

Lam, P. J. and Bishop, J. K. B.: The continental margin is a key source of iron to the HNLC North Pacific Ocean, Geophys. Res. Lett, 35(7), doi:10.1029/2008GL033294, 2008.

Mahowald, N. M., Engelstaedter, S., Luo, C., Sealy, A., Artaxo, P., Benitez-Nelson, C., Bonnet, S., Chen, Y., Chuang, P. Y., Cohen, D. D., Dulac, F., Herut, B., Johansen, A. M., Kubilay, N., Losno, R., Maenhaut, W., Paytan, A., Prospero, J. M., Shank, L. M. and Siefert, R. L.: Atmospheric Iron Deposition: Global Distribution, Variability, and Human Perturbations*, Annu. Rev. Marine. Sci., 1(1), 245-278, doi:10.1146/annurev.marine.010908.163727, 2009.

Martin, J.: Iron deficiency limits phytoplankton growth in the north-east Pacific subarctic,, 1988. 
Martin, J. H., Coale, K. H., Johnson, K. S., Fitzwater, S. E., Gordon, R. M., Tanner, S. J., Hunter, C. N., Elrod, V. A., Nowicki, J. L., Coley, T. L., Barber, R. T., Lindley, S., Watson, A. J., Van Scoy, K., Law, C. S., Liddicoat, M. I., Ling, R., Stanton, T., Stockel, J., Collins, C., Anderson, A., BIDIGARE, R., Ondrusek, M., Latasa, M., Millero, F. J., Lee, K., Yao, W., Zhang, J. Z., Friederich, G., Sakamoto, C., Chavez, F., Buck, K., Kolber, Z., Greene, R., Falkowski, P., Chisholm, S. W., Hoge, F., Swift, R., Yungel, J., Turner, S., Nightingale, P., Hatton, A., Liss, P. and Tindale, N. W.: Testing the iron hypothesis in ecosystems of the equatorial Pacific Ocean, Nature, 371(6493), 123-129, doi:10.1038/371123a0, 1994.

Moore, J. K. and Braucher, 0.: Observations of dissolved iron concentrations in the World Ocean: implications and constraints for ocean biogeochemical models, Biogeosciences Discuss., 4(2), 1241-1277, 2007.

Planquette, H., Fones, G. R., Statham, P. J. and Morris, P. J.: Origin of iron and aluminium in large particles $(>53 \mu \mathrm{m})$ in the Crozet region, Southern Ocean, Marine Chemistry, 115(1-2), 31-42, doi:10.1016/j.marchem.2009.06.002, 2009.

Planquette, H., Statham, P. J., Fones, G. R., Charette, M. A., Moore, C. M., Salter, I., Nédélec, F. H., Taylor, S. L., French, M., Baker, A. R., Mahowald, N. and Jickells, T. D.: Dissolved iron in the vicinity of the Crozet Islands, Southern Ocean, Deep Sea Research Part II: Topical Studies in Oceanography, 54(18-20), 1999-2019, doi:10.1016/j.dsr2.2007.06.019, 2007.

Rose, A. L. and Waite, T. D.: Kinetics of iron complexation by dissolved natural organic matter in coastal waters, Marine Chemistry, 84(1), 85-103, doi:10.1016/S0304-4203(03)00113-0, 2003.

Sarmiento, J. L. and Toggweiler, J. R.: A new model for the role of the oceans in determining atmospheric pCO 2, Nature, 308(5960), 621-624, 1984.

Shaked, Y. and Kustka, A.: A general kinetic model for iron acquisition by eukaryotic phytoplankton, Limnology and Oceanography, 2005.

Strzepek, R. F., Hunter, K. A., Frew, R. D., Harrison, P. J. and Boyd, P. W.: Iron-light interactions differ in Southern Ocean phytoplankton, Limnology and Oceanography, 57(4), 1182-1200, doi:10.4319/lo.2012.57.4.1182, 2012.

Tagliabue, A., Mtshali, T., Aumont, O., Bowie, A. R., Klunder, M. B., Roychoudhury, A. N. and Swart, S.: A global compilation of dissolved iron measurements: focus on distributions and processes in the Southern Ocean, Biogeosciences, 9(6), 23332349, doi:10.5194/bg-9-2333-2012, 2012. 
Chapter 2: Piranha: a chemical method for dissolution of polyethersulfone filters and laboratory inter-comparison of marine particulate digests

IN PREP FOR JOURNAL: Limnology and Oceanography: Methods

Daniel C. Ohnemus ${ }^{1,2 *}$, Robert M. Sherrell ${ }^{3,4}$, Maria Lagerstöm ${ }^{3}$, Peter L. Morton5, Benjamin S. Twining 6 , Sara M. Rauschenberg', Maureen E. Auro², Phoebe J. Lam²

${ }^{1}$ MIT-WHOI Joint Program in Oceanography, Massachusetts Institute of Technology/Woods Hole Oceanographic Institution, Woods Hole, MA 02543, USA ${ }^{2}$ Department of Marine Chemistry and Geochemistry, Woods Hole Oceanographic Institution, Woods Hole, MA 02543, USA

${ }^{3}$ Institute of Marine and Coastal Sciences, Rutgers University, New Brunswick, NJ 08904, USA

${ }^{4}$ Department of Earth and Planetary Sciences, Rutgers University, Piscataway, NJ 08854, USA

${ }^{5}$ Department of Earth, Ocean and Atmospheric Sciences, Florida State University, Tallahassee, FL 32306, USA

${ }^{6}$ Bigelow Laboratory for Ocean Sciences, East Boothbay, ME 04544, USA

*Corresponding author. Email: dan@whoi.edu

Running head: PIRANHA DIGEST AND PARTICLE INTERCOMPARISON 


\section{Acknowledgements}

We thank Captain Chris Curl and the crew of the $R / V$ Melville, who provided outstanding leadership and shipboard assistance during the Great Calcite Belt-I cruise, along with Chief Scientist Barney Balch. Sample collection was assisted by Steven Pike and analyses were assisted by Scot Birdwhistell at WHOI, and Michael Bizimis (U. South Carolina) for digestion method development at FSU. Funding was provided by U.S. National Science Foundation (NSF) \#0961660 and \#0928289 to B. Twining, NSF \#0648353 and \#0838995 to R.M. Sherrell; NSF \#0960880 and \#0963026 to P.J. Lam; and WHOI Academic Programs Office Graduate Fellowship and Williams College Tyng Fellowship assistance to D. Ohnemus. 


\section{Abstract}

The US GEOTRACES program will generate marine particulate trace metal data over spatial scales and depth resolutions never before sampled. In preparation for these analyses, we conducted a four laboratory intercomparison exercise to determine our degree of intercalibration and to examine how several total digestion procedures perform on marine particles collected on polyethersulfone (PES, Pall Supor $^{\mathrm{TM}}$ ) filters. In addition, we present a new chemical method for complete dissolution of PES filters using a combination of sulfuric acid and hydrogen peroxide (piranha reagent) that can be conducted using minimal specialized equipment. Intra-laboratory subsampling variability (RSD: $1 \sigma / \overline{\mathrm{x}}, \%$ ) for $\sim 10 \mathrm{~L}$ seawaterequivalent filtered particulate samples was measured at an element-dependent 19\%, while inter-laboratory variability accounted for an additional 5-42\% variability. Lab- and element-specific trends in recoveries are discussed, though all digestion methods tested appear to completely solubilize particulate material. We recommend rigorous determination of digest and filter process blanks, as some particulate elements (namely $\mathrm{Pb}$ and $\mathrm{Zn}$ ) have natural abundances that approach these values. 


\section{Introduction}

Polyethersulfone (PES) membrane filters are an increasingly common choice for marine particulate collection due to their low blanks, high volume throughput, and relative ease of handling (Planquette and Sherrell 2012) (Bishop et al. 2012). As a result of these properties, PES filters (specifically Supor ${ }^{\mathrm{TM}}$, Pall Corporation) were chosen as the primary collection membrane for many particulate trace elements and isotopes (pTEI) as part of US participation in the international GEOTRACES program. The chemical resistance that gives PES filters their durability and ease of handling, however, can present analytical difficulties when total filter digestion and/or complete recovery of filtered material are desired. Standard mineral acid-based total digestion procedures (various mixtures of $\mathrm{HCl} / \mathrm{HF} / \mathrm{HNO}_{3}$ ) \{Eggimann:1976tk\} conducted in temperature ranges compatible with PFA vials $\left(<260^{\circ} \mathrm{C}\right)$ only partially depolymerize and deform or fragment the PES matrix. The resulting solutions can be challenging to process further or analyze, not only because of the presence of solids in the digest solution that can clog the introduction systems of analytical instruments, but also because soluble PES organic polymers or mono/oligomers complicate the sample matrix to varying degrees depending on sample and may precipitate at later procedural steps.

Total dissolution of PES filters can be accomplished through the use of highpressure/high-temperature microwave digestion systems (e.g., Anton Paar Multiwave 3000, L.F. Robinson, pers. comm.) or high pressure ashers (T.J. Horner, pers. comm.), though these systems are costly, have low sample throughput, and may lose volatile elements such as Cd. Perchloric acid fully dissolves the PES matrix at atmospheric pressure and typical hot plate temperatures (Anderson et al. 2012), but requires special handling and fume hoods with wash-down capabilities that are unavailable or undesirable to many labs. In order to fully digest and efficiently process the large number of particulate samples collected during US segments of the international GEOTRACES program, we sought a chemical method that could both dissolve the PES matrix and be scaled to allow high throughput sample processing.

Piranha solution-typically a 3:1 v/v mixture of concentrated sulfuric acid and hydrogen peroxide-is a strong oxidizing agent typically used to clean organics 
from substrates such as silicon wafers and laboratory glassware \{Yang:1975tq\}. We describe a procedure that utilizes piranha solution to dissolve the PES matrix. The procedure can be conducted entirely in PFA vials on a hotplate, allowing the digestion to be conducted cleanly and with minimal specialized equipment. When followed by a more traditional high temperature, mineral acid total digest, both the PES matrix and filtered particulate material are completely solubilized, and a uniform sample matrix is generated that is appropriate for further chemical processing or direct analysis.

We compare the piranha digestion method to several other digestion methods used by US laboratories that are measuring total marine particulate trace element concentrations in association with the US GEOTRACES program. Replicate subsamples of marine particles collected on Supor filters were distributed to each lab (Labs 1-4) in order to assess the comparability of each lab's "typical" digestion and analytical methods. Our goals were to determine the intercomparability of our procedures and to quantify our degree of intercalibration in the digestion of marine particles collected on PES filters. We were specifically interested in determining: 1) the general state of our intercalibration, considering both natural heterogeneity of particulate samples and our different digestion procedures; 2) whether the piranha digest, which was in development alongside the intercomparison exercise, accesses any additional particulate material that could be occluded or adsorbed by residulal filter material during procedures that do not fully dissolve PES filters; 3 ) if complete filter dissolution from the piranha digest is associated with increases in filter blanks.

\section{Materials and procedures}

\section{Reagents and equipment}

All reagents, including sulfuric acid, were Optima-grade (Fisher) unless otherwise mentioned. Supor® PES filters (Supor800, $142 \mathrm{~mm}$ diameter, $0.8 \mu \mathrm{m}$ pore size; Pall) were cleaned prior to use by immersion in $60^{\circ} \mathrm{C} 1.2 \mathrm{M}$ trace metalgrade hydrochloric $(\mathrm{HCl})$ acid (Fisher) for $12 \mathrm{hr}$, then rinsed by immersion in ultrapure water ( $>18.2 \mathrm{M} \Omega \bullet \mathrm{cm}$ Milli-Q water; EMD Millipore) that was changed 
frequently until the rinse water was no longer acidic (Committee 2010). PFA vials with flat-bottom interiors (15mL; Savillex) were found to provide even heat distribution to vial contents and thus efficient drying times. Round-bottom vials, which were not tested, are easier to clean due to a lack of internal edges, but likely increase drying times due to their thicker bottom construction. Matched vial lids (33 mm, Savillex) were used which have an interior flange that, when placed loosely on vial tops, allows for moderate vapor venting while preventing spatter from bursting bubbles from transferring to the vial threads.

Vials and lids were cleaned using the procedure described in (Auro et al. 2012). Briefly, vial and lid interiors were first hand-rinsed with Milli- $Q$ water and cleanwipes (Kimtech W4; Kimberly Clark) to remove any physically adhered material, then submerged in closed $1 \mathrm{~L} P F A$ jars and heated at $170-200^{\circ} \mathrm{C}$ (hotplate surface temperature) for $12 \mathrm{hr}$ in sequential solutions of $8 \mathrm{~N}$ reagent-grade nitric acid $\left(\mathrm{HNO}_{3}\right)$, then $6 \mathrm{~N}$ trace metal-grade $\mathrm{HCl}$. Vial/lid pairs were then refluxed individually with $1-2 \mathrm{~mL} \mathrm{Optima}^{\mathrm{TM}}$-grade $\mathrm{HNO}_{3}\left(16 \mathrm{~N}, 4 \mathrm{hr}, 135^{\circ} \mathrm{C}\right)$, rinsed with Milli$\mathrm{Q}$ water, and dried prior to use. All digest and cleaning procedures were conducted in a HEPA-filtered hood within a class 100/ISO 5 cleanroom.

An acid-inert hotplate capable of maintaining temperatures $\geq 230^{\circ} \mathrm{C}$ without exceeding the PFA upper service limit of $260^{\circ} \mathrm{C}$ is critical to the piranha procedure. Use of a heating block to insulate the vial sides also greatly decreases sulfuric acid (b.p. $337^{\circ} \mathrm{C}$ ) drying time. Some of the authors utilize plate/block combinations manufactured by Analab SARL (France) and fitted for the Savillex vials described, though several other manufacturers exist. Regardless of hotplate manufacturer, we strongly recommend using a non-contact, infrared thermometer to confirm hotplate surface temperatures and determine surface heating gradients. This allows the highest temperature to be maintained without risking damage to PFA vials.

\section{Particulate samples used in intercomparison}

Three filtered marine particle samples (GCM12, 17 and 38) and one dipped blank filter (GCM 45) collected during the Great Calcite Belt-I cruise (Figure 1) were selected to provide a wide range of lithogenic and biogenic element concentrations 
("loadings") for intercomparison (Table 1). Dipped blank filters-one filter set per station, contained within a folded, $1 \mu \mathrm{m}$-mesh envelope to prevent particle adherence-were deployed in a perforated, acid-cleaned polypropylene container attached to the pump frame to allow seawater exposure during the deployment \{Bishop:2012il\}. Dipped blanks were processed identically to samples upon recovery and represent a full process filter blank. An additional sample (GCM13) with moderately high biogenic and lithogenic particle loading was selected to determine intra-lab subsample variability.

Sample collection was via in-situ battery-powered pumps (McLane WTS-LV) suspended from a non-metallic hydrowire (Aracom miniline). Pumps operated for 2-2.5 $\mathrm{hr}$ at a programmed rate of $8 \mathrm{~L} / \mathrm{min}$ in a dual-flowpath configuration detailed in (Committee 2010) that allowed for simultaneous collection of particles on two filter types. A "Mini-MULVFS" $142 \mathrm{~mm}$ filter holder configuration was used, which has been shown to result in homogeneous filtered particle distribution and prevents loss of large particles (Bishop et al. 2012). Acid-leached $51 \mu \mathrm{m}$ polyester screens that retained larger particles were upstream of the paired $0.8 \mu \mathrm{m}$ (Supor800, 142 $\mathrm{mm}$ diameter) filters discussed in this study. The paired configuration of $0.8 \mu \mathrm{m}$ Supor filters was a compromise that increased retention of fine particles by the bottom filter for an effective pore size of $\sim 0.6 \mu \mathrm{m}$ from the sum of top and bottom filters, while having much better particle distribution and filtration characteristics than a single $0.45 \mu \mathrm{m}$ filter (Bishop et al. 2012). Only results from the top filters (0.8-51 $\mu \mathrm{m}$ particles) are discussed in this study. Seawater volumes collected through the Supor flowpath and the volume-equivalent (L seawater) on subsamples distributed to the participants are detailed in Table 1.

After recovery, samples and blanks were lightly misted with Milli-Q water over gentle vacuum to reduce sea salt retention, dried at $60^{\circ} \mathrm{C}$ on acid-cleaned plastic supports in a stainless steel oven within a HEPA-filtered environment, and bagged in clear polyethylene clean room bags (KNF Flexpak). Rapid misting with water is intended to quickly reduce salt loading without exposing cells to an extended period of hypotonic stress \{Collier:1984ug\}, though we acknowledge that 
some slight loss, especially of biogenic elements (e.g. P, Cd), is inevitable through this procedure.

\section{Intercomparison sample distribution}

Each of the four participating labs received three replicate subsamples (described further below) from each of the four filter pairs and was free to digest and analyze the subsamples as they wished. One lab digested all samples using a single digest procedure, while the others conducted multiple digest procedures. Because we were limited by sample availability, there are relatively few replicates for each lab/digest treatment ( $n=3$ max; frequently $n=1$ or $n=2$ ). Unlike a larger intercalibration exercise of dissolved TEIs (e.g. SAFe intercalibration for $\mathrm{dFe}$ \{Johnson:2007uf\}) in which large volumes of uniform, readily available samples can be used for repeated analysis and consensus generation, the intercalibration of marine particulates poses additional challenges, primarily to do with limitations imposed by the most common particle sample collection methods. Here we used $142 \mathrm{~mm}$ filters through which $\sim 250 \mathrm{~L}$ had been pumped. This restricted the number of replicate subsamples and participants. We therefore conducted a collaborative, rather than blind, intercomparison exercise wherein results were discussed during multiple iterations. Early results focused on the possibility that the piranha digest had elevated recoveries for some elements, and later iterations focused on addressing lab-specific biases in methodology and/or processing of results. Each digest procedure was eventually conducted by at least two labs, and re-runs of several filters and digest solutions helped to generate the procedures and state of intercalibration presented here. 


\section{Procedures}

Filter subsampling, distribution, instructions to participants

1. Supor filters and dipped blanks used in the intercomparison were subsampled on acid-leached clear acrylic sheets using new stainless steel surgical blades and a rectangular acrylic template $(15 \mathrm{~mm} \times 25 \mathrm{~mm}=3.75$ $\mathrm{cm}^{2} ; 3 \%$ of the filter active area of $125 \mathrm{~cm}^{2}$ ). All acrylic components and Tefzel ${ }^{\circledR}$ forceps used for sample manipulation were acid-cleaned prior to use. Variation attributable to heterogeneities in particle distribution on the filter is discussed later in the text.

2. Supor subsample pairs (top and bottom filters) were cut simultaneously, and each participating lab received $n=3$ subsample pairs from each sample. Labs were free to digest all three subsamples in triplicate using a single digest, or to test up to three different methods. Analyses reported were from each lab's "standard suite" of reported elements, as no analytical list or methodology was prescribed. We present results for elements reported by two or more labs, from digestions of the top Supor filters only $(0.8-51 \mu \mathrm{m}$ particulate size fraction).

3. Though not utilized in this intercomparison study, larger filter subsamples"pie-slice" filter wedges-can be cut from Supor filters using ceramic rotary blades (Cadence Inc.) suitable for use in a commercially available plastic rotary fabric cutter (Olfa). To guide rotary cuts, cutting sheets were placed atop a second acrylic sheet that had pre-drawn, radiating guidelines etched into it. For some filter types, including pre-filters, blanks, and lightly loaded single Supors, the stack can be placed on a light box (McMaster-Carr) which aids guideline observation during rotary cuts. 


\section{Piranha digestion}

1. Filters were placed into vials, ideally with sample side facing downwards or folded inwards. Small filters (e.g., $25 \mathrm{~mm}$ circular filters) fit snugly into flatbottom 15mL Savillex vials, allowing minimal volumes of reagent to be used in future steps. Larger filters (e.g. pie-slices from $142 \mathrm{~mm}$ filters) may need to be folded or cut into smaller pieces to prevent the filter from protruding out of solution and to minimize reagent usage.

2. Piranha solution is volumetrically 3 parts concentrated $(18.4 \mathrm{M}, 98 \% \mathrm{w} / \mathrm{w})$ sulfuric acid to 1 part concentrated $(30-32 \% \mathrm{w} / \mathrm{w})$ hydrogen peroxide. Sulfuric acid was added first, with the volume adjusted to the amount of filter material to be digested, sample loading, and sample type. Larger filters, higher loadings, or more refractory organic components may require larger volumes. For the intercomparison described herein, $1.5 \mathrm{~mL}$ of sulfuric acid was used for all samples and blanks. Lids were then placed atop loosely, but with threads aligned (lids level), to prevent loss from spatter of the viscous sulfuric bubbles that may form and break. The filter was left to soak for 20 minutes at room temperature.

4. Lids were then lifted slightly, and an initial volume of 1 part concentrated hydrogen peroxide was added to each vial ( $0.5 \mathrm{~mL}$ in this study), which generates the piranha solution. Lids were immediately replaced in the same manner as before to allow venting but prevent loss associated with spatter. Vials were swirled gently to mix, then replaced in PFA-coated heating blocks at a hot-plate temperature of $110{ }^{\circ} \mathrm{C}$.

The piranha solution fizzes as it heats, and small bubbles that give the solution its name noticeably began to attack the filter. Lids remained loosely in place to keep any spatter inside the vials. Highly particulate-loaded filters did not always fully dissolve during this step, but the solution was allowed to react for 30-60 minutes to dissolve the most readily available organic material. Lightly loaded filters and blanks, however, occasionally turned yellow-brown or fully dissolved at this step. 
Care was exercised when lifting lids from the vials, as water condensing inside reacts violently when dropping into the solution below. Lids were tapped or gently shaken prior to lifting squarely and gently upwards, to prevent sample loss. Samples that consumed peroxide comparatively quickly, or that reacted especially violently were noted, as these samples often required extra peroxide reagent in later steps.

5. Once the reaction began to subside and the mixture was no longer fizzing vigorously (typically no longer than 60 mins.), another $0.5 \mathrm{~mL}$ peroxide was added to each vial, caps were loosely replaced as before, and the hotplate temperature increased to $200{ }^{\circ} \mathrm{C}$. During this step the solution continued to dissolve the PES matrix, with filters browning in color before fully dissolving.

Undissolved filter pieces, or semi-digested viscous material adhered to the sides of the vial, sometimes persisted depending on sample loading. Additional 100-200 $\mu \mathrm{L}$ aliquots of peroxide were added to digest this material, if present, though vials were cooled slightly prior to addition, as fizzing and spatter upon addition of peroxide is intense at this temperature. Process blanks (reagents only) and filter blanks (unused and/or "dipped" filters) underwent the same procedures as samples. If any solutions became notably dilute due to peroxide addition, preventing the digestion from continuing as noted by decreased fizzing vigor and/or increased volume despite remaining filter material, solutions were allowed to evaporate and reduce in volume (uncovered, once reaction had ceased) before further peroxide additions.

6. Lids were removed carefully and vials and inverted lids were then dried at $235-250{ }^{\circ} \mathrm{C}$. PFA-coated heating blocks that insulate the vial sides significantly decreased the drying time required, allowing moderate volumes of reagent (1-2 mL) to be dried in only a few hours. In the absence of heating blocks, clustering vials together can help increase the temperature of the vial 
walls. Periodic tapping of the jars/blocks/hotplate can help move condensed sulfuric droplets from vial walls to the bottom, speeding drying.

7. Optional: if a small droplet of sulfuric acid remains at this point which is undesirable to carry into future steps (e.g. interference with column chemistry), vials can be cooled, the contents resuspended in a small aliquot of Milli-Q water or $8 \mathrm{~N}$ nitric acid, then step 6 repeated until the droplet is removed. The size of any sulfuric acid droplet remaining decreases with repeated dry-downs, including those associated with subsequent digestion procedures, which may make this step unnecessary. Additional ultrapure peroxide or nitric acid additions should provide negligible addition to the digest/acid procedural blanks, especially in comparison to sulfuric acid and filter-sourced blank levels. Nevertheless, digest acid blanks with identical additional treatments may be prepared alongside to quantify this blank contribution.

8. With the PES matrix oxidized, other mineral acid total digestion procedures can be performed on the remaining particulate material. 


\section{Total particulate digestions}

1. Three particle digestion methods were used by the authors; they are detailed below, and then compared herein. The first digest (D1) is modeled after procedures described by Cullen and Sherrell (1999) and in revised form in Planquette and Sherrell (2012). Briefly, it is a refluxing method using 50\% $(8 \mathrm{M}) \mathrm{HNO}_{3} / 10 \%(2.9 \mathrm{M})$ hydrofluoric (HF) acid $(\mathrm{v} / \mathrm{v})$ at $110{ }^{\circ} \mathrm{C}$ for 4 hours in which the filter piece is not submerged in acid, but is instead adhered to the inside wall of the digestion vial, sample side facing inwards. For this study, $1.0 \mathrm{~mL}$ of reagent was used. The second digest (D2) is a variation on the procedure described by Eggimann and Betzer (1976), adapted by author P. Morton into a single total digestion. It employs a freshly prepared mixture of $\mathrm{HNO}_{3}, \mathrm{HCl}$, and $\mathrm{HF}$ acids (4M each) in Milli-Q water. Filters are submerged in the mixture and heated for $4 \mathrm{hr}$ at $110^{\circ} \mathrm{C}$. In this study, $2.0 \mathrm{~mL}$ of D2 reagent volume was used for filter samples and $4.0 \mathrm{~mL}$ for lithogenic-rich certified reference materials (CRMs). The third digest (D3) is the piranha digest followed by digest $\mathrm{D} 2$.

For all three digestion methods, after refluxing in their respective reagents, vials were cooled, uncapped, and heated to dryness at $110^{\circ} \mathrm{C}$. For digests preceded by the piranha procedure, a brief ( $2 \mathrm{hr}$, open vial) drying step at $>235^{\circ} \mathrm{C}$ was appended to further reduce any remaining sulfuric acid droplet volume, if present.

2. For the piranha method (D3), final dry residues were resuspended in a small volume (200-500 $\mu \mathrm{L})$ of freshly prepared $50 \% \mathrm{HNO}_{3} / 15 \% \mathrm{H}_{2} \mathrm{O}_{2}(v / v)$ and loosely capped (as in the earlier portion of the piranha digestion), then heated at $110^{\circ} \mathrm{C}$. After vigorous bubbling ceased, vials were uncapped and dried at $135^{\circ} \mathrm{C}$. This step helps ensure removal of HF present in the digests and can be repeated for any samples that retain any significant-typically yellowish-coloration (presumably indicating undigested organic material). 
3. A final aliquot of $100 \mu \mathrm{L}$ conc. $\mathrm{HNO}_{3}$ was added, and the solution dried at $110^{\circ} \mathrm{C}$ to near-dryness (D1) or dryness (D2 and D3). For analysis, residues were resuspended in either concentrated $\mathrm{HNO}_{3}$ which was then diluted to $5 \%(v / v)$ with Milli-Q water (D1), or directly in $5 \% \mathrm{HNO}_{3}$ (D2 and D3).

\section{ICP-MS analyses}

Concentration measurements of all elements discussed in the text were conducted by Sector Field Inductively Coupled Mass Spectrometetry (SF-ICP-MS). At WHOI, digests were analyzed on an Element-2 ICP-MS (Thermo Scientific) operated by the WHOI Plasma Facility. Analyses at Rutgers were conducted on an Element-1 (Thermo) ICP-MS using procedures described in (Planquette and Sherrell 2012). Each lab used its own sample inlet system, analytical method, standardization, and drift correction procedures. The most consistent results, and those presented here, were obtained when labs utilized and corrected to a sole internal drift and sample matrix suppression monitor of ${ }^{115}$ In (typically at $0.5-1 \mathrm{ppb}$ concentration). Each lab was free to analyze their digest solutions at any (or multiple) dilutions, as we note that DOM- and salt-derived matrix can result in element-dependent In-normalization effects at low dilutions, but may approach detection limits at higher dilutions. Quantification was performed using external standard curves prepared gravimetrically from individual element ICP-MS standards into a sample matrix similar to the final digest solutions (typically $5 \%$ $\left.\mathrm{HNO}_{3}\right)$. 


\section{Assessment}

\section{Certified reference materials}

Recovery of several Certified Reference Materials (CRMs) by Lab 2 using digest D3 (n.b. D3 is D2 preceded by the piranha digestion) are presented in Table $2 \mathrm{a}$; values for digest D2 alone, as performed by labs 4 and 3 are shown in Tables $2 \mathrm{~b}$ and 2c, respectively. BCR414 is a freshwater plankton CRM; MESS3 and PACS-2 are marine sediments from the Beaufort Sea and Esquimalt Harbor, B.C., respectively. RGM-1 is a rhyolite-derived terrestrial CRM from Glass Mountain, California. For digest D3 (Table 2a), we digested 5-6 replicates of 10-35 mg of each CRM, amounts that are notably below the CRM recommended subsample weights (BCR414: $100 \mathrm{mg}$; MESS3, PACS-2: $250 \mathrm{mg}$ ), to avoid possible fine-scale inhomogeneity and "nugget" effects for these materials. The smaller subsamples were chosen to be closer to suspended particulate matter (SPM) loadings encountered in marine water column samples (Table 3) in our typical digest volumes, and thus represent a compromise between reproducibility and environmental relevance. Even at these smaller masses, the CRM masses used only bear comparison to extremely lithogenic-rich marine particle samples, such as those in benthic nepheloid layers or in high-energy coastal systems.

Commercially available CRMs are not perfect analogues of suspended marine particulates because they tend to have much higher lithogenic content (e.g. marine sediment CRMs) and tend to have much lower (or no) salt component, which significantly affects the matrix of most suspended marine particulate samples. For cost, detection-limit, and efficiency reasons, marine particle samples are generally digested in only a few mL of acid solution, which leads to strong discrepancy between the loadings of typical marine particulate samples and the recommended subsample masses for commonly used CRMs (Table 3). This limits the usefulness of CRMs when developing or assessing digestion procedures for marine particle studies. NIST2703, a relatively new marine sediment trace element standard that is certified for weights $<10 \mathrm{mg}$, may be useful in addressing these concerns, but it is expensive and not yet widely used. 
With these caveats in mind, CRMs are still an important step in method development, and we observe mean recoveries for the marine sediment CRMs MESS and PACS that are, considering our uncertainties at these low masses, within or approaching certified values. Recoveries by piranha (D3) for $\mathrm{Pb}$ (Table 2a) were slightly low and variable in both lithogenic CRMs, perhaps indicating an unknown source of volatilization or loss during the procedure. We note good recoveries for normally highly refractory $\mathrm{Ti}\{$ Bowie:2010cb\} from both lithogenic CRMs using the piranha procedure, which was also observed in digest $\mathrm{D} 2$ alone (Tables $2 \mathrm{~b}, \mathrm{c}$ ). Recoveries for the BCR414 plankton standard by D3 (Table 2a) trended slightly high (mean: 116\%) and were more variable, perhaps due to weight-associated issues at low masses and/or matrix effects associated with sulfuric acid. Taken as a whole, both digests D3 (piranha + D2) and D2 alone recover trace elements of interest within or very nearly approaching certified and consensus values for a range of CRMs, excepting slightly low recoveries of Pb by D3. Recoveries of several CRMs using D1 have been reported previously (Planquette and Sherrell 2012).

\section{Subsample variability (intra-lab comparison)}

Subsample variability was examined using $\mathrm{n}=5$ replicate subsamples from across a single Supor filter [GCM13, Table 4] that were then digested and analyzed by Lab 2 using digest D3. Relative standard deviations (RSDs, or 1-sigma relative to sample mean) were found to be $\leq 5 \%$ for all elements except Ti and Th, which had RSDs of $7 \%$ and $9 \%$, respectively. This variability includes contributions of analytical uncertainties as well as any heterogeneity in particulate distribution on the filter. The uncertainty of the subsampling plus analysis is significantly less than previously observed for Supor filters: Maiti et al. \{Maiti:2012gy\} found 16.8 \% variability in ${ }^{234} \mathrm{Th}$ counts from a $142 \mathrm{~mm} 0.45 \mu \mathrm{m}$ Supor sample collected from the surface oligotrophic North Atlantic, and Bishop et al. 2012 found $17 \%$ and $45 \%$ variability in particle loading on $293 \mathrm{~mm} 0.8 \mu \mathrm{m}$ and $0.45 \mu \mathrm{m}$ Supor filters, respectively, collected from $845 \mathrm{~m}$ in the oligotrophic North Pacific. The GCM13 sample used for this exercise was a coastal sample from $50 \mathrm{~m}$ below the base of the euphotic zone. The lower variability observed here is likely due to the more 
homogeneous particle distribution at higher particle loadings, better particle distribution on $0.8 \mu \mathrm{m}$ compared to $0.45 \mu \mathrm{m}$ Supor filters, improved filter holders, and possibly to better filter characteristics on $142 \mathrm{~mm}$ compared to $293 \mathrm{~mm}$ Supor filters. The values reported here can thus be used as a lower bound for subsample/intra-lab variability when examining digest-specific and inter-lab results.

\section{Digest and filter blank intercomparison}

The four participating labs returned data from up to $n=3$ sample replicates for each element and digest, with two labs reporting results of a single digest (Lab 1, D1 only; Lab 4, D2 only) and the other labs reporting results from two digests (Lab 2: D1 and D3; Lab 3: D2 and D3). Table 5 presents the digest blank values (digest solution only; no filters) and processed filter dipped blank (GCM45) group mean values returned from participating labs. We find that for many, if not most, elements the digest blanks are significant when compared to the processed filter blanks at the subsample size distributed $\left(3.75 \mathrm{~cm}^{2}\right)$. For small filters such as these, digest blanks may thus be an important source of signal and perhaps uncertainty in low abundance measurements. Notably, there seem to be few systematic digest-derived trends in digest or filter blanks, despite differences in acid combinations and analytical procedures utilized by the participants. Exceptions include filter blanks by digest D3 for $\mathrm{Zn}$ and $\mathrm{Cu}$ which appear slightly elevated. Filter blanks are discussed further in discussions of the digests, but we note that $\mathrm{Cu}$ has a typically high sample-to-blank loading ratio, which obviates these concerns. Lab 3 reported elevated digest and filter blanks for several elements resulting from low instrument sensitivity, difficulties that have since been addressed by manually optimizing the magnet alignment and increasing the middle argon pressure beyond the recommended range.

As a potentially significant and/or variable source of signal, digest blanks (or processed filter blanks that include them) could significantly affect blanksubtractions or detection limits in field-relevant particle measurements when concentrations are inherently unknown. Regardless of the ultimate sources of blank (digest or filter), we recommend determining and reporting blank values with 
sufficient rigor to ascertain both the absolute magnitude of blank corrections and the expected error propagation associated with each element.

\section{Sample results and general trends}

Reported subsample results from all individual labs and digests ( $\overline{\mathrm{x}}_{\text {indiv: }} \mathrm{D} 1$ : green symbols; D2: blue symbols; D3: red-orange symbols; error bars: $\pm 1 \sigma_{\text {indiv }}$ ), along with the group mean ( $\left.\overline{\mathrm{x}}_{\text {group }}\right)$ and group variability $\left(+/-1 \sigma_{\text {group }}\right.$ and $2 \sigma_{\text {group }}$ ) for each element and sample are shown in Figure 2. Group variability values $\left(\mathrm{RSD}_{\text {group }}=1 \sigma_{\text {group }} / \overline{\mathrm{x}}_{\text {group }}\right.$, expressed in percent $)$ are shown for each element and sample as numeric annotations. Digest blanks, but not dipped filter blanks, have been subtracted from all displayed results. Elements are divided among Figures 2a-d by their analytical behaviors and dominant marine particle-type associations: biogenic-type elements (Figure 2a: $\mathrm{Cd}, \mathrm{Co}, \mathrm{Cu}, \mathrm{Mo}, \mathrm{Ni}, \mathrm{P}, \mathrm{Sr}, \mathrm{V}$ ) that were highest in the coastal euphotic zone (EZ) sample (GCM 17), lithogenic-type elements (Figure 2b: Al, Fe, Ti, Th) that were highest in the deep coastal sample (GCM 38), elements that fit neither trend (Figure 2c: $\mathrm{Ba}, \mathrm{Mn}$ ), and near-blank elements (Figure 2d: $\mathrm{Cr}, \mathrm{Pb}$, $\mathrm{Zn}$ ) that were never observed in strong excess of the filter blank.

Across the three samples, we observed a broad range in particulate concentrations for different elements as was the intent with the sample selection. Elemental concentrations varied over six orders of magnitude (Figure $3 \mathrm{~b}$ ) across all elements measured, and over three orders of magnitude for some biogenic elements such as $\mathrm{P}$ and $\mathrm{Cd}$, exhibiting the wide dynamic ranges common to marine particulate composition. Group variability (RSD group) values for all samples, averaged for each element, are summarized in Table 4, in increasing order of overall group variability. Group variability for the lowest relative abundance and/or more contaminationprone marine elements $(2 \mathrm{~d}: \mathrm{Cr}, \mathrm{Zn}, \mathrm{Pb})$ are notably higher than those with relatively low blanks and/or high sample-to-blank ratios (e.g. Mn, Cd). These trends, and several digest- and lab-specific trends are discussed further in the Digest Intercomparison section.

Group (inter-lab) variability appeared generally lower for elements with higher sample loading and higher sample-to-blank ratios $\left(\mathrm{RSD}_{\text {group }}\right.$, Figure 2, numeric 
annotations, Figure 3d). We were interested in whether this effect is also observed for individual lab-reported sample replicate uncertainties ( $\left.\mathrm{RSD}_{\text {indiv }}\right)$ at higher loading. Individual replicate uncertainties (Figure 2: error bars) and group variability were uncorrelated on their own (Figure 3a), though uncertainties appear to decrease when plotted as a function of sample loading ( $3 \mathrm{~b})$. This trend is even stronger when plotted against sample-to-blank loading ratios, a behavior which is also observed for group variability: as the sample-to-blank loading ratio increases above $\approx 10: 1$, sample replicate and group RSDs generally approach and/or fall below $10 \%$, nearer to the observed GCM13 subsample variability of 1-9\% (Figure 3, open symbols). Increased analytical precision at higher loading should be a relatively insignificant portion of this behavior, so trends of RSD vs. sample loading suggest that blank determinations, in addition to any lab or digest specific trends (discussed further below) are the key source of inter-lab variability across the full concentration range of marine particles. At the lower end of loading, blank variability-whether Supor filter-derived or digestion process-derived-is almost certainly a key source of error for many, if not most, elements. As mentioned during the discussion of digest and filter blanks, the degree to which uncertainties (or variability) in blanks are known will directly influence the confidence in concentrations for low-loaded elements.

Individual uncertainties for several key biogenic and lithogenic elements are shown in Figure 3e against sample-to-blank loading ratios (from within Figure 3b). Many elements ( $\mathrm{Ba}, \mathrm{Cd}, \mathrm{Co}, \mathrm{Cu}, \mathrm{Ni}, \mathrm{P}, \mathrm{Zn}$ ), including bioactive and/or biogenic particulate elements, show strong decreases in uncertainty as blank-relative loading increases. Lithogenic elements (Fe, Th, Ti, V) do not show this trend (c.f. Fig 3e, Ti), suggesting that variability in digest- or lab-specific particulate recoveries from replicate-to-replicate are more important than relative loading and filter blanks when considering lithogenic particles. 


\section{Digest intercomparison}

To systematically examine the lab- and digest-dependent trends in recoveries, we calculate and plot z-scores (the number of standard deviations above or below the group mean) for several elements of note in Figure 4. Z-scores are defined as:

Z-score $=\left(\mathrm{X}_{\text {sample }}-\overline{\mathrm{x}}_{\text {group }}\right) / 1 \sigma_{\text {group }}$

Lab/digest replicate uncertainties, when available, are similarly normalized, allowing lab replicate confidence (error bars, Figure 4) to be assessed relative to group performance:

z-score-error $=1 \sigma_{\text {sample }} / 1 \sigma_{\text {group }}$

Generally, there appear to be few systematic digest- (D1: blue, D2: green, D3: orange-red) or lab-related biases in recoveries from the intercomparison subsamples (Figure 2), though the exceptions are noted and discussed here.

Focusing more closely on the near-blank elements (Figure 2d), marine particulate $\mathrm{Cr}$ is not measureable due to high $\mathrm{Cr}$ in Supor filter blanks relative to samples across all digests, a difficulty that was also observed by Cullen and Sherrell (1999) on polycarbonate filters. Lead and zinc concentrations in most samples were found to be only slightly higher than filter blanks at the loadings examined (Figure 2d). These two elements appear to be best determined using digest D1, which had both the lowest and most consistent $\mathrm{Pb}$ and $\mathrm{Zn}$ blanks. Digest D2 may be suitable for $\mathrm{Pb}$ (Lab 3--pale blue points) and possibly also for Zn (lab 4-dark blue points), but suffered from an elevated dipped blank for Zn in lab 3's D2 results (pale blue points). Both labs that used digest D3 reported comparatively elevated and more variable filter blanks for $\mathrm{Zn}$ and $\mathrm{Pb}$, leading to a higher detection limit for these elements. Digest D3 was also associated with $<100 \%$ and more variable $\mathrm{Pb}$ recoveries (Table 2a) in the lithogenic CRMs only. Whether this is a true digest-related bias or loss, or whether it is specific to these particular CRMs is unknown, as recoveries for BCR were generally quite good for D3. Better constrained detection limits and recoveries for $\mathrm{Pb}$ (and other such elements that are near the filter blank level) may allow for suitable correction and thus determination of field sample $\mathrm{Pb}$ concentrations, assuming detection limits and filter blanks are found to be stable. 
The most noticeable digest-related bias is that complete digestion of the PES matrix by the piranha digest method (D3 = piranha + D2) results in elevated $\mathrm{Zn}$ in the dipped blank filter (Figure 4, Zn, orange and red bars). This filter-associated $\mathrm{Zn}$ is concomitantly seen as elevated $\mathrm{Zn}$ in the three samples (Figure 2d, Zn). Subtraction of the elevated Zn dipped blank values for D3 largely removes this positive bias from samples (not shown), but the higher variability in Zn blanks increases $\mathrm{Zn}$ detection limits for D3, making it less suitable for low marine particulate sample loadings of Zn, such as many oligotrophic euphotic zone samples. The ultimate source of elevated $\mathrm{Zn}$ in the D3 digestion (but not in D2 when conducted alone) is the subject of conjecture. One possibility is that $\mathrm{Zn}$ associated with Supor filter manufacture (either in polymer reagents or introduced via mechanical processes) is deeply associated within the PES polymer matrix. This $\mathrm{Zn}$ pool is only released after complete PES matrix digestion by the D3 method, but not (or to a lesser degree) by cleaning procedures or incomplete PES digestions in D1 and D2. Another possibility is that increased handling and procedural steps associated with the piranha digest allow more opportunities for $\mathrm{Zn}$ contamination. Filter-derived $\mathrm{Cr}$, by comparison, is present in filter blanks regardless of the digest utilized (and completeness of filter digestion) at a level unsuitably high for marine particulate $\mathrm{Cr}$ determination. Method D1 appears to have the lowest $\mathrm{Zn}$ and smallest variability in the dipped blank filters, making it the most suitable digestion method requiring low $\mathrm{Zn}$ detection limits. Method D2 exhibited somewhat intermediate levels of Zn compared to D1 and D3, but inter-lab variability and the lack of intra-lab replicates for this element makes this difficult to confirm. For $\mathrm{Zn}$ (but not $\mathrm{Pb}$ ), group variability decreases after dipped blank values are subtracted (Table 4), indicating that variation in filter blanks between digest types is a factor in Zn's high group variability.

Z-score plots for Fe and Mn (Figure 4) demonstrate the slightly low lithogenic-type elemental recoveries for Lab 1/D1 (dark green bars), but not D1 as a whole (c.f. Lab 2, D1: light green bars; also Table 6b, Lab 1). Agreement was improved when ICP-MS drift-correction was conducted using a single mid-mass (115In) correction, rather than several elements (e.g. Sc, In, Tl) spanning the ICP-MS method's mass range. Why the use of multiple mass drift correctors occasionally 
leads to this discrepancy between labs is unknown, though elevated concentrations of lithogenic material in particulates can make ppb-level spikes for typical driftcorrector elements occasionally insufficient. Element-specific matrix effects due to elevated salt content in marine particulate samples, despite distilled water misting during filter processing, may also be a factor here, as greater sample dilution sometimes improved recoveries relative to the group (not shown). Lab 2 notes greater consistency between analyses and elemental profiles when sample dilutions, and therefore matrix effects, are at least comparatively consistent.

Higher recoveries by Lab 3 (Figure 4, V; Table 6b, Lab 3) for V and P using D2 were possibly due to contamination as a result of additional sample handling (syringe filtration) necessitated after PES filters fragmented during the D2 digestion. Clogging of ICP-MS inlet systems was observed by several labs due to PES-polymers in solution and filter fragments, though careful control of lower temperatures during the $\mathrm{D} 2\left(\mathrm{HNO}_{3} / \mathrm{HCl} / \mathrm{HF}\right)$ digestion $\left(<105^{\circ} \mathrm{C}\right)$, or preventing filter immersion in acid (as in D1, which also keeps filter temperature slightly lower than that of acid in bottom of vial) can minimize this phenomenon. Lab 2 noted elevated recoveries of $\mathrm{Sr}$ and $\mathrm{Ba}$ relative to the group using D1 (but not D3) (Figure 4, Sr and Ba) for undetermined reasons. This was unlikely to be digest-depending since Lab 1's D1 digest did not show the positive bias.

Across all elements and within the constraints of this intercomparison dataset, it is difficult to assess whether individual labs or distinct digests showed any strong systematic biases in either high or low elemental recoveries (Tables 6a-6c) or replicate variability (Table 7). Without additional participants and analyses of samples these trends appear of borderline significance, especially when considering the broad range in variability (reported 1SD errors, Table 6) across many elements. Nevertheless, most digest-related trends expressed as elevated recoveries ultimately appear to be lab-sourced, rather than digest-specific (e.g. D2, which is skewed slightly higher due to elevated Lab 3 recoveries; Table 6a, b). Some lab-specific results (e.g. Lab 1, slightly low recoveries for high lithogenic samples) are suggestive of slight trends but are not significant when considering the amount variability present within a small sample set. With the exception of $\mathrm{Zn}$ and possibly $\mathrm{Pb}$, the 
complete PES dissolution accomplished by the piranha procedure generated sample and blank variability comparable to the other two digestion procedures (D3, Table 6b, 7a).

Finally, we note that for 8 of 17 elements measured by all labs ( $\mathrm{Al}, \mathrm{Ba}, \mathrm{Cd}, \mathrm{Fe}$, $\mathrm{Mn}, \mathrm{Sr}, \mathrm{Th}, \mathrm{Ti}$ ), group variability is no more than $10 \%$ in excess of subsample variability [Table 4]. For all other elements except for $\mathrm{Zn}$ and $\mathrm{Pb}$ (Co, $\mathrm{Cu}, \mathrm{Mo}, \mathrm{Ni}, \mathrm{P}$, V), group variability is no more than $18 \%$ in excess of subsample variability. These results quantify the current state of an on-going group effort for marine particle composition intercomparison, given the many variations in digestions, analytical procedures, and particulate sample heterogeneity.

\section{Discussion}

Our intercomparison suggests overall that the three total particulate digestion procedures tested (D1, D2, D3) solubilize similar pools of filtered marine particulate material. We see no evidence that occlusion of particles in incompletely-digested filter substrate (e.g. D1, D2) is a problem. The Supor filter matrix and digest blanks are important sources of error for several low abundance particulate metals ( $\mathrm{Cr}, \mathrm{Zn}$, and possibly $\mathrm{Pb})$ at the collection volumes and subsample sizes examined ( 1.8$2.7 / \mathrm{cm}^{2}$ ), with the D3/piranha digest presenting higher blanks for $\mathrm{Zn}$ associated with its completeness of PES filter dissolution or increased filter handling associated with the procedure. Selection of a total digest procedure should thus be based on whichever best suits the sample type, laboratory configuration, and scalability requirements at hand, keeping in mind the pros and cons summarized below.

Partial dissolution or filter fragmentation of the PES matrix that are observed in D2 and occasionally in D1 can generate small filter bits and introduce PES polymers into the digest solutions, especially at higher $\left(>105^{\circ} \mathrm{C}\right)$ digestion temperatures. These components can make later chemical procedures difficult due to reprecipitation, necessitate additional sample manipulations such as filtration, or lead to clogging when samples are introduced by free-aspiration into ICP-MS instruments that lack forced-loop inlet systems. Digest D1 ( $\left.\mathrm{HNO}_{3} / \mathrm{HF}\right)$, as tested, also produces consistently low filter blanks for $\mathrm{Zn}$. As a reflux method that requires 
filters to be adhered to vial walls, however, D1 can be difficult to conduct on larger filter subsamples without alteration of the procedure, as vial wall area is a limitation.

Digest $\mathrm{D} 2\left(\mathrm{HCl} / \mathrm{HNO}_{3} / \mathrm{HF}\right)$ is a full-submersion total digest that thereby addresses some of D1's procedural requirements, and which also includes $\mathrm{HCl}$ within its acid mixture. This acid may be helpful to certain elemental or particulate material recoveries, but such an effect was not observed for the samples, CRMs, and elemental suites tested here, consistent with previous results by Bowie (Bowie et al. 2010). It may also have a sufficiently low Zn filter blank (e.g., see D2, Lab 4 in Figs. 2d, 4) compared to marine particulate Zn loadings. When D2 is conducted on Supor filters at temperatures $>105^{\circ} \mathrm{C}$ (or without exacting temperature control), however, the acid mixture was observed to fragment the PES matrix, which can lead to problems previously described.

D3, the piranha procedure followed by D2, resolves the PES-associated problems caused by D1 and D2 by generating a consistent, low-organic (colorless) sample matrix that is suitable for direct analysis or further sample preparatory or digestion procedures. It is, however, associated with increased $\mathrm{Zn}$ blanks relative to D1 and D2 which seems to be associated with the complete digestion of the Supor matrix. The piranha procedure utilizes sulfuric acid, which necessitates a longer subboiling dry-down if conducted in PFA vials, and may require additional high-heat dry-down steps, usually brief, to ensure minimal transfer of sulfuric acid into the sample matrix, if undesired. Compared to other complete PES digestion methods (e.g. microwave bomb digestions, high temperature ashers), however, the piranha chemical digest may be more scalable for high sample throughput and thus comparatively easy to implement if full removal of the PES matrix is desired or required. 


\section{Comments and recommendations}

\section{General recommendations}

We note the potential for significant contributions from digest blanks at low loadings of particles and/or on small filter subsamples. Precise determination, monitoring and reporting of digest (or combined digest-filter) blanks thus appears critical when conducting measurements of large suites of elements across field samples of unknown concentrations. More rigorous blank assessments can only improve measurements for elements which can have low blank-relative loadings $(\mathrm{Mo}, \mathrm{Pb}, \mathrm{Zn}, \mathrm{V})$, if only by demonstrating the degree of blank-subtraction uncertainty.

Matrix effects driven by residual seasalt or dissolved organic matter, specifically matrix-suppression associated with ICP-MS measurements of digest solution that are diluted minimally to maximize analytical signals, may not affect all samples or elements evenly. It may be prudent or necessary to analyze selected samples at multiple dilutions to assess for these effects, which are sometimes element-specific and thus not directly observable via selected drift-monitoring elements. This recommendation may be especially important for filtered samples that have not been misted with deionized or distilled water to minimize salt retention during filter processing and drying. It may also be prudent to conduct standard addition checks to random samples during the analytical processes, to verify that the drift-monitoring strategy being used are properly correcting for any matrix effects present in actual digest solutions.

\section{Variations on piranha}

Several alternative approaches to the piranha digest procedure have been suggested to the authors that, though not tested here directly, may be useful in certain circumstances. Some digestion procedures, such as total digests using mineral acids including $\mathrm{HNO}_{3}$ and $\mathrm{HF}$, could be performed before the piranha digestion, though their effects on the PES matrix would need to be examined. A more sparing volume of piranha reagent could later be used to remove the lower mass of remaining PES fragments or polymers following the total digest. Performing the piranha procedure first, however, as conducted here, has the benefit of allowing later 
dry-downs associated with total digests to further remove any sulfuric acid that remains. The intercomparison described in this work utilized PES filter subsamples that were small enough to be dissolved using a minimal volume of sulfuric acid, so the difference between performing the piranha procedure before or after the total digest, though untested, is expected to be unimportant for our purposes.

The piranha procedure could also be conducted in vials/vessels with melting points above the boiling point of sulfuric acid (e.g. borosilicate glass, quartz), allowing reagent drydown to be conducted at temperatures nearer or above that sulfuric boiling point, thus obviating the need for fine-temperature-control hotplates. Clearly, total digestions using HF would not be suitable in such vessels, although evaluation of the process blanks associated with non-PFA containers would be a useful additions to general procedural knowledge, as such containers are possibly suitable depending on digestion type and blank requirements.

M. Lohan and A. Milne (pers. comm.) have used a variation of the piranha procedure for small Supor filters in which only a few hundred $\mu \mathrm{L}$ of sulfuric acid are added initially, which absorbs into the PES matrix. A larger volume (1-2mL) of hydrogen peroxide is then added, and the piranha reagent that forms in association with the filter membrane is enough to destroy the PES matrix without additional peroxide aliquot additions. This variation also allows less sulfuric acid reagent to be used, which reduces drying times. In general, we recommend varying and adjusting the piranha procedural volumes the ordinal use of the piranha reagents with respect to other digestion processes to optimize specific sample or laboratory requirements. 


\section{References}

Anderson, R. F., M. Q. Fleisher, L. F. Robinson, R. L. Edwards, J. A. Hoff, S. B. Moran, M. R. V. D. Loeff, A. L. Thomas, M. Roy-Barman, and R. Francois. 2012. GEOTRACES intercalibration of $230 \mathrm{Th}, 232 \mathrm{Th}, 231 \mathrm{~Pa}$, and prospects for $10 \mathrm{Be}$. Limnol. Oceangr. Methods 10: 179-213.

Auro, M. E., L. F. Robinson, A. Burke, L. I. Bradtmiller, M. Q. Fleisher, and R. F. Anderson. 2012. Improvements to 232-thorium, 230-thorium, and 231protactinium analysis in seawater arising from GEOTRACES intercalibration. Limnol. Oceangr. Methods 10: 464-474.

Bishop, J. K. B., P. J. Lam, and T. J. Wood. 2012. Getting good particles: Accurate sampling of particles by large volume in-situ filtration. Limnol. Oceangr. Methods 10: $681-710$.

Bowie, A. R., A. T. Townsend, D. Lannuzel, T. A. Remenyi, and P. van der Merwe. 2010. Modern sampling and analytical methods for the determination of trace elements in marine particulate material using magnetic sector inductively coupled plasma-mass spectrometry. Analytica Chimica Acta 676: 15-27.

Committee, 2. G. S. A. I. 2010. Sampling and Sample-handling Protocols for GEOTRACES Cruises. 1-238.

Cullen, J. T., and R. M. Sherrell. 1999. Techniques for determination of trace metals in small samples of size-fractionated particulate matter: Phytoplankton metals off central California. Marine Chemistry 67: 233-247.

Eggimann, D. W., and P. R. Betzer. 1976. Decomposition and analysis of refractory oceanic suspended materials. Analytical chemistry 48: 886-890.

GeoReM: Geological and Environmental Reference Materials database, maintained by the Max Plank Institute, Mainz, Germany. http://georem.mpch-mainz.gwdg.de/

Planquette, H., and R. M. Sherrell. 2012. Sampling for particulate trace element determination using water sampling bottles: methodology and comparison to in situ pumps. Limnol. Oceangr. Methods 10: 367-388. 


\section{Figures and figure legends}

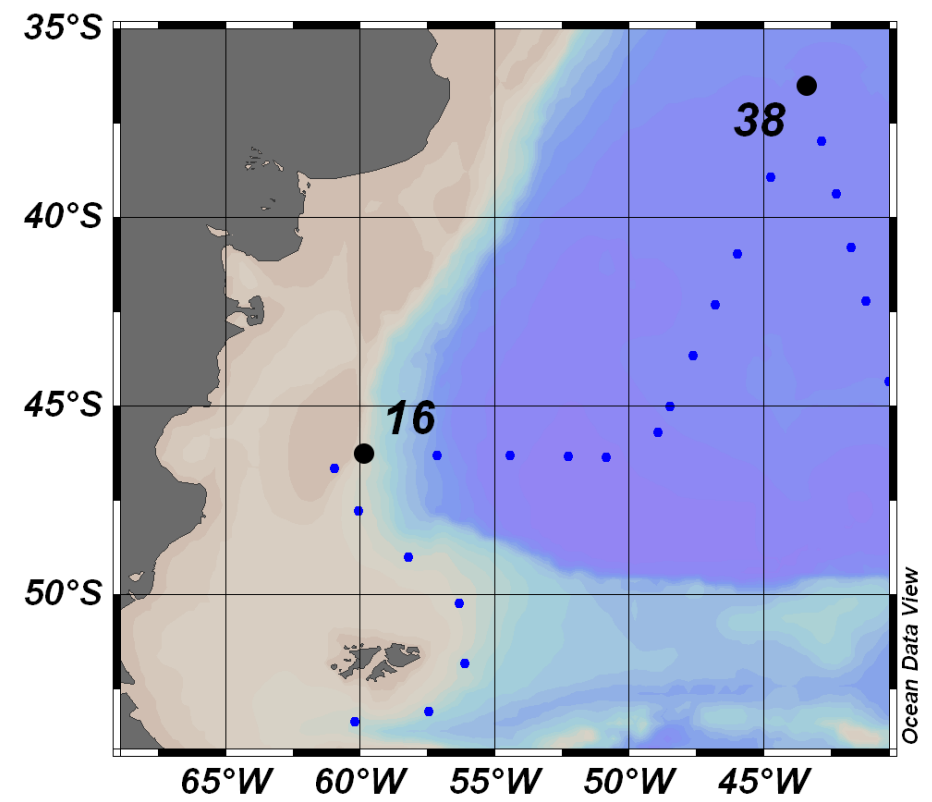

Fig. 1. Station locations along $R / V$ Melville cruise MV1101 in the South Atlantic east of Argentina where intercomparison samples were collected. GCM12, 13 and 17 were collected at station 16 (water column depth $=753 \mathrm{~m}$ ). GCM38 and 45 were collected at station 38 (water column depth $4952 \mathrm{~m}$ ). 
FIGURE 2A:
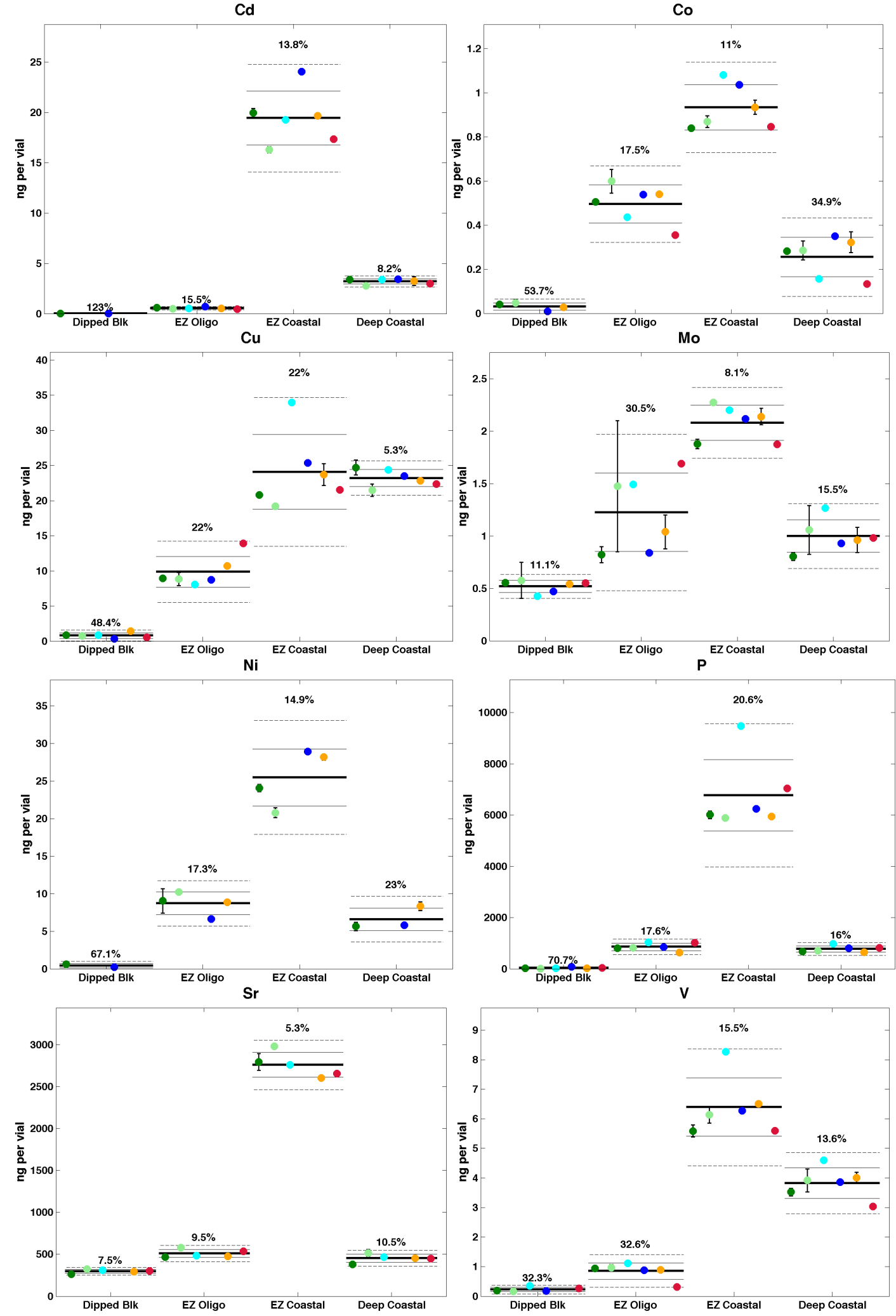
Figure 2B:
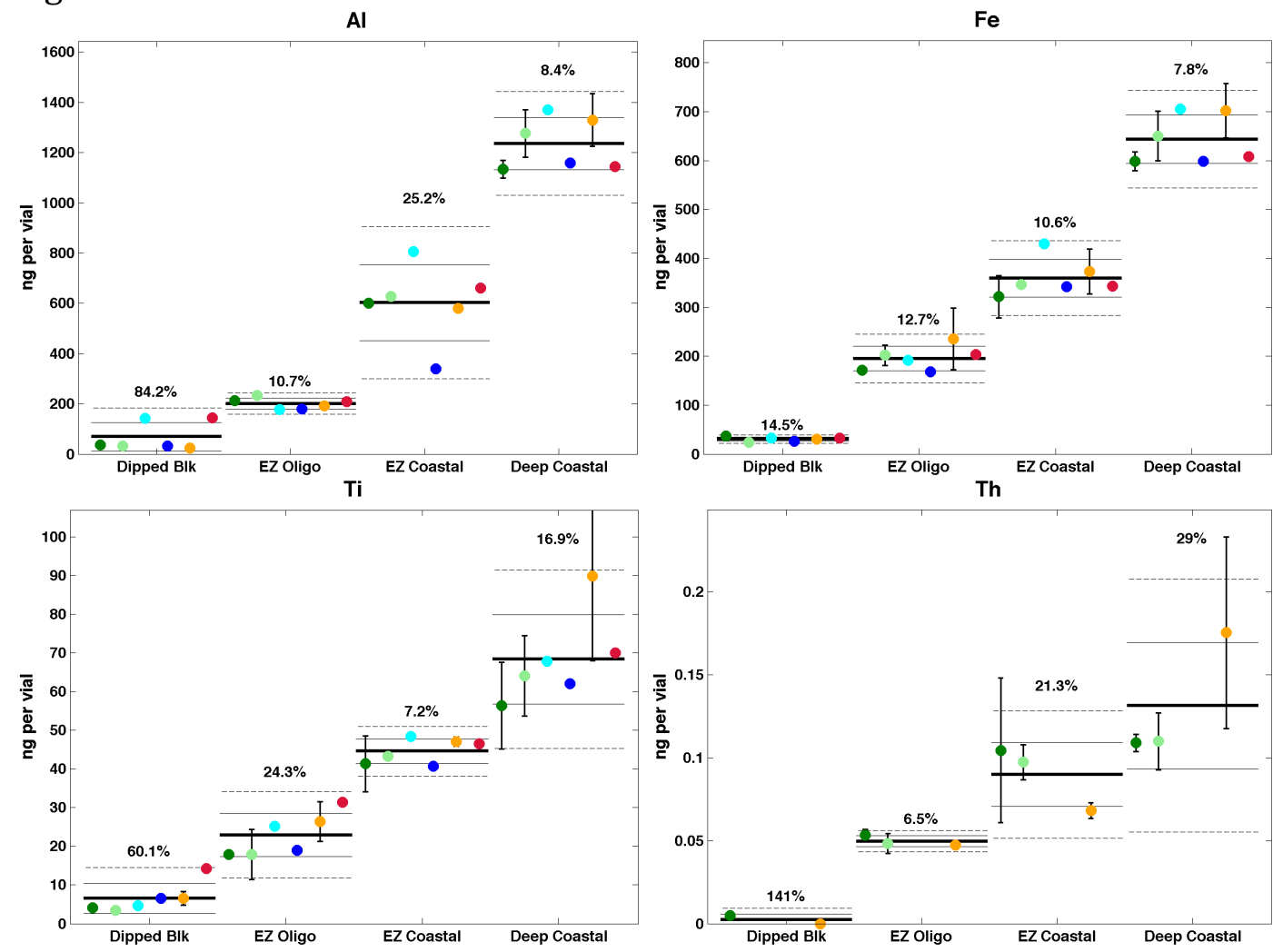

\section{FIGURE 2C:}
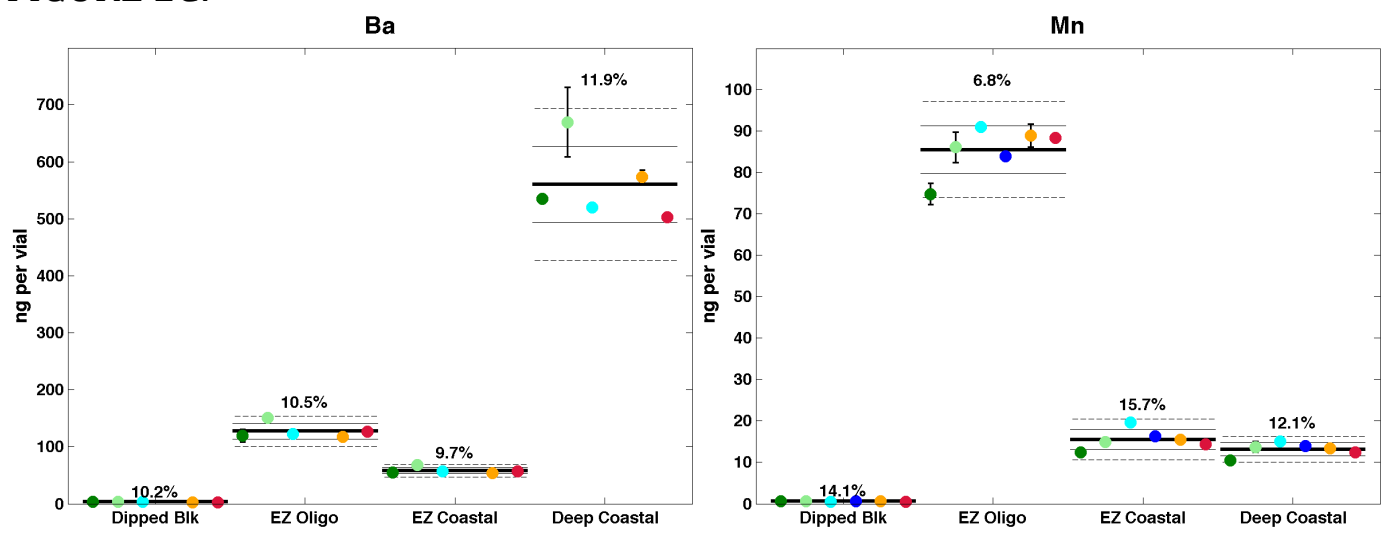
FIGURE 2D:
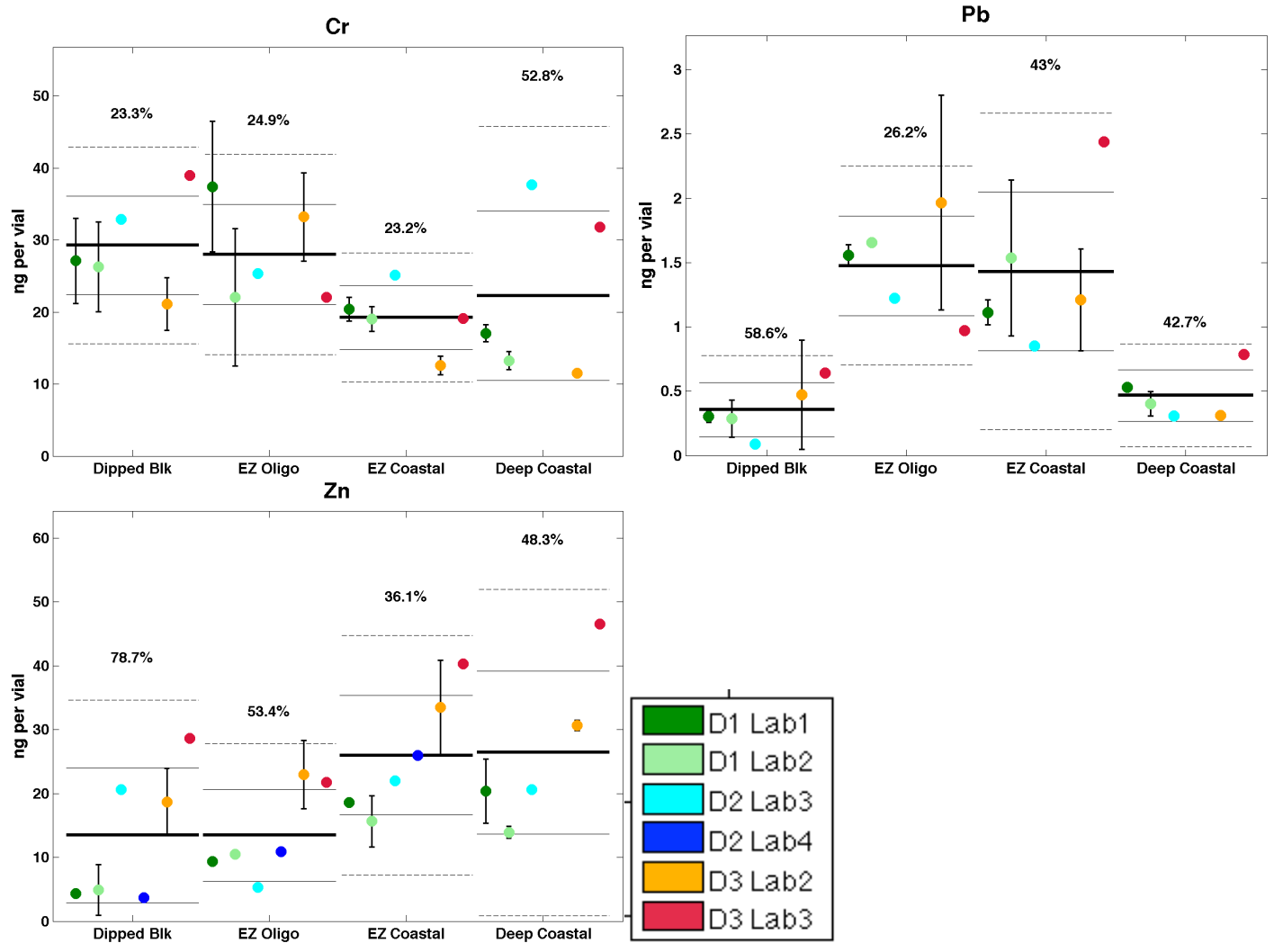

Fig. 2: Intercomparison results for all measured elements, digests and labs (ng per subsample; digest blanks, but not filter blanks, have been subtracted). Elements are grouped (2a: Cd, Co, Cu, Mo, Ni, P, Sr, V; 2b: Al, Fe, Ti, Th; 2c: Ba, Mn; 2d: Cr, Pb, Zn) by distribution on filters and marine particle-type association which is discussed further in the text. Sample names (x-axis) are as described in Table 1. Thick solid lines: group mean ( $\overline{\mathrm{x}}_{\text {group }}$ ); thin solid lines: $\overline{\mathrm{x}}_{\text {group }} \pm 1 \sigma_{\text {group }}$; broken lines: $\overline{\mathrm{x}}_{\text {group }} \pm 2 \sigma_{\text {group }}$. Numeric annotations: group relative standard deviation $\left(\mathrm{RSD}_{\text {group }}=1 \sigma_{\text {group }} / \overline{\mathrm{x}}_{\text {group }}\right.$, expressed in percent), which generally decreases with increased particle loading (increased sample-to-blank ratio). Error bars: $\pm 1 \sigma_{\text {indiv }}$ of subsample replicates for D1 Lab 1, D1 Lab 2, and D3 Lab 2. 
Figure 3A:

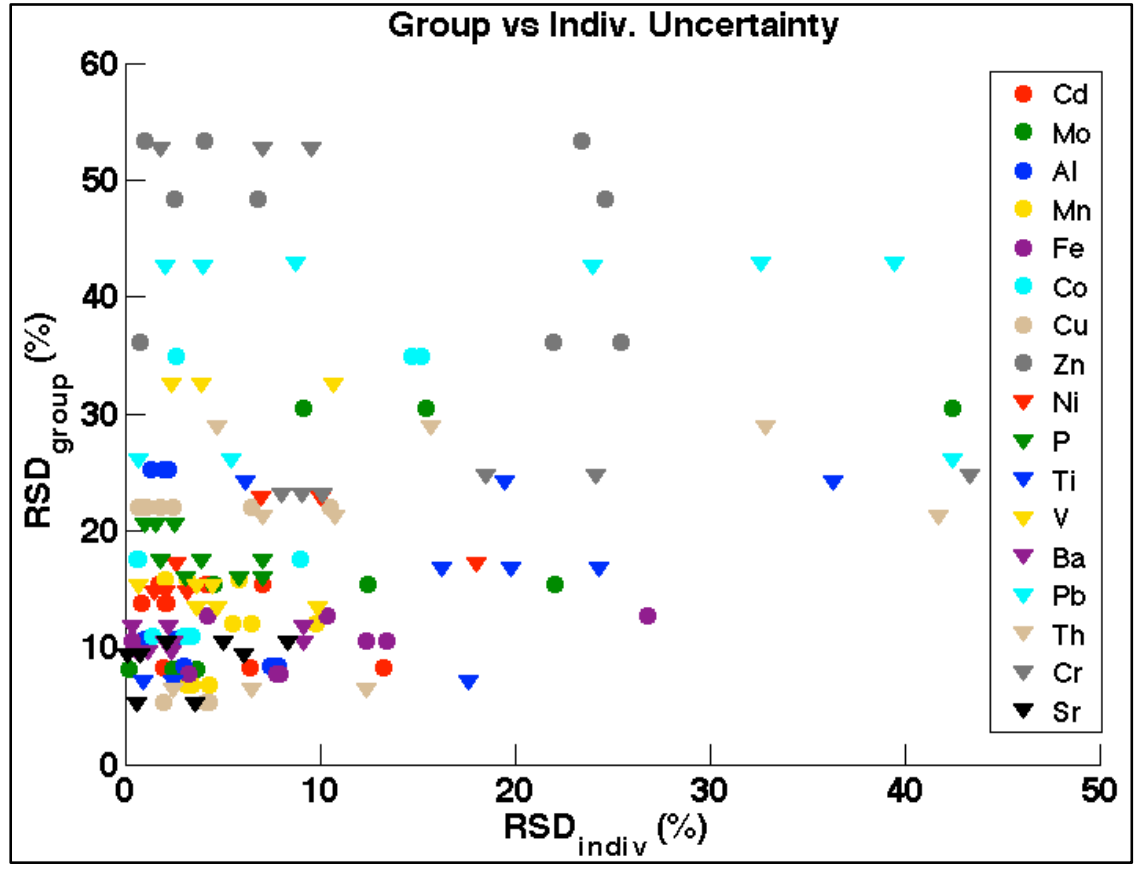

Figure 3B:

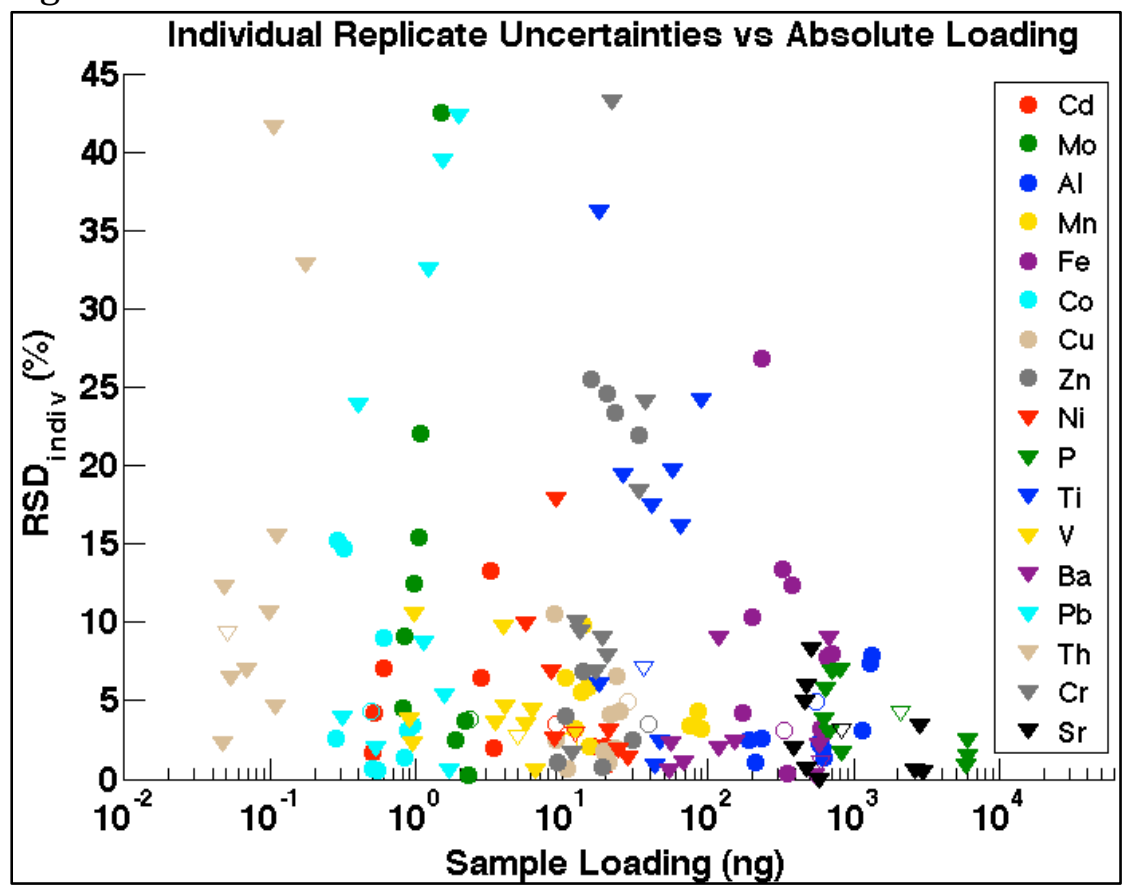


Figure 3C:

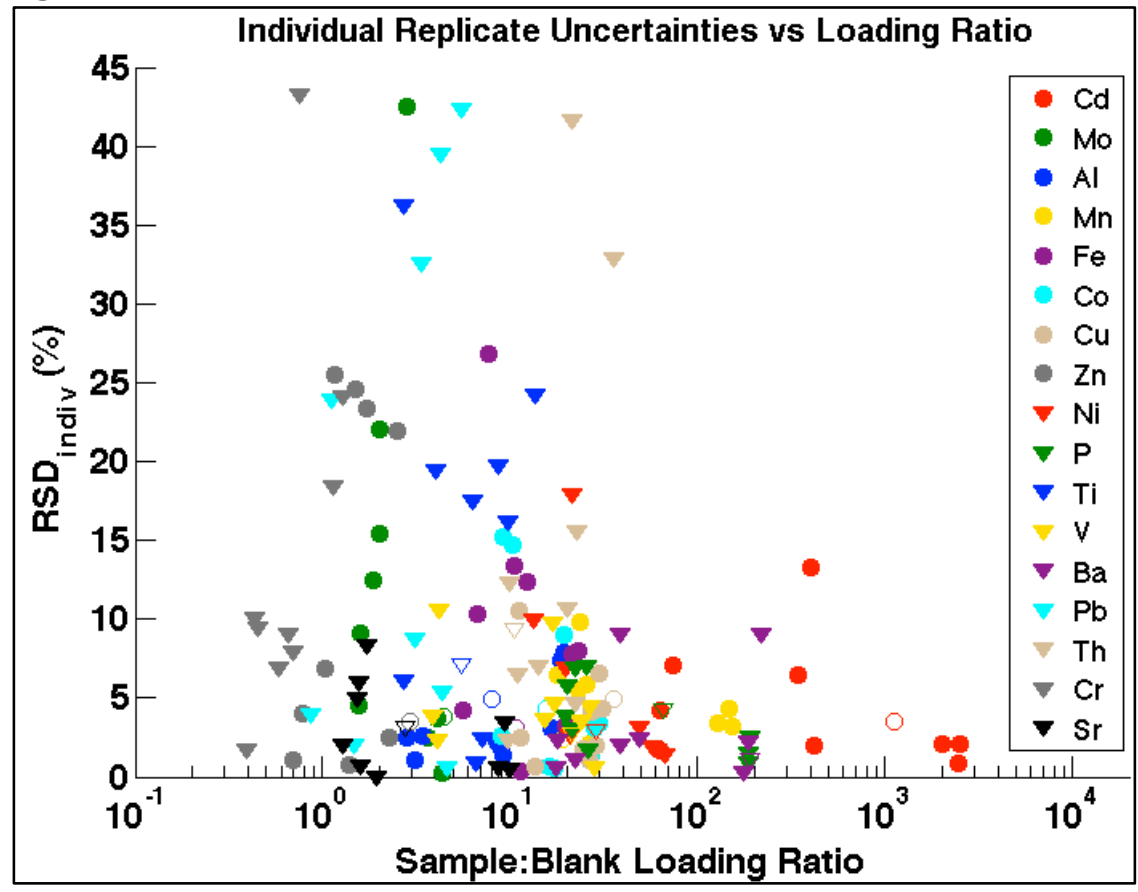

Figure 3D:

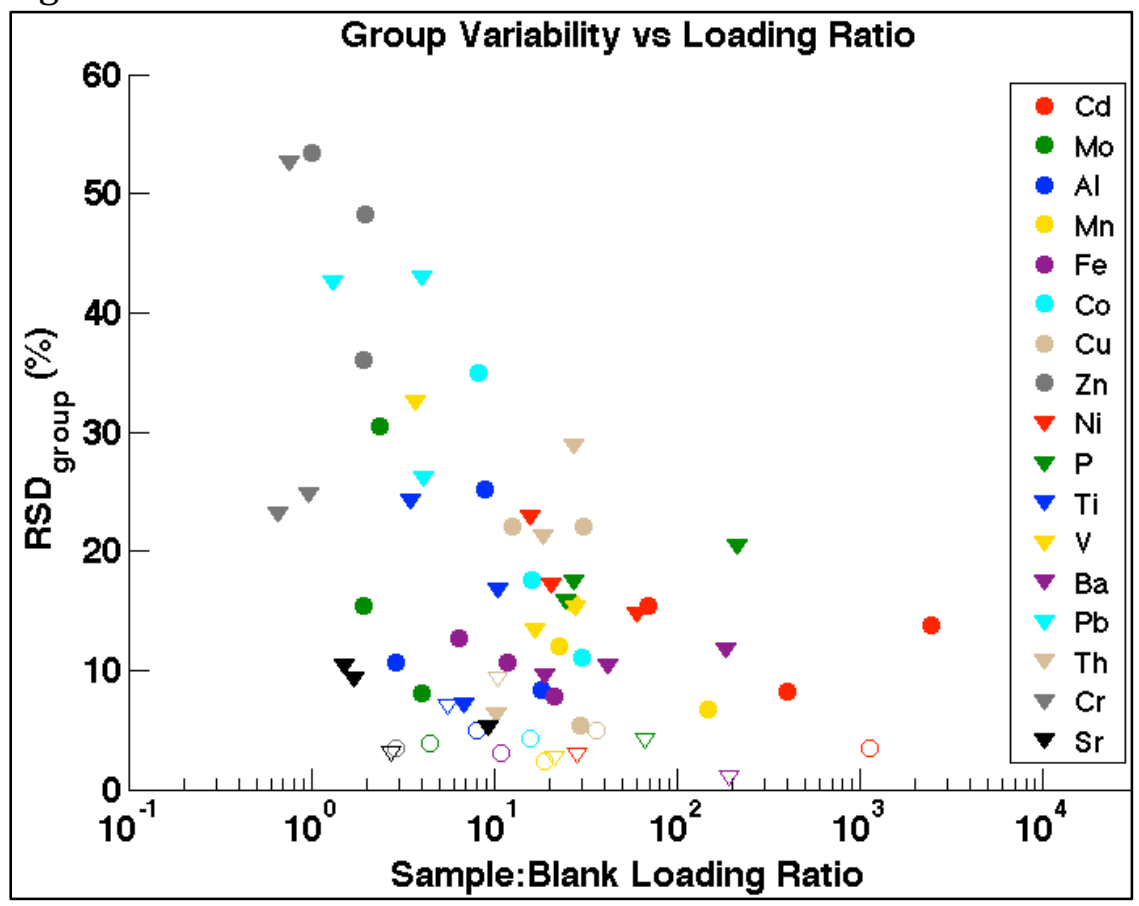


Figure 3E:
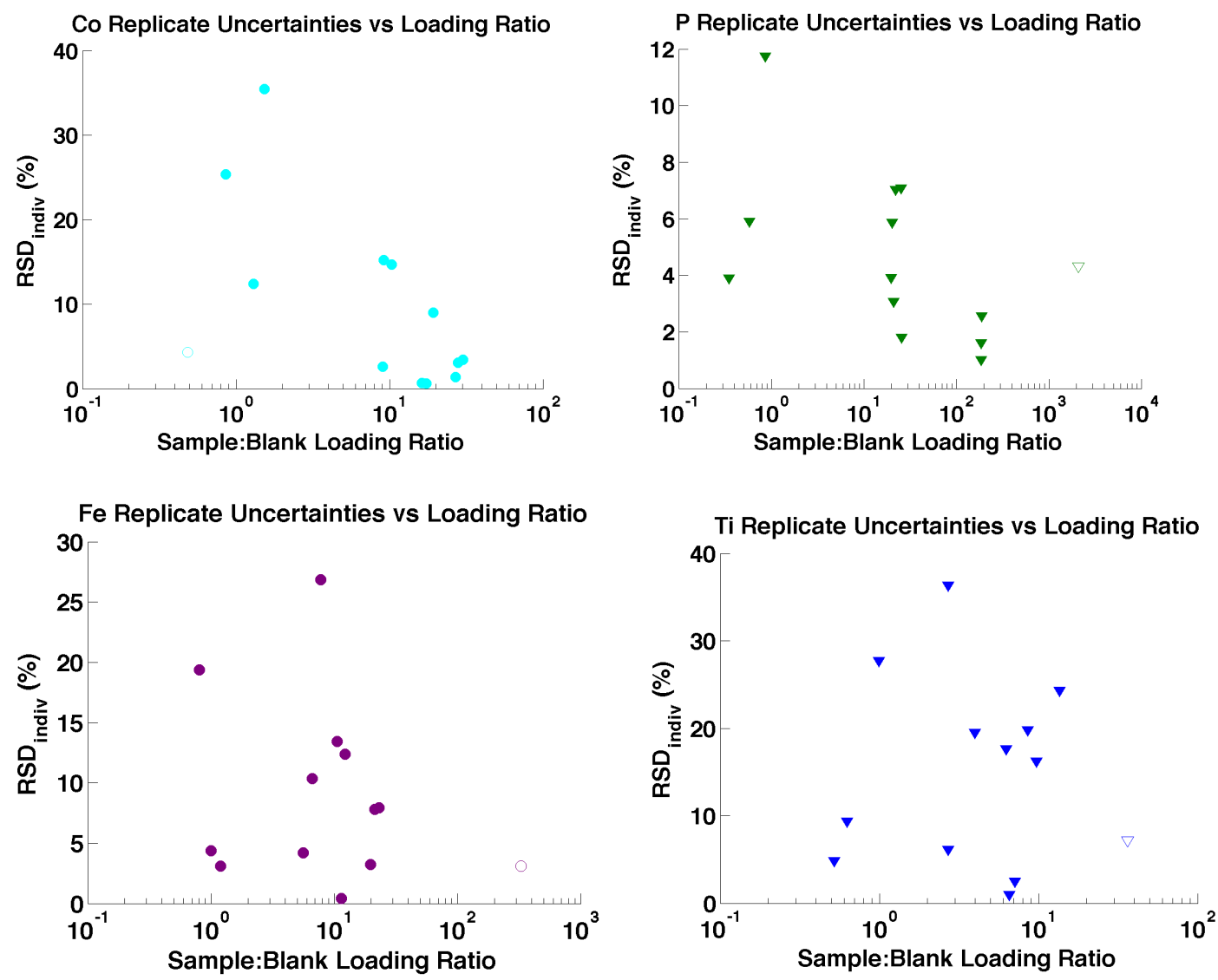

Fig. 3: Increased particulate element concentrations ("loadings") and increased sample-to-blank relative loadings are generally associated with decreased individual and group uncertainties. 3a: group variability ( $\mathrm{RSD}_{\text {group }}$ ) and individually reported replicate uncertainties $\left(\mathrm{RSD}_{\text {indiv }}\right)$ for all elements and non-blank samples appear largely uncorrelated. $3 \mathrm{~b}$ and $\mathrm{c}$ : Individually reported replicate uncertainties $\left(\mathrm{RSD}_{\text {indiv }}\right)$ for all elements and non-blank samples plotted as a function of (3b) reported sample loading (3c) sample-to-dipped-blank loading ratio (reported sample concentration/GCM45 group mean). 3d: Group variability (RSD group) for each element and non-blank sample plotted as a function of sample-to-dipped-blank loading ratio (group sample mean/GCM45 group mean). Open symbols: subsample variability (intra-lab, GCM13, Lab2-D3). 3e: Selected plots of key biogenic (upper: Co, P) and lithogenic (lower: Fe, Ti) element replicate uncertainties from within (3c). 

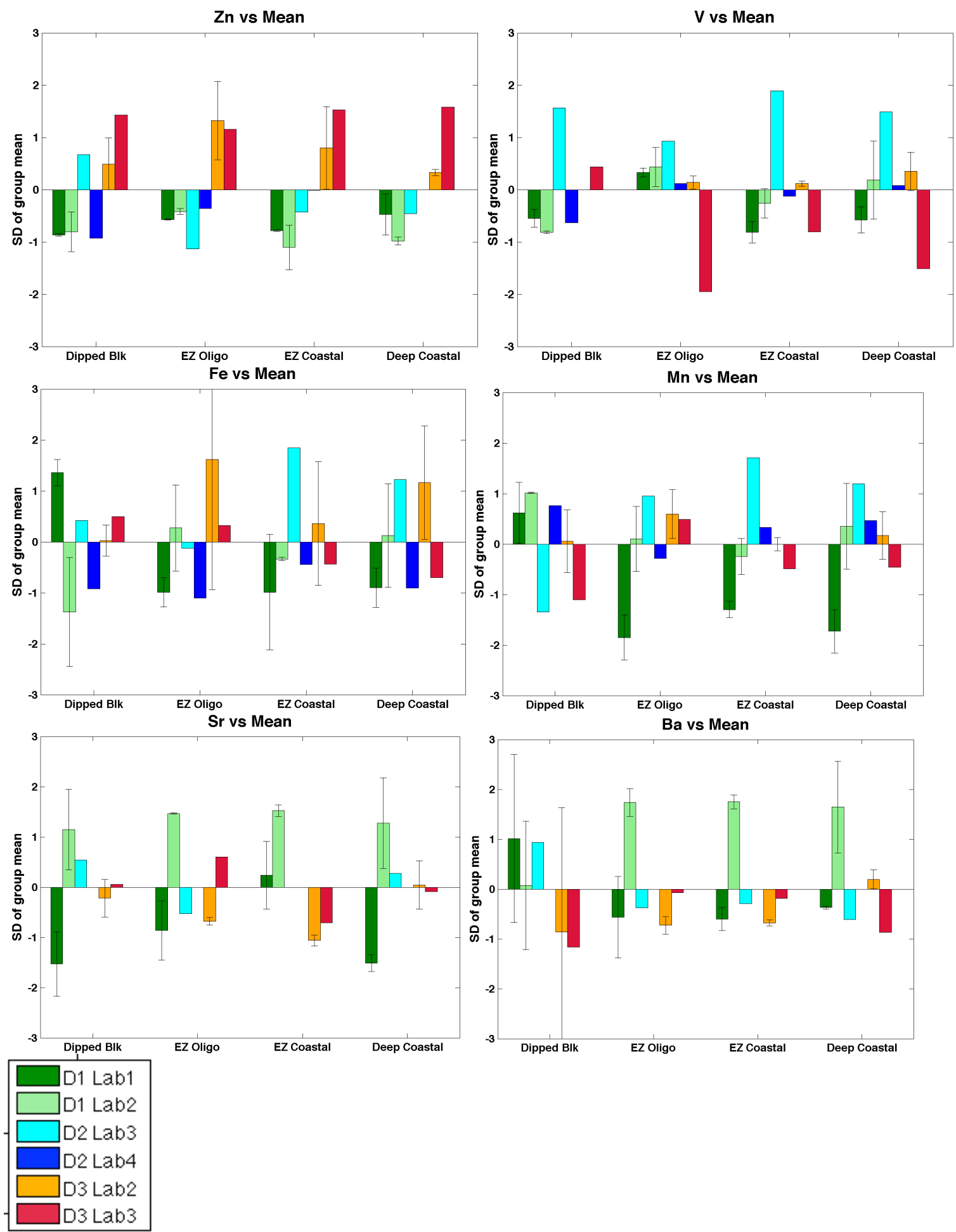

Fig. 4: Z-score anomaly plots (mean-subtracted results normalized to group uncertainty) for elements with notable digest- or lab-specific trends. Error bars: intra-lab replicate uncertainties ( $1 \sigma$, when available) similarly normalized to group uncertainty. $Z n$ : the piranha digest (D3: orange and red bars) is associated with 
elevated dipped blank and sample values for $\mathrm{Zn}$, compared to lower values for D1 (green bars) and D2 (blue bars). V: Lab 3, D2 runs slightly high for V (and P, not shown), possibly due to contamination associated with syringe-filtration of the sample prior to ICP-MS analysis, necessitated by undigested PES-polymers and fragments clogging the free-aspiration introduction system. Fe and Mn: Lab 1, D1 (dark green bars) but not D1 itself (c.f. Lab 2, D1: light green bars) runs slightly lower than the group for these and several other lithogenic elements. D: Sr and Ba): Lab 2, D1 (light green bars) but not D1 itself (c.f. Lab 1, D1: dark green bars) runs slightly higher than the group for Ba and Sr. 


\section{Tables}

\begin{tabular}{|c|c|c|c|c|c|c|}
\hline $\begin{array}{r}\text { Sample ID \& } \\
\text { descriptor }\end{array}$ & Usage & Stn\# & Depth (m) & $\begin{array}{r}\text { Total Supor } \\
\text { volume } \\
\text { filtered (L) } \\
\end{array}$ & $\begin{array}{r}\text { Subsample } \\
\text { volume } \\
\text { equivalent (L) }\end{array}$ & Particulate regime description \\
\hline $\begin{array}{r}\text { GCM12: } \\
\text { EZ Coastal }\end{array}$ & IC & 16 & 60 & 298.9 & 9.5 & $\begin{array}{r}\text { Continental margin-influenced euphotic zone: } \\
\text { high biogenic, high lithogenic }\end{array}$ \\
\hline $\begin{array}{r}\text { GCM17: } \\
\text { Deep Coastal }\end{array}$ & IC & 16 & 650 & 300.1 & 9.6 & $\begin{array}{r}\text { Continental margin-influenced deep: } \\
\text { low biogenic, high lithogenic }\end{array}$ \\
\hline $\begin{array}{r}\text { GCM38: } \\
\text { EZ Oligotrophic }\end{array}$ & IC & 38 & 121 & 231.2 & 7.4 & $\begin{array}{l}\text { Oligotrophic euphotic zone: } \\
\text { low biogenic, low lithogenic }\end{array}$ \\
\hline $\begin{array}{r}\text { GCM45: } \\
\text { Dipped blank }\end{array}$ & IC & 38 & 1020 & 0 & 0 & Dipped blank \\
\hline $\begin{array}{r}\text { GCM13: } \\
\text { Costal Sub-EZ }\end{array}$ & IV & 16 & 110 & 331.6 & 10.6 & $\begin{array}{l}\text { Continental margin-influenced, } 50 \mathrm{~m} \text { below } \\
\text { euphotic zone: med. biogenic, high lithogenic }\end{array}$ \\
\hline
\end{tabular}

Table 1. Intercomparison sample IDs with collection details and brief descriptions of the expected particulate regimes. EZ: euphotic zone. IC: laboratory inter-comparison; IV: intra-lab subsample variability test (Lab 2, D3). 


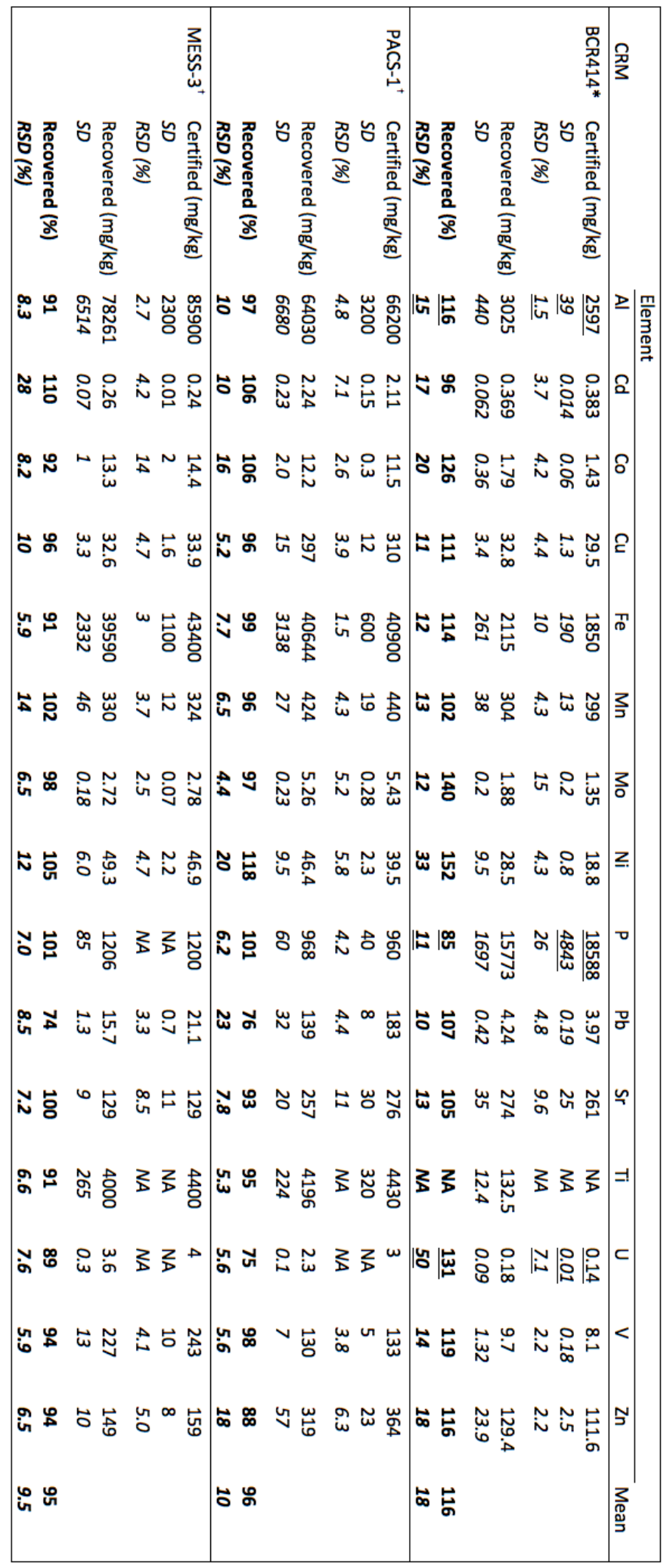




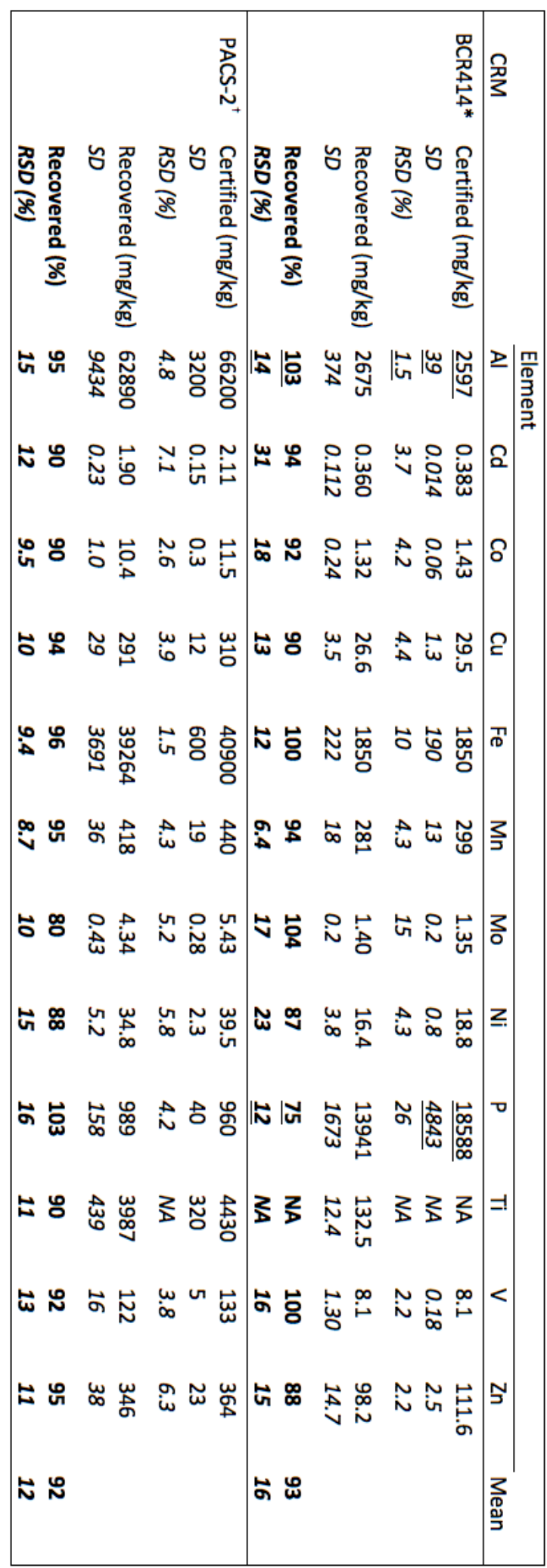




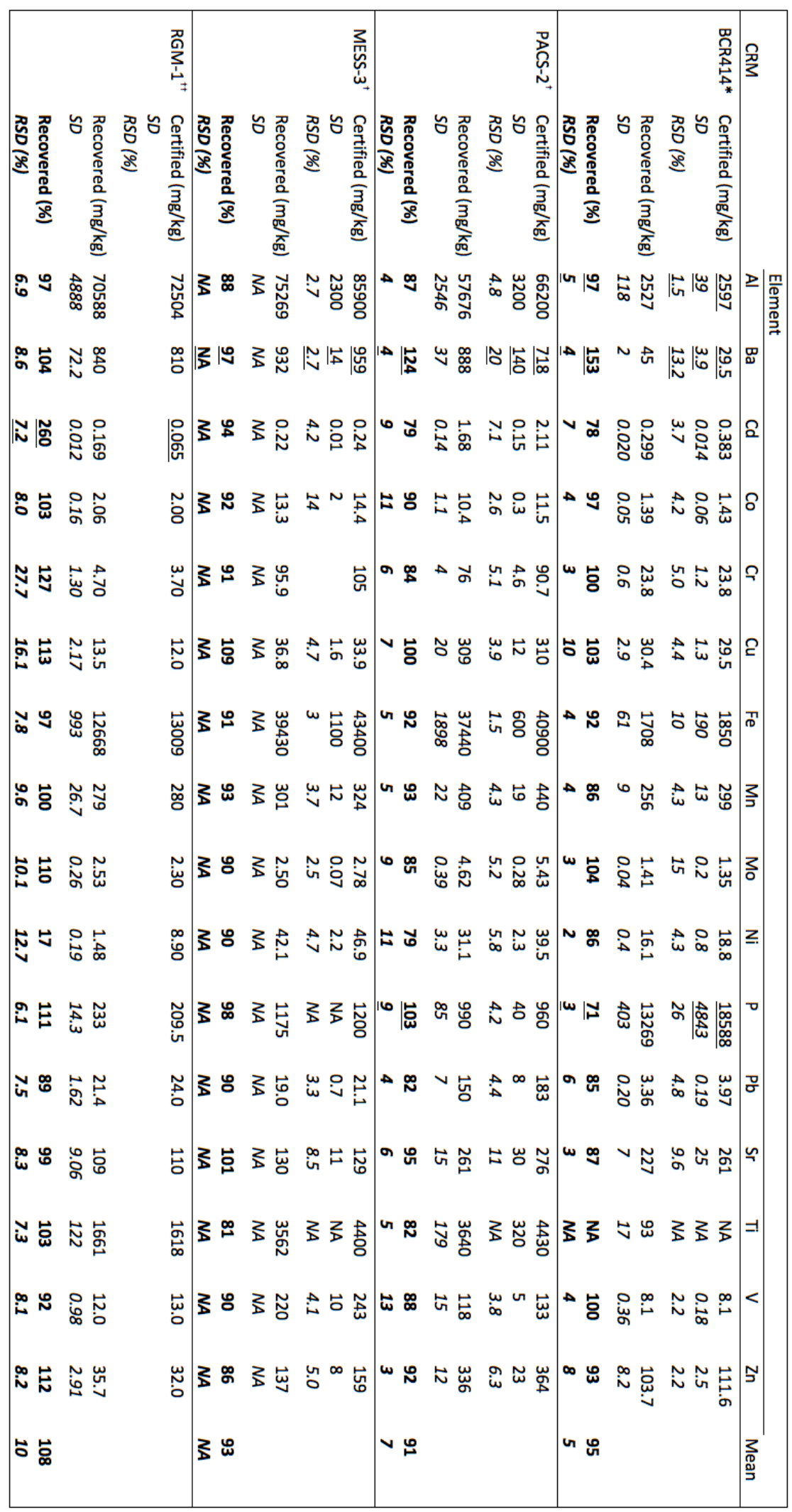


Table 2a-c (preceding three pages). Recoveries for certified reference materials by various labs and digests: a) lab 2 using digest D3; b) lab 4 using digest D2; c) lab 3 using digest D2. For each CRM, certified values ( $\mathrm{mg} / \mathrm{kg}$ ) with absolute (1SD) and relative uncertainties (RSD, \%) are shown, along with recovered values and absolute uncertainties (1SD). Bold: recovered values and uncertainties converted to percent certified for summarization purposes. Underlined: comparisons to uncertified informational values from the GeoReM CRM database [see references]. NA: Not applicable (no certified or information values for comparison). *BCR414 is CRM414:

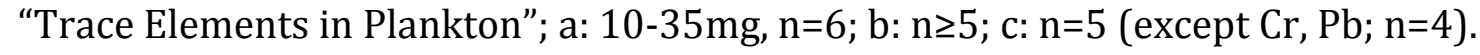
†PACS-1 and MESS-3 "Marine Sediment Reference Materials for Trace Metals", Canadian National Research Council; a: 10-35mg, $n=5$; b: $n \geq 5$; c: $n=5$ (except Cd, Co, Mo, $\mathrm{Ni}, \mathrm{V} ; \mathrm{n}=4$ ). ${ }^{+} \mathrm{RGM}-1$ is USGS rhyolite-derived glass mountain standard; $\mathrm{c}: \mathrm{n}=5$. 


\begin{tabular}{|c|c|c|}
\hline Sampling Region & $\begin{array}{r}\text { Typical* } \\
\text { [SPM] }(\mu \mathrm{g} / \mathrm{L})\end{array}$ & $\begin{array}{r}\text { Expected mass } \\
\text { SPM (mg per 15L } \\
\text { subsample) }\end{array}$ \\
\hline Marine benthic boundary layer & 1200 & 18 \\
\hline Oligotrophic surface ocean & 30 & 0.45 \\
\hline Mid-water column, open ocean & 10 & 0.15 \\
\hline
\end{tabular}

Table 3: Expected loadings of suspended particulate matter (SPM) in marine particulate subsamples from select oceanographic regions assuming typical SPM concentrations * [US North Atlantic GEOTRACES results, Lam et al., in prep] and a subsample representing a filtered volume of 15L. For comparison, recommended masses for commonly used CRMs are typically 100-250mg. 


\begin{tabular}{|c|c|c|c|c|c|}
\hline \multirow[b]{2}{*}{ Element } & \multirow{2}{*}{$\begin{array}{c}\text { GCM13 subsample } \\
\text { variability } \\
\text { (intralab; } R S D, \% \text { ) }\end{array}$} & \multicolumn{2}{|c|}{$\begin{array}{c}\text { Mean } \mathrm{RSD}_{\text {group }}(\%) \text { for samples } \\
\text { GCM12, } 17 \text { and } 38\end{array}$} & \multirow{2}{*}{$\begin{array}{l}\text { (Mean group variability } \\
\text { with blanks) - (GCM13 } \\
\text { subsample variability) }\end{array}$} & \multirow{2}{*}{$\begin{array}{c}\text { Mean } \\
\text { Sample:Blank } \\
\text { Loading Ratio }\end{array}$} \\
\hline & & $\begin{array}{c}\text { Filter blanks not } \\
\text { subtracted }\end{array}$ & $\begin{array}{c}\text { Filter blanks } \\
\text { subtracted }\end{array}$ & & \\
\hline $\mathrm{Sr}$ & 3 & 8 & 13 & 5 & 4.2 \\
\hline $\mathrm{Fe}$ & 3 & 10 & 12 & 7 & 13.2 \\
\hline $\mathrm{Ba}$ & 1 & 11 & 11 & 10 & 80.8 \\
\hline $\mathrm{Mn}$ & 2 & 12 & 12 & 10 & 65.5 \\
\hline $\mathrm{Cd}$ & 4 & 12 & 12 & 8 & 961.6 \\
\hline Al & 5 & 15 & 28 & 10 & 9.9 \\
\hline $\mathrm{Ti}$ & 7 & 16 & 17 & 9 & 6.9 \\
\hline $\mathrm{Cu}$ & 5 & 16 & 18 & 11 & 24.1 \\
\hline Mo & 4 & 18 & 35 & 14 & 2.8 \\
\hline$P$ & 4 & 18 & 18 & 14 & 88.4 \\
\hline $\mathrm{Ni}$ & 3 & 18 & 21 & 15 & 32 \\
\hline Th & 9 & 19 & 17 & 10 & 18.5 \\
\hline V & 3 & 21 & 25 & 18 & 16 \\
\hline Co & 4 & 21 & 21 & 17 & 18 \\
\hline $\mathrm{Cr}$ & ND & 34 & 11 & ND & 0.8 \\
\hline $\mathrm{Pb}$ & ND & 37 & 38 & ND & 3.1 \\
\hline $\mathrm{Zn}$ & 4 & 46 & 35 & 42 & 1.6 \\
\hline $\mathrm{Ag}$ & 4 & ND & ND & ND & ND \\
\hline $\mathrm{Nd}$ & 4 & ND & ND & ND & ND \\
\hline $\mathrm{U}$ & 4 & ND & ND & ND & 4.9 \\
\hline$Y$ & 1 & ND & ND & ND & 73.1 \\
\hline
\end{tabular}

Table 4. Data column 1: intra-lab subsample variability (Lab 2, D3) observed within $\mathrm{n}=5$ subsamples across a single 142mm Supor filter (GCM13, Station 16,112m depth). Data columns 2 and 3: element-specific group variability (mean $\mathrm{RSD}_{\text {group }}$ ) for the three non-blank samples across all digests and labs, before and after subtraction of lab- and digest-specific dipped filter blanks (GCM45). Data column 4: mean group variability (before blank subtraction) minus intra-lab subsample variability (data column 1). Data column 5: mean sample-to-filter blank loading ratio (ng:ng) for the three non-blank samples. 


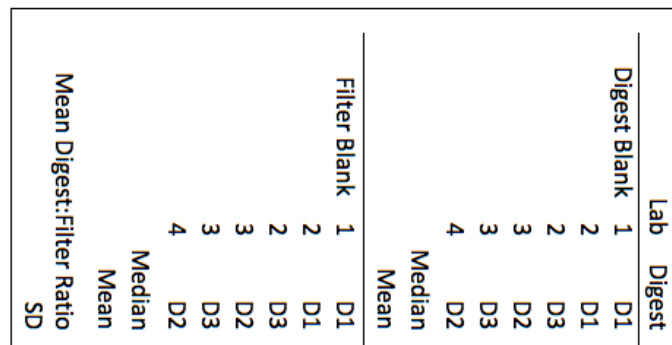
芯 范

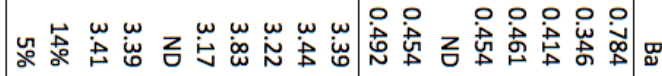

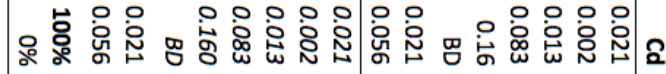

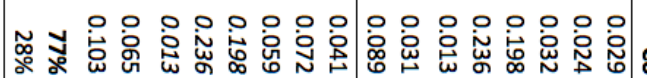

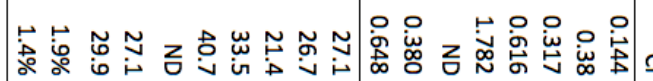

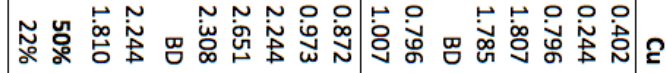

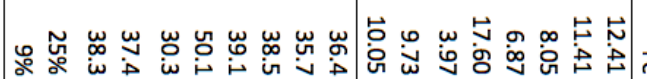
W O O O O O O O O O O O O O O

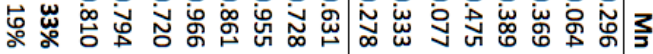

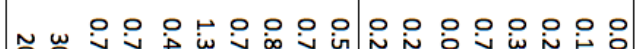

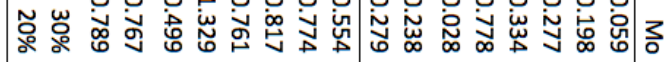

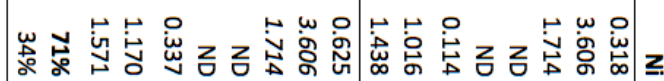

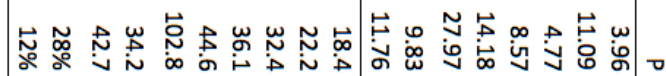

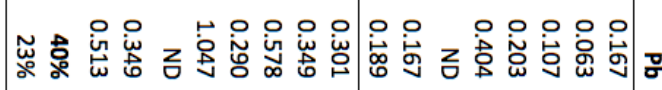

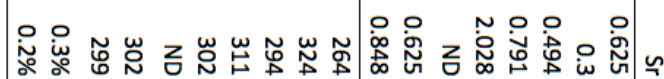

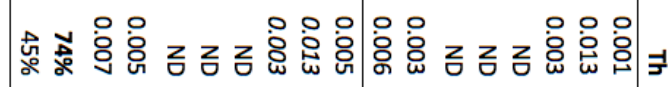

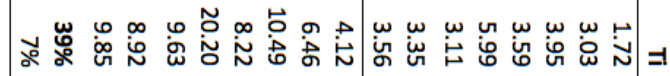

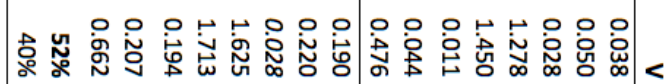

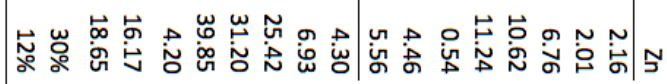


Table 5 (preceding page). Digest blanks and dipped filter blanks in ng per vial for each lab and digest. Filter blanks have not had digest blanks subtracted. Median and mean values across all labs and digests are also shown. Bottom rows: mean digest-tofilter blank ratio (and standard deviation) for each of lab/digest combinations, representing the "typical" digest-to-filter blank ratio observed by participants for a $3.75 \mathrm{~cm}^{2}$ "dipped blank" filter. Italics: filter blanks equivalent to digest blanks. Bold: elements for which digest blanks are $\geq 33 \%$ of the filter blank at this subsample size. ND: not determined; BD: below detection. 


\begin{tabular}{|l|l|l|l|l|l|l|}
\hline \multicolumn{2}{|l|}{ Table 6A } & \multicolumn{4}{l|}{ Mean z-score, all elements; individual labs/digests } \\
\hline Lab & Digest & $\begin{array}{l}\text { Dipped BCM45 } \\
\text { GCM Oligo }\end{array}$ & $\begin{array}{l}\text { GCM Coastal } \\
\text { GCM }\end{array}$ & $\begin{array}{l}\text { Deep Coastal } \\
\text { GCM12 }\end{array}$ & $\begin{array}{l}\text { All samples } \\
\text { GCM17 }\end{array}$ & and db $( \pm 1$ SD $)$ \\
\hline 1 & D1 & +0.03 & -0.19 & $\mathbf{- 0 . 4 8}$ & $\mathbf{- 0 . 5 2}$ & $-0.28 \pm 0.46$ \\
\hline 2 & D1 & -0.15 & +0.29 & -0.11 & -0.12 & $-0.03 \pm 0.70$ \\
\hline 2 & D3 & -0.02 & +0.13 & -0.14 & +0.29 & $+0.07 \pm 0.58$ \\
\hline 3 & D2 & +0.09 & -0.12 & $\mathbf{+ 0 . 9 0}$ & $\mathbf{+ 0 . 5 9}$ & $+0.36 \pm 0.56$ \\
\hline 3 & D3 & $\mathbf{+ 0 . 4 6}$ & +0.12 & -0.11 & -0.20 & $+0.02 \pm 0.50$ \\
\hline 4 & D2 & $\mathbf{- 0 . 4 3}$ & -0.34 & +0.04 & -0.01 & $-0.19 \pm 0.73$ \\
\hline
\end{tabular}

\begin{tabular}{|l|l|l|l|l|l|}
\hline Table 6B & \multicolumn{6}{|l|}{ Mean z-score, all elements; digests averaged } \\
\hline Digest & $\begin{array}{l}\text { Dipped Blk } \\
\text { GCM45 }\end{array}$ & $\begin{array}{l}\text { EZ Oligo } \\
\text { GCM38 }\end{array}$ & $\begin{array}{l}\text { EZ Coastal } \\
\text { GCM12 }\end{array}$ & $\begin{array}{l}\text { Deep Coastal } \\
\text { GCM17 }\end{array}$ & $\begin{array}{l}\text { All samples } \\
\text { and db }( \pm 1 S D)\end{array}$ \\
\hline D1 & -0.31 & -0.07 & $\mathbf{- 0 . 5 1}$ & -0.31 & $-0.16 \pm 0.60$ \\
\hline D2 & $\mathbf{+ 0 . 4 7}$ & -0.21 & $\mathbf{+ 0 . 7 2}$ & $\mathbf{+ 0 . 4 7}$ & $+0.11 \pm 0.63$ \\
\hline D3 & -0.18 & +0.24 & -0.24 & -0.18 & $-0.05 \pm 0.62$ \\
\hline
\end{tabular}

\begin{tabular}{|l|l|l|l|l|l|}
\hline Table 6C & \multicolumn{6}{l}{ Mean z-score, all elements; labs averaged. } \\
\hline Lab & $\begin{array}{l}\text { Dipped Blk } \\
\text { GCM45 }\end{array}$ & $\begin{array}{l}\text { EZ Oligo } \\
\text { GCM38 }\end{array}$ & $\begin{array}{l}\text { EZ Coastal } \\
\text { GCM12 }\end{array}$ & $\begin{array}{l}\text { Deep Coastal } \\
\text { GCM17 }\end{array}$ & $\begin{array}{l}\text { All samples } \\
\text { and db }( \pm 1 S D)\end{array}$ \\
\hline 1 & +0.03 & -0.19 & $\mathbf{- 0 . 4 8}$ & $\mathbf{- 0 . 5 2}$ & $-0.28 \pm 0.46$ \\
\hline 2 & -0.09 & +0.21 & -0.12 & +0.09 & $+0.02 \pm 0.61$ \\
\hline 3 & +0.27 & +0.00 & $\mathbf{+ 0 . 4 0}$ & +0.20 & $+0.19 \pm 0.68$ \\
\hline 4 & $\mathbf{- 0 . 4 3}$ & -0.34 & +0.04 & -0.01 & $-0.19 \pm 0.56$ \\
\hline
\end{tabular}

Tables 6a-6c. Standardized recoveries (mean z-score for all elements) for a: each individual lab/digest combination; $b$ : means of the three digests; and c: means of the four labs. Digest-related trends for D2 (b) primarily indicate Lab 3's elevated recoveries for high lithogenic samples. Slightly low recoveries for high-lithogenic samples GCM12 and GCM17 by Lab 1 (c) are of undetermined significance due to the small size of the study. Bold: six (a) or four (b, c) most anomalous values. 


\begin{tabular}{|l|l|l|}
\hline Digest & $\begin{array}{l}\text { Mean RSD } \\
\text { (samples } \& \\
\text { blank) }\end{array}$ & $\begin{array}{l}\text { Mean RSD } \\
\text { (samples only) }\end{array}$ \\
\hline D1 & $\begin{array}{l}10 \pm 8 \% \\
(\mathrm{n}=136)\end{array}$ & $\begin{array}{l}8 \pm 6 \% \\
(\mathrm{n}=102)\end{array}$ \\
\hline D2 & $\mathrm{ND}$ & $\mathrm{ND}$ \\
\hline D3 & $\begin{array}{l}11 \pm 10 \% \\
(\mathrm{n}=132)\end{array}$ & $\begin{array}{l}9 \pm 7 \% \\
(\mathrm{n}=99)\end{array}$ \\
\hline
\end{tabular}

\begin{tabular}{|l|l|l|}
\hline Lab & $\begin{array}{l}\text { Mean RSD } \\
\text { (sampliv } \\
\text { blank) }\end{array}$ & $\begin{array}{l}\text { Mean RSD } \\
\text { (samples only) }\end{array}$ \\
\hline 1 & $\begin{array}{l}8 \pm 6 \% \\
(\mathrm{n}=68)\end{array}$ & $\begin{array}{l}7 \pm 5 \% \\
(\mathrm{n}=51)\end{array}$ \\
\hline 2 & $\begin{array}{l}11 \pm 9 \% \\
(\mathrm{n}=136)\end{array}$ & $\begin{array}{l}9 \pm 7 \% \\
(\mathrm{n}=102)\end{array}$ \\
\hline 3 & ND & ND \\
\hline 4 & ND & ND \\
\hline
\end{tabular}

Tables 7a and 7b. Relative uncertainties of individual (replicate) measurements associated with each a: digest, or b: lab. Within the data provided, there seems to be insufficient evidence that replicate variability is either digest or lab-dependent. ND: no data (insufficient sample replicates, or uncertainties not reported). 
Chapter 3: Cycling of Lithogenic Marine Particulates in the US GEOTRACES North Atlantic Zonal Transect

Daniel C. Ohnemus ${ }^{1,2}$, Phoebe J. Lam²

${ }^{1}$ MIT-WHOI Joint Program in Oceanography, Massachusetts Institute of Technology/Woods Hole Oceanographic Institution, Woods Hole, MA 02543, USA ${ }^{2}$ Department of Marine Chemistry and Geochemistry, Woods Hole Oceanographic Institution, Woods Hole, MA 02543, USA

*Corresponding author. Email: dan@whoi.edu

\section{ACKNOWLEDGEMENTS}

Collection and analysis of marine particulates on this scale is not possible without the help of many talented people. We thank Captain Adam Seamans, the crew of the R/V Knorr (cruises KN199 and KN204), and chief scientists Bill Jenkins, Ed Boyle, and Greg Cutter. All provided exceptional leadership and shipboard support during our many weeks at sea and in the years of planning beforehand. Collection of particulate samples at sea was in collaboration with Paul Morris, Stephanie Owens, Steve Pike, Sylvain Rigaud, Kuanbo Zhao, and with the help of Sara Rauschenberg. Land-based efforts included the support of Matt Charette, Ken Buesseler, Ben Twining, Maureen Auro, and Paul Henderson. Analyses were greatly assisted by Scot Birdwhistell, Paul Field, and Rob Sherrell. Ti XANES spectra of model compounds provided by Matthew Marcus. The operations of the Advanced Light Source at Lawrence Berkeley National Laboratory are supported by the Director, Office of Science, Office of Basic Energy Sciences, US Department of Energy under contract number DE-AC02-05CH11231. R. Shelley and W. Landing provided aerosol samples for Ti $\mu$ XANES measurements and African Dust composition ratios. Funding was provided by the National Science Foundation (OCE \#0963026 to PJL), the International and US GEOTRACES Offices, and fellowship assistance from the 
Williams College Tyng Fellowship and MIT/WHOI Academic Programs Office to DCO.

\author{
ABSTRACT \\ In this paper, we present, describe, and model the first size-fractionated (0.8- \\ $51 \mu \mathrm{m} ;>51 \mu \mathrm{m}$ ) water column particulate trace metal results from the US \\ GEOTRACES North Atlantic Zonal Transect (NAZT) in situ pumping survey, with a \\ focus on the lithogenic tracer elements $\mathrm{Al}, \mathrm{Fe}$ and $\mathrm{Ti}$. This examination of basin- \\ wide, full-depth distributions of particulate elements elucidates many inputs and \\ processes-some for bulk lithogenic material, others element-specific-which are \\ presented via concentration distributions, elemental ratios, size-fractionation \\ dynamics, and steady-state inventories. Key lithogenic inputs from African dust, \\ North American boundary interactions, the Mediterranean outflow, hydrothermal \\ systems, and benthic nepheloid layers are described. Using the most inert lithogenic \\ tracer, $\mathrm{Ti}$, we develop a 1-D model for lithogenic particle distributions, and test the \\ sensitivities of size-fractionated open ocean profiles of Ti to biotically-driven \\ aggregation, disaggregation, and vertical particulate sinking. We discuss \\ applications of this lithogenic model to particle cycling in general, and about POC \\ cycling specifically.
}

\title{
1. INTRODUCTION
}

In marine systems, lithogenic particles are refractory assemblages of crustally-derived minerals that, to first order, transit through the water column largely unaltered. Lithogenic particles are one of three overarching classes of particles present in marine systems, together with biogenic particles (living and dead organic matter and mineral skeletons) and other abiotically-derived authigenic particles produced and cycled in situ (e.g. Fe and Mn oxides, barite). Lithogenics, as a major class of particulate matter, are typically not a dominant component of marine vertical particle fluxes in much of the open ocean (Francois et al., 2002), far away from lithogenic inputs such as aeolian dust and lateral transport of continental margin sediments. The subtropical North Atlantic, however, due to its location 
beneath perhaps the broadest, most intensely dust-dominated atmospheric regimes on Earth (Mahowald et al., 2005), may well be considered an exception among marine particle regimes: lithogenics account for between $40-72 \%$ of the vertical sediment trap flux at productive margin systems near Cape Verde (Ratmeyer et al., 1999), compared to typically less than $20 \%$ (and frequently less than 5\%) at open ocean stations distant from aeolian dust sources (Francois et al., 2002). The North Atlantic, where $43 \%$ of annual dust deposition is estimated to occur (Jickells, 2005), thus provides an opportunity to examine lithogenic particle distributions and behaviors in a basin dominated by lithogenic inputs.

The inputs, internal cycling, transport, and deposition of lithogenic material could be considered a marine lithogenic cycle in its own right, whereby large quantities (1 Pg/year (Ginoux et al., 2004; Mahowald et al., 2009) of crustal or crustal-like particulates cycle through the world oceans. Although this material is at least conceptually refractory, it nonetheless participates in the biogeochemical cycling of many trace elements by acting as a source of dissolved trace elements from dissolution, a scavenging surface for bioactive metals, and a ballasting agent for marine aggregates. Long-range aeolian and subsurface lateral (Lam and Bishop, 2008) inputs of lithogenic material are of special importance due to their ability to deliver bio-limiting micronutrients directly to productive surface ocean ecosystems.

In this paper we present, examine, and model the first basin-wide, full-depth zonal transect of marine lithogenic material. Through examination of three elements- $\mathrm{Al}, \mathrm{Fe}$, and $\mathrm{Ti}-$ that act predominantly as lithogenic particulate tracers, we find that the lithogenic cycle is more complex, and potentially interesting, than typically considered. Concentration distributions of these three elements, on their own, provide information about aeolian, lateral/margin, bottom resuspension, and hydrothermal inputs, which are major controls on the basin's total metal fluxes. Lithogenic tracer elemental ratios are shown to provide further insight into element-specific alteration processes and site-specific inputs in a manner that single-element concentration profiles cannot.

The refractory nature of lithogenic titanium and its dust-dominated input to the surface of the N. Atlantic subtropical gyre presents an opportunity to model 
vertical particulate distributions and thus examine dynamic particle aggregation/disaggregation/sinking processes using a relatively inert tracer. We present a one-dimensional particulate model that qualitatively describes the upper and mid-water column distribution of refractory particulate metals in marine systems, and perform sensitivity tests on how variations in aggregation, disaggregation, and sinking rate constants affect the two size fractions $(>51 \mu \mathrm{m} ; 0.8$ $51 \mu \mathrm{m})$ collected.

\section{METHODS}

\subsection{Study Region}

Particulate samples were collected at 22 stations across the subtropical $\mathrm{N}$. Atlantic during US GEOTRACES cruises KN199-04 and KN204-01 aboard the $R / V$ Knorr (Fig. 1). Cruise KN199-04 in Oct. 2010 occupied stations 10-01 through 10-12 in the eastern basin. Key stations (Fig. 1, annotations) occupied included stn. 10-01 near Lisbon and within influence of the Mediterranean outflow, stn. 10-09 located $200 \mathrm{~km}$ west of the Mauritanian shelf break, and stn. 10-12 at the TENATSO time series site 70km NE of Cape Verde. Cruise KN204-01 in Oct-Nov 2011 occupied stations 11-01 through 11-24 from Woods Hole to Cape Verde. Key stations occupied included seven pumping stations along Line $\mathrm{W}$ between Woods Hole and Bermuda at the BATS site (stn. 11-10); stn. 11-16 at the TAG hydrothermal site along the mid-Atlantic ridge (TAG/MAR); and a KN204/KN199 cross-over station at TENATSO/Cape Verde (stn. 11-24).

\subsection{Particulate Sampling}

The dataset described herein comprises seventeen elements (Ag, $\mathrm{Al}, \mathrm{Ba}, \mathrm{Cd}$, $\mathrm{Co}, \mathrm{Cu}, \mathrm{Fe}, \mathrm{Mn}, \mathrm{Nd}, \mathrm{Ni}, \mathrm{P}, \mathrm{Pb}, \mathrm{Th}, \mathrm{Ti}, \mathrm{V}, \mathrm{Y}, \mathrm{Zn}$ ) and two particulate size classes (0.8$51 \mu \mathrm{m}$, and $>51 \mu \mathrm{m}$ ), though we focus in this publication on the predominantly lithogenic tracers Al, Fe, and Ti. Particulates were collected via in situ batterypowered pumps (McLane WRT-LV), in a modified dual-flow configuration further described in (Committee, 2010; Lam and Morris, pat. pending) as part of the US GEOTRACES North Atlantic transects aboard the R/V Knorr (cruises KN199-4, Oct 
2010, stations 10-01 through 10-12; and KN204-1A/B, Nov-Dec 2011, stations 1101 through 11-24).

Stations $(n=22)$ were sampled typically at sixteen-point depth resolution over two casts within ca. 24 hours: a shallow cast during which eight depths were sampled in the upper $1000 \mathrm{~m}$ (four depths in the upper $200 \mathrm{~m}$ ), and a deep cast during which eight pumps sampled between $1000 \mathrm{~m}$ and the ocean floor. During the 2011 cruise, but not the 2010 cruise, a $12 \mathrm{kHz}$ pinger was attached to the bottom of the hydrowire, which allowed closer sampling of near-bottom depths and benthic nepheloid layers when conditions permitted. Pumps were deployed along a tracemetal hydrowire (Hytrel-jacketed Vectran) and, once at depth, operated for four hours at initially programmed pumping speeds of $8 \mathrm{~L} / \mathrm{min}$. Each pump is configured with two parallel flowpaths ("QMA" and "Supor") each of which filtered first through a $51 \mu \mathrm{m}$ polyester pre-filter (hereafter the "large size fraction" or LSF, retaining particles $>51 \mu \mathrm{m}$ ), and then through either paired $0.8 \mu \mathrm{m}$ polyethersulfone (Supor ${ }^{\mathrm{TM}}$ )

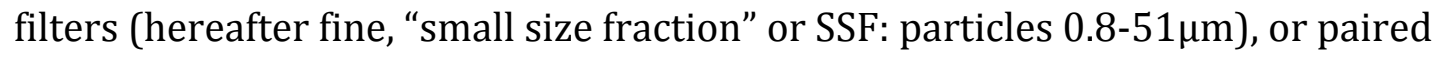
quartz (Whatman QMA) filters (not discussed here). Both QMA and Supor flowpaths were independently flow-metered to determine volume filtered. The combined pump outflow was metered separately to ensure volume determination in the event of a single flowmeter failure or lockage. Typical total volumes filtered were $1500-1700 \mathrm{~L}$, with $30 \%$ of volume (median: 461L) passing via the Supor flowpath and the rest (median: 1167L) passing via the QMA flowpath. Filters and pre-filters were $142 \mathrm{~mm}$ in diameter (126mm active diameter), acid-cleaned prior to use as detailed in (Committee, 2010), and manipulated in HEPA-filtered clean environments using trace-metal techniques.

Immediately after pump recovery, particles on one-eighth wedge subsamples of the QMA-side pre-filters (LSF, mean: 145.9L seawater equivalent) were rinsed from the polyester pre-filter onto acid-cleaned $25 \mathrm{~mm}, 0.8 \mu \mathrm{m}$ Supor ${ }^{\mathrm{TM}}$ disc filters using $0.2 \mu \mathrm{m}$-filtered surface seawater from a contamination-free, towed underway system (Bruland et al., 2005). Primary Supor (SSF) pump filters and the rinsetransferred disc filters were dried at room temperature in a laminar flow bench and then stored in trace-metal/particulate-free cleanroom polyethylene bags. Back in 
the land-based laboratory, a 1/16 wedge of the top Supor filter (representing the 0.8-51 $\mu \mathrm{m} \mathrm{SSF}$; mean: $28.9 \mathrm{~L}$ seawater equivalent) was excised using a ceramic rotary blade (Cadence Inc.).

\subsection{Analytical Techniques}

SSF wedges and LSF discs were digested identically, in total, using the (D3, "piranha") procedure outlined in (Ohnemus et al., in prep.). Briefly, filters were first digested using a sulfuric acid and peroxide mixture (piranha reagent) at high heat to digest particulate organic material and the Supor filter matrix, then remaining refractory material was digested using a $\mathrm{HCl} / \mathrm{HNO}_{3} / \mathrm{HF}$ ( $4 \mathrm{~N}$ each) acid mixture at $135^{\circ} \mathrm{C}$ for 4 hours. All digests were conducted in Teflon vials (Savillex). Final digest material was resuspended in 5\% nitric acid for analysis via ICP-MS (Element 2, Thermo Scientific) at the WHOI Plasma Facility, Woods Hole, MA. Elemental recoveries are good for several certified reference materials using this procedure and are presented in (Ohnemus et al, in prep). Indium (10ppb) was utilized as an internal drift monitor and for matrix/salt suppression correction (typically $<10 \%$ ). Elemental concentrations were standardized to external dilutions of a combined trace metal standard prepared with approximately crustal abundances from ICP/AA elemental standards in 5\% nitric acid.

\subsection{Synchrotron X-ray Methods}

Images of intact, dried LSF aggregates still on the polyester pre-filters and SSF extended XANES Ti-spectra were collected via synchrotron at beamline 10.3.2 at the Advanced Light Source, Berkeley CA. LSF images were collected by $\mu$ XRF mapping using the following collection parameters: map dimensions varied between $750 \mu \mathrm{m}-2600 \mu \mathrm{m}$; scale bars: $100 \mu \mathrm{m}$; beam energy: $10 \mathrm{keV}$; pixel dwell time: 50ms; pixel size: $10 \mu \mathrm{m} \times 10 \mu \mathrm{m}$, beam size ca. $11 \times 6 \mu \mathrm{m}$. SSF extended Ti- $\mu$ XANES spectra were collected by first mapping at $5197 \mathrm{eV}$ (Ba L3 minus $50 \mathrm{eV}$ ) to locate $\mathrm{Ti}$ "hotspots" as in LSF maps, typically over a 500 x $500 \mu \mathrm{m}$ area of the filter. Extended $\mu X A N E S$ were collected at multiple spots between $4930 \mathrm{eV}$ and $5150 \mathrm{eV}$ (Ti) or 7006-7412 eV (Fe) using a beam size of ca. 6 × $6 \mu \mathrm{m}$. Primary calibrations for 
$\mu X A N E S$ were to Ti and Fe-metal foils (Ti-edge at $4966.40 \mathrm{eV}$; Fe-edge at 7110.75 $\mathrm{eV}$ ) and thereafter to persistent internal beamline optical "glitches" at fixed energies.

\subsection{A Note On Units and Plotting Conventions}

For ease of comparison to the many dissolved trace metals being collected simultaneously as part of the GEOTRACES program, measurements of particulate metal concentrations in this paper are reported in molar units (typically nanomoles per L of filtered seawater), with metal ratios similarly expressed as mole ratios. In some cases, primarily when discussing relationships to crustal material, units of mass or mass ratios will be expressly mentioned.

In section plots plotted in Ocean Data View (Schlitzer, 2013), the western boundary stations 11-01 through 11-08 (to the left of the first black dividing line between sub-plots at the first $\mathrm{x}$-axis break) are plotted on a slightly enlarged scale than the rest of the zonal transect (stations 11-10 through 11-22, and 10-12 through 10-09), and the meridional section from Mauritania to Lisbon (10-7 through 10-01). This prevents the very strong lateral particulate gradients along the western boundary portion of the transect from being unrealistically contoured and allows point-to-point display of actual particulate data. We have also added $300 \mathrm{~km}$ distance padding between the cruise-overlap stations at Cape Verde (stns. 10-12 and 11-24) to allow data from both occupations to be viewed simultaneously. Spatial changes in the western boundary lateral signals may be observed in the depth-binned surface views (Fig. 8).

We have used plotting settings that allow each sample (marked with black dots in sections) to be rendered as accurately as possible in its associated depth/spatial range, with minimal smoothing across sampling points.

\section{RESULTS}

\subsection{Dataset At A Glance: Elemental Correlations}

The particulate dataset as a whole represents small size fraction (SSF) and large size fraction (LSF) particulate material in 344 samples from 22 oceanographic 
stations, typically at 16-point depth resolution. We find the highest lithogenic concentrations (e.g. of particulate iron) associated with strong proximal inputs at continental margins, benthic nepheloid layers, and hydrothermal systems. Filtering out these samples ( $\mathrm{pFe}>7 \mathrm{nmol} / \mathrm{L}$ ) initially to focus on the bulk of the dataset (leaving $n=309 / 344$ samples), we find numerous strong bivariate correlations between particulate elements (Table 1). Among the strongest positive correlations within fine particulate matter (Table $1 \mathrm{a}$, underlined, bold values, $\mathrm{R}>0.85$ ) are those between elements that are commonly considered tracers of lithogenic material: $\mathrm{Al}$, $\mathrm{Fe}, \mathrm{Ti}$, and ${ }^{232} \mathrm{Th}$; the first three best exhibit the lithogenic features that will be the major focus of this paper. The strength of these relationships across many orders of magnitude in particulate abundance (unfiltered full dataset, entire basin) is demonstrated in Figs. 2a-c (note log scales), indicating the extensiveness of lithogenic relative elemental abundances and therefore lithogenic particles themselves, across the entirety of the basin including the deep interior. Deviation from these trends additionally describes several element-specific phenomena (2a-c, annotations; see figure caption) and can indicate specific particulate inputs and processes, features which are investigated further herein.

Many other elements exhibit multiple, and strong $(R>0.5 x)$, bivariate correlations to lithogenic tracers in the SSF-notably $\mathrm{Nd}, \mathrm{Y}, \mathrm{V}, \mathrm{Mn}, \mathrm{Ni}$, and $\mathrm{Pb}$ - and thus have distributions primarily described by lithogenic particulates.

Negative correlations between particulate phosphorus, which can be considered a biomass indicator, and the lithogenic-like elements in the SSF (Table 1a, P, bold italics) reflect the surface maximum of biological production and biomass accumulation contrasted with the relative minima of lithogenic elements in the upper water column. We show in the modeling section of our discussion that the processes explaining these observations are linked through near-surface aggregation and sinking of large particles.

Bivariate correlations within the large size fraction (LSF, Table 1b) indicate similarly strong internal lithogenic relationships among $\mathrm{Al}, \mathrm{Fe}$, Ti and ${ }^{232} \mathrm{Th}$. Additionally, strong biogenic/authigenic relationships among particulate $\mathrm{P}, \mathrm{Co}, \mathrm{Cd}$, and $\mathrm{Mn}$ are also observed. These biotically-driven (P-to-X) particulate relationships 
are often stronger in the LSF than the SSF. The relative abundance of particulate organic matter is lower in the SSF below the euphotic zone compared to the LSF (Lam et al. in prep), which may explain the weaker biogenic signals in the SSF.

Principal component analysis (PCA) was conducted on a subset of the SSF dataset for which full elemental data are available ( $n=199$ of 344 samples). Excluded from the analysis were the elements $\mathrm{Ag}, \mathrm{Nd}, \mathrm{Ni}$, and $\mathrm{Zn}$ (which were not analyzed at all stations, or which had many samples below detection) and the high abundance samples ( $\mathrm{pFe}>7 \mathrm{nmol} / \mathrm{L})$, as in Table 1 . All elements were first meancentered and normalized to their standard deviations. PCA was conducted, in part, using the "PLS_Toolbox" for MATLAB developed by Eigenvector Research, Inc.

The first five principal components together explain $91.3 \%$ of total dataset variance (Fig. 3). The first component (50\% of total variance) is strongly indicative of lithogenic material, since it describes $>85 \%$ of the variances for known lithogenic tracers $\mathrm{Al}, \mathrm{Fe}$, Ti and ${ }^{232} \mathrm{Th}$, and $>50 \%$ of variances for $\mathrm{V}, \mathrm{Y}$, and $>60 \%$ for $\mathrm{Pb}$. The second principal component (18.0\% of total variance) describes what is primarily biogenic particulate variability associated with $\mathrm{P}, \mathrm{Co}, \mathrm{Cd}$, and $\mathrm{Mn}$ distribution patterns. The third component largely describes $\mathrm{Ba}$ and $\mathrm{Cd}$, which share subsurface maxima features beneath high productivity margin stations. The distributions and variations within the biogenic and authigenic tracers (components 2 and 3) are the subjects of a separate publication (Ohnemus and Lam; in prep). Further principal components typically describe remaining variance that is largely element specific: the fourth mostly describes particulate $\mathrm{Cu}$ variance, highlighting the unique nature of this element; the fifth describes $\mathrm{Mn}$ and $\mathrm{Pb}$ variances, which have been previously implicated in co-transport via Mn-oxides (Boyle et al., 2005; Sherrell and Boyle, 1992).

\subsection{General Oceanic Distribution of Lithogenic Particles}

Concentration sections of the primary lithogenic tracers (Al, Fe, Ti) are presented in Fig. 4 for the small size fraction. Considering the strong degree of elemental correlation previously described, the overarching views illustrated by sections of particulate $\mathrm{Al}, \mathrm{Fe}$ and $\mathrm{Ti}$ are unsurprisingly quite similar, though several 
inputs and processes are more notable in specific elements. Highest lithogenic concentrations by several orders of magnitude (see Fig. 4, caption for absolute amounts) were observed in active benthic nepheloid layers (BNL) when these layers were successfully sampled at both western and eastern margins. Lowest overall lithogenic concentrations were observed in the euphotic zone (0-200m depth) at nearly all stations, with surface or near-surface/deep chlorophyll max (DCM) minima that are especially pronounced in the subtropical gyre (stns. 11-12 through 11-22 and 10-05; typically <600pM Fe, SSF). These low surface concentrationsand the frequent absence of any mixed layer lithogenic maximum that would normally be considered evidence for aeolian/dust inputs-are, we will show, not in conflict with general understanding of the North Atlantic as strongly influenced by aeolian deposition, as also proposed by Dammshaüser et al. (2013).

Mid-water column (500-3000m) lithogenic inventories are elevated nearer the continental margins compared to the corresponding open ocean loads. In the eastern basin, high lithogenic loads are observed between Cape Verde and Mauritania beneath the Saharan dust plume (stns. 10-09 through 10-12; and 11-24) and near Lisbon (stn. 10-01) within influence of the Mediterranean outflow. In the western basin, stations along oceanographic Line W from Cape Cod to Bermuda (stns. 11-01 through 11-10) show elevated lithogenic concentrations associated with boundary current/shelf interactions along the North American continent. Hydrothermal inputs near the mid-Atlantic ridge system (MAR) are most evident in the Fe sections. Elevated pFe loads were observed within the neutrally-buoyant hydrothermal plume sampled near the TAG hydrothermal site (stn. 11-16; up to $46 \mathrm{nM} \mathrm{pFe}$ at $3300 \mathrm{~m})$.

Size partitioning between the LSF $(>51 \mu \mathrm{m})$ and SSF $(0.8-51 \mu \mathrm{m})$ size classes are comparable for all three lithogenic tracers, a section of which is presented for Fe in Figure 5 (LSF/Total). With few exceptions, below ca. 500m lithogenic particulates are predominantly (80-90\%) observed in the SSF (Fig. 5). Lithogenic LSF relative abundances are consistently highest, however, near the ocean surface, where $50-80 \%$ of lithogenic material partitions into the LSF between the mixed layer and $200 \mathrm{~m}$, decreasing to $25-40 \%$ between $200-500 \mathrm{~m}$ depth, and then $5-15 \%$ 
below. Micro x-ray fluorescence ( $\mu \mathrm{XRF}$ ) images (Fig. 6) of LSF particles from a range of depths at stn. 10-09 (and stn. 10-11 and 10-12, not shown) along the MauritaniaCape Verde portion of the transect visually demonstrate that lithogenic particles in the LSF are due to near-surface packaging of micron-sized aeolian particles into large $(>51 \mu \mathrm{m})$ marine aggregates, and not large $(>51 \mu \mathrm{m})$ lithogenic particles.

\section{Discussion}

We begin our discussion by examining the different regional particulate inputs notable in the lithogenic concentration and ratio sections. We then examine several of the element-specific behaviors and size-fractionation processes observed in the transect. Finally, we present a 1-D aggregation/disaggregation/sinking model that describes upper and mid-ocean particulate dynamics as illustrated by the relatively inert particulate lithogenic tracer titanium.

\subsection{Bulk Input Composition Ratios}

Many surface, mid-water, and benthic distribution features are more obvious in ratio sections of the tracers (Fig. 7 a-f), which also serve to illustrate regions influenced by various particulate inputs. Elevated element-specific inputs or particulate accumulation processes (such as scavenging from dissolved phases and active biological uptake) show as warm colors in plots where that element is the numerator.

Over such large spatial scales, one may expect the water column to act as a lithogenic particle integrator, wherein ratios expressed across a basin-wide section indicate bulk composition of dominant annual or inter-annual lithogenic inputs. Key crustal ratios are indicated as scale-bar annotations in Figure 7 (caption), from several commonly cited references of crustal composition. Ratios measured in African dust sampled near Cape Verde and digested for total elemental composition (data from R. Shelley, and W. Landing, pers. comm.) are also included ("AD") for comparison. Notably, no single crustal estimate (dust, UCC, or BCC) explains all three tracer ratios consistently, emphasizing that element-specific in situ behaviors (namely Al scavenging, Fe biotic uptake and scavenging, and differential Ti 
compositions) can effect significant departure of marine particulate ratios from mean crustal abundances, assuming those abundances do act as appropriate bulk particulate input end-members.

Titanium ratio sections (Fig. 7c, 7f) highlight variation in crustal input composition, as titanium is a more minor, and thereby variable, component of continental minerals than $\mathrm{Al}$ or Fe (Ti: $0.72 \% \mathrm{wt}$. of bulk continental crust/BCC, versus Al: $15.9 \%$ wt. and Fe: 6.7 \%wt.; Rudnick and Gao, 2003). Sections across the North Atlantic demonstrate differences in input dominance between sites primarily influenced by African dust ("AfDust") versus those primarily influenced by the North American boundary particulates ("NAm") or the Med-outflow ("Med"). Bulk particulate input variations are also notable in the Ti/Al section, wherein open ocean stations between $\mathrm{CV}$ and Bermuda exhibit ratios largely reflective of African Dust ("AfDust") lithogenic inputs (Ti/Al between 0.037-0.045), while near-shelf stations influenced by N. American margin particulates ("NAm") possess generally lower Ti/Al ratios (0.028-0.040) better described by bulk continental crust.

Lithogenic source variability is especially notable in the Fe/Ti ratio distributions (cf. Figs. 7b, 7f vs. 7c, 7g) where relative enrichment in Ti abundance near Cape Verde seems to drive sub-surface ( $>300 \mathrm{~m}$ depth) local deficits in the $\mathrm{Fe} / \mathrm{Ti}$ ratio. Similarly striking elevated ratios are seen in relative abundances of particulate iron in the deep mid-basin (Figs. 5a; 7a-b; 7d-e), reflecting mid-Atlantic ridge (MAR) hydrothermal ("HT") inputs, likely of fine Fe-oxyhydroxides, which appear to influence mid-water composition ratios many hundreds of kilometers away from the ridge system.

Aluminum ratio sections (Figs. 7a, 7d) demonstrate boundary and depthdependent scavenging of this metal ("SCAV") near the continental margins, especially in the SSF, and elevated concentrations in Med-outflow lithogenic particulates ("MED"), benthic nepheloid layers (BNL) along the western boundary, and the upper $500 \mathrm{~m}$ along line $\mathrm{W}$ perhaps in association with detached/intermediate shelf nepheloid layers. Elevated $\mathrm{Al} / \mathrm{Fe}$ ratios in the western portion of the section may also be in association with boundary current-associated 
resuspension of old (UCC-like) N. American crustal material (Lisitzin, 1972; Moran and Moore, 1991) which has an elevated Al content ("UCC ${ }_{T}$ ").

Elevated particulate iron ratios are also observed in surface waters in the SSF, but less so in the LSF, which we hypothesize is associated with active biological accumulation and recycling of Fe primarily in small organisms ("BIO", Fig. 7b and 7e). Fe/Ti ratios near the surface are generally higher (at or above african dust ratios) in the SSF than LSF, indicating that biological uptake and recycling of Fe as a micronutrient occurs primarily within these fine, biogenic particles.

Notably absent from the particulate concentration and ratio plots are any readily apparent influences of the African oxygen minimum zone (OMZ), located in the 200-1500m depth range between Cape Verde and Mauritania. Significant OMZassociated concentration maxima are observed for many dissolved trace metals and macronutrients due to remineralization sources and increased residence times at low oxygen concentrations (e.g. Noble et al., 2012; Fitzsimmons et al. 2013). Elevated dissolved Fe in the OMZ (Fitzsimmons et al., 2013) might be expected to precipitate as $\mathrm{Fe}$ oxyhydroxides in the strong oxygen gradients both above $(200 \mathrm{~m})$ but especially below (1000-1500) the OMZ. There is little evidence for this in the Fe:Ti ratios (Figs. 7b, 7e), however, as the high flux of lithogenic material in this region from African dust appears to mask any such signal, at least in the particulate totals presented here. An increase in the weak-leachable fraction of Fe or other scavengable metals may be expected within these oxygen gradients, but such signals will be present against a background of the elevated local lithogenic loads associated with African dust and thus may be very slight.

\subsection{Benthic Nepheloid Layers}

Benthic nepheloid layers (BNLs) are notable in this dataset for the extremely high concentrations of lithogenic particles observed. Western margin BNLs were observed at 4 of 7 stations between Woods Hole and Bermuda (3 of which were successfully sampled) and were found to extend nearly $1000 \mathrm{~m}$ off the ocean bottom in the case of the BNL at BATS (stn. 11-10; Fig. 4). Prior ocean surveys of marine particle distribution including the LDGO Nephelometry survey, GEOSECS and the 
HEBBLE program (Gardner et al., 1983) identified and quantified BNLs using nephelometry, bottle filtration, and sediment traps. They noted the great intensity of BNLs on the western margin (Biscaye and Eittreim, 1977), and postulated the importance of benthic isopycnal structure in constraining BNL vertical extent (Brewer et al., 1976). We observed concentrations of particulate Fe in westernbasin nepheloid layers that approached the micromolar level $\left(\mathrm{pFe}_{\text {total }}=973 \mathrm{nM}\right.$, stn. 11-04), nearly three orders of magnitude greater than the mean mid-water column (1000-3000m, open ocean) pFe concentrations of $1 \mathrm{nM}$. The extreme concentration variability of near-bottom lithogenics over several orders of magnitude are also shown in Figure 10d using particulate Ti as an indicator.

We note key chemical differences between eastern and western boundary BNL particulates, which likely reflect different underlying sedimentary redox states resulting from different water column structures and the overlying productivity regimes. The only eastern boundary BNL successfully sampled during the 2010 cruise (no altimeter or pinger was present to determine wire distance above bottom) was located at stn. 10-09, 200km from the Mauritanian coast and beneath the strongest segment of the Saharan dust plume (Mahowald et al., 2009).

The Mauritanian/eastern BNL was most notable in its strong enrichment in particulate iron (and manganese, not shown) evident relative to Ti in Fig. 7b ("BNL 10-09") compared to the overlying mid-water column particles, indicative of a reducing sedimentary source of $\mathrm{dFe}$ and $\mathrm{dMn}$. Reprecipitation of these metals nearer the sediment-water interface or in the overlying water column leads to authigenic oxide formation, which enriches $\mathrm{pFe}$ and $\mathrm{pMn}$ concentrations in suspended matter relative to Ti. This chemical distinction reflects the BNL's location beneath the Mauritanian upwelling system and the associated high productivity (Carr, 2001) and flux (Ratmeyer et al., 1999) of organic carbon, creating benthic conditions amenable to sustained, suboxic sedimentary diagenesis.

BNL lithogenic ratios along the western margin, by comparison (Fig. 7, BNLs 11-04/-08/-10), do not show notable relative Fe or Mn enrichment compared to overlying particles, and may even be slightly Fe poor (cf. BNL 11-08, Fig. 7b) relative to Ti. This contrasts with previous observations of Fe excesses in North Atlantic 
BNLs (Lambert et al., 1984) that were calculated using fixed Al:Fe mass ratios of 2:1 (Al:Fe mole ratio of 4:1; cf. Fig. 7a: lower ratios would indicate Fe excesses). Our data show little evidence for Fe excess in the BNLs, especially in comparison to most of the rest of the water column (Figs. 7a,b). Lambert et al. also observe no Mn excess at GEOSECS stn. 120 (their closest reported station to our transect; near our station 11-14) and only slight Fe enrichment there (13\%). The extremely high lithogenic concentrations observed in western-boundary BNLs may indicate that continued, presumably turbulent, resuspension of the large amounts of sedimentary material necessary to sustain such intense BNLs, is precluding (or masking, via large mass inputs) any reductive sedimentary processes and/or authigenic oxide formation, should either be present.

Most open ocean stations between $\mathrm{CV}$ and Bermuda exhibit decreases in the SSF Ti/Al ratio near the ocean floor (typically Ti:AlsSF $\leq 0.035$, compared to overlying ratios $\geq 0.035$ ), regardless of whether a benthic nepheloid layer was observed at the time of sampling. These near-bottom ratios may represent both proximal and distal effects. Proximal effects may include sedimentary release of dAl during diagenesis and in situ scavenging onto local suspended particulates, enhanced scavenging rates of $\mathrm{dAl}$ because of higher near-bottom particle loads in the case of nepheloid layers (Rutgers van der Loeff and Boudreau, 1997), or local resuspension of Al-enriched sediments (Murray and Leinen, 1996). Distal influences potentially include far-field suspended lithogenic signatures associated with deep water masses, including AABW and NADW, and any initial and/or acquired signatures of suspended particles therein (Diekmann et al., 2004; Petschick et al., 1996).

Slight, but notable increases in lithogenic LSF relative abundance near the ocean bottom in association with lithogenic maxima at eastern basin stations could alternatively (or additionally) indicate in situ particle aggregation occurring near the ocean bottom (cf. Figs. 4 and 5, stns. 11-20 through 11-24, 10-05, and 10-07; increasing litho. concentrations and LSF partitioning from $\leq 25 \%$ LSF mid-water column to 25-35\% LSF near-bottom). These weak, near-bottom nepheloid-like signals are likely more prevalent in the open ocean than the charismatic, particle- 
dense, boundary-associated BNLs observed nearer the margins, and may involve fundamentally different, subtler water column resuspension and particulate dynamics (McCave, 1983). McCave noted a 2- to 3-fold increase in coarse mode particulates (measured by Coulter Counter over a 1.26-32 $\mu \mathrm{m}$ size range) up to 500 meters above bottom (m.a.b.) near the Nova Scotian continental rise, even at relatively quiescent stations. He attributed these near-bottom coarse mode excesses to a mixture of resuspended coarse-mode particles (primarily <250 m.a.b., particles which resisted ultrasonic disaggregation) and temporal variation in vertically-sourced large aggregates. Our observation of a relative increase in $>51 \mu \mathrm{m}$ (LSF) lithogenic aggregates $>500 \mathrm{mab}$ at otherwise quiescent stations is thus somewhat unexpected. Though untested, our $>51 \mu \mathrm{m}$ LSF aggregates, would not be expected to resist ultrasonic disaggregation, as most lithogenic material itself is $<51 \mu \mathrm{m}$. We assume that horizontal inputs of LSF material are not significant at these sites, and hypothesize that nepheloid resuspension is insufficient to place $>51 \mu \mathrm{m}$ material $>500$ m.a.b. We observe this feature at multiple stations in the open ocean, so in the absence of linked variability in surface-sourced aggregates at multiple stations, we must implicate in situ aggregation of SSF material into the LSF and/or increased LSF residence times of vertically sourced material nearer the ocean bottom to explain the increase in relative LSF aggregate abundances $>500$ m.a.b.

\subsection{Unique Ti Mineralogy Near Cape Verde}

Subsurface particulates collected near the Cape Verde islands were especially high in Ti content (Fig. 7c, 7f; "CV"; stns. 10-10 through 10-12, 400-800m and 2000$4000 \mathrm{~m}$ ) which we suspected represented proximal dust or lateral inputs of Ti-rich, basaltic minerals from the Cape Verde Islands hotspot. We examined the Timineralogy of several SSF marine particles samples and, for comparison, an aerosol sample of African dust collected on the same cruise. Two marine particulate samples collected near Cape Verde (stn. 10-12, 800m and 2000m) and two marine

particulate samples dominated by African continental inputs near Africa/Mauritania (stn. 10-09, 800m and 2000m) were compared with an African-dominated aerosol 
sample also collected near stn. 10-09 (provided by R. Shelley and W. Landing) using extended micron-scale x-ray absorption near-edge spectroscopy ( $\mu$ XANES) across the Ti K-edge ( $4980 \mathrm{eV}$ ) at the Advanced Light Source (ALS, beamline 10.3.2). We compared the Ti-speciation multiple Ti "hotspots" in these samples to a small $(n=6)$ but diverse library (Fig. 8a) of Ti-bearing minerals previously collected at the beamline (M. Marcus, pers. comm.). The library consisted of the Ti-oxides $\left(\mathrm{TiO}_{2}\right)$ rutile and anatase, and the common Ti-bearing mineral phases ilmenite $\left(\mathrm{Fe}^{2+} \mathrm{TiO}_{3}\right)$, biotite (a mica), and augite (a pyroxene/silicate).

Extended XANES spectra were collected for $\mathrm{n}=10-12 \mathrm{Ti}$ "hotpots" per sample. The pre-edge subtracted and normalized spectra were then fit using a linear combination of up to 3 model compounds from the mineral library to determine the relative composition for each spot. The model-fit relative abundances were summed over all spots to produce an overall composition estimate for each sample, with the caveat that each spot was weighted equally regardless of spot intensity.

Good model fits (sum of squared residuals $<7 \times 10^{-4}$ ) were observed for the near-Africa (stn 10-09) marine and aerosol samples using the mineral library alone. These samples were primarily mixtures of the Ti-oxides anatase and rutile, with smaller contributions of ilmenite $\left(\mathrm{FeTiO}_{3}\right)$ and biotite (mica) (Fig. 8b). Excellent compositional agreement between the stn. 10-09, 800m marine sample and the African dust sample confirm that aerosols or aerosol-like mineral assemblages are the main source of Ti to the water column in the region just off the African coast. The deeper (stn. 10-09, 2000m) African marine sample, which potentially expresses influence from lateral slope/margin sediments (Conway and John, in prep), lacked the ilmenite and mica components found in the aerosol sample and the $800 \mathrm{~m}$ water column sample. Instead, a corresponding increase in relative rutile composition was observed, indicating that water column or sedimentary diagenetic processing of Ti-bearing minerals may have occurred. $\mathrm{Fe}^{2+}$ present in ilmenite can be diagenetically removed either reductively or oxidatively, leaving behind a rutile matrix (Morad and Aldahan, 1986). A separate, lateral source of rutile-rich lithogenic material, perhaps from margin/slope sediments, is also a possibility. 
On its own, the Ti mineral library did a poor job (bad model fits, sum-ofsquared residuals $>10^{4}$ ) fitting spectra of Cape Verdean-influenced marine particulates. Inclusion of an otherwise unidentified but distinct Ti-XANES spectrum that was frequently observed in the Cape Verdean samples (8. 9a, "GT6058, CV Mineral") as a library end-member, however, significantly improved model fits. The apportionment ascribed to this unknown mineral exceeds $50 \%$ in marine sample near CV (stn 10-12, 800m), and approaches 20\% in the deeper (stn. 10-12, 2000m) CV-influenced sample. The Cape Verde Islands (CVI) and associated plateau are geologically sourced from a mantle hotspot and are thereby rich in fresh basaltic minerals. Many mantle hotspots, including Cape Verde, have elevated and/or highly variable Ti rock content (Ti:Al $=\sim 0.5$ by wt.; Davies et al., 1989; Prytulak and Elliott, 2007) compared to the well weathered continental material present in Saharan aerosols (Ti:Al $\sim 0.07$ by wt.; Stuut, 2005). Titano-magnetite and titanomaghaematite are two notable Ti-rich Fe-oxides often found in such basaltic mineral assemblages that are notably absent from our spectral library and may be considered candidates for this material. Comparison of our unidentified CV spectrum to Ti-spectra for these and other common, Ti-rich minerals could aid in their identification in the water column.

Regardless of the exact mineral identification, surface (aeolian) and/or subsurface (lateral) erosion of the CVI plateau are, together, leading to a pointsource-like water column resuspension of Ti-rich lithogenic material. This may be true for other ocean island hotspots as well, including Hawaii, Samoa, Iceland, and the Galapagos, which have modern magma sources known to be Ti-rich (Jackson et al., 2008). We are unable to determine specifically whether dust or lateral inputs of $\mathrm{CV}$-sourced lithogenic particles are the ultimate source of this Ti-rich material, though we note that the LSF possesses strikingly higher Ti:Al ratios than the SSF (Fig 7c, f). If this indicates the Ti-rich end-member is found in greater relative abundance in the LSF, an ultimate dust source appears more likely: surfacepackaged LSF aggregates should reflect local dust inputs more directly, as discussed further in our model, while the SSF would represent a grander mixture of CV and 
African-sourced dust. An ultimate lateral input, by comparison, would be expected to impart a stronger (Ti-rich) SSF signal than LSF, which is not observed.

Away from CV, elevated Ti/Al ratios in LSF and SSF particles were observed at occasional depths between 0-500m at open ocean stations 11-16 through 11-20, and may reflect recent, episodic, or inter-annual variation in inputs of Ti-rich dust. If so, African dust-generating regions with elevated Ti/Al ratios (Stuut, 2005) are more likely to be the source of the Ti-rich dust than CV itself due to Africa's greatly dominant dust generating capacity.

\subsection{Hydrothermal/MAR Inputs}

Hydrothermal systems, though not traditionally lithogenic in nature, are nevertheless a significant source of particulate Fe directly into the submarine water column. X-ray Absorption Near Edge Spectroscopy (XANES) of a SSF sample from $3300 \mathrm{~m}$ in the TAG hydrothermal plume at station 11-16 showed that fine particulate Fe spectra were dominated by 6-line ferrihydrite (not shown). Note that since the particulate samples were dried and stored at room temperature for $\sim 10$ months prior to analysis, oxidation of potential nano-scale pyrite in the sample (Yücel et al., 2010) could have occurred, but previous work has shown that micronsized pyrite is stable in particulate samples stored under these conditions (Lam et al., 2012). We observe Fe-enrichment of SSF particles in the 2000-3000m depth range throughout the western gyre (Fig. 4b, "HT"), indicating that fine, presumably MAR-sourced Fe-oxyhydroxides have far-field influence on particle distributions. Examination of how this particulate signal changes with distance from ridge sources may shed light on fine particle sinking rates and subsurface packaging behaviors in the deep ocean.

Strong absolute particulate Fe concentration enrichments were not observed at similar depths at flanking stations $11-14$ and $11-18,500 \mathrm{~km}$ to the west and east respectively, but notable relative $\mathrm{Fe} / \mathrm{Ti}$ and $\mathrm{Fe} / \mathrm{Al}$ enrichments were noticeable in the SSF at those stations, especially to the west (Fig. 7b) where long-term geostrophic flow of neutrally buoyant plume particles is expected (LaCasce and Speer, 1999). Further comparison of the abundances of the lithogenic metals, other 
important hydrothermal carrier phases (specifically Mn-oxides), and trace metal signatures of other key hydrothermally sourced particulate elements $(\mathrm{Ag}, \mathrm{Cd}, \mathrm{V}, \mathrm{Zn})$ will be the subject of a separate publication.

\subsection{Evidence for scavenging}

In our section, $\mathrm{Al}$ displayed notable scavenging-like enrichment onto fine particles relative to Ti at stations near ocean margins (red points in Fig. 9; also Fig 7a: stns. 10-09, stns.. 11-01 through 11-06) exhibiting up to $40 \%$ enrichment over open ocean ratios. Enrichment of $\mathrm{Al}$ is also suggested versus depth, with 20-30\% enrichment appearing typical below $2000 \mathrm{~m}$ even in open ocean stations. These results are consistent with previous observations of $\mathrm{Al}$ scavenging relative to $\mathrm{Ti}$ in the equatorial Pacific (Murray and Leinen, 1996), and suggest that using un-leached particulate $\mathrm{Al}$ totals alone for lithogenic normalization could lead to overestimation of the lithogenic fraction, particularly in near-margin or deep particle samples. The US GEOTRACES North Atlantic zonal transect cruises occurred during periods of very low diatom productivity, even at the margins. Since opal has been implicated in the scavenging of dissolved Al (Middag et al., 2009), times of higher diatom productivity could result in even higher excess pAl due to scavenging.

Of all the elemental ratios plotted, $\mathrm{Ti} / \mathrm{Al}$ distributions were most similar between SSF and LSF, suggesting that Ti is less susceptible, on basin-wide scales, to particulate ratio-altering amounts of scavenging and biological recycling processes. Such processes should influence the SSF more strongly due to its (generally) higher relative abundances, longer residence times, and greater surface area for scavenging compared to the LSF.

\subsection{Lithogenic Normalization}

Which element ( $\mathrm{Al}, \mathrm{Fe}$, or $\mathrm{Ti}$ ) is the best choice as a lithogenic normalizer? The answer lies in which assumptions about crustal abundance and in situ elementspecific variations are least likely to fail at any given site. Biological Fe enrichment in fine surface particulates (Fig. 7b) eliminates Fe as a general marine lithogenic normalizer, at least in the upper ocean and in particle regimes where Fe-enriched 
biotic contributions significantly vary in time. $\mathrm{Al}$ is the more traditional choice for crustal normalization, as it varies minimally between various canonical continental crustal sources (UCC: 8.04 wt.\% vs. BCC 8.41 wt.\%; Taylor and McLennan, 1995), but scavenging of Al near margins could lead to an overestimate of the lithogenic fraction.

As a minor and more source-variable component of crustal material than Fe or $\mathrm{Al}$, Ti may prove useful in indicating point-sources of distinct mineralogy, thus allowing tracking of local aeolian or lateral particulate inputs, as demonstrated with the high relative abundances observed in particles near Cape Verde (Fig. 5c and 5f). These Ti signals may also be preserved in proximal, if not distal, marine sediments depending on Ti mineral diagenesis. But is Ti useful as a general lithogenic normalizer as well? Ti has the disadvantage of varying greatly as a function of different source material (e.g., UCC Ti $=0.3 w t \%$ and BCC Ti $=0.54 w t \%$ ). But while Ti is more variable, it has the advantage of not being as affected by scavenging (cf. Al) or biological uptake (cf. Fe). Its utility as a lithogenic normalizer thus depends on the likelihood of significant variations in the Ti composition of lithogenic particle sources in time and space, and the possibility to correct or constrain for these compositional differences.

In the water column, Ti may be especially useful for determining excess (nonlithogenic) particulate $\mathrm{Fe}$, since the ratio of Fe:Ti remains relatively constant between source regions (Fig. 7, source arrows). Throughout the deep section, Tirich African dust-like ratios are observed throughout the majority of the mid-basin (near CV excepted), while Ti-poor and/or Fe-rich (Lambert et al., 1984) particles from N. America are observed more generally in the western basin along Line W. This type of broad input homogeneity is conducive to meaningful lithogenic determinations using this element. As we improve our understanding of marine lithogenic particle inputs, source/end-member compositional variations, and in situ scavenging behaviors of lithogenic elements, we can improve lithogenic corrections conducted using $\mathrm{Al}$ and $\mathrm{Ti}$.

\subsection{Aeolian and Lateral Lithogenic Inputs}


Terrestrially derived aeolian input of mineral dust is considered to dominate exogenous lithogenic particulate delivery into the upper water column in the subtropical North Atlantic (Jickells, 2005; Mahowald et al., 2005). If strongly vertical packaging and sinking processes dominate lithogenic behaviors, the standing water column inventories of lithogenic metals may thus be expected to broadly reflect the basin's aeolian deposition patterns. Regions where water column inventories show positive deviations from aeolian patterns should indicate lateral sources of lithogenic material from the continental margin, and/or natural variations in vertical processes. To isolate and discuss the broad distribution of these features in the lithogenic dataset, we divide the section into several depth ranges $(0-200 \mathrm{~m}$; $200-1000 \mathrm{~m} ; 1000-3000 \mathrm{~m}$ ) and examine the station-by-station total particulate $\mathrm{Ti}$ inventories (Figs. 10a-c) along with bottom-most sample concentrations (Fig. 10d).

High lithogenic inventories are noted nearer the margins for all depth ranges. Surface lithogenic inventories (Fig. 10a, 0-200m), which are generally very low compared to other depth ranges, display rapid decreases away from the $\mathrm{N}$. American margin along Line $\mathrm{W}$ and away from the African margin at Mauritania, and a slight local maximum is observed near Cape Verde at the TENATSO station ca. $70 \mathrm{~km}$ from the island chain. These distributions are consistent with surface inventories of lithogenic particles that reflect more variable effects of recent (order: days to weeks) dust events and any short-range, proximal coastal or shelf-sourced lateral inputs (See 4.8: Lithogenic Residence Times).

Open-ocean inventories in the $0.2 \mathrm{~km}-1 \mathrm{~km}$ depth range (Fig. 10b), by comparison, are larger and steadily decrease from east to west (stns. 11-22 to 1110). This inventory pattern broadly reflects the basin-scale annual dust deposition patterns estimated by modeled dust deposition (Mahowald et al., 2005), which is provided for comparison (Fig. 10e). Decreasing mid-water column lithogenic inventories away from the African coast in the Mauritania-CV transect could be consistent with both patterns of aeolian deposition (Mahowald et al., 2009) and/or lateral transport from the African margin. Dissolved tracers including ${ }^{228} \mathrm{Ra}$ (halflife 5.75y; Charette et al. in prep), however, suggest little lateral transport in this 
region, implicating a primarily dust source of lithogenics on the basin's eastern margin near Africa.

Elevated near-margin inventories along line $\mathrm{W}$ in both the $0.2-1 \mathrm{~km}$ and the $1 \mathrm{~km}-3 \mathrm{~km}$ depth ranges (Fig. 10b and 10c), however, appear unsupported by dust deposition patterns alone and are thus consistent with lateral sources of lithogenic material. We observe elevated lithogenic concentrations in the $1-2 \mathrm{~km}$ depth range along Line W (Fig. 4, "LSW"; Fig 10c, western margin) associated with the Labrador seawater water mass, as identified by CFC concentrations and T-S characteristics (Smethie, in prep). Labrador seawater is a portion of North Atlantic Deep Water that impinges upon and interacts with the N. American slope (Bower et al., 2011), picking up lithogenic material and dissolved metal signatures (many authors, in prep) along its near-margin transit.

The Mediterranean outflow ("MED” Fig 4; Stn 10-01, and Fig. 10c) is another prominent lateral feature sampled at stn. 10-01 that demonstrates the strongly vertical behavior of lithogenic particulates, even in the fine size fraction. McCave and Hall (2002) extensively documented Mediterranean water (MW) turbidity using transmissometry, noting the rapidity with which MW loses its suspended particulate load as it exits the Gulf of Cadiz and transits along the Portuguese shelf (cf. their Fig. 3). At our station 10-01, located NE of their station M42-02, we observed Mediterranean-sourced fine particulates beginning at $420 \mathrm{~m}$ depth, with a maximum at $695 \mathrm{~m}$ where pFe was measured at $57 \mathrm{nM}$ in the SSF, consistent with prior turbidity measurements. We note that this MW-associated particulate signal is especially Al-rich (Fig. 7a), a signature visible throughout all depths beneath the absolute concentration maximum, indicating settling of suspended particulate matter out of its MW source.

\subsection{Lithogenic Residence Times}

Calculation of lithogenic particulate residence times at any given depth, or within a given depth range, requires knowledge of the inventory and either the input or removal fluxes. We can calculate inventories from our concentration measurements taken at single points in time, but must rely on estimates of input or 
removal fluxes, both of which can vary significantly in both time and space. Nonetheless, the exercise of generating residence times and export fluxes can illustrate how lithogenic inventories may help constrain both marine packaging and export systems as well as lithogenic inputs themselves.

Using station-by-station inventories of particulate Ti in various surface depth ranges (Table 3), estimates of the annual average input rates of aerosol dust from the Aeronet_Median deposition model (Aerocom, 2013), and assuming a Ti composition of $0.56 \%$ by weight, we calculate open ocean lithogenic particle residence times in the upper $200 \mathrm{~m}$ between $30-60 \mathrm{~d}$, and residence times in the upper $1000 \mathrm{~m}$ of $0.5-2 \mathrm{y}$. Calculated residence times near the western margin (stns.. 11-01 through 11-06) and in the east near Lisbon (stn.. 10-01) when dust is assumed as the only lithogenic input, are unrealistically high (decades), reflecting these regions' significant lateral sources of lithogenic Ti that are unsupported by aeolian dust. In the open ocean, however, the assumption of aeolian dust as the only lithogenic input flux is more appropriate. We can calculate the steady state net sinking (export) speeds through each depth layer by dividing the thickness of the layer by the residence times. Again, calculated sinking rates along Line $\mathrm{W}$ and near Lisbon are unrealistic due to the dominant lateral sources of lithogenic material at these stations. Nonetheless, two major trends are notable in the open ocean portion of the transect: a general increase in net speed from west to east, and a general decrease in net speed as the depth of integration increases (4.9-9.6 m/day W-to-E through $200 \mathrm{~m} ; 2.2-6.3 \mathrm{~m}$ /day W-to-E through $1000 \mathrm{~m}$ ).

Our observation that net sinking speed decreases with depth is primarily due to the fact that the relative proportion of rapidly-sinking LSF particles decreases dramatically between the upper $200 \mathrm{~m}$ and the $200-1000 \mathrm{~m}$ depth range (Table 3 ) as lithogenic-bearing LSF marine aggregates are remineralized beneath the euphotic zone. In the deep ocean interior, $80-90 \%$ of the lithogenic particulates are found in the SSF (Fig. 5), which has a greatly decreased, if not negligible, mean sinking speed. Mean deep integration residence times are more reflective of this net "slower" mixture of predominantly fine particles. Assuming these fine particles have a negligible $(0 \mathrm{~m} / \mathrm{d})$ sinking speed, and that $80 \%$ of lithogenic mass partitions into the 
SSF below ca. $300 \mathrm{~m}$, bulk sinking speeds (LSF+SSF) on the order of 2-6 m/d correspond to LSF sinking speeds of $10-30 \mathrm{~m} / \mathrm{d}$. This is not to say that all LSF particles fall within these speed ranges - many particles and aggregates may greatly exceed these speeds-simply that in a two-size fraction reduction of the natural system, these represent the bulk speeds required to balance inputs, inventories, and each size-fraction's relative abundances.

Calculations indicating decreasing residence times (or increasing particulate sinking speeds; or both) from west to east are less straightforward to explain. Both results are directly sensitive to the assumed (in this case: annual) dust input rates, with the shorter residence times in the upper 200m (order: weeks) more likely to be biased by recent temporal variations in actual dust inputs. For greater depths of integration, however, the trends are more likely to be appropriately matched to annual dust flux estimates. The main driver of our longitudinal variations in residence times and mean sinking speeds is the observation that the gradients in $\mathrm{Ti}$ inventories (a 2- to 3-fold increase from BATS to stn. 11-22, depending on the depth of integration) are less than the gradients in estimated dust fluxes (a 7-fold increase from BATS to stn. 11-22; Jickells, 2005). Overestimation of dust fluxes in the east or underestimation in the west could account for these trends. If the dust input trends are considered correct, however, we must invoke relative increases in particle removal processes under the regions of higher dust inputs. Faster relative lithogenic removal in the east could be due to additional lithogenic ballasting of sinking particles (Dunne et al., 2007; Ternon et al., 2010; Lima et al, 2013) and differences in biotic community structure that may alter export rates (Guidi et al., 2009; Henson et al., 2012; Lam et al., 2011).

Our dataset does suggest a potential export event with higher sinking speeds than those calculated from mean residence times. A putative Fe/Ti-rich LSF "export event" (Figs. 7d,e), perhaps of biogenic material possessing elevated Fe/Ti ratios, was observed as a rapidly sinking, narrow ratio anomaly at five stations (11-12 through 11-20) in the central gyre (Table 2). There is no obvious anomaly in the absolute LSF concentrations of Fe (not shown), and archive photographs of relevant and surrounding pre-filters did not show visual indication of any notable LSF 
particle shifts. This feature was therefore likely not a large perturbation to the flux of Fe, but following it does allows us to calculate a sinking speed of this putative export event. Assuming export occurred simultaneously at all five stations, and that each station was sampled approximately three days apart (Table 2), we calculate roughly depth-resolved sinking speeds of $95-180 \mathrm{~m} / \mathrm{d}$. These particle-specific sinking rates are greatly elevated compared to the mean vertical sinking speeds calculated previously and used later in our model parameters, but are consistent with higher-end sinking speeds from within a broad natural spectrum of particleclasses (Timothy et al. 2013) with similarly wide-ranging sinking rates (McDonnell and Buesseler, 2010).

Single depths showing elevated Fe/Ti ratios were observed between $0-200 \mathrm{~m}$ at stns.. 11-14 through 11-18, perhaps indicative of new production in near-surface waters of particles similar to the export event particles. We cannot, however, identify these particles specifically or demonstrate consistency between stations and depths using only our lithogenic elemental ratios.

Given slow expected net particle sinking rates at depth, we assess whether horizontal transport of suspended particles should affect our 1D assumption in calculating inventories and residence times. Mean zonal flow in the deep interior (order: $0.1 \mathrm{~cm} / \mathrm{s}$; Schott and Stommel, 1978) would necessitate ca. $5787 \mathrm{~d}$ (almost 16 years) to transit $500 \mathrm{~km}$, the typical distance between our open ocean stations. Even if we assume a slow mean deep particle sinking speeds on the order of $0.3 \mathrm{~m} / \mathrm{d}$ (ca. $3.4 \times 10^{-4} \mathrm{~cm} / \mathrm{s}$ ), vertical particle sinking should still dominate over horizontal mixing on lithogenic-relevant timescales across these station distances.

\subsection{Lithogenic Particle Cycling 1-D Model: Context}

In the upper ocean, strong partitioning of lithogenic material to the LSF (typically $>30 \% \mathrm{LSF}$, and often $>50 \%$ ) is at first surprising, given that dust is delivered in the SSF. No significant exogenous particulate input (aeolian, hydrothermal, or lateral) relevant to this section has significant size distributions in the $>51 \mu \mathrm{m} / \mathrm{LSF}$ range. Near-surface partitioning of lithogenics into the LSF indicates the importance of biotically-controlled aggregation processes in 
transferring particles from the SSF to the LSF, thus controlling the size-partitioning of lithogenic particles in the upper ocean. The dominant partitioning of lithogenic particles into the SSF for most of the ocean interior is consistent with the supply of lithogenics from dust in the SSF (Moore, 2008; Ratmeyer et al., 1999; Sedwick et al., 2005 ) and/or the lateral transport of margin derived micron-sized sediments (Lam and Bishop, 2008; Lam et al., 2012).

In XRF maps (Fig. 6), LSF aggregates from the mixed layer (0-30m, stn 10-09) were found to contain aeolian particles almost ubiquitously, while aggregates sampled from the deep chlorophyll maximum (DCM, 51m stn 10-09), beneath the mixed layer, are nearly completely free of them. Despite this oceanographic setting being among the dustiest on the planet, both XRF images of pFe (Fig. 6) and concentration profiles (Fig. 11) show that the DCM (typically 40-60m depth) has a very low abundance of lithogenic elements. Since the major external source of lithogenic particles is from the deposition of aeolian mineral dust to the surface ocean, these fine, suspended particles appear to be trapped in the mixed layer, which is isolated from the DCM, and are only transported to depth via aggregation into larger, sinking particles. The presence of a lithogenic shadow zone at the DCM suggests that disaggregation processes and direct sinking of fine lithogenic particles from above are unable to act as a net source of lithogenics directly beneath the mixed layer. Most lithogenic particles deposited in the mixed layer appear to rapidly and efficiently bypass the DCM as they are transported to depth. This has the effect of creating the strongest and most consistently observed concentration gradients in lithogenic metals at depths below rather than above the DCM.

Beneath the euphotic zone (Fig $6 \mathrm{OMZ}$ ), both aeolian-rich and aeolian-poor aggregates, presumably from the mixed layer and the DCM, respectively, are observed. In the 150-400m depth range, most aggregates begin to disaggregate, coincident with the appearance of SSF Ba/barite maxima (not shown)and indicative of organic matter remineralization and marine aggregate disassociation (Bishop, 1988). Large aggregates containing aeolian particulates are also observed in deep (>1500m) samples (Fig. 6, Deep), many of which are likely fast-sinking, dustcontaining fecal pellets generated either in the mixed layer or beneath the DCM by 
zooplankton. Taken as a whole, these images demonstrate that shallow aggregation, large particle sinking, and deep disaggregation are dominant processes controlling the vertical distribution and cycling of lithogenic particles.

We observe that in the open ocean portion of the section (stns.. 11-12 through 11-22), away from the direct influence of continental margins, several consistent features in lithogenic metal profiles indicate that aeolian input of mineral dust to the mixed layer is the dominant source of lithogenic particulate material to the water column. Deep metal ratios, especially Fe:Ti (Fig 7c), are generally consistent with those in dust collected near Mauritania. Station-by-station inventories in the upper $1000 \mathrm{~m}$ for the most inert lithogenic tracer, Ti (Fig. 10c), decrease from east to west, as is generally expected from trends in modeled and measured dust deposition fluxes from Northern Africa into the basin's surface waters (Mahowald et al., 2009). Depth profiles for particulate Ti (Fig. 11) also share a common and consistent shape in the open ocean, with the SSF (Fig. 11a) exhibiting variously pronounced local maxima $(10-75 \mathrm{pM})$ in the mixed layer, minima at the DCM (5-19pM), and remineralization-like local maxima between 150-500m depth. Profiles for the LSF (Fig. 11b) are somewhat noisier but demonstrate generally constant distributions in the 5-50pM range, with perhaps slight surface maxima (855pM), minima near the DCM, and various local maxima beneath.

Profiles of Ti size-fractionation also exhibit a common shape across the gyre (Fig. 11c), which are largely driven by low SSF abundances within and just beneath the mixed layer. In the $0-200 \mathrm{~m}$ depth range, the SSF typically accounts for $25-60 \%$ of total lithogenics, with a DCM minimum of $<20 \%$ SSF. The proportion of SSF particles increases quickly beneath the DCM at all stations, with most but not all (70-90\%) of the lithogenic material found in the SSF by $250-300 \mathrm{~m}$, a size partitioning ratio that continues into the deep (Fig. 11, lower panels). Upper ocean partitioning of Ti into the LSF is notable especially in the mixed layer, despite aeolian inputs nearly entirely into the SSF (Ratmeyer et al., 1999). Short expected residence times (Table 3) relative to input fluxes, indicate that LSF-packaging is occurring both rapidly and continuously in situ. 


\subsection{Lithogenic Particle Cycling 1-D Model: Description}

We begin by assuming that biotically-driven aggregation (and disaggregation) are the major drivers of lithogenic particle partitioning between the SSF and the LSF in the upper ocean. There are no known significant inputs of LSF Ti, nor are there any known biological Ti uptake processes, so we can also assume that all Ti entering the system does so as fine aeolian material into the mixed layer. Abiotic scavenging of Ti on the relevant particulate timescales (Table 3) in the upper ocean will also be neglected. Preliminary weak leachable Ti fractions (not shown) along the Mauritanian transect were typically $<1 \%$ of the total Ti signal, confirming Ti scavenging as a minimal source of error.

Vertically, we assume that gravity-driven large particulate sinking is the primary transport mechanism, and that horizontal transport is negligible in the open ocean section of the transect. We can thus describe any 1-D pair of SSF and LSF profiles using a multi-box model. The only input of Ti is the local dust flux $\left(F_{\text {dust }}\right)$, which is entirely into the SSF in the mixed layer. Aggregation and disaggregation between the SSF and LSF are described by the first-order rate constants $\beta_{\text {agg }}$ and $\beta_{\text {disagg }}$ (often represented in the literature as $\beta_{2}$ and $\beta-2$, respectively); and vertical transport of SSF and LSF particles between depths is attributable to their respective sinking speeds $\omega_{\text {SSF }}$ and $\omega_{\text {LSF, }}$, respectively, which is effectively converted to a rate by dividing by the thickness $(\mathrm{Z})$ of the box.

In any given box $i$, the change in concentration for the two size fractions can thus be described using a pair of first-order ordinary differential equations:

$$
\begin{aligned}
& \frac{d S S F_{i}}{d t}=F_{d u s t, i}+\beta_{-2, i} L S F_{i}-\beta_{2, i} S S F_{i}-\frac{\omega_{S S F, i}}{Z} S S F_{i}+\frac{\omega_{S S F, i-1}}{z_{i-1}} \operatorname{SSF}_{i-1} \\
& \frac{d L S F_{i}}{d t}=\beta_{2, i} S S F_{i}-\beta_{-2, i} L S F_{i}-\frac{\omega_{L S F, i}}{z_{i}} L S F_{i}+\frac{\omega_{L S F, i-1}}{z_{i-1}} L_{S F} F_{i-1}
\end{aligned}
$$

This is a simplified version of the conceptual models used to model scavenging and removal by particles of thorium isotopes (Clegg and Whitfield, 1993; Clegg et al., 1991; Marchal and Lam, 2012) that retains the particle dynamics terms 
only. We postulate that since Ti is relatively inert, we can ignore the scavenging and remineralization terms that transfer material between dissolved and small size fractions for simulating the concentration profiles of SSF and LSF pTi. The typical thickness of the mixed layer was $60 \mathrm{~m}$ during our transect, which we use as the size of the top box. Boxes are well mixed and are spaced below the mixed layer to highlight general profile behaviors: every $10 \mathrm{~m}$ in the upper $100 \mathrm{~m}$ below the $60 \mathrm{~m}$ mixed layer, every $25 \mathrm{~m}$ through $300 \mathrm{~m}$, and as necessary $>300 \mathrm{~m}$ (e.g. to follow feature propagation in long model runs.)

We begin by setting the model parameters in increasing order of uncertainty. For simplicity, we first assume a constant dust input rate. We use a constant input flux of $2 \mathrm{mg} / \mathrm{m}^{2} /$ day of lithogenic material, around the mean deposition observed at Bermuda (Jickells et al., 1998) as a baseline dust input. Assuming all dust is deposited into the $<51 \mu \mathrm{m}$ size-fraction, a Ti/Al mass ratio of 0.07 (typical of African dust collected between Cape Verde and Mauritania (Stuut, 2005) and R. Shelley (in prep), and an Al crustal weight abundance of 8\% (Taylor and McLennan, 1995), this yields $270 \mathrm{nmol} \mathrm{Ti}_{\text {SsF }} / \mathrm{m}^{2} /$ day entering the mixed layer.

We apply uniform sinking speeds to the SSF box and to the LSF box, assuming that the fastest vertical transport occurs via the LSF, recognizing that this is a simplification of the sinking speed spectrum observed in particles (McDonnell and Buesseler, 2012). We assign the SSF a zero sinking speed ( $\omega_{S S F}=0 \mathrm{~m} /$ day) to start. For initial runs, we use an LSF sinking speed of $16 \mathrm{~m} / \mathrm{d}$, a typical value observed for large aggregate sinking speeds estimated by (McDonnell and Buesseler, 2012) using video plankton recorder (VPR) images and gel traps near Bermuda. For all parameters presented here, the model was started with zero-inventory (empty water column) and run for 20 years, which was shown by comparison to 200 year runs to have reached steady state.

\subsection{Lithogenic Particle Cycling 1-D Model: Results}

Our goal was to simulate the general lithogenic profile shapes and inventory behaviors observed in the N. Atlantic (Fig. 11) using this box model, and test their sensitivities to reasonable estimates of the disaggregation, aggregation, and sinking 
parameters. Ordinary differential equations were solved using a Runge-Kutte ODE45 parameterization in MATLAB (MathWorks, Natick MA).

The magnitude of the aggregation and disaggregation rate constants, and any vertical variation associated with these rates in the upper water column, are the least constrained parameters and thus our first point of exploration. Most literature estimates for these rates are derived from inverse models of dissolved and particulate thorium isotope activities $\left({ }^{234} \mathrm{Th},{ }^{228} \mathrm{Th},{ }^{230} \mathrm{Th}\right)$ and particle concentration or flux below the euphotic zone (eg. Bacon and Anderson 1982). Published compilations of inverse estimates of scavenging and particle dynamics rates demonstrate the large spatiotemporal variability and uncertainties associated with these rate estimates (Marchal and Lam, 2012). Nevertheless, disaggregation rates (1-1000 $\left.\mathrm{yr}^{-1}\right)$ appear generally dominant to aggregation rates (0.1-100 $\left.\mathrm{yr}^{-1}\right)$, which is conceptually consistent with our understanding of most of the deep ocean as dominated by remineralization, disaggregation and fragmentation of large aggregates rather than their production.

Assuming a constant dust input $\left(2 \mathrm{mg} / \mathrm{m}^{2} / \mathrm{d}\right)$ and LSF sinking speed (16 $\mathrm{m} / \mathrm{d}$ ) as discussed previously, we explore the sensitivity of Ti profiles to the disaggregation (disagg) and aggregation (agg) rate ratio (disagg:agg) in several constant ratio scenarios. Size-fractionation below ca. $300 \mathrm{~m}$ was fairly constant in our observations (Fig. 11c, lower panel), so we focus first on modeled scenarios of deep $(>300 \mathrm{~m})$ profiles where the disagg:agg ratio has been varied between 1:1 and 10:1. If the deep disagg:agg ratio is set to $1: 1$ throughout the deep water column, lithogenic material partitions evenly (50\%) between the SSF and LSF (Fig. 12a, blue line). Increasing the deep disagg:agg ratio increases the partitioning to the SSF fraction (Fig. 12a, green, orange, and red lines). We thus observe that the disagg:agg ratio is the primary determinant of lithogenic size-fractionation between the SSF and LSF. Our observed deep lithogenic partitioning of 75-85\% in the SSF (Fig. 11c, lower panel) indicates the overall deep water column disagg:agg ratio in our model is constrained between approximately 3:1 to $6: 1$.

To examine specific effects of absolute aggregation rates, we next leave the disagg:agg ratio constant at 6:1 throughout the entire water column (as in Fig. 12a, 
orange trace) and examine the case of an absolute aggregation rate of $50 \mathrm{yr}^{-1}$ (thus, $300 \mathrm{yr}^{-1}$ for disaggregation; Fig. 12b, blue traces). Examining the surface boxes (0200m; Fig. 12b) we observe an elevated mixed layer lithogenic concentration with a rapid decrease to lower and constant SSF concentrations below. All other parameters (namely, dust inputs, LSF sinking speeds and disagg:agg ratios) being the same, the size of this mixed layer maximum is dependent on the absolute aggregation rate, which is also shown varied to values of 100 and $300 \mathrm{yr}^{-1}$ (Fig. 12b, green and red traces). This sensitivity shows that slower mean surface aggregation rates should lead to larger steady-state mixed layer lithogenic concentrations. This behavior alone may be useful in constraining mean surface aggregation rates in marine systems where ${ }^{234} \mathrm{Th}$ export deficits are minimal but lithogenic input fluxes and particulate concentrations are measureable.

Allowing aggregation and/or disaggregation rate constants to vary with depth in the upper 200m (Fig. 12c, lower panels), allows creation of a sub-euphotic minimum in SSF particulates (Dammshäuser and Croot, 2012) and the upper watercolumn LSF dominance that we observe in the actual water column (Fig. 11). We choose to demonstrate this by allowing aggregation to increase towards the surface above $200 \mathrm{~m}$, and holding disaggregation rate constants fixed throughout the water column. Aggregation rates that reach a maximum near the surface and decrease with depth below ca. $100 \mathrm{~m}$ seem reasonable given that particle concentrations and biological activity (and thus biologically-mediated aggregation) should decrease with depth below the euphotic zone.

As previously described, surface aggregation rate constants that are too small ( < ca. $50 \mathrm{yr}^{-1}$ ) in the surface, even at this fixed and relatively low dust input rate, create mixed layer inventories that are larger than observed. Conversely, surface aggregation rates that are too large would fail to produce the slight surface lithogenic maxima observed across most of the transect. In this third scenario, we have used deep rates of $60 \mathrm{yr}^{-1}$ for disaggregation and $10 \mathrm{yr}^{-1}$ for aggregation below $200 \mathrm{~m}$, and we allow aggregation to increase monotonically above $200 \mathrm{~m}$, reaching parity with disaggregation (60 $\left.\mathrm{yr}^{-1}\right)$ between $0-100 \mathrm{~m}$ (Fig. 12c, lower panels). Thus configured, the model produces lithogenic size partitioning and concentration 
profiles remarkably similar to those observed in the western basin by varying only three rate constant parameters and imposing a reasonable aggregation rate constant profile shape (Fig. 12c, upper panels).

Thus far, sinking speeds have been set as constant throughout the entire water column. In general, varying the sinking speeds produces fairly simple model responses, with the LSF speed being the more sensitive of the two, partially because the SSF is expected to have a narrower range of appropriate variability. Allowing the SSF to settle at $0.5 \mathrm{~m} / \mathrm{d}$ (Fig. $12 \mathrm{~d}$ ) slightly bows the LSF profile and smoothes all profiles. This smoothing effect is primarily observed just below the mixed layer where SSF concentration gradients are greatest: fine particles can now settle slowly from the mixed layer, which slightly changes the shape of, but doesn't eliminate, the DCM lithogenic shadow zone.

Varying the speed of the LSF, by comparison, has a strong effect on the entire lithogenic inventory: greater LSF speeds decrease the steady-state concentration of the LSF, which directly reduces lithogenic residence times and total lithogenic abundances. This effect is observed in Figure 12e where we monotonically increase the LSF speed from 16 to $20 \mathrm{~m} / \mathrm{d}$ in the bottom $2000 \mathrm{~m}$, leading to a steady decline in Ti inventory with depth. From another perspective, if elevated dust inputs in one region lead to a greater mean LSF sinking speed there (i.e., due to an increase in lithogenic ballasting), lithogenic particle inventories would be comparatively smaller than expected from the increase in mean dust flux (which is otherwise directly proportional to lithogenic inventory; not shown). This may be the case in the North Atlantic, where Ti inventories in the eastern side basin are only 2-3x greater than in the west (Table 3) despite 7-10x estimated increases in dust fluxes.

Interesting temporal system behaviors can be observed by varying dust inputs rather than using constant fluxes. Aggregation and disaggregation processes may also vary significantly in time and space, but considering the high degree of uncertainty associated with those values and their variations with depth, here we only consider dust deposition variations, which are relatively better known. As an example, we return to a constant sinking speed scenario $(16 \mathrm{~m} / \mathrm{d}$ for $\mathrm{LSF}, 0.1 \mathrm{~m} / \mathrm{d}$ for SSF) with relatively higher aggregation rates (30 $\mathrm{yr}^{-1}$ for deep aggregation; 180 
$\mathrm{yr}^{-1}$ for disaggregation below $300 \mathrm{~m}$; disagg:agg parity in the upper $100 \mathrm{~m}$ as in Fig. 12c) but now assign a Bermudian-like seasonal dust input flux that has a strong summer maximum (Fig 12f). Dust data are estimated from monthly deposition estimates of the "AEROCOM_Median" model across the North Atlantic; (AEROCOM, 2013) which have been fitted continuously using a smooth sum of sines interpolation in MATLAB. Model output at several time points during the 20th year are presented (lower panels) to display major features in particle variation.

Both surface and deep lithogenic concentration profiles exhibit time-varying responses to seasonal dust forcing. At these rates, mixed layer concentrations reach their annual maxima simultaneous with maximum dust arrival (Jul), but subsurface concentrations lag slightly, reaching maxima in late September. In general, net particle propagation speeds are closest to LSF speeds (here: $16 \mathrm{~m} / \mathrm{d}$ ) in the surface, where partitioning to the LSF is highest. The net speed then slows to reflect the absolute and relative increase in fine SSF material $(0.1 \mathrm{~m} / \mathrm{d}$, here) beneath the euphotic zone. The annual summer dust pulse propagates downward throughout the autumn, with maxima in both small and large concentration profiles below $300 \mathrm{~m}$. By January the summer dust pulse is seen as a maximum around $500 \mathrm{~m}$ and is more noticeable in the SSF than the LSF. Both size fraction maxima continue to relax and disperse vertically throughout the winter. Following through to the next annual dust event (Aug.), we can still observe the remnant of the previous year's dust pulse around $1000 \mathrm{~m}$. It is thus theoretically possible to generate lithogenic particle-driven profiles with two (or multiple) subsurface maxima using only 1-D processes and a time-varying dust input.

LSF sinking speeds and deep agg:disagg rates determine the amplitude of the lithogenic pulses that propagate down the water column. Faster deep aggregation rates and sinking speeds lead to higher amplitude dust pulses. Notably, any variations in LSF concentrations predicted by such input-varying behaviors should be correlated with temporal changes in sediment trap fluxes, assuming most vertical mass flux is sinking via the LSF as modeled. Depending on true oceanic aggregation and sinking speed parameters, sediment traps positioned at widely-spaced depths (e.g. $1000 \mathrm{~m}$ and $3000 \mathrm{~m}$ ) could even record what would appear to be "simultaneous" 
dust/flux events with infinite sinking speeds that are in fact dust pulses propagating down the water column from two separate dust events.

Residence time calculations show that the water column maintains an inventory record of both short-term (days to weeks) and long-term (months to years) external lithogenic inputs depending on the depth of integration. Given estimates or measurements of lithogenic input fluxes, it should be possible to constrain water column processes (aggregation, disaggregation and sinking) that operate on these inventories. Our model results also suggest that temporal variations in lithogenic inputs may impart notable signals in time-series observations of refractory particle profiles. In combination with global dust models of aeolian inputs, improved data on water column lithogenic inventories may be a useful indicator of dust deposition patterns as imprinted upon and re-worked by the ocean's biological pump, perhaps eventually helping to constrain the activities of both.

\subsection{Applications of inert particle model to other particle types}

Modeling an inert lithogenic tracer provides a starting point for understanding some of the rates that must be controlling particle cycling in general. These include parameters such as aggregation/disaggregation rates and sinking speeds that are relevant to the biological pump and to other bioactive trace metals, but difficult to calculate directly. Can we apply the results of the 2-box model developed here for lithogenic particle distributions to understand the dynamics of POC cycling and the biological pump?

At one extreme, we can imagine that POC behaves exactly like lithogenic particles with respect to aggregation, disaggregation, and sinking in the nearsurface, but that it also experiences remineralization, a process not applicable to lithogenics. Indeed, 2-box models that model particle dynamics often add a remineralization loss of small particulates (e.g. Clegg et al. 1991). We observed POC to be partitioned less strongly to the large size fraction than lithogenics $(10-60 \%$ for POC compared to $50-80 \%$ for lithogenics) in surface waters, however (Lam et al., in prep). This implies a need for an additional remineralization term between the 
small and large size fraction to account for remineralization or assimilation of POC by zooplankton during aggregation into large $>51 \mu \mathrm{m}$ particles.

The other extreme-that POC behaves nothing at all like lithogenic particles-is not likely considering that the aggregation and disaggregation processes that act on the lithogenic particles are presumed to be biologically mediated and driven by POC consumption. However, differences in size distributions for POC compared to lithogenic particles may alter the effective aggregation rates experienced by the bulk POC compared to bulk lithogenic pools. Fine lithogenic particulates also have a narrower particle size spectrum (1-20 micron-range, if sourced completely from dust (Ratmeyer et al., 1999; Stuut, 2005) compared to particulate organic matter, which spans the full range of sizes from organic polymers, viruses, bacteria, pico- and nano-plankton, etc. (McCave, 1984), (Lal, 1977). These different organic pools may interact with $>51 \mu \mathrm{m}$ aggregation processes differently than lithogenics, so further investigation is needed to determine the applicability of lithogenic-derived rate estimates to other estimates of these parameters.

\section{Conclusions}

The size-fractionated lithogenic metals $\mathrm{Al}, \mathrm{Fe}$, and $\mathrm{Ti}$ demonstrate the intensity and extent of many basin-scale lithogenic inputs (aeolian, lateral, hydrothermal, and benthic) and key oceanographic processes (scavenging, biotic uptake, aggregation/disaggregation, vertical sinking, and lateral transport). In the upper ocean, lithogenic particles are demonstrated to have strong, rapid packaging into the $>51 \mu \mathrm{m}$ fraction within the mixed layer, minimal abundances just below the mixed layer at sub-mixed layer DCM depths, and elevated overall abundances beneath the euphotic zone. Lateral, hydrothermal, and benthic resuspension of lithogenic elements are observed to be intense, locally-important sources at some stations, with African dust inputs appearing to dominate lithogenic compositions across most of the basin's interior. Aggregation, disaggregation and sinking modeled using a two size-fraction 1-D box model of particulate Ti can successfully describe 
lithogenic distributions and demonstrates the range of effects that parameter and input variations have on size-fractionated lithogenic concentration profiles.

\section{References}

AEROCOM Phase II Interface. [online] Available from: http://aerocom.met.no/ (Accessed 17 August 2013)

Biscaye, P. E. and Eittreim, S. L.: Suspended particulate loads and transports in the nepheloid layer of the abyssal Atlantic Ocean, Marine Geology, 23(1), 155-172, 1977.

Bishop, J.: The barite-opal-organic carbon association in oceanic particulate matter, Nature, 332, 24, 1988.

Bower, A., Lozier, S. and Gary, S.: Deep-Sea Research II, Deep-Sea Research Part II, 58(17-18), 1798-1818, doi:10.1016/j.dsr2.2010.10.060, 2011.

Boyle, E. A., Bergquist, B. A., Kayser, R. A. and Mahowald, N.: Iron, manganese, and lead at Hawaii Ocean Time-series station ALOHA: Temporal variability and an intermediate water hydrothermal plume, Geochimica et Cosmochimica Acta, 69(4), 933-952, doi:10.1016/j.gca.2004.07.034, 2005.

Brewer, P. G., Spencer, D. W., Biscaye, P. E., Hanley, A., Sachs, P. L., Smith, C. L., Kadar, S. and Fredericks, J.: The distribution of particulate matter in the Atlantic Ocean, Earth and Planetary Science Letters, 32(2), 393-402, 1976.

Bruland, K. W., Rue, E. L., Smith, G. J. and DiTullio, G. R.: Iron, macronutrients and diatom blooms in the Peru upwelling regime: brown and blue waters of Peru, Marine Chemistry, 93(2-4), 81-103, doi:10.1016/j.marchem.2004.06.011, 2005.

Carr, M.-E.: Estimation of potential productivity in Eastern Boundary Currents using remote sensing, Deep-Sea Research Part II, 49(1), 59-80, 2001.

Clegg, S. L. and Whitfield, M.: Application of a generalized scavenging model to time series $234 \mathrm{Th}$ and particle data obtained during the JGOFS North Atlantic bloom experiment, Deep-Sea Research Part I, 40(8), 1529-1545, 1993.

Clegg, S. L., Bacon, M. P. and Whitfield, M.: Application of a generalized scavenging model to thorium isotope and particle data at equatorial and high-latitude sites in the Pacific Ocean, Journal of Geophysical Research: Oceans (1978-2012), 96(C11), 20655-20670, 1991.

Cochran, J. K., Buesseler, K. O., Bacon, M. P., Wang, H. W., Hirschberg, D. J., Ball, L., Andrews, J., Crossin, G. and Fleer, A.: Short-lived thorium isotopes (234Th, 228Th) as indicators of POC export and particle cycling in the Ross Sea, Southern Ocean, 
Deep-Sea Research Part II, 47(15), 3451-3490, 2000.

Committee, 2. G. S. A. I.: Sampling and Sample-handling Protocols for GEOTRACES Cruises,, 1-238 [online] Available from:

http://www.geotraces.org/libraries/documents/Intercalibration/Cookbook.pdf, 2010.

Dammshäuser, A. and Croot, P. L.: Low Colloidal Associations of Aluminium and Titanium in Surface Waters of the Tropical Atlantic, Geochimica et Cosmochimica Acta, 1-45, doi:10.1016/j.gca.2012.07.032, 2012.

Dammshäuser, A., Wagener, T., Garbe-Schönberg, D. and Croot, P.: Particulate and dissolved aluminum and titanium in the upper water column of the Atlantic Ocean, Deep-Sea Research Part I, 73(C), 127-139, doi:10.1016/j.dsr.2012.12.002, 2013.

Davies, G. R., Cliff, R. A., Norry, M. J. and Gerlach, D. C.: A combined chemical and PbSr-Nd isotope study of the Azores and Cape Verde hot-spots: the geodynamic implications, Geological Society, London, Special Publications, 42(1), 231-255, doi:10.1144/GSL.SP.1989.042.01.15, 1989.

Dunne, J. P., Sarmiento, J. L. and Gnanadesikan, A.: A synthesis of global particle export from the surface ocean and cycling through the ocean interior and on the seafloor, Global Biogeochem. Cycles, 21(4), GB4006, doi:10.1029/2006GB002907, 2007.

Fitzsimmons, J. N., Zhang, R. and Boyle, E. A.: Marine Chemistry, Marine Chemistry, 154(C), 87-99, doi:10.1016/j.marchem.2013.05.009, 2013.

Francois, R., Honjo, S., Krishfield, R. and Manganini, S.: Factors controlling the flux of organic carbon to the bathypelagic zone of the ocean, Global Biogeochem. Cycles, 16(4), 34-1-34-20, doi:10.1029/2001GB001722, 2002.

Gardner, W. D., Richardson, M. J., Hinga, K. R. and Biscaye, P. E.: Resuspension measured with sediment traps in a high-energy environment, Earth and Planetary Science Letters, 66, 262-278, 1983.

German, C. R. and von Damm, K. L.: Hydrothermal processes, The oceans \& marine geochemistry (Treatise on geochemistry series, Vol. 6), Elsevier, 181-222, 2006.

Ginoux, P., Prospero, J. M., Torres, O. and Chin, M.: Long-term simulation of global dust distribution with the GOCART model: correlation with North Atlantic Oscillation, Environmental Modelling \& Software, 19(2), 113-128, doi:10.1016/S1364-8152(03)00114-2, 2004.

Guidi, L., Stemmann, L., Jackson, G. A., Ibanez, F., Claustre, H., Legendre, L., Picheral, M. and Gorsky, G.: Effects of phytoplankton community on production, size and export of large aggregates: A world-ocean analysis, Limnology and Oceanography, 
54(6), 1951, 2009.

Henson, S. A., Sanders, R. and Madsen, E.: Global patterns in efficiency of particulate organic carbon export and transfer to the deep ocean, Global Biogeochem. Cycles, 26(1), doi:10.1029/2011GB004099, 2012.

Jackson, M. G., Hart, S. R., Saal, A. E., Shimizu, N., Kurz, M. D., Blusztajn, J. S. and Skovgaard, A. C.: Globally elevated titanium, tantalum, and niobium (TITAN) in ocean island basalts with high 3He/ 4He, Geochem. Geophys. Geosyst., 9(4), Q04027, doi:10.1029/2007GC001876, 2008.

Jickells, T. D.: Global Iron Connections Between Desert Dust, Ocean Biogeochemistry, and Climate, Science, 308(5718), 67-71, doi:10.1126/science.1105959, 2005.

Jickells, T. D., Dorling, S., Deuser, W. G., Church, T. M., Arimoto, R. and Prospero, J. M.: Air-borne dust fluxes to a deep water sediment trap in the Sargasso Sea, Global Biogeochem. Cycles, 12(2), 311-320, 1998.

LaCasce, J. H. and Speer, K. G.: Lagrangian statistics in unforced barotropic flows, Journal of Marine Research, 57(2), 245-274, 1999.

Lal, D.: The oceanic microcosm of particles, Science, 198(4321), 997-1009, 1977.

Lam, P. J. and Bishop, J. K. B.: The continental margin is a key source of iron to the HNLC North Pacific Ocean, Geophys. Res. Lett, 35(7), doi:10.1029/2008GL033294, 2008.

Lam, P. J. and Morris, P. J.: In situ marine sample collection system and methods, Pat. Pending, (13/864,655)

Lam, P. J., Doney, S. C. and Bishop, J. K. B.: The dynamic ocean biological pump: Insights from a global compilation of particulate organic carbon, $\mathrm{CaCO} 3$, and opal concentration profiles from the mesopelagic, Global Biogeochem. Cycles, 25(3), doi:10.1029/2010GB003868, 2011.

Lam, P. J., Ohnemus, D. C. and Marcus, M. A.: The speciation of marine particulate iron adjacent to active and passive continental margins, Geochimica et Cosmochimica Acta, 80, 108-124, 2012.

Lambert, C. E., Bishop, J., Biscaye, P. E. and Chesselet, R.: Particulate aluminium, iron and manganese chemistry at the deep Atlantic boundary layer, Earth and Planetary Science Letters, 70(2), 237-248, 1984.

Lima, I. D., Lam, P. J. and Doney, S. C.: Dynamics of particulate organic carbon flux in a global ocean model, Biogeosciences Discuss., 10(9), 14715-14767, doi:10.5194/bgd-10-14715-2013, 2013. 
Lisitzin, A. P.: Sedimentation in the world ocean, 1972.

Mahowald, N. M., Baker, A. R., Bergametti, G., Brooks, N., Duce, R. A., Jickells, T. D., Kubilay, N., Prospero, J. M. and Tegen, I.: Atmospheric global dust cycle and iron inputs to the ocean, Global Biogeochem. Cycles, 19(4), n/a-n/a, doi:10.1029/2004GB002402, 2005.

Mahowald, N. M., Engelstaedter, S., Luo, C., Sealy, A., Artaxo, P., Benitez-Nelson, C., Bonnet, S., Chen, Y., Chuang, P. Y., Cohen, D. D., Dulac, F., Herut, B., Johansen, A. M., Kubilay, N., Losno, R., Maenhaut, W., Paytan, A., Prospero, J. M., Shank, L. M. and Siefert, R. L.: Atmospheric Iron Deposition: Global Distribution, Variability, and Human Perturbations*, Annu. Rev. Marine. Sci., 1(1), 245-278, doi:10.1146/annurev.marine.010908.163727, 2009.

Marchal, O. and Lam, P. J.: What can paired measurements of Th isotope activity and particle concentration tell us about particle cycling in the ocean? Geochimica et Cosmochimica Acta, 90(C), 126-148, doi:10.1016/j.gca.2012.05.009, 2012.

McCave, I.: Size spectra and aggregation of suspended particles in the deep ocean, Deep Sea Research Part A Oceanographic Research ..., 1984.

McCave, I. N.: Particulate size spectra, behavior, and origin of nepheloid layers over the Nova Scotian continental rise, Journal of Geophysical Research: Oceans (19782012), 88(C12), 7647-7666, 1983.

McCave, I. N. and Hall, I. R.: Turbidity of waters over the Northwest Iberian continental margin, Progress in Oceanography, 52(2), 299-313, 2002.

McDonnell, A. M. P. and Buesseler, K. O.: A new method for the estimation of sinking particle fluxes from measurements of the particle size distribution, average sinking velocity, and carbon content, Limnol. Oceangr. Methods, 10, 329-346, doi:10.4319/lom.2012.10.329, 2012.

Middag, R., de Baar, H. J. W., Laan, P. and Bakker, K.: Dissolved aluminium and the silicon cycle in the Arctic Ocean, Marine Chemistry, 115(3-4), 176-195, doi:10.1016/j.marchem.2009.08.002, 2009.

Moore, J.: Sedimentary and mineral dust sources of dissolved iron to the world ocean, Biogeosciences, 2008.

Morad, S. and Aldahan, A. A.: Alteration of detrital Fe-Ti oxides in sedimentary rocks, Geological Society of America Bulletin, 97(5), 567-578, doi:10.1130/00167606(1986)97<567:AODFOI>2.0.C0;2, 1986.

Moran, S. B. and Moore, R. M.: The potential source of dissolved aluminum from resuspended sediments to the North Atlantic Deep Water, Geochimica et Cosmochimica Acta, 55(10), 2745-2751, 1991. 
Murray, R. W. and Leinen, M.: Scavenged excess aluminum and its relationship to bulk titanium in biogenic sediment from the central equatorial Pacific Ocean, Geochimica et Cosmochimica Acta, 60(20), 3869-3878, 1996.

Noble, A. E., Lamborg, C. H., Ohnemus, D. C., Lam, P. J., Goepfert, T. J., Measures, C. I., Frame, C. H., Casciotti, K. L., DiTullio, G. R., Jennings, J. and Saito, M. A.: Basin-scale inputs of cobalt, iron, and manganese from the Benguela-Angola front to the South Atlantic Ocean, Limnology and Oceanography, 57(4), 989-1010, doi:10.4319/lo.2012.57.4.0989, 2012.

Prytulak, J. and Elliott, T.: TiO 2 enrichment in ocean island basalts, Earth and Planetary Science Letters, 263(3), 388-403, doi:10.1016/j.epsl.2007.09.015, 2007.

Ratmeyer, V., Fischer, G. and Wefer, G.: Lithogenic particle fluxes and grain size distributions in the deep ocean off northwest Africa: Implications for seasonal changes of aeolian dust input and downward transport, Deep-Sea Research Part I, 46(8), 1289-1337, 1999.

Rudnick, R. L. and Gao, S.: Composition of the continental crust, Treatise on Geochemistry, 3, 1-64, 2003.

Rutgers van der Loeff, M. and Boudreau, B. P.: The effect of resuspension on chemical exchanges at the sediment-water interface in the deep sea-A modelling and natural radiotracer approach, Journal of Marine Systems, 1997.

Schlitzer, R.: Ocean Data View, 2013, [online] Available from: http://odv.awi.de/, 2013.

Schott, F. and Stommel, H.: Beta spirals and absolute velocities in different oceans, Deep Sea Research, 25(11), 961-1010, 1978.

Sedwick, P. N., Church, T. M., Bowie, A. R., Marsay, C. M., Ussher, S. J., Achilles, K. M., Lethaby, P. J., Johnson, R. J., Sarin, M. M. and McGillicuddy, D. J.: Iron in the Sargasso Sea (Bermuda Atlantic Time-series Study region) during summer: Eolian imprint, spatiotemporal variability, and ecological implications, Global Biogeochem. Cycles, 19(4), n/a-n/a, doi:10.1029/2004GB002445, 2005.

Sherrell, R. and Boyle, E.: The trace metal composition of suspended particles in the oceanic water column near Bermuda, Earth and Planetary Science Letters, 111(1), 155-174, 1992.

Stuut, J.-B.: Provenance of present-day eolian dust collected off NW Africa, J. Geophys. Res, 110(D4), doi:10.1029/2004JD005161, 2005.

Taylor, S. R. and McLennan, S. M.: The geochemical evolution of the continental crust, Reviews of Geophysics, 33(2), 241-265, 1995. 
Ternon, E., Guieu, C., Loÿe-Pilot, M.-D., Leblond, N., Bosc, E., Gasser, B., Miquel, J.-C. and Martín, J.: The impact of Saharan dust on the particulate export in the water column of the North Western Mediterranean Sea, Biogeosciences, 7(3), 809-826, 2010 .

Timothy, D. A., Wong, C. S., Barwell-Clarke, J. E., Page, J. S., White, L. A. and Macdonald, R. W.: Climatology of sediment flux and composition in the subarctic Northeast Pacific Ocean with biogeochemical implications, Progress in Oceanography, 116, 95-129, doi:10.1016/j.pocean.2013.06.017, 2013.

Yücel, M., Konovalov, S. K., Moore, T. S., Janzen, C. P. and Luther, G. W., III: Chemical Geology, Chemical Geology, 269(3-4), 364-375, doi:10.1016/j.chemgeo.2009.10.010, 2010. 


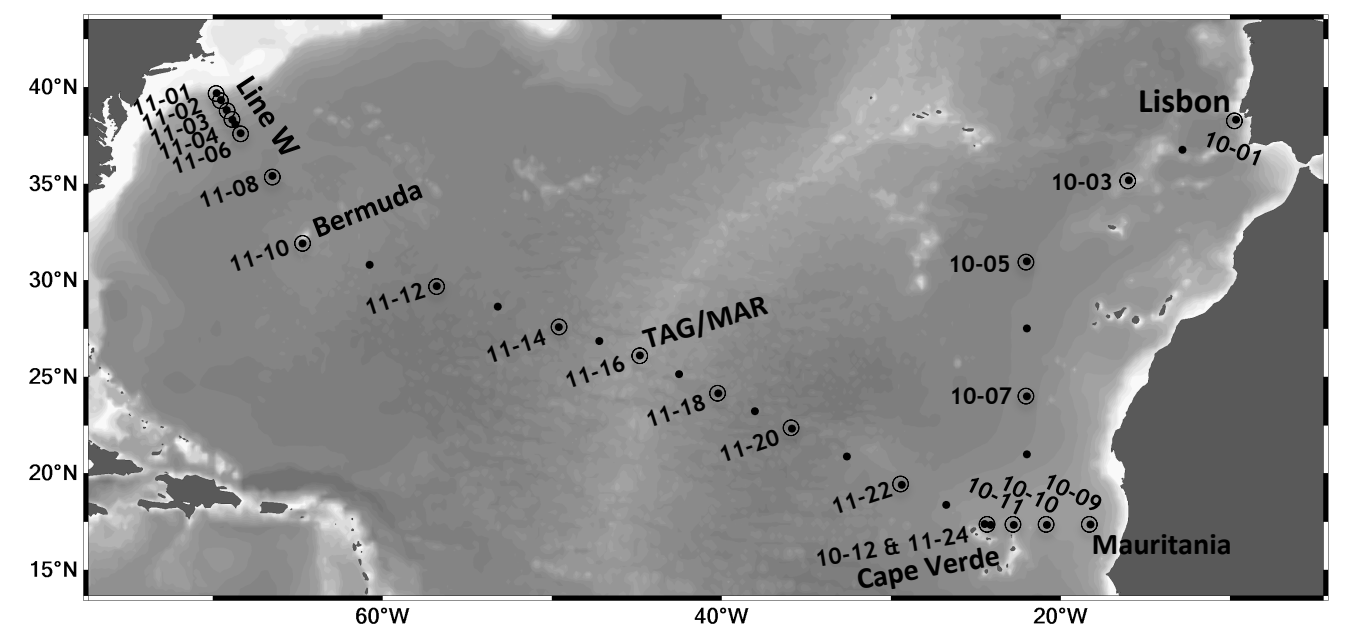

Figure 1: Oceanographic stations from $R / V$ Knorr cruises KN199-4 in Oct 2010 (stations 10-xx) and KN204-1 in Nov-Dec 2011 (stations 11-xx) where particulate samples were collected (circles and annotations). 
A
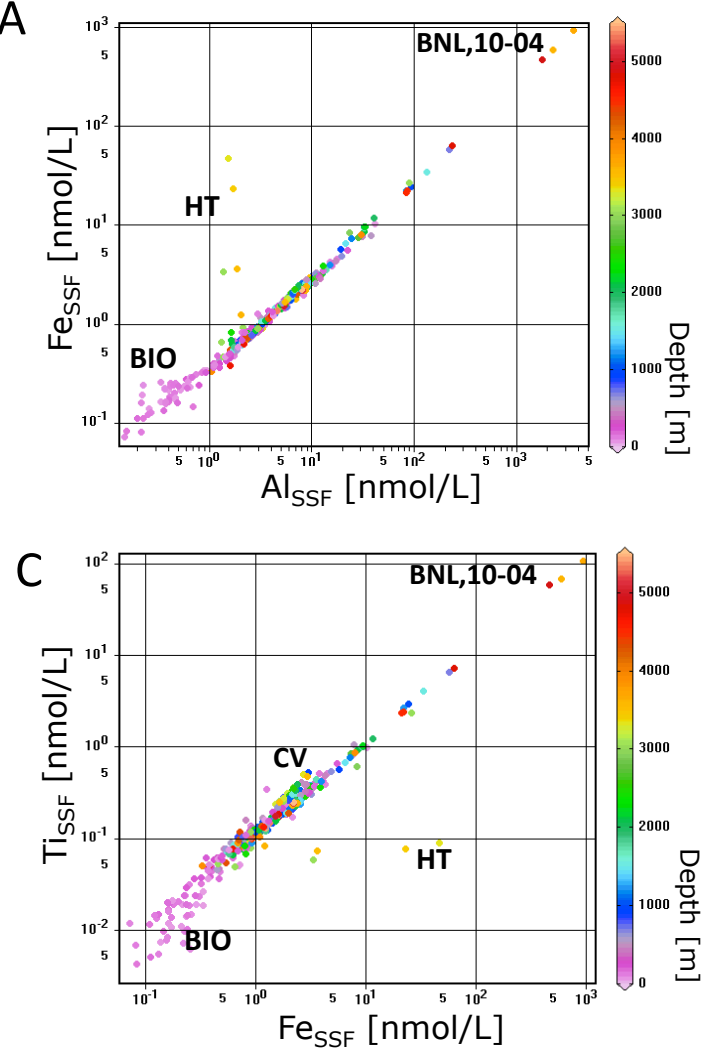

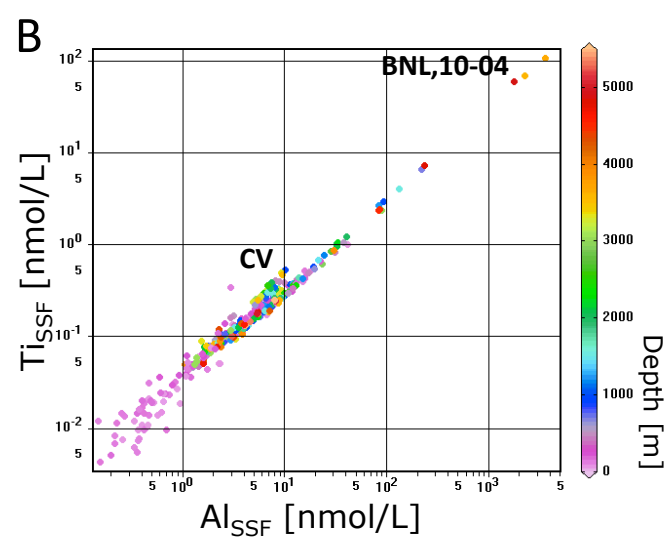

$\mathrm{Al}_{\mathrm{SSF}}[\mathrm{nmol} / \mathrm{L}]$

Figure 2: Concentration scatterplots (SSF) of A: Al/Fe, B: Al/Ti, C: Fe/Ti on log scales for the entire $\mathrm{N}$. Atlantic dataset demonstrating the strong correlations observed between lithogenic elements across many orders of magnitude. Color scales (right) indicate sample depth. Annotations: key regional inputs and notable processes (not all shown in all figures). HT: hydrothermal. CV: Cape Verde. BNL: benthic nepheloid layer (station number). BIO: biotic uptake. AfDust: African dust inputs. SCAV: scavenging. MED: Mediterranean outflow. LSW: Labrador seawater. NAm: North American boundary particulates. 


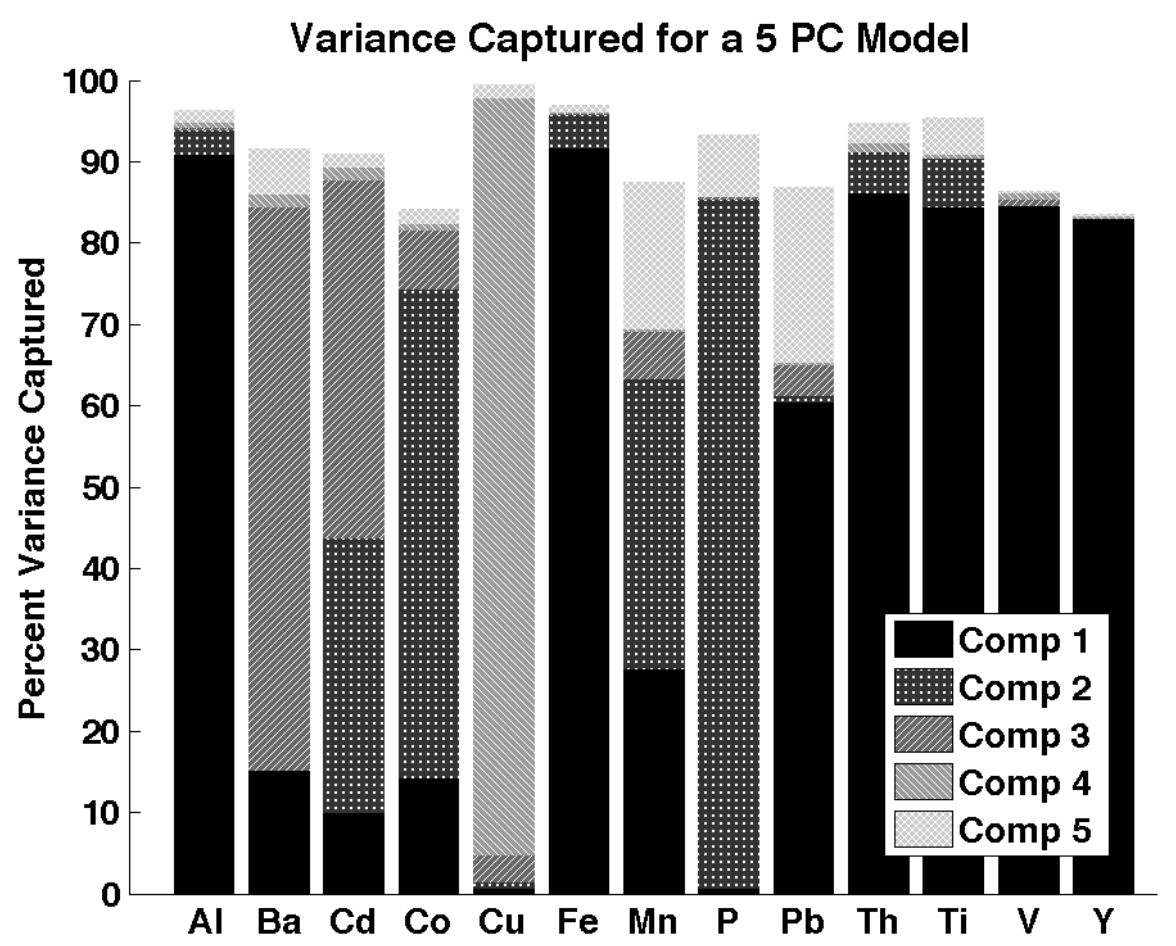

Figure 3: Variance of 13 particulate elements captured by the first 5 principal components in principal component analysis. Source data are a large subset of the SSF dataset $(\mathrm{n}=309 / 344$ samples) filtered as in Table 1 to remove extremely high concentration samples. Component 1 captures $50.0 \%$ of total dataset variance and most lithogenic elemental variances; Comp 2: 18.0\%; Comp 3: 10.4\%; Comp 4: 7.8\%; Comp 5: 5.2\%. 

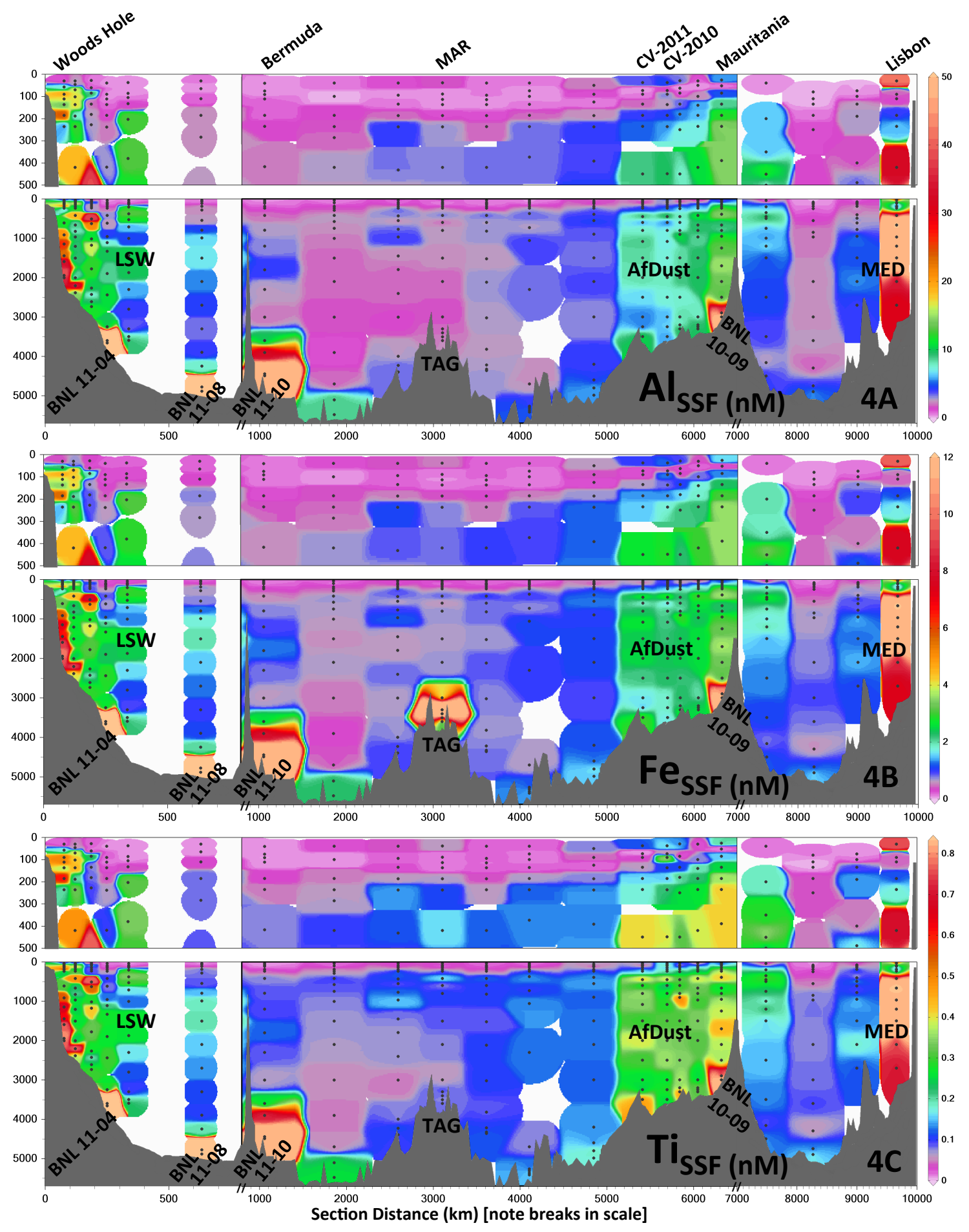
Figure 4 (previous page): Concentration sections of $\mathrm{A}$ ) $\mathrm{Al}_{\mathrm{SSF}} \mathrm{B}$ ) $\mathrm{Fe}_{\mathrm{SSF}}$ and C) $\mathrm{Ti}_{\mathrm{SSF}}$ in units of nmol/L. X-axes: section distance $(\mathrm{km})$, including breaks (double bars) to consolidate views; note the change in scale between breaks. Minor x-ticks located every $100 \mathrm{~km}$. Figure annotations: notable inputs and processes as described in Figure 2. Concentrations in excess of plotted ranges include BNL 11-04 (Al:

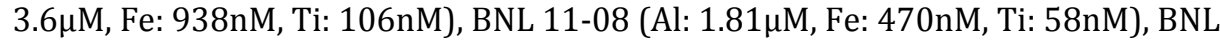
11-10 (Al: 84.8 nM; Fe: 21.4 nM; Ti: 2.3nM), TAG (Fe: $46.6 \mathrm{nM}$ ), BNL 10-09 (Fe: $26.3 \mathrm{nM}$ ), MED (10-01, 665m, Al: 222nM; Fe: 57.6nM; Ti: 6.47nM).

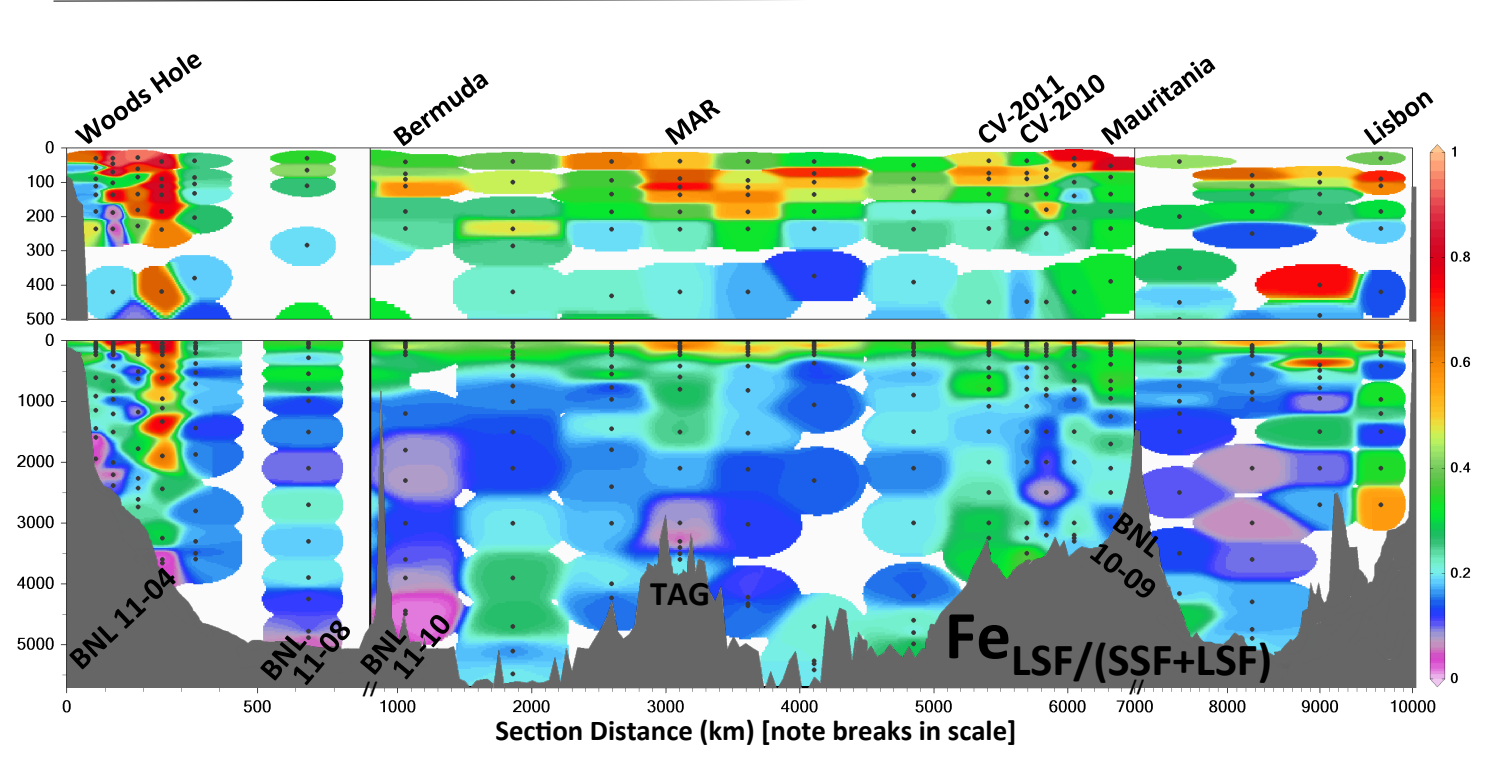

Figure 5 (this page): Typical lithogenic particulate size-fractionation, shown here for $\mathrm{Fe}$, as $\mathrm{Fe}_{\mathrm{LSF}} / \mathrm{Fe}_{(\mathrm{SSF}+\mathrm{LSF})}$. Lithogenic material partitions strongly into the LSF in the upper $200 \mathrm{~m}$ at most stations, with SSF abuandances dominating in the sub-surface interior. 


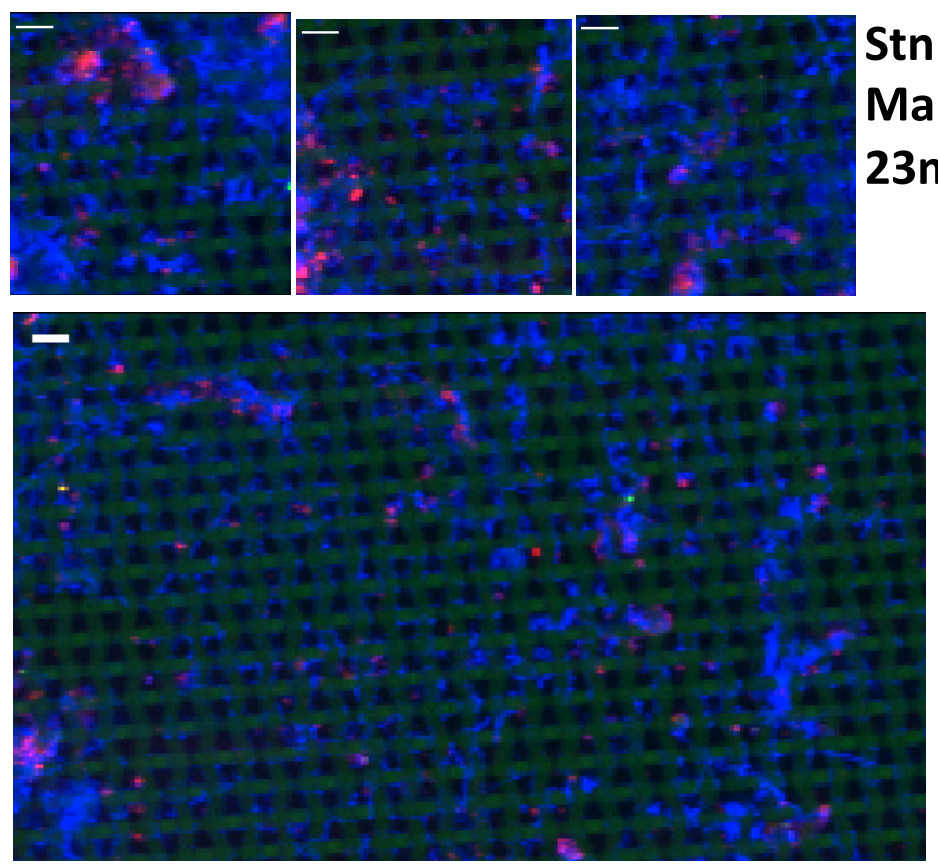

Stn 10-09

Mauritania

23m (mixed layer)

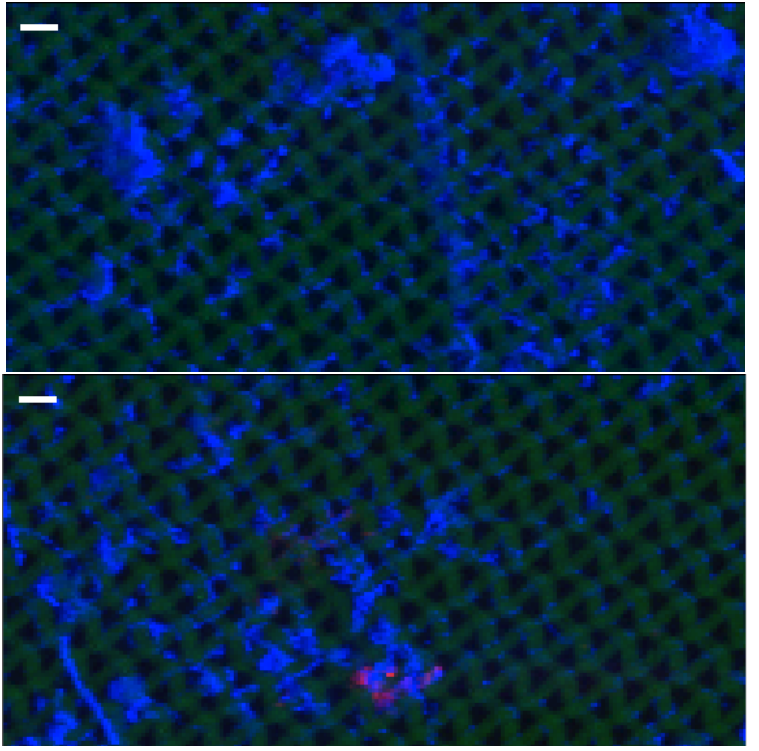

Stn 10-09

Mauritania

52m (DCM) 


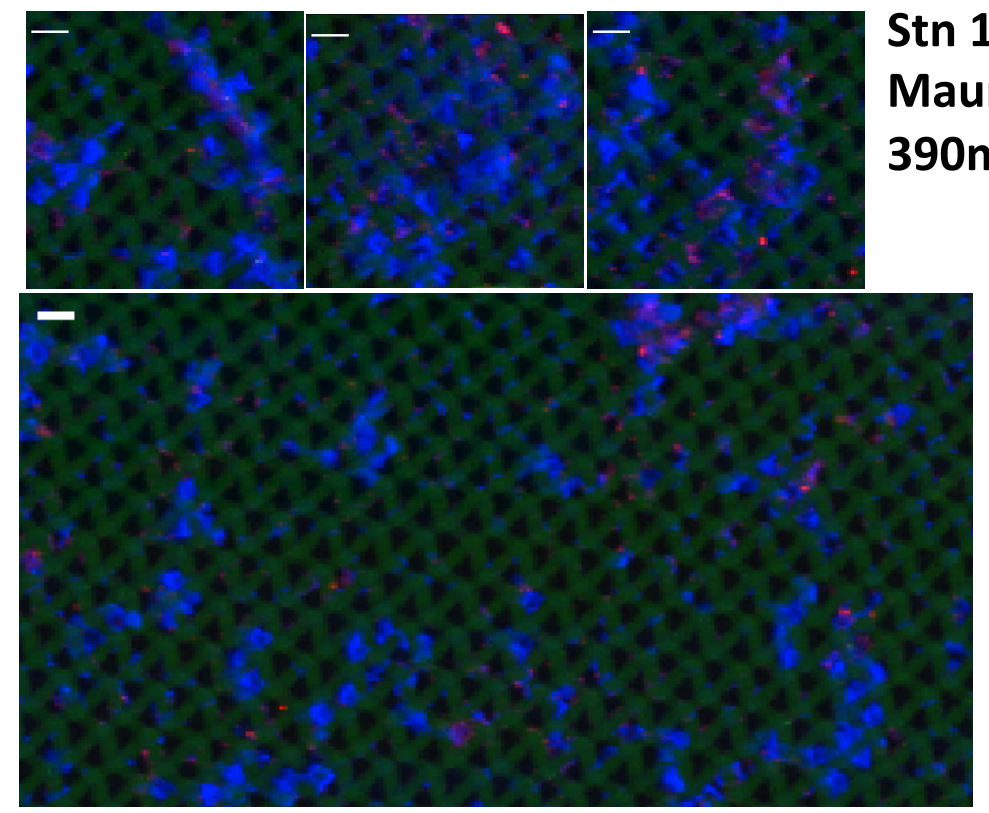

Stn 10-09

Mauritania

390m (OMZ)

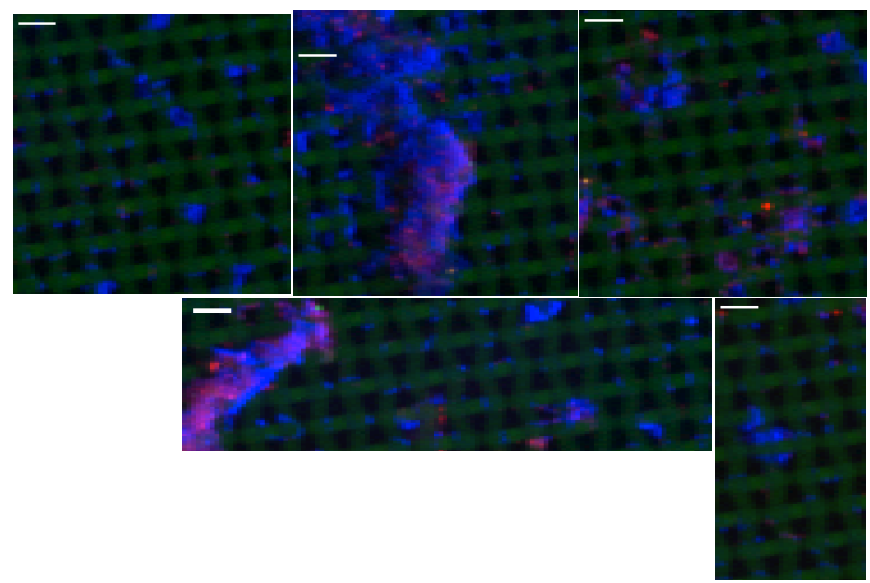

Stn 10-09

Mauritania 1700m (Deep)

Figure 6 (including preceding page): $\mu \mathrm{XRF}$ maps of $>51 \mu \mathrm{m}$ marine aggregates on polyester prefilters from several depths near Africa/Mauritania (Stn. 10-09). Green: pTi, showing the prefilter's $51 \mu \mathrm{m}$ grid spacing for scale. Red: particulate Fe, seen in fine aeolian dust particles incorporated and retained in the large size-fraction within large aggregates. Blue: particulate $\mathrm{Cl}$ (sea-salt) which is preferentially retained in aggregates as samples dry, allowing visualization of organic aggregate shapes. 

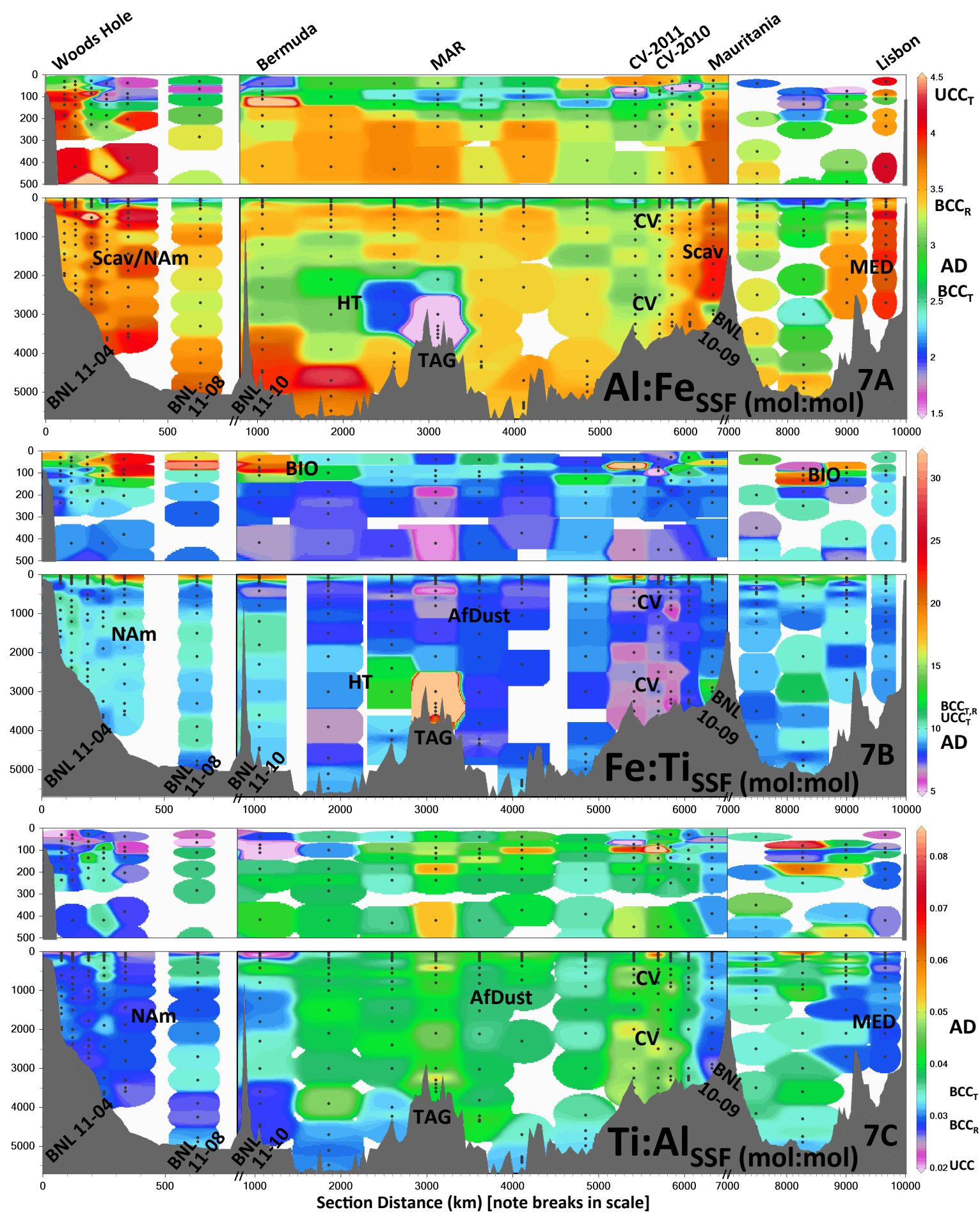

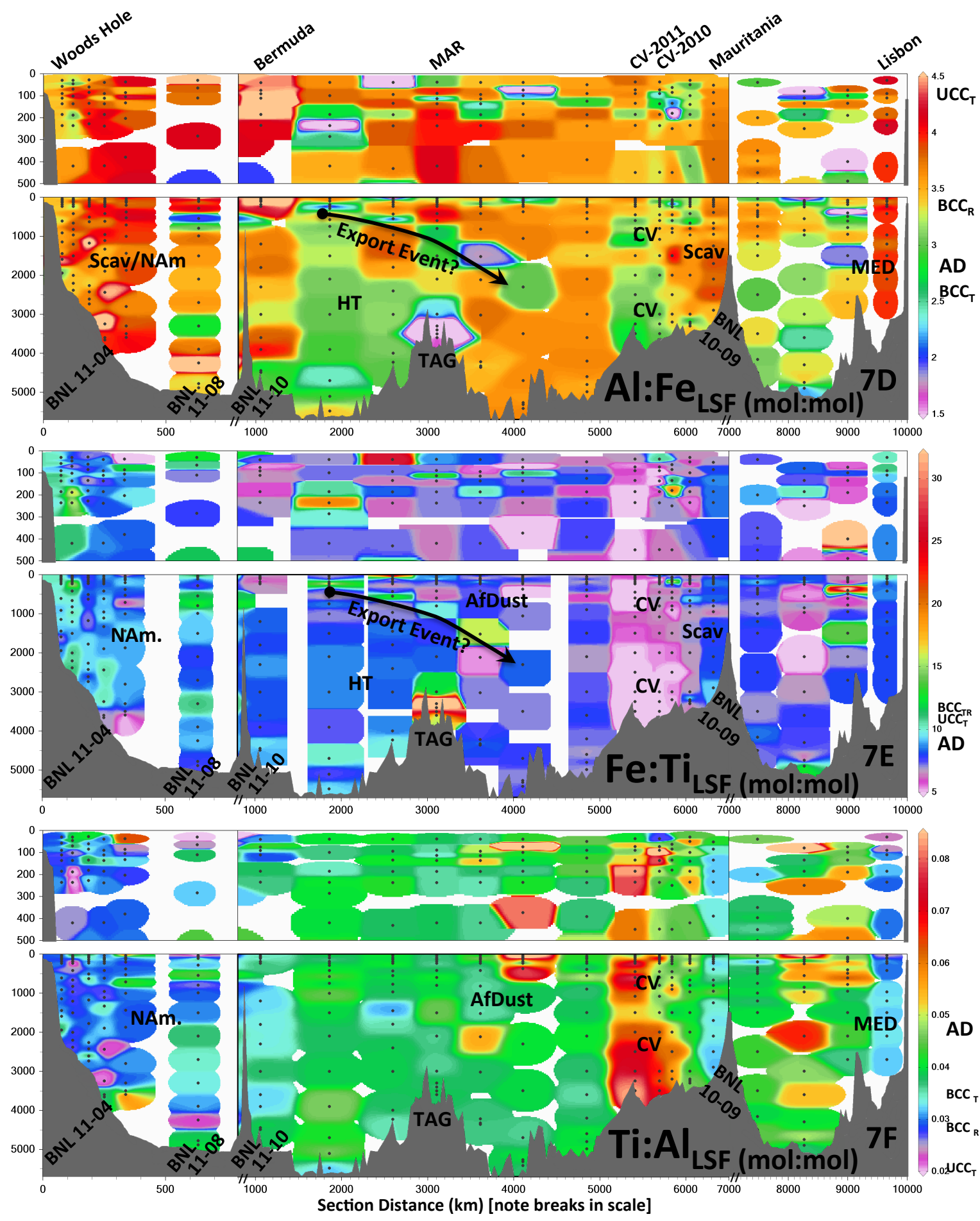
Figure 7 (preceding two pages): Mole ratio sections of A: $(\mathrm{Al} / \mathrm{Fe})_{\mathrm{SSF}}, \mathrm{B}:(\mathrm{Fe} / \mathrm{Ti})_{\mathrm{SSF}}, \mathrm{C}$ : $(\mathrm{Ti} / \mathrm{Al})_{\mathrm{SSF}} \mathrm{D}:(\mathrm{Al} / \mathrm{Fe})_{\mathrm{LSF}}, \mathrm{E}:(\mathrm{Fe} / \mathrm{Ti})_{\mathrm{LSF}}$, and $\mathrm{F}:(\mathrm{Ti} / \mathrm{Al})_{\mathrm{LSF}}$. X-axes: section distance $(\mathrm{km})$, including breaks (double bars) to consolidate views. Minor x-ticks located every

$100 \mathrm{~km}$. Figure annotations: notable inputs and processes as described in Figure 2. Scale bar annotations: key crustal ratios including bulk continental crust (BCC) from $\left(\mathrm{BCC}_{\mathrm{T}}\right)$ [Taylor and McClennan, 1995] and $\left(\mathrm{BCC}_{\mathrm{R}}\right)$ [Rudnick and Gao, 2003], upper continental crust $\left(\mathrm{UCC}_{\mathrm{T}}\right)$ [Taylor and McClennan, 1995], and bulk African Dust (AD) collected during KN199 near Mauritania [W. Landing and R. Shelley, pers. comm]. 

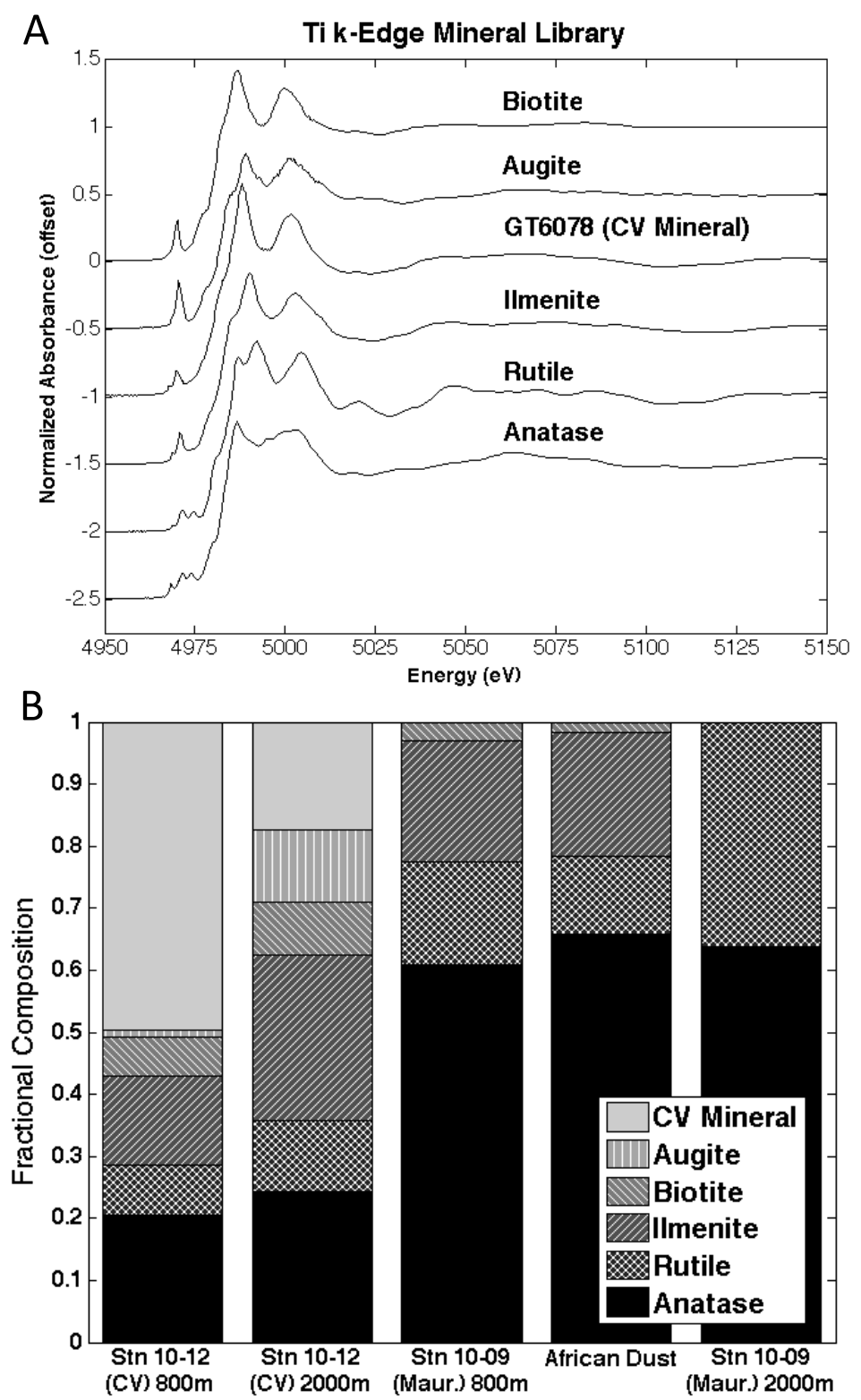

Figure 8: Top: Ti K-edge $\mu$ XANES spectral library, along with unidentified CV mineral spectrum. Bottom: Linear combination fits of multiple spectra $(\mathrm{n}=10-12 \mathrm{Ti}$ "hotspots" per sample) using (non-negative) scalable components from the mineral library were used to assign Ti-mineral composition to each sample. 

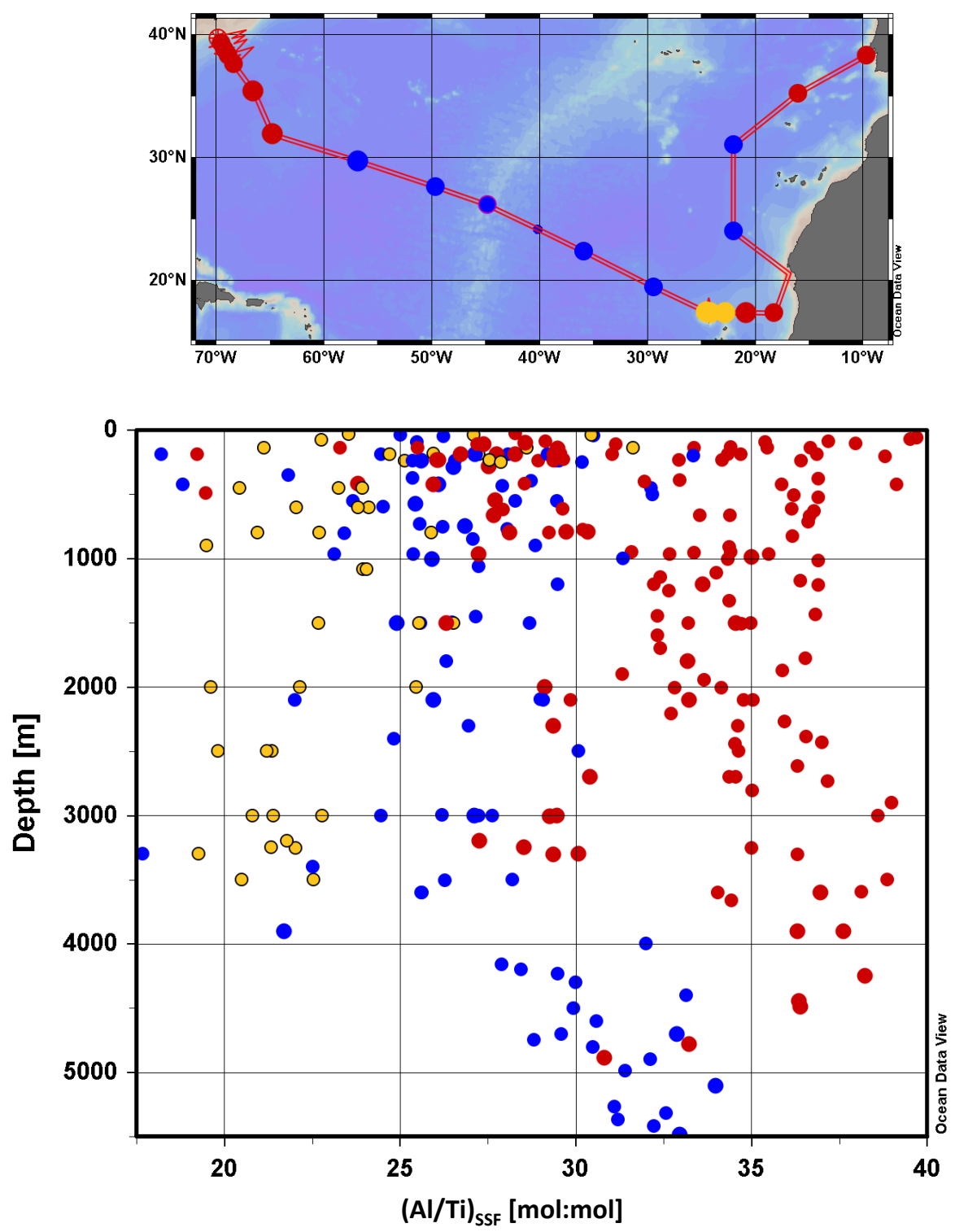

Figure 9: Al enrichment on fine particles, relative to $\mathrm{Ti}$, noted near ocean margins. Red: nearershore stations where $\mathrm{Al}$ is found in greater relative abundance throughout the water column. Blue: open ocean stations which generally show $\mathrm{Al}$ enrichment with depth. Yellow: stations with elevated Ti from Cape Verdean lithogenic material, which decreases the Al/Ti ratio. 

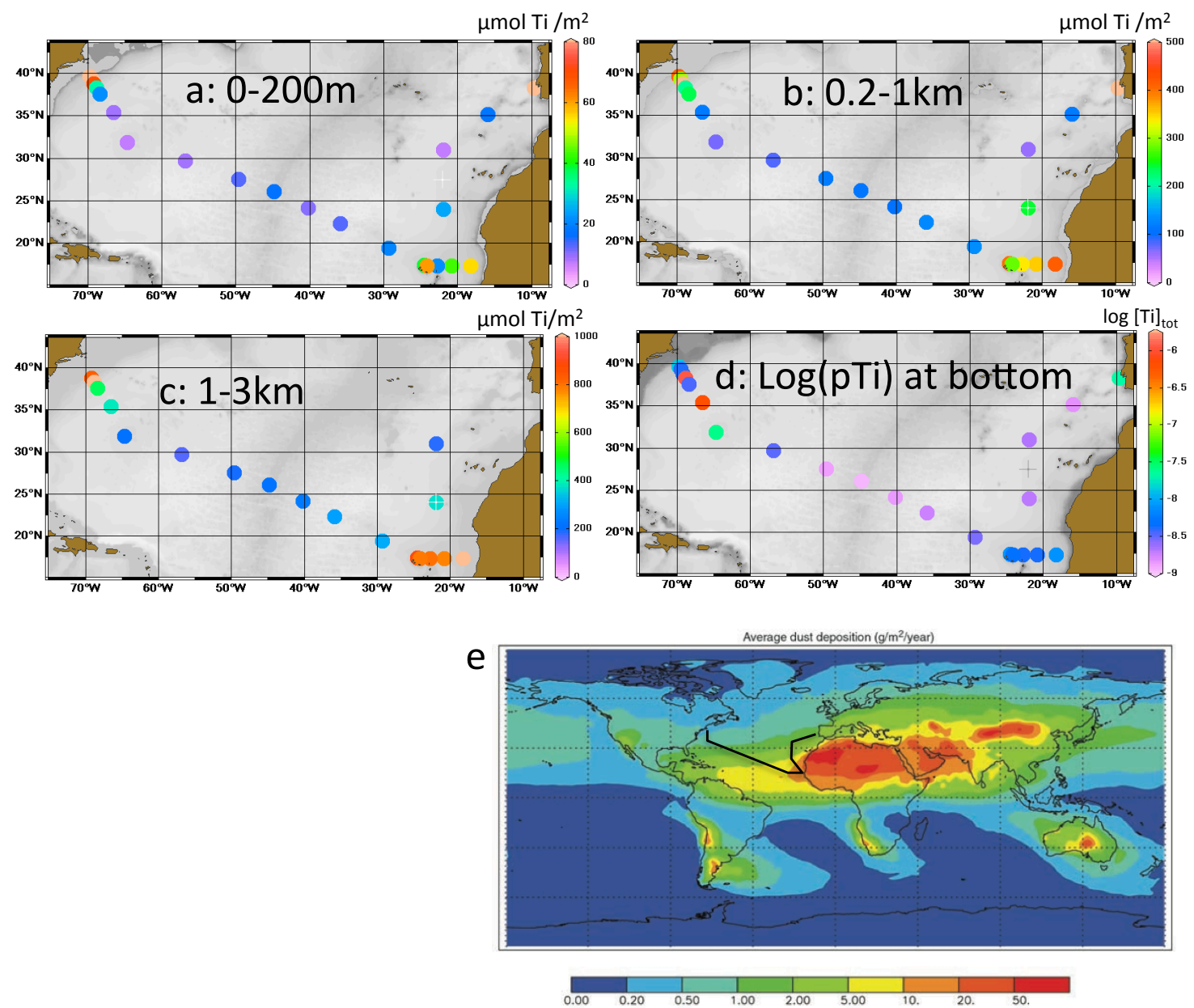
Figure 10 (preceding page): a-c: Total (SSF+LSF) particulate titanium inventories through several depth ranges. A (0-200m): Surface Ti inventories highlight recent dust inputs (order days to weeks) and proximal coastal/margin sources of lithogenics that decrease quickly away from the continents and point-sources (CV). B (200m-1 km): Across the open ocean, a broad increasing lithogenic inventory from Bermuda to Cape Verde follows from expected dust-deposition patterns (cf. Figure 6e: dust desposition by [Jickells et al., 2005]). Along Line $W$ and near the Med. outflow, margin-sourced lateral lithogenic inputs are evident. $C(1 \mathrm{~km}-3 \mathrm{~km})$ : Near N. America, strong lateral inputs of lithogenics associated with Labrador seawater (LSW) sustain a mid-water column inventory that decreases away from the continental slope. Increased water column inventories are observed between African and Cape Verde in association with the high vertical fluxes of aeolian dust there.

d: Total particulate Ti at bottom sampling depth (log scale) showing the strong benthic nephleoid layers (BNLs) at Stns 11-04 and 11-08 (red dots); the weaker, but thick boundary layer near Bermuda, and barely evident (in Ti) BNL at adjacent to Mauritania. The Med outflow particulate plume is evident at Stn 10-01.

e: Mahowald (2005) [reprinted with permission]. Annual dust deposition model estimates; note non-linear color scaling. Cruise transects are shown in black. 

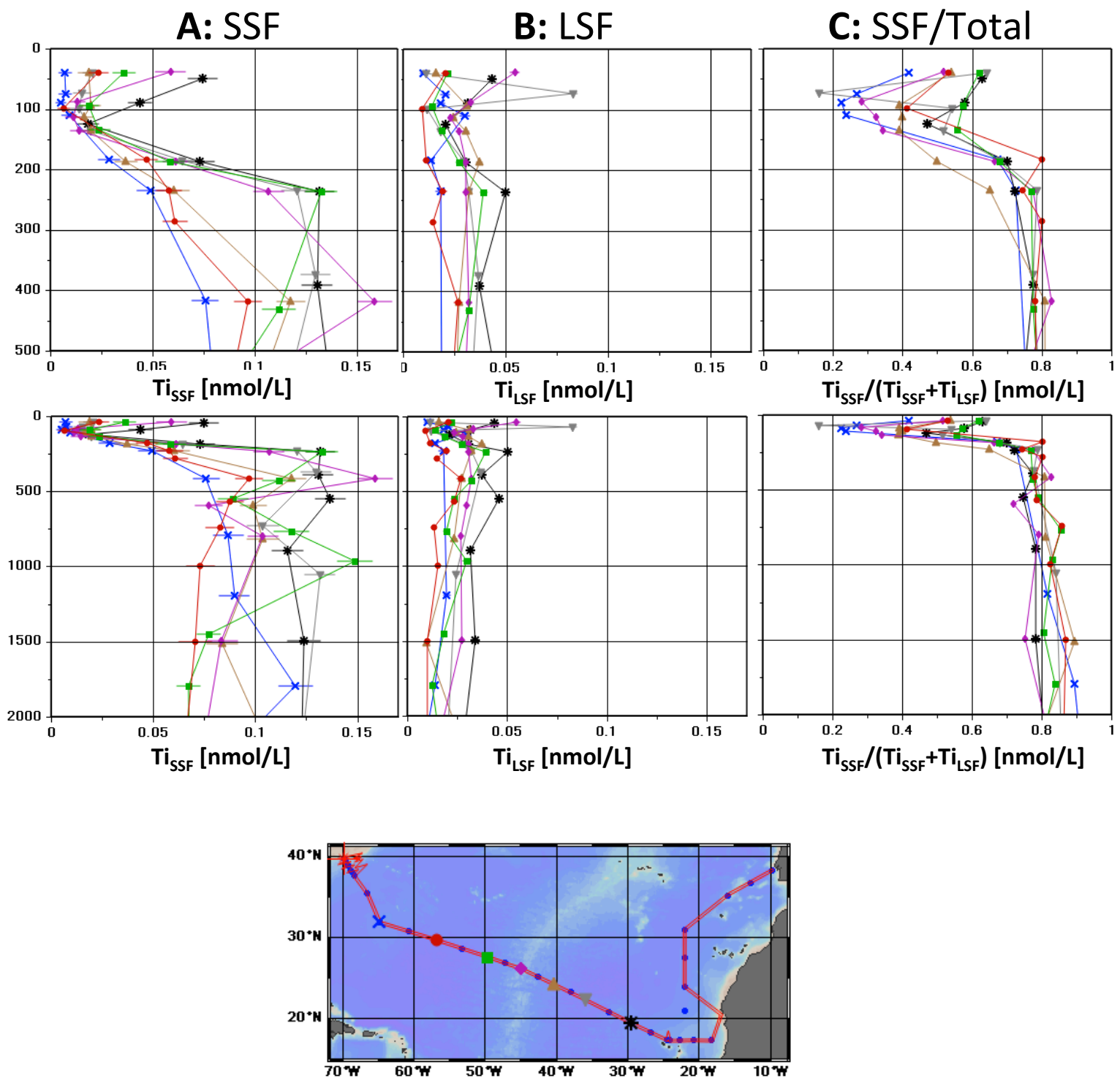

Figure 11a-c: Particulate Ti profiles for the upper water column $(0-500 \mathrm{~m}$, top row) and deep $(0-2000 \mathrm{~m}$, bottom row $)$ in the a: SSF, b: LSF, and c: SSF/(SSF+LSF). Only open ocean stations are plotted (map), presumably stations with minimal laterally-sourced lithogenic influences. 

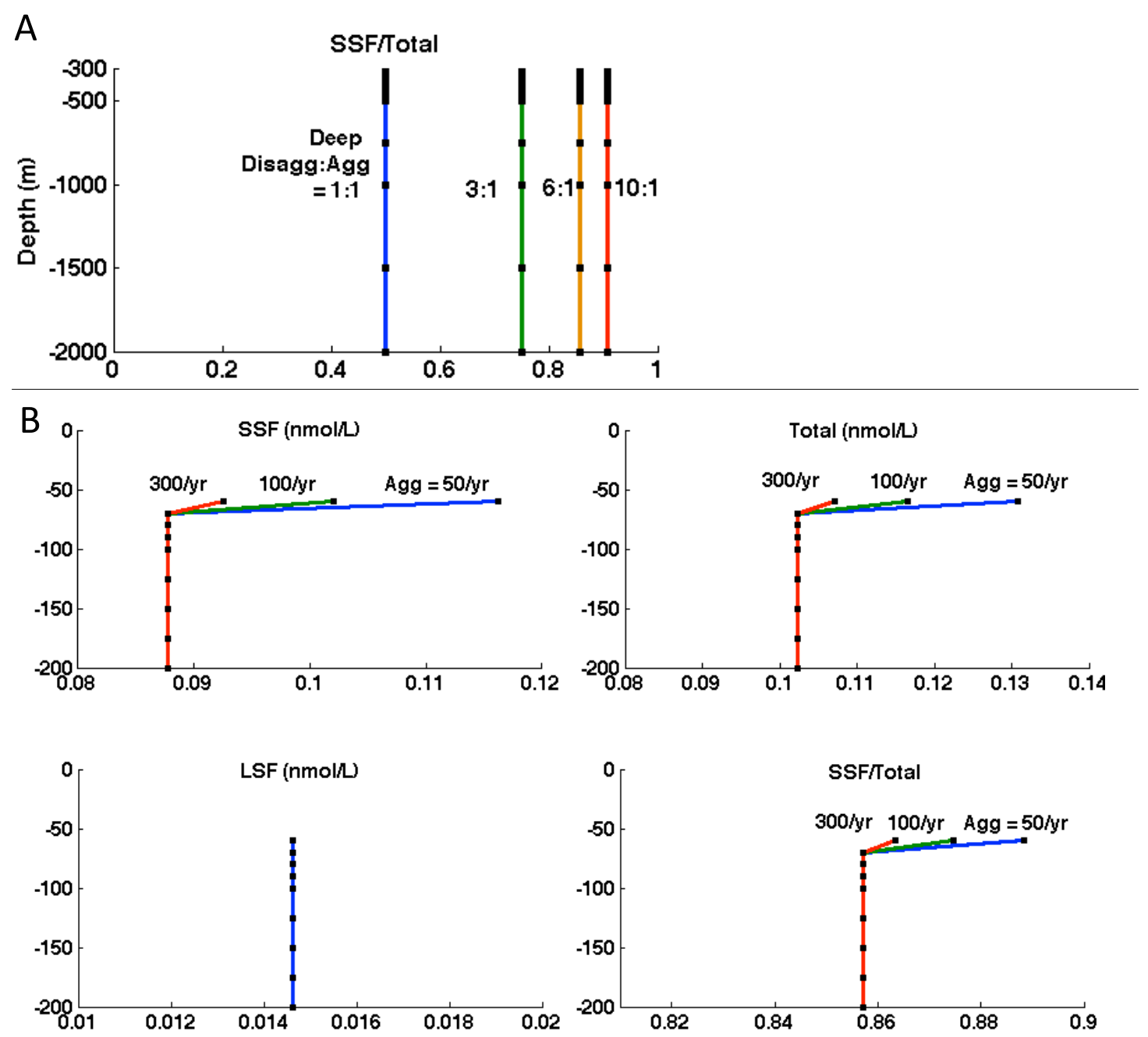

Figure 12: 1D agg/disagg/sinking model responses and results.

A: The deep ( $>300 \mathrm{~m})$ disagg:agg rate ratio controls the deep size-fractionation (SSF:Total) of inert lithogenics. In constant dust scenarios, this behaviour occurs generally regardless of upper water column structure or the absolute agg and disagg rates. Different colors display model runs with deep disagg:agg rate ratios between 1:1 and 10:1. Observed deep fractionation (75-85\% SSF; Figure 13c) indicates ratios between 3:1 and 6:1 are appropriate. $\mathrm{B}$ : Varying the absolute mean aggregation rate controls the relative size of the surface mixed layer lithogenic maximum. Dust inputs are held constant at $2 \mathrm{mg} \mathrm{m}^{-2} \mathrm{~d}^{-1}$, disagg:agg ratios at $6: 1$ throughout the entire water column, and sinking rates at $16 \mathrm{~m} / \mathrm{d}$ (LSF). Only the absolute aggregation rate is varied between $50 \mathrm{yr}^{-1}$ and $300 \mathrm{yr}^{-1}$. 

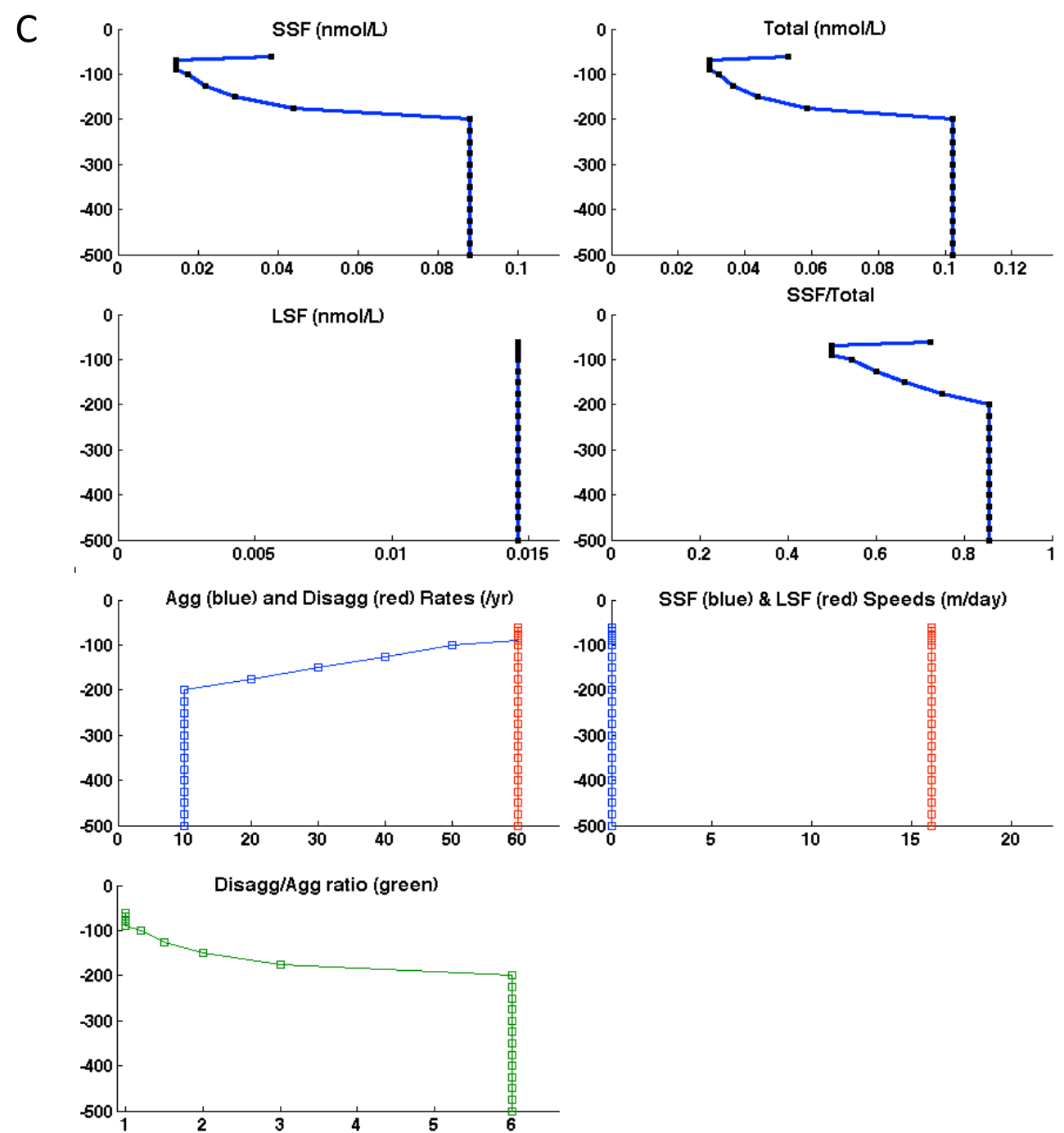

Figure 12 cont'd. C: Allowing aggregation rates to increase towards the surface (bottom panels) generates lithogenic concentration and size-fraction profiles remarkably similar to those observed in the ocean (cf. Figure 11). 
D
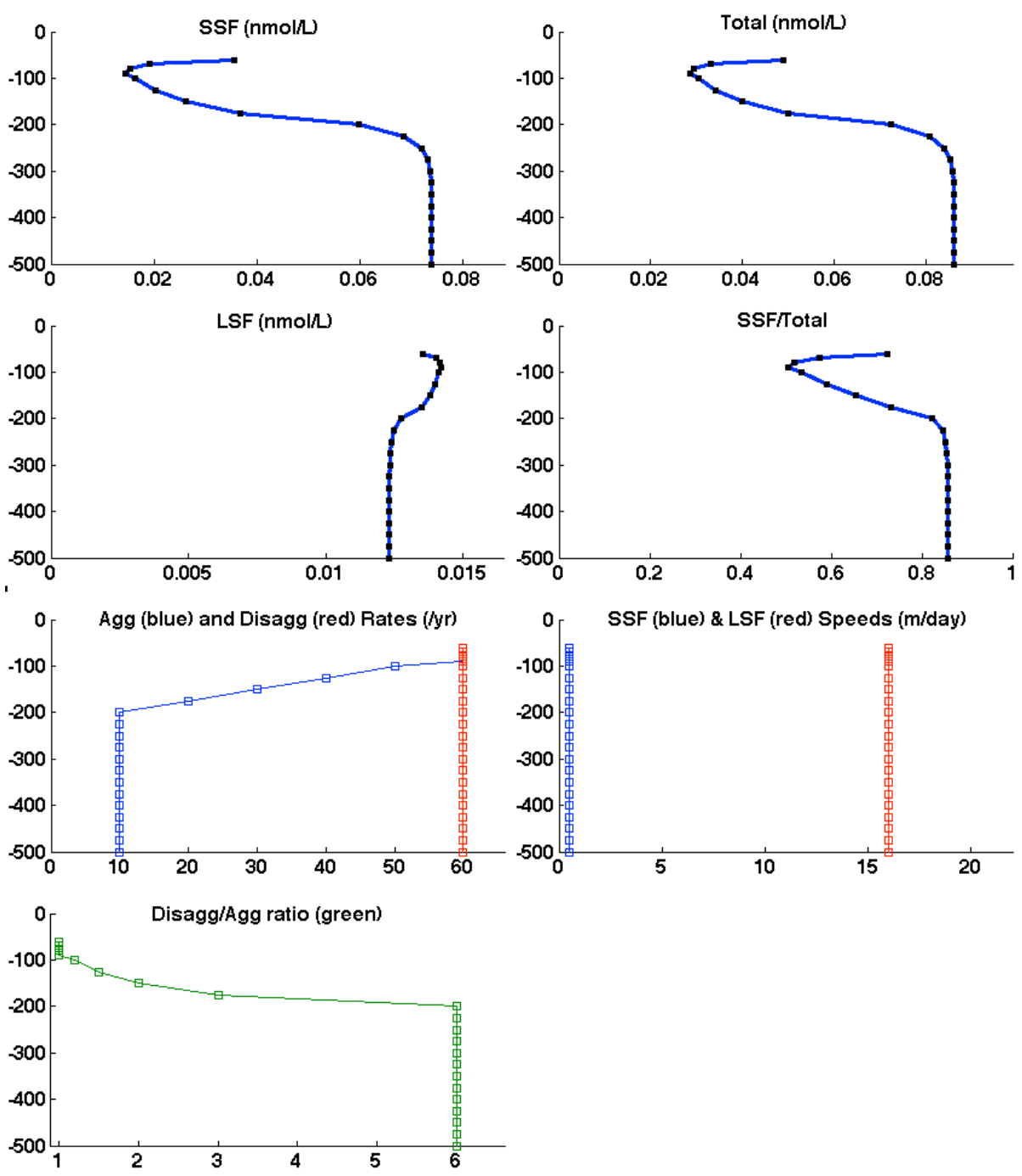

Figure 12 cont'd.

D: Imparting an SSF settling speed (shown: $0.5 \mathrm{~m} / \mathrm{d}$ ) generates curvature in both the LSF and SSF profiles at shallow depths and slightly decreases the steady-state lithogenic inventory [note slight drop in scale along $\mathrm{x}$-axes vs. $14 \mathrm{c}$ ] and may account for some observed nearsurface variations in LSF abundances [Figure 13b, upper panels]. 

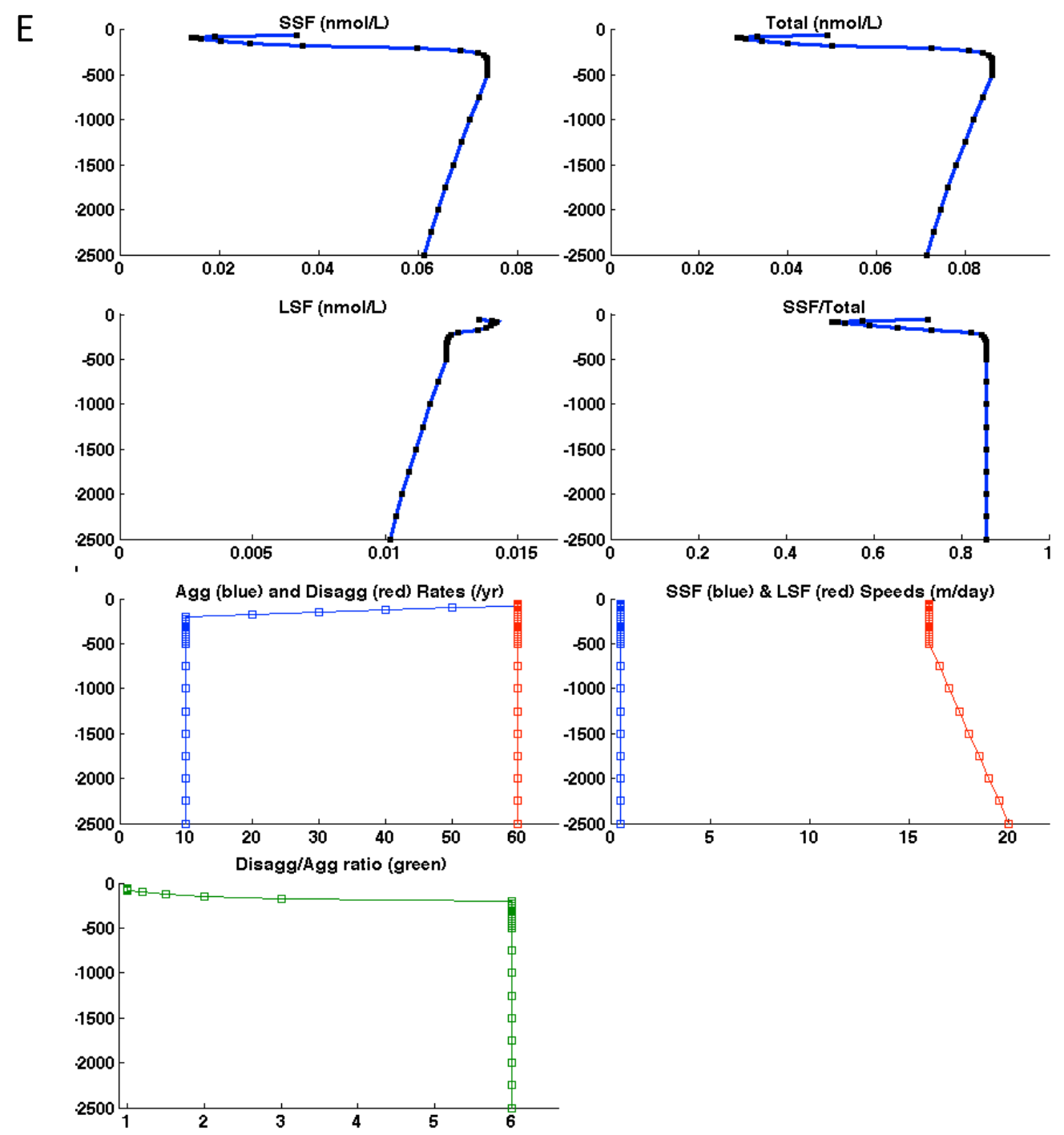

Figure 12 cont'd

E: Allowing the LSF sinking speed to increase with depth (here, increasing from 16 to $20 \mathrm{~m} / \mathrm{d}$ in the lower $2000 \mathrm{~m}$; bottom panels) decreases the total inventory at those depths proportionally.

F (following two pages): Imparting a time-varying dust input (upper left) and otherwise standard model parameters (upper two rows), time-varying dust responses (lower panels) are generated. 
$\mathrm{F}$
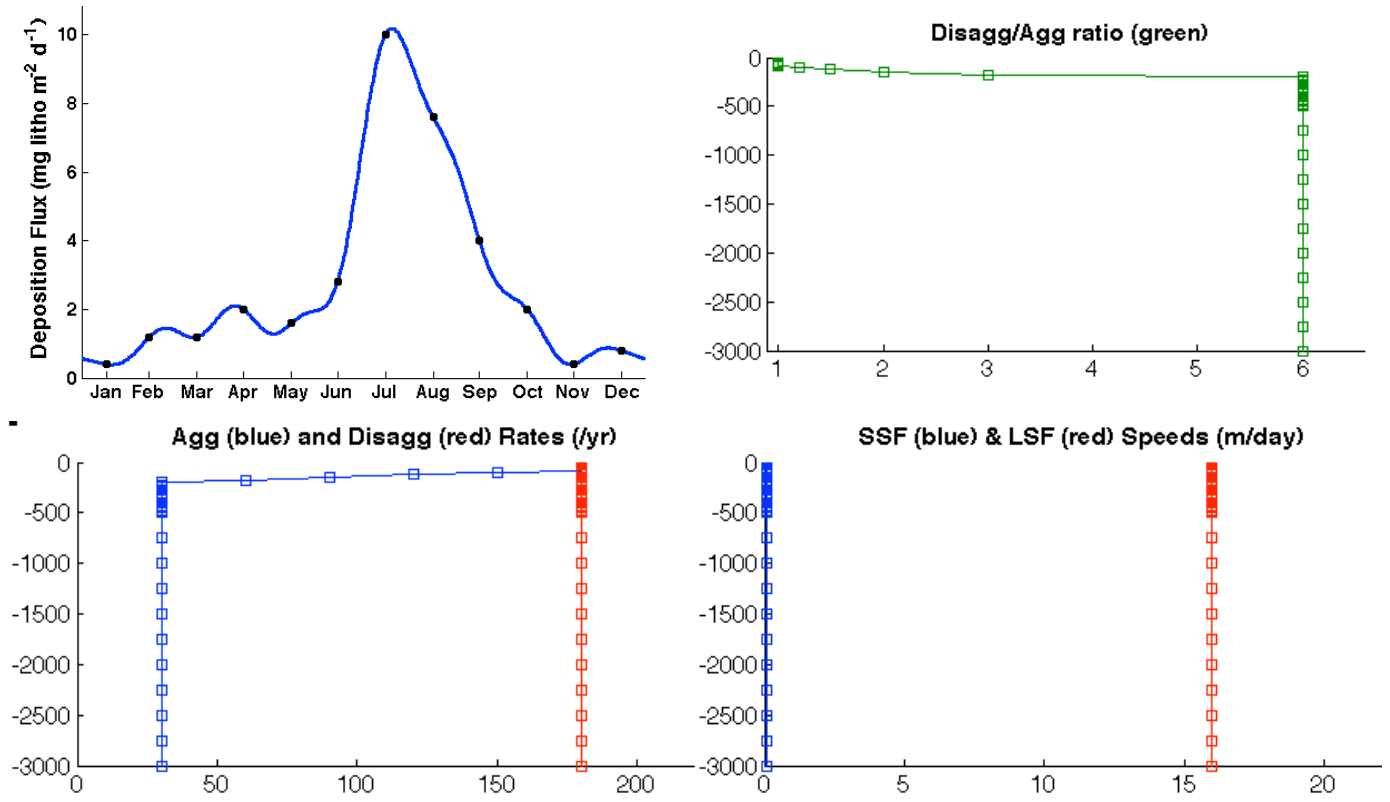


\section{F cont'd}
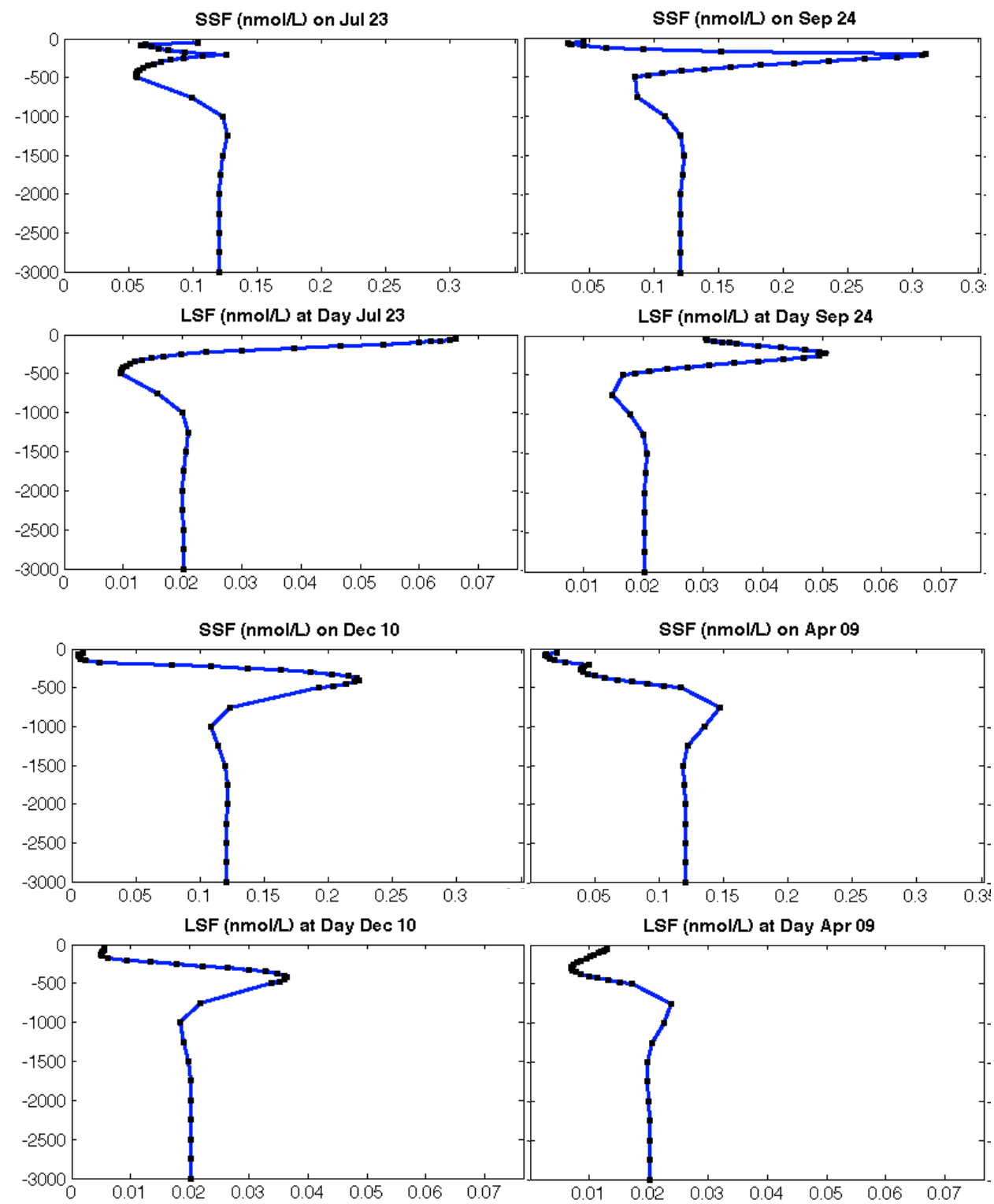


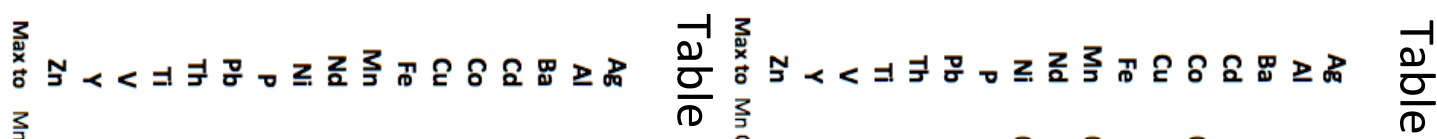

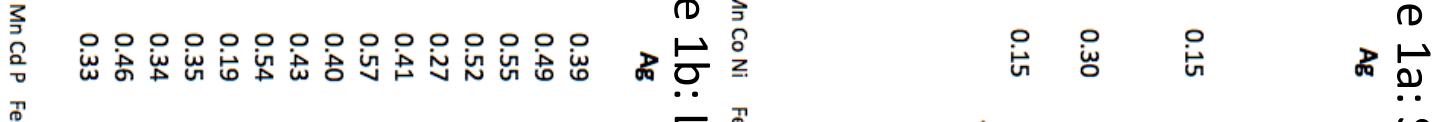

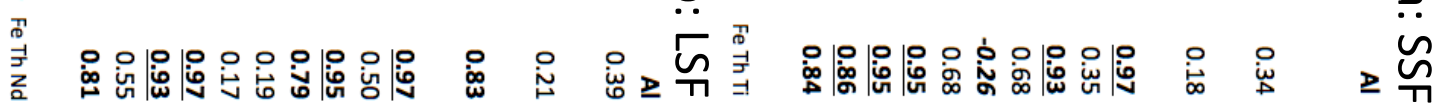

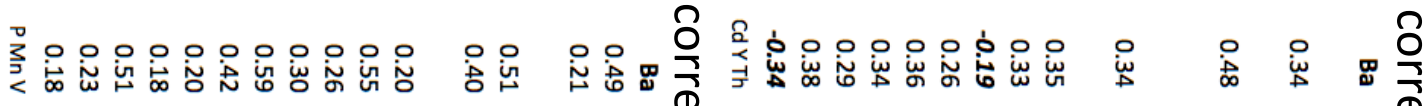

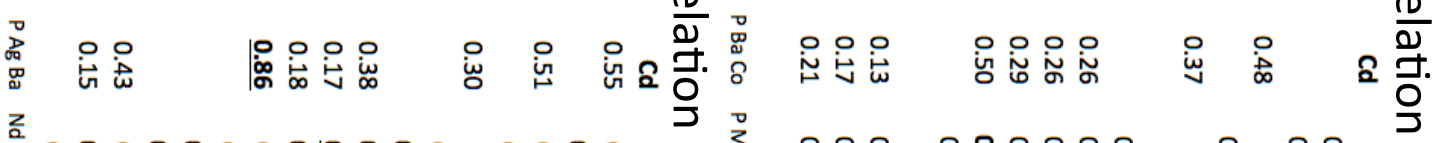

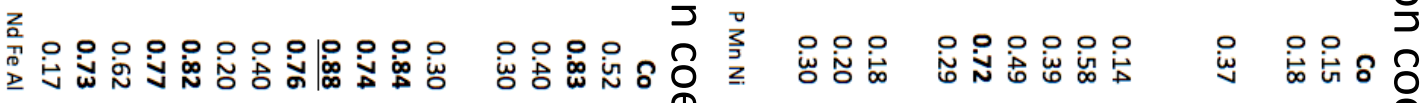

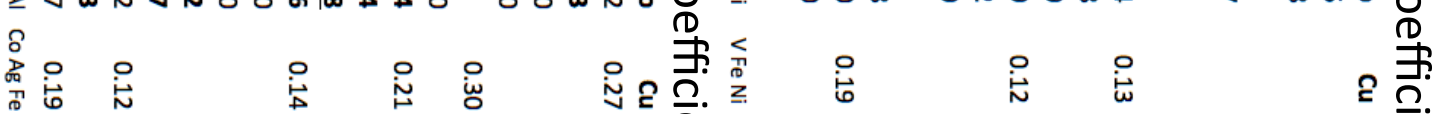

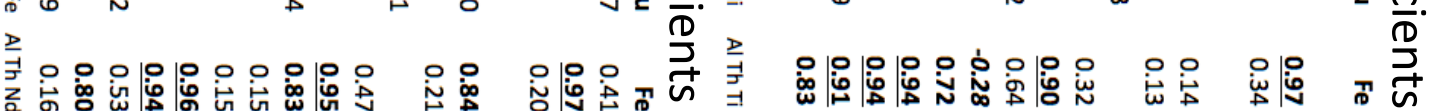
言

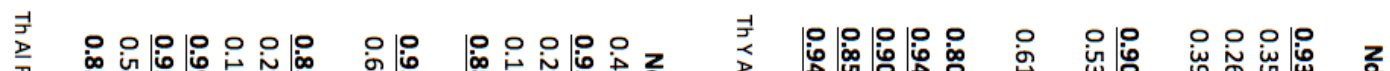

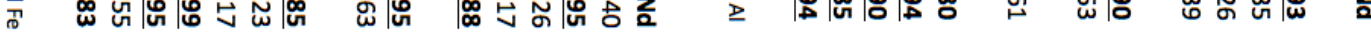

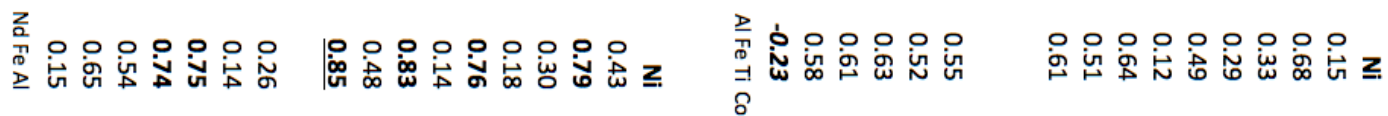

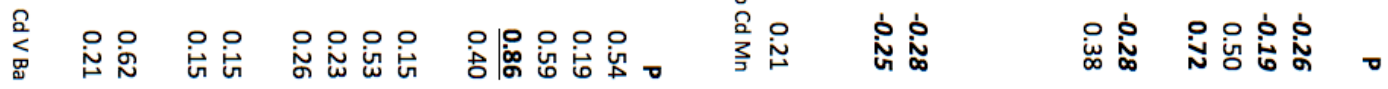

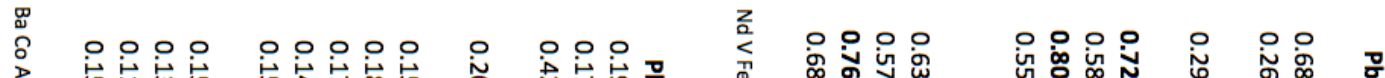
辛

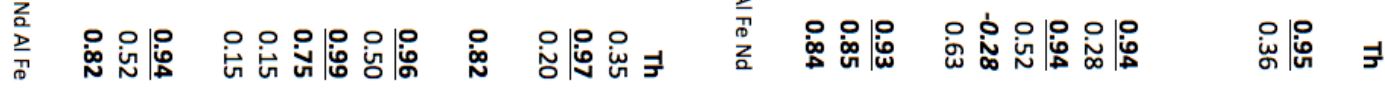

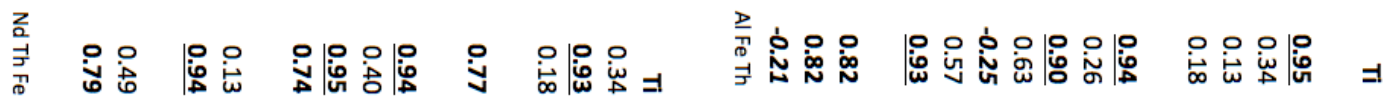

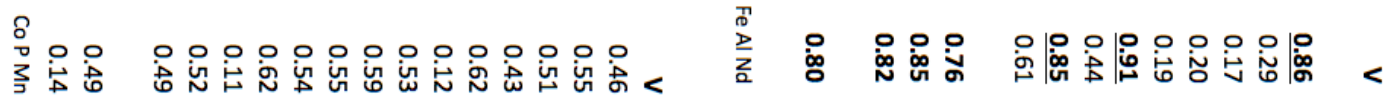

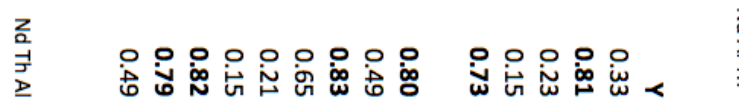

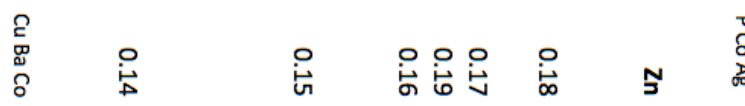

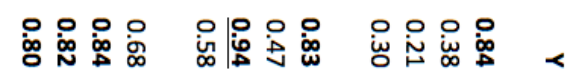

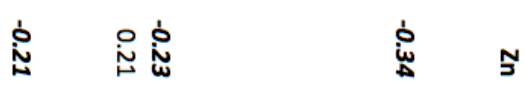


Table 1 (preceding page): Bivariate elemental correlation coefficients (R) for the small size fraction (SSF, 1a) and large size fraction (LSF, 1b) within a large subset of the data. Dataset has been filtered to remove extremely high concentration samples present at benthic nepheloid layers, coastal/margin samples and immediately proximal to the MAR/hydrothermal system by selecting for $\mathrm{pFe}<7 \mathrm{nM}$, leaving $n=309 / 344$ (SSF) and 308/344 (LSF) samples. Correlation coefficients are shown where $\mathrm{p}<0.05$ (t-test). Bold italics: negative correlations. Bold only: positive correlations where $0.7 \leq \mathrm{R} \leq 0.85$. Bold underline: positive correlations where $\mathrm{R}>0.85$. Bottom row: strongest positive correlations for each element. Strongest positive correlations in the SSF are among lithogenic tracer elements ( $\mathrm{Al}, \mathrm{Fe}, \mathrm{Ti},{ }^{232} \mathrm{Th}$ ) along with $\mathrm{Nd}, \mathrm{V}$, and $\mathrm{Y}$. Negative correlations in the SSF are observed between biogenic and lithogenic particulate tracers, driven by rapid shallow export of lithogenic particles (see discussion). Within the LSF, strong biogenic and authigenic correlations among particulate $\mathrm{P}, \mathrm{Co}, \mathrm{Mn}$ are observed in addition to the typical lithogenic correlations.

\begin{tabular}{|rrrrrr|}
\hline Station & $\begin{array}{r}\text { Mid-sampling } \\
\text { date/time (GMT) }\end{array}$ & $\begin{array}{r}\text { Time since } \\
\text { Export [days] }\end{array}$ & $\begin{array}{r}\text { Depth of Max } \\
\text { (Fe/Ti) })_{\text {LSF }}[\mathrm{m}]\end{array}$ & $\begin{array}{r}\text { [me/Ti) } \\
{[\text { LSF }}\end{array}$ & $\begin{array}{r}\text { Vertical } \\
\text { Velocity [m/d] }\end{array}$ \\
\hline $11-12$ & $11 / 23 / 1111: 22$ & 0.0 & 236 & 19.3 & NA \\
$11-14$ & $11 / 26 / 1119: 22$ & 3.3 & 551 & 12.7 & 94.5 \\
$11-16$ & $11 / 29 / 118: 18$ & 5.9 & 801 & 9.8 & 96.2 \\
$11-18$ & $12 / 2 / 1114: 41$ & 9.1 & 1520 & 15.8 & 140.5 \\
$11-20$ & $12 / 4 / 1122: 57$ & 11.5 & 2300 & $? 8.3$ & 179.7 \\
\hline
\end{tabular}

Table 2: Assuming simultaneous export of the $(\mathrm{Fe} / \mathrm{Ti})_{\mathrm{LSF}}$ anomaly first observed at three depths (185-285m) at station 11-12 and then at single, progressively deeper depths through stn. 11-20, we calculate export speeds of 95-180 m/d for these Ferich large particles. Notably, the absolute concentrations associated with this event (not plotted) do not appear as signficant deviations from nearby profiles, indicating they represent only a rare subset of the LSF particle population, and not a significant absolute "flux" of Fe. 


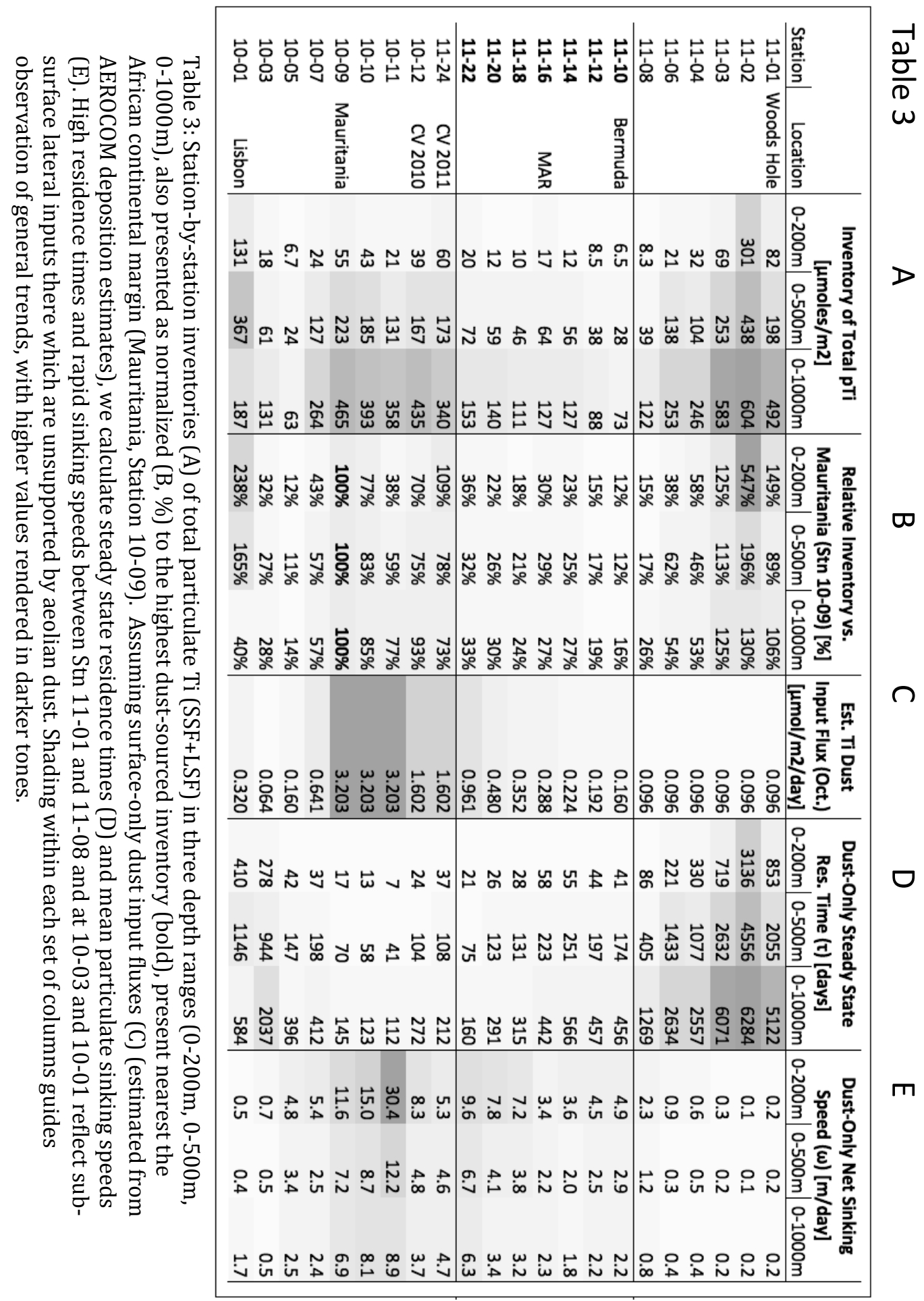


Chapter 4: Bioavailability of Synthetic ${ }^{57} \mathrm{Fe}-$ Minerals to HNLC Surface Seawater Communities

IN PREP FOR JOURNAL: Limnology and Oceanography

Daniel C. Ohnemus ${ }^{1,2 *}$, Glenn A. Gaetani ${ }^{3}$, Phoebe J. Lam²

${ }^{1}$ MIT-WHOI Joint Program in Oceanography, Massachusetts Institute of

Technology/Woods Hole Oceanographic Institution, Woods Hole, MA 02543, USA

${ }^{2}$ Department of Marine Chemistry and Geochemistry, Woods Hole Oceanographic Institution, Woods Hole, MA 02543, USA

${ }^{3}$ Department of Geology and Geophysics, Woods Hole Oceanographic Institution, Woods Hole, MA 02543, USA

${ }^{*}$ Corresponding author. Email: dan@whoi.edu

\section{ACKNOWLEDGEMENTS}

We thank Captain Dave Murline, Chief Scientist Barney Balch, and the crew of the $R / V$ Roger Revelle cruise RR1202 and for their excellent leadership and shipboard support. Ben Twining and Sara Rauschenberg aided in collection of incubation source water. Sarah Rosengard, Jason Hopkins, Angel Ruacho, and Patrick Holligan greatly assisted with McLane pump operations. Melissa Miller of the UCSD/SIO STS group conducted on-board nutrient analyses. We thank Scot Birdwhistell of the WHOI Plasma Facility for analytical assistance. Funding was provided by the National Science Foundation (OCE \#0960880 and PLR \#0838921 to P.J. Lam), and fellowship assistance from the Williams College Tyng Fellowship and MIT/WHOI Academic Programs Office to DCO.

\section{ABSTRACT}

We report the results of a series of bottle incubation experiments utilizing ${ }^{57} \mathrm{Fe}$-enriched synthetic minerals ( ${ }^{57} \mathrm{Fe}$-ferrihydrite, and ${ }^{57} \mathrm{Fe}$-fayalite) immobilized on acrylic slides to examine iron bioavailability of refractory mineral particles to whole marine communities. In an Fe-limited HNLC incubation conducted near the Crozet Islands, both minerals drove increased Chl production over blank treatments, 
and increased biomass in mineral-amended bottles was correlated with increased ${ }^{57} \mathrm{Fe}$ transfer from both minerals. Bottles from an offshore, silica-limited incubation showed only slight growth responses and minimal ${ }^{57} \mathrm{Fe}$ incorporation, but a marked growth response to a slide prepared with natural mineral biotite. Hg-poisoned controls from both incubations demonstrated measureable transfer of ${ }^{57} \mathrm{Fe}$ from refractory minerals into suspended particulates over natural-abundance ${ }^{57} \mathrm{Fe}$, indicating that light-dependent, abiotic solubilization of Fe from particulate minerals and its reprecipitation in suspended particles may be a ubiquitous phenomenon underlying a portion of particulate iron bioavailability.

\section{INTRODUCTION}

It is well established that in high nutrient, low chlorophyll (HNLC) regions of the world ocean, availability of micronutrient iron is a primary limiting factor on biotic productivity (Boyd et al., 2007; Martin, 1988). As marine primary production and associated carbon export via the oceanic biological pump are critical terms in global carbon cycling budgets, understanding iron cycling and its bioavailability in seawater has thus been of central focus to biogeochemical studies for decades. The question of what defines bioavailability of Fe was reviewed recently by (Shaked and Lis, 2012), who suggest that iron bioavailability should not be considered "all or nothing" but instead a spectrum that depends on available Fe-substrates, natural organic compounds including specific and non-specific ligands, and biotic organisms present for growth within the multitude of marine environments.

At the level of the individual phytoplankter cell and its ability to acquire iron from the environment, however, bioavailable Fe is considered to be Fe in dissolved forms only ((Morel et al., 2008) and references therein), with the exception of organisms large enough to directly phagocytize colloidal and pFe (Barbeau et al., 1996; Nodwell and Price, 2001). The specific cellular mechanisms that access either FeL (ligand-bound) or Fe' pools of dFe continue to be investigated mechanistically (Kustka et al., 2005; Shi et al., 2010), but in general, particulate and colloidal iron are not considered to be directly bioavailable to marine phytoplankton (Rich and Morel, 1990; Wells et al., 1983) in the absence of dissolution processes. General 
bioavailability of particulate $\mathrm{Fe}$ is thus dependent on the processes that release and/or maintain particle-sourced Fe in forms (Fe', FeL) that are directly or indirectly acquirable by organisms.

The dominant apparent solubilization processes in seawater often involve tandem light-ligand-particle interactions, albeit with sometimes indirect mechanisms of action. Borer et al. (Borer et al., 2005) showed that the strong siderophores DFOB and aerobactin, in the presence of light and Fe-oxides goethite and lepidocrocite, accelerated the dissolution of crystalline iron by acting as Fe(II) shuttles. A study comparing model iron complexes and natural in situ ligands in sub-Antarctic waters (Maldonado et al., 2005) indicated in situ ligands were strongly photo-labile, and that natural assemblages of ligands produced a 15 -fold increase (over model compounds) in Fe-uptake in light experiments. More recently, Hassler et al. (Hassler et al., 2011) demonstrated that simple, environmentally common mono- and poly-saccharides can greatly enhance bio-uptake of iron as part of the natural "organic soup" of ligands in Southern Ocean waters.

Certain species have Fe acquisition systems that target particles, in the surface perhaps most notably Trichodesmium spp., that "mine" pFe from lithogenic dust particles (Rubin et al., 2011). In the deep ocean, biologically mediated alteration and acquisition of Fe by chemoautotrophs is the basis for entire ecosystems of marine organisms (reviewed by (Orcutt et al., 2011), and refs. therein). Some diatoms, including Rhizosolenia are known to migrate vertically by adjusting their buoyancy when nitrogen-stressed to "gather" nutrients at the deep nutricline in the NW Pacific (McKay et al., 2000). Constitutive expression of Festress markers in these species made it unclear if this behavior encourages Feacquisition, though they hypothesize it would be dependent on the depth of the ferricline. The dissolved ferricline is often associated with a particulate lithocline, which in the Northwest Pacific is laterally-sourced (Lam and Bishop, 2008), but can also be sourced vertically from aeolian deposition and remineralization, as observed in the N. Atlantic (Ohnemus and Lam, in prep).

Particulate Fe makes up a significant, if not frequently dominant, portion of total Fe present in the oceans (Johnson et al., 1997; Landing and Bruland, 1987; 
Mahowald et al., 2009), so the extent to which the multitude of particulate poolsinnumerable lithogenic minerals and various biogenic/organic and authigenic Fephases generated and recycled in situ-are bioavailable for biotic uptake and growth at the surface is thus an important question but one that is difficult to examine directly. Prior incubation studies utilizing bioparticulate- ${ }^{59} \mathrm{Fe}$ (Hutchins et al., 1993) and dissolved-57Fe isotopic amendment into natural seawater (Hurst and Bruland, 2007) noted rapid and continuous in situ recycling and regeneration of particulate Fe pools. Hurst et al. implicated the cycling of Fe between dFe (soluble and colloidal) and pFe pools as evidence that $\mathrm{pFe}$ may act as a bioavailable Fe source (i.e. of $\mathrm{dFe}$ ). Many other natural seawater incubations utilizing dissolved Fe amendments (Chever et al., 2010; Moore et al., 2007b) allow for prompt observation of community responses and sensitivities to Fe-additions in combination with other parameters. However, the underlying particulate-centered dissolution and recycling processes in natural seawater that are ultimately the sources of most bioavailable Fe remain poorly understood.

In this study, we utilize synthetically prepared ${ }^{57} \mathrm{Fe}$-enriched minerals to examine the bioavailability of inorganic and mineral pFe more directly. Natural Fe comprises four stable isotopes, of which ${ }^{56} \mathrm{Fe}$ is the major isotope $(91.8 \%)$ and ${ }^{57} \mathrm{Fe}$ a minor isotope (2.82\%). We synthesized two particulate mineral phases that were $>96 \%{ }^{57} \mathrm{Fe}$ : ferrihydrite, an $\mathrm{Fe}^{3+}$ oxy-hydroxide chosen to be reflective of poorlycrystalline suspended Fe(III) oxides commonly found in marine particle assemblages (Lam et al., 2012) and the early authigenic phase formed after precipitation of dissolved Fe in oxygenated seawater; and fayalite, an $\mathrm{Fe}^{2+}$ silicate chosen to be reflective of primary lithogenic silicates. Through immobilization of these phases onto acrylic slides after (Birkefeld 2005) and bottle incubation of the slides in iron-limited, whole seawater surface communities for $12-14 \mathrm{~d}$, we sought to ascertain whether biotic communities incorporated ${ }^{57} \mathrm{Fe}$ from source minerals into biomass via any combination of abiotic or biotic processes.

\section{METHODS}

2.1 Mineral Synthesis 
${ }^{57} \mathrm{Fe}$ was purchased as hematite $\left(\mathrm{Fe}_{2} \mathrm{O}_{3}\right)$ from Isoflex, USA (actual batch isotopic composition: ${ }^{57} \mathrm{Fe} 96.64 \%$; ${ }^{56} \mathrm{Fe} 1.38 \%$; ${ }^{58} \mathrm{Fe} 1.97 \%$ ). Ferrihydrite was synthesized according to the 2-line ferrihydrite procedure of Schwertmann and Cornell (2008). ${ }^{57} \mathrm{Fe}_{2} \mathrm{O}_{3}$ was first dissolved in concentrated nitric acid at $60^{\circ} \mathrm{C}$. ${ }^{57} \mathrm{Fe}\left(\mathrm{NO}_{3}\right)_{3}(1 \mathrm{M})$ was titrated slowly with $0.1 \mathrm{M} \mathrm{NaOH}$ to $\mathrm{pH} 9$, then dialyzed behind $100 \mathrm{kDa}$ dialysis tubing (Fisher) in a Milli-Q water bath (Millipore; $18.2 \mathrm{M} \Omega$ ) that was frequently changed for five days. Ferrihydrite was then removed from dialysis tubing, freeze-dried, and homogenized with a mortar and pestle for $60 \mathrm{~min}$ to produce a fine powder. The freeze drying of ferrihydrite notably aggregates and ages the mineral (Raiswell et al., 2010), though grinding (and the resulting decreased grain size) should increase surface area. Taken together with the long period between mineral synthesis and incubation ( 6 months), our ${ }^{57} \mathrm{Fe}$-ferrihydrite is likely to be far more refractory than many natural, fresh assemblages of Feoxyhydroxides present in the euphotic ocean. Micron-scale x-ray absorption near edge spectroscopy ( $\mu$ XANES) of slide-bound ferrihydrite conducted after the incubation experiment at the Advanced Light Source (Berkeley, CA) beamline 10.3.2, and spectral fitting to an Fe-mineral library (Lam et al., 2012) indicated a mixture of 2L-ferrihydrite and biogenic iron oxyhydroxide e.g. (Toner et al., 2009) indicating the mixture had not significantly aged to $6 \mathrm{~L}$-ferrihydrite.

${ }^{57} \mathrm{Fe}$-fayalite $\left({ }^{57} \mathrm{Fe}_{2} \mathrm{SiO}_{4}\right)$ was prepared by petrogenic reduction of ${ }^{57} \mathrm{Fe}_{2} \mathrm{O}_{3}$ in the presence of quartz $\left(\mathrm{SiO}_{2}\right) \cdot{ }^{57} \mathrm{Fe}_{2} \mathrm{O}_{3}$ (Isoflex) and $\mathrm{SiO}_{2}$ (Sigma, ultrapure) were dried at $600^{\circ} \mathrm{C}$ for $24 \mathrm{hrs}$ in porcelain crucibles, then cooled. $\mathrm{SiO}_{2}$ was added to a slight stoichiometric excess (1.1 Si: $1 \mathrm{Fe}_{2}$ ) to support complete reaction of $\mathrm{Fe}$, and the mixture ground by automated mortar and pestle under ethanol for 24 hours. The mixture was transferred to a $\mathrm{Ni}^{0}$-metal bucket and suspended within a petrogenic furnace (Deltech) at $1050^{\circ} \mathrm{C}$ in a reducing $\mathrm{CO} / \mathrm{CO}_{2}$ atmosphere $\left(\log \mathrm{fO}_{2}=-\right.$ $11.6 \mathrm{M}$ ) for $4 \mathrm{~d}$. Atmospheric oxygen fugacity was monitored by zirconia electrode and was held within the fayalite-magnetite-quartz (FMQ) buffering region throughout the reaction (O'Neill, 1987). At the end of firing, the reaction was quenched into DI-water, and the pellet removed and thoroughly ground with a mortar and pestle (90min) until homogeneity and visual grain size were similar to 
the ferrihydrite, which had been prepared previously. Grains were initially confirmed as fayalite by Fe:O:Si stoichiometry using SEM-EDS and later by $\mu \mathrm{XRD}$ at the Advanced Light Source (Berkeley, CA) beamline 10.3.2. XANES fitting of slideimmobilized grains indicated the presence of magnetite as a possible component fit (typically $<20 \%$ in fewer than $20 \%$ of grains). The fayalite powder should therefore be considered as being a mixture of mostly $\mathrm{Fe}^{2}$-silicate (fayalite), with a small but non-trivial yet crystalline $\mathrm{Fe}^{3}$-oxide (magnetite) component.

\subsection{Slide Preparation}

Incubation slides were designed after (Birkefeld et al., 2005), who immobilized a range of inorganic mineral particulates in epoxy resin (c.f. their Figs. 1-3) for 4-18 months to examine dissolution kinetics in soil systems. Square slides $\left(4 \mathrm{~cm}^{2}\right)$ were cut from acrylic sheets (3/32" thickness; McMaster-Carr), numbered with an engraver, and acid-cleaned in $10 \% \mathrm{HCl}$ for 7 days. In a HEPA-filtered clean space, clear, UV-resistant, two-part marine epoxy (West System 105/207 mixture) was prepared by mass in small batches and applied evenly in a thin film using the edge of a second slide as an applicator across one face of the slide. A pre-weighed aliquot of mineral was placed into a small plastic dusting barrel (attached to a compressed air source) with a circular aperture approximately $2 / 3$ the width of the slide surface area. Slides were held a few $\mathrm{mm}$ away from the chamber aperture and the mineral was sprayed directly into the setting epoxy film. The spray pattern was no larger than the chamber aperture, indicating most, if not all, mineral sprayed had impacted the slide/epoxy surface. Microscopic imaging of the slide surfaces showed some finer particles were buried (inaccessible) beneath the epoxy resin, though most retained a slight (10-50\%) surface exposure to the environment as in (Birkefeld et al, 2005). Epoxy was allowed to set for 3 days in a HEPA-filtered environment.

Exact masses of mineral deposited could not be determined as epoxy was, by design, setting during the mineral application. Further, variation in mineral embedding (degree of mineral inaccessibility beneath epoxy surfaces) also represented a source of mineral loading uncertainty. As an experimental 
compensation for these uncertainties, slides were loaded at two different levels, LO (110 $\pm 13 \mu \mathrm{g}$ mineral) and HI (294 $\pm 24 \mu \mathrm{g}$ mineral), to examine for dose-dependent growth and/or ${ }^{57} \mathrm{Fe}$-transfer. Effective mineral concentrations are poorly constrainable in this case of immobilized, variously exposed mineral particles. Considering approximately $10-50 \%$ of particle spherical area is exposed, and assuming that less than $12 \%$ of a $50 \mu \mathrm{m}$ particle is at its surface (highly uncertain for ferrihydrite), we can estimate that on order of $1 \%$ of particle mass is actually exposed to the environment. Assuming 55\%wt. Fe (calculated for fayalite; ferrihydrite may be as high as $63 \%$ depending on hydration or molecular formula used), 1\% exposure effective concentrations are presented in Table 1.

These experiments were designed to fully immobilize the labeled mineral pool, allowing separation at experiment end between the target biogenic and authigenic particles (suspended biogenic/organic and authigenic/inorganic phases) and the source minerals. The disadvantage of this immobilization is an inability to directly quantify available surface-available mineral without altering the original slides, as would be necessary if the goal was to measure absolute mineral solubility or uptake rates requiring normalization to the amount of mineral added. More precise dissolution and/or uptake-kinetics experiments using labeled minerals are an intriguing future possibility assuming quantification can be conducted via suitable methods.

\subsection{Marine Particulate Sample Collection}

Water column particulates used in description of the oceanographic particle regime and in particle addition experiments were collected via in situ batterypowered pumps (McLane) using a dual-flow methodology described in (Committee, 2010) and (Ohnemus et al., in prep). Pumps operated for $1.5 \mathrm{hr}$ at an initial flowrate of $8 \mathrm{~L} / \mathrm{min}$. Large-size fraction $(\mathrm{LSF},>51 \mu \mathrm{m}$ ) particulates were collected first, on acid-cleaned polyester screens. Fine particulates were collected downstream of LSF particles on paired, acid-cleaned $0.8 \mu \mathrm{m}$ polyethersulfone Supor filters. During filter processing after pump recovery, screens and filters were misted lightly with Qwater under gentle vacuum to reduce salt retention. A subsection of the LSF 
(typically $1 / 2$ a screen, representing ca. $120 \mathrm{~L}$ of seawater) was rinsed onto $25 \mathrm{~mm}$ Supor disc filters using filtered surface seawater that were later bisected for total digestion analyses. The remaining screens, including those used for weak leaches, and all Supor filters were dried in a HEPA-filtered AirClean flowbench and bagged. The upper (top) Supor filter (0.8-51 $\mu \mathrm{m}$ particulates) was later subsampled and analyzed for suspended ("susp") particulate concentrations. Filters were processed and subsampled only in HEPA-filtered environments using trace-metal techniques (Ohnemus and Lam, in prep).

\subsection{Incubation Source Waters}

Two subantarctic stations were chosen as incubation sources to contrast different recent ambient Fe environments. Station 27/Inc. 1 was located at the edge of the Crozet platform in post-summer bloom waters (late February) that had likely recently become Fe-limited (Pollard et al., 2007). Station 43/Inc. 2 was located in the open subantarctic ocean, upstream of the Kerguelen Islands. Whole surface seawater from $20 \mathrm{~m}$ depth was collected in a $20 \mathrm{~L}$ Go-Flo bottle suspended from a Kevlar trace-metal clean wire at two stations: (Stn $\left.27 ; \mathrm{T}=8^{\circ} \mathrm{C}\right)$ and $\left(\operatorname{Stn} 43 ; \mathrm{T}=7^{\circ} \mathrm{C}\right)$. In a HEPA filtered clean area, seawater was transferred to a large acid-cleaned carboy with headspace, sealed, and kept in the lit incubation chamber $\left(\mathrm{T}=8^{\circ} \mathrm{C}\right)$ while incubation bottles were prepared. Incubations 1 and 2 overlapped temporally and utilized the same walk-in incubator space. Initial temperature conditions for Inc. 1 $\left(\mathrm{T}=8^{\circ} \mathrm{C}\right)$ thus determined the settings for Incubation 2, making incubation conditions slightly warmer than ambient for the second incubation.

\subsection{Incubation Design}

Prior to incubation start, in a HEPA-filtered clean environment, mineral slides were first "conditioned" by agitating inverted slides gently in a small bath of incubation source water for 10 minutes. Conditioning ideally removed labile surface contaminants and any loose particulates present on the slide surfaces.

Slides were then suspended in $250 \mathrm{~mL}$ (main incubation bottles) or 1L (time-course bottles) seawater just below the surface using a loop of acid-cleaned polypropylene 
fishing line that was closed into the bottle cap to aid retrieval. Main incubation bottles were used to study full-term ${ }^{57} \mathrm{Fe}$ transfer from immobilized minerals with replication ( $\mathrm{N}=2$ or 3 ), while larger time-course bottles, which had nominally identical mineral loadings as small bottles and thus initially 4-fold diluted effective mineral concentrations [Table 1], were used for time-course biological (nutrient drawdown, Chl production) and were conducted without replication. Our use of smaller volumes $(250 \mathrm{~mL})$ and long incubation times (12-13d) for the main incubation was intended to allow adequate time to observe particulate bioavailability. This came at the expense of relatively greater "bottle effects" than short-term, larger-bottle dissolved element additions experiments, as our small volumes likely amplified any bottle, dilution, or chip-related (epoxy leaching, surface area, mineral effects) effects.

Bottles were prepared in small ( $\mathrm{n}=2$ or 3 ) batches to minimize temperature stresses on biotic communities. Poisoned controls ( $250 \mathrm{~mL}$ bottles only) were prepared identically, with the addition of a $100 \mu \mathrm{L} / \mathrm{L} \mathrm{SW}$ spike from a saturated (in $>18 \mathrm{M} \Omega$ clean water) $\mathrm{HgCl}_{2}$ solution. Sealed bottles, which included headspace, were secondarily capped with clean plastic bags to prevent contamination of the bottle lids and necks without obscuring bottle walls. Replicate bottles were then placed in a series of ordered rows (Row 1 closest to light source, Rows 2 and 3 sequentially further away) within a walk-in cooler $\left(\mathrm{T}=8^{\circ} \mathrm{C}\right)$ facing a blue fluorescent light bank (Phillips TL-D 18W/18 2' blue bulbs). Bottles with no chip added (whole seawater only) are described as unamended treatments herein. Bottles with a blank chip added (epoxy only, no mineral) are described as blank or blank slide treatments. Variations in growth responses due to bottle placement (light effects) were not anticipated across replicates, so lighting levels were not explicitly determined for each bottle. Photon flux measurements using a PAR sensor indicated front row (Row 1 ) illumination was $29 \mu \mathrm{mol}$ photons $/ \mathrm{m}^{2} / \mathrm{sec}$, and rear row (Row 3 ) illumination was $22 \mu \mathrm{mol}$ photons $/ \mathrm{m}^{2} / \mathrm{sec}$. These light levels are within the range of light-limitation $\left(<46 \mu \mathrm{mol} / \mathrm{m}^{2} / \mathrm{sec}\right.$ ) for many Antarctic diatom cultures (Fiala and Oriol, 1990) and thus reflective of conditions in the lower portion of the deep chlorophyll max, where lithogenic pFe concentration gradients are often large (Lam 
et al., 2012)Ohnemus and Lam, in prep). The incubator was kept on a $12 \mathrm{hr} / 12 \mathrm{hr}$ light/dark schedule. A full list of incubation treatments with the number of replicates for each type is presented in Table 2 .

\subsection{Nutrient and Chlorophyll Analyses}

On-board nutrient analyses (dissolved nitrate, nitrite, ammonium, silicate, and phosphate) were conducted by the Scripps Institution of Oceanography, Oceanographic Data Facility (SIO/ODF) group. Chlorophyll- $\alpha$ (Chl-a, or Chl) was extracted from QMA filters into acetone $(10 \mathrm{~mL})$ at $-20^{\circ} \mathrm{C}$ in darkness for $>12 \mathrm{hrs}$. Chl-a concentrations were determined on-board using a Turner Designs fluorometer calibrated with high purity chlorophyll-a standards (Balch et al., 2011).

\subsection{Particulate Leaches, Digests, and Analyses}

In a HEPA-filtered environment, one-liter time-course bottles were subsampled at three time-points (250mL each, Inc. 1: days 1, 4, and 7; Inc. 2: days 3, 8 and 11), and at incubation sacrifice (all bottles, $250 \mathrm{~mL}$ ) at day 12 (Inc. 1) or 13 (Inc. 2). Time-course aliquots were analyzed for $\mathrm{Chl}$-a concentration (utilizing typically $50 \mathrm{~mL})$ and nutrients $(30 \mathrm{~mL}$, large bottles only) with the remainder $(170-200 \mathrm{~mL})$ filtered for suspended particle measurements onto $0.2 \mu \mathrm{m}$ polycarbonate filters (Nucleopore). Filters were folded in half, transferred to Millipore petri-slides, briefly dried, covered, and stored at room temperature in clean sealed bags until analysis.

Primary (weak) leaching of filters was conducted in acid-cleaned $2 \mathrm{~mL}$ microcentrifuge tubes using a slight modification of the $\mathrm{HAc}_{\mathrm{T}+\mathrm{R}}$ procedure (Berger et al., 2008), which was designed to access bioavailable/labile particulate trace metals. The leach (conducted with $1 \mathrm{~mL}$ leach volume per filter) is $25 \%$ ultrapure (Seastar) acetic acid (HAc) with $0.02 \mathrm{M}$ hydroxylamine hydrochloride (Sigma, ReagentPlus) for $2 \mathrm{hr}$ at RT that begins with a brief $(10 \mathrm{~min}) 90-95^{\circ} \mathrm{C}$ heating step that aids in solubilizing organic/protein-bound metals. Leaches were centrifuged during the final $30 \mathrm{~min}$ of reaction to pelletize any large particulates/minerals, after which half the leachate volume $(0.5 \mathrm{~mL})$ was carefully removed. Leachate aliquots were dried in acid-cleaned (Auro et al., 2012) Teflon vials at $110^{\circ} \mathrm{C}$ and amended with two 
separate $(200 \mu \mathrm{L}) 16 \mathrm{M}$ (conc.) $\mathrm{HNO}_{3}$ additions to digest the acetic acid matrix. Final pellets were resuspended in $5 \% \mathrm{HNO}_{3}(1 \mathrm{~mL})$ for analysis via ICP-MS.

After analyses of the first incubation, we noted filter leach blanks for $\mathrm{Al}$ $(0.32 \pm 0.09 \mathrm{nM})$ and $\mathrm{Fe}(0.27 \pm 0.08 \mathrm{nM})$ that were high relative to expected marine particle loadings in incubation bottles: Coale et al. (Coale et al., 2005) report typical sub-polar front marine particulate HAc-leachable Fe values of $<0.02 \mathrm{nM}$. These blanks would be acceptable for filtrations of larger volume, open-ocean samples, but several liters of incubation filtrate would be required to surpass these digestassociated blanks for Fe in our bottle incubations. Prior to analysis of the second incubation, leach stock was cleaned by addition of $2 \mathrm{~g}$ Chelex-100 resin (pre-treated using the procedure of Price et al., (1988)) followed by shaking for 10 minutes, then centrifugation to remove the resin. Backgrounds, especially for leachable Fe, were improved (Fe: $0.07 \pm 0.01 \mathrm{nM}$; Al: $0.19 \pm 0.03 \mathrm{nM}$ ), though still above measurement levels for absolute leachable concentrations of these metals in our small volume, Felimited systems. We thus refrain from interpreting the $\mathrm{Al}$ and ${ }^{56} \mathrm{Fe}$ leachable results in incubation samples (Supplementary materials) directly as an indicator of natural metal behaviors, as most of the signal is likely associated with leach blanks. Water column concentration profiles (Fig. 2) from in situ pumps, however, which were conducted using much larger volumes of filtered particles, were well in excess of leach detection limits.

Despite Fe blanks that interfered with determination of natural Fe responses in incubations, measured Fe values were well constrained, with fully-propogated analytical mean Fe uncertainties for all samples $=5.6 \pm 2.1 \%$. NB: all uncertainties reported herein are presented as $\pm 1 \sigma .{ }^{56} \mathrm{Fe} /{ }^{57} \mathrm{Fe}$ abundance ratios for both natural marine sources and leach blanks were observed within error of natural abundances of the isotopes (control and blank ${ }^{56} \mathrm{Fe} /{ }^{57} \mathrm{Fe}$ mean $=2.39 \% \pm 0.10 \%$; natural ratio $2.31 \%)$. We are thus able to correct measured ${ }^{57} \mathrm{Fe}$ abundances for natural abundance Fe (both environmental and leach-sourced) using ${ }^{56} \mathrm{Fe}$ to isolate the ${ }^{57} \mathrm{Fe}$ associated with the added mineral-bound tracer, which we report as ${ }^{57} \mathrm{Fe}_{\mathrm{xs}} .{ }^{57} \mathrm{Fe}_{\mathrm{xs}}$ determinations from leaches and totals have had ${ }^{56} \mathrm{Fe}$-associated errors propagated into their uncertainties. Blanks and detection limits for ${ }^{57} \mathrm{Fe}$ were determined using 
acid process blanks and filtered samples (un-amended controls and blank-slide replicates) that had ${ }^{57} \mathrm{Fe}$ abundances only associated with sample handling. Blank values for Inc. 1 were $0.07 \pm 0.01 \mathrm{ng}$; for Inc. 2: $0.12 \pm 0.11 \mathrm{ng}$. Values below blank

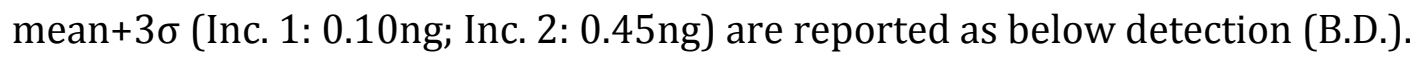

Refractory digestions were conducted on incubation samples sequentially by quantitatively transferring the filter, remaining leachate, and any pellet (via four $0.5 \mathrm{~mL}$ rinses with Q-water) to Teflon vials. Transfers were digested for $2 \mathrm{hr}$ at $135^{\circ} \mathrm{C}$ in sealed vials using a mixture of $\mathrm{HNO}_{3} / \mathrm{HCl} / \mathrm{HF}$ acids ( $4 \mathrm{~N}$ each, $4 \mathrm{~mL}$ ) described further as digest D2 in (Ohnemus and Lam, in prep). Filters, which remained intact after digestion, were removed and rinsed with ultrapure-water into the vial. The digest solution was then dried at $135^{\circ} \mathrm{C}$, then the pellet treated identically to the weak leach (two $16 \mathrm{M} \mathrm{HNO}_{3}$ additional dry-downs followed by resuspension in $1 \mathrm{~mL}$ $5 \% \mathrm{HNO}_{3}$ for analysis). The second digest has been corrected for the portion associated with the transferred leachate from the first weak leach by subtraction to derive "refractory" values.

Due to greater sample availability, pump samples were subject to weak leaches and total (refractory) digestions separately (non-sequentially), but are reported in a manner consistent with the (sequential) filtered incubation samples: the total digest is corrected for the leachable digest and reported as a refractory value.

Analyses were conducted at the WHOI Plasma Facility using an Element2 inductively coupled plasma mass spectrometer (ICP-MS, Thermo). ${ }^{115} \operatorname{In}(0.5 \mathrm{ppb})$ was utilized as an internal analytical drift monitor and for matrix/salt suppression correction (typically 5-15\%). Elemental concentrations were standardized to external dilutions of a combined trace metal standard prepared with approximately crustal abundances from ICP/AA elemental standards in $5 \% \mathrm{HNO}_{3}$. Natural abundances of ${ }^{56} \mathrm{Fe} /{ }^{57} \mathrm{Fe}$ in standards and blanks were consistently observed and isotopic ratios were monitored throughout the run via frequent acid blanks and mid-run standards.

\section{RESULTS}




\subsection{Water Column Particulates at Incubation Sites}

Marine particulates collected via in situ pumps (Committee, 2010; Lam and Morris, n.d.) at two incubation water source stations (Fig. 1) were analyzed for Al, P, and Fe to provide oceanographic context and determine initial incubation

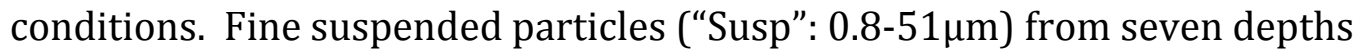
shallower than $1 \mathrm{~km}$ (three in the upper $100 \mathrm{~m}$ ) were digested in parallel for leachable ("Lch") and refractory ("Ref") particle abundances. Large size-fraction particulates ("LSF": > $51 \mu \mathrm{m}$; Fig. 2, asterisks) were only analyzed at the surface $(20 \mathrm{~m}$ depth, incubation source water) and the particulate-addition source depth (Stn 27, $200 \mathrm{~m}$; leachable values). Incubation-specific data are summarized in Table 1 with full particulate profiles shown in Figure 2. Mixed layer depths (MLD), defined as potential density anomaly $>0.05$ vs. $0 \mathrm{~m}$, were $83 \mathrm{~m}$ at Stn 27 and $86 \mathrm{~m}$ at Stn 43 .

\subsubsection{Particulate Fe Distributions}

The coastal incubation (Inc. 1, Stn 27) was conducted using unfiltered surface $(20 \mathrm{~m})$ seawater collected over the slope of the Crozet Islands (Fig. 1, zoomed view), approximately 48km ENE from the nearest land outcrop (Îlots des Apôtres). Surface $(20 \mathrm{~m})$ concentrations of total (leachable + refractory) lithogenic particles were low (20m: $\mathrm{pFe}_{\text {susp,tot }}=3.3 \mathrm{ng} \mathrm{L}^{-1}$; $\mathrm{pFe}_{\mathrm{LSF}, \text { tot }}=3.8 \mathrm{ng} \mathrm{L}^{-1} ; 80 \mathrm{~m}$ : $\mathrm{pFe}_{\text {susp,tot }}=4.2 \mathrm{ng} \mathrm{L}^{-1} ; \mathrm{pFe}_{\mathrm{LSF}, \text { tot }}$ N.D.). Our observed LSF values are significantly lower than those measured by Planquette et al. (2009) at their M3 site in early January 2005 at $80 \mathrm{~m}$ depth: pFe $\mathrm{LSF}_{\mathrm{LF}}$ at their station M3.7 (2005-01-10): $21.4 \mathrm{ng} \mathrm{L}^{-1}$; M3.8 (2005-01-12): $37.0 \mathrm{ng} \mathrm{L}^{-1}$. During our sampling in late February (2011-02-26), the Crozet-associated region was well post-austral summer blooms, and most lithogenic particles had likely been exported from the euphotic zone.

Surface $\mathrm{pFe}_{\text {susp }}$ concentrations in the offshore incubation (Stn 43) were even lower ( $0.3 \mathrm{ng} \mathrm{L}^{-1}$ ) than at Crozet, with most euphotic zone pFe observed in the LSF $(>51 \mu \mathrm{m})$, typical of aggregation of lithogenics into large particles in open ocean euphotic systems (Ohnemus and Lam, in prep). This large, refractory fraction $\left(\mathrm{pFe}_{\mathrm{LSF}, \mathrm{tot}}=13.5 \mathrm{ng} \mathrm{L}^{-1}\right)$ was elevated even compared to Stn $27\left(\mathrm{pFe} \mathrm{LSF}_{\text {,tot }}=3.8 \mathrm{ng}\right.$ $\mathrm{L}^{-1}$ ) though its leachable portion was below detection, suggesting the natural 
bioavailable and/or actively cycling $\mathrm{pFe}$ LSF pools were minimal there (Planquette et al., 2009).

At Crozet, water masses in the northern section of the rise (i.e. Stn 27) are generally "downstream" of the plateau's influence (Planquette et al., 2009; Pollard et al., 2007). We noted a subsurface particulate lithocline in support of this influence that appeared associated with the Crozet shelf below $100 \mathrm{~m}$ depth $\left(\mathrm{pFe}_{\text {susp }}\right.$ increasing rapidly from $3.3 \mathrm{ng} \mathrm{L}^{-1}$ at $20 \mathrm{~m}^{2}$ and $5 \mathrm{ng} \mathrm{L}^{-1}$ at $80 \mathrm{~m}$ to $20 \mathrm{ng} \mathrm{L} \mathrm{L}^{-1}$ by $200 \mathrm{~m}$ and $39 \mathrm{ng} \mathrm{L}^{-1}$ at $600 \mathrm{~m}$; bottom depth: $689 \mathrm{~m}$ ). No subsurface lithocline was observed at Stn 43 in the open sub-polar ocean, by comparison, where $p F e_{\text {susp }}$ was $<10 \mathrm{ng} \mathrm{L}^{-1}$ throughout the water column. Water column LSF particulates from $200 \mathrm{~m}$ depth at Stn 27 were used in a dose-dependent particulate addition experiment (Inc1+P). Concentrations of leachable $\mathrm{Al}, \mathrm{Fe}$ and $\mathrm{P}$ from these LSF particles are also presented.

At source depths for incubation water $(20 \mathrm{~m})$, similar proportions of suspended leachable iron were observed at both stations $(37.8 \%$ at Stn $27 ; 39.9 \%$ at Stn 43), despite a factor of 10 difference in absolute abundance. Planquette et al (2011), using a different estimate of "Biogenic Fe" calculated via Al/Fe ratios, observed similar percentages on large $>53 \mu \mathrm{m}$ particles (mean: $23 \%$ ) at stations north of the Crozet plateau. Both of our incubation stations also exhibited strong subsurface minima in absolute and percent leachable $\mathrm{pFe}$ susp (80-120m at Inc. 1: 1116.5\% leachable $\mathrm{Fe}_{\text {susp,; }}$ 85-120m, Inc. 2: 3.4-7.8\% leachable $\mathrm{pFe}$ susp) in association with the base of the deep fluorescence/chlorophyll maxima (DCM) which were generally broad between 25-80m depth (Fig. 2B). We cannot determine directly, using only a leach, whether the increased absolute and percent leachable $\mathrm{pFe}_{\text {susp }}$ in surface waters is due to an increase in biotically-bound $\mathrm{pFe}$ in fine plankton, or an increase in leach-labile inorganic $\mathrm{pFe}_{\text {susp }}$ in shallow waters (i.e. due to an ongoing cycle of photo-reduction and re-precipitation of fresh, inorganic $\mathrm{pFe}$ oxyhydroxides there). Nevertheless, it is notable that surface biotic communities used in the incubations at both sites have access to pools of (or are continuously generating) leachable $\mathrm{pFe}$, whether that $\mathrm{Fe}$ is incorporated into biomass or present in the form of suspended authigenic phases. Fine particles at the DCM, by comparison, are less leachable, suggesting either an absolute lack of input/in-situ-generation of 
bioavailable Fe there, and/or net removal of leachable Fe at those depths (i.e. due to aggregation and sinking removal of particulate matter from the euphotic zone).

\subsubsection{Particulate P distributions}

Surface biomass (measured as particulate P) was greater at Stn. 27 than Stn 43 ( $\mathrm{P}_{\text {tot }} 567 \mathrm{ng} \mathrm{L}^{-1}$ vs. $323 \mathrm{ng} \mathrm{L}^{-1}$, respectively), though leachable P concentrations across both size fractions (Susp + LSF) were similar at the two sites (220 ng L $\mathrm{L}^{-1}$ vs. $201 \mathrm{ng} \mathrm{L}^{-1}$ ). Leachable suspended particulate $\mathrm{P}$ varied more widely than Fe in the surface, from $41 \%$ leachable (Stn 27) to 63\% leachable (Stn 43), likely due to differences in community structure. Most leachable $\mathrm{P}$ was found in LSF particles at Stn 43, which was located near the boundary between the sub-polar and polar fronts and where the surface community was dominated by large Rhizosolenia diatoms. Stn. 27 was characterized by a more mixed biotic assemblage, including coccolithophores and diatoms (Planquette et al., 2009) associated with an ironlimited, post-bloom, late summer system. Both incubation regimes, like most in this portion of the subantarctic ocean, were expected to be iron-stressed based on excess surface nitrate and phosphate $\left(\mathrm{T}_{0}\right.$, Fig $\left.3 \mathrm{E}-\mathrm{F}, 3 \mathrm{I}-\mathrm{J}\right)$, though incubation 2 had a notable depletion in surface silicate (Fig. $3 \mathrm{H}$ ) indicating silica-stress may have influenced growth rates (Moore et al., 2007b; Pollard et al., 2007).

\subsection{Time-Course Bottle Experiments}

One-liter time-course bottles (Fig. 3) were subsampled for Chl-a (Fig. 3A-D), nutrients (Fig. 3E-N), and suspended particulates $\left({ }^{57} \mathrm{Fe}_{\mathrm{xs}, \mathrm{lch}} \mathrm{Fig} 30-\mathrm{P}\right)$ at three points throughout the incubations, primarily to track Chl-production and nutrient drawdown. (Particulate ${ }^{57} \mathrm{Fe}$ - transfer was an ancillary focus in time-course bottles due to changing mineral:seawater ratios throughout the experiment.) The $\mathrm{T}_{0}$ chlorophyll time-point sample from Inc. 1 was lost, so individual $1 \mathrm{~L}$ bottles were subsampled for Chl-a at Day 1. All Inc. 1 bottles, including the unamended control and blank treatments, exhibited strong macronutrient drawdown and chlorophyll production throughout the experiment, which was terminated $\left(\mathrm{T}_{\mathrm{F}}=\right.$ day 12) during exponential growth as the incubation approached silicate depletion [Figure 3G]. 
Error bars are absent as large incubation bottles were not replicated $(n=1)$, so we only cautiously examine treatment-specific trends. The lack of statistically significant treatment trends may, however, be due to the greater dilution factor in time-course bottles compared to small $(250 \mathrm{~mL})$ bottles, especially early in the incubation when the mineral:seawater ratio was $4 \mathrm{x}$ more dilute. In support of this, we note that in small bottles, variation in mineral:seawater ratios vis-à-vis differential slide loadings ( $\approx 3 \mathrm{x}$ difference in mineral loading between HI vs. LO) was enough to cause growth response variations (c.f. Fig. 6G).

In Incubation 1, the blank slide treatment surpassed all mineral treatments (in $\mathrm{Chl}$ production and $\mathrm{NO}_{3}$ drawdown) by the final time point. This most likely indicates contamination during repeated sub-sampling, or suggests simply wide variability in bottle-to-bottle (rather than different treatment) growth responses, appropriate considering the rather narrow spread in drawdown for other major nutrients between treatments at $\mathrm{T}_{\mathrm{F}}$. The possibility also exists that mineral presence in some way inhibited late logarithmic stage growth, though this is not supported by results from the small $(250 \mathrm{~mL})$ bottles in which mineral treatments responded with elevated growth over the blank (discussed further herein) and where mineral:seawater ratios were greater. Within mineral treatments, the slight general trend in ordering of Chl production (Fay HI > Fay LO $\approx$ Ferri Hi $\approx$ Ferri LO) is consistent with small bottle results, though $95 \%$ confidence intervals of slopes to linear fits of log-growth responses (not shown) do not indicate significant differences between treatments.

Leachable ${ }^{57} \mathrm{Fe}_{\mathrm{xs}}$ was quite variable in large bottles, perhaps due to changing dilution effects of mineral:seawater ratios and due to removal of variably leachable organic phases during the time-course. Surprisingly, many bottles in Incubation 1 exhibited an apparent decrease or loss of leachable ${ }^{57} \mathrm{Fe}_{\mathrm{xs}}$ by the final time-point, if not earlier. This suggests a shift from the labile to the refractory fraction of the ${ }^{57} \mathrm{Fe}_{x s}$ pool during the late incubation. Previous culture experiments using $\mathrm{dFe}$ amendments have noted cultures can become Fe-stressed in extended periods ( $>5 \mathrm{~d}$ ) of incubation after strong growth due to community uptake of all bioavailable Fe (Davey and Geider, 2001; Moore et al., 2007b; Price, 2005). How such iron becomes 
sequestered into organic (or inorganic) phases that are inaccessible to the weak leach, and what the identity of those phases are in high biomass (late incubation) systems, is unclear.

In Incubation 1 we observed a nitrate drawdown of 10-12 $\mu \mathrm{mol} / \mathrm{L}$; silicate 2$2.6 \mu \mathrm{mol} / \mathrm{L} ;$ phosphate: $0.7 \mu \mathrm{mol} / \mathrm{L}$. Typical $\Delta \mathrm{Si}(\mathrm{OH})_{4}: \Delta \mathrm{NO}_{3}$ removal ratios for local diatom species are $>1: 1$ (Moore et al., 2007a), so our observed $\Delta \operatorname{Si}(\mathrm{OH})_{4}: \Delta \mathrm{NO}_{3} \approx 1: 5$ is consistent with a mixed community response in which diatoms were a minor component (Twining and Baines, 2013). Due to the low light levels $\left(<30 \mu \mathrm{mol} / \mathrm{m}^{2} / \mathrm{sec}\right)$ in our incubations, diatom growth was possibly both $\mathrm{Fe}-$ and light-stressed, comparable to natural observations of deep mixed layer systems in the region.

We observed only moderate Chl production and macronutrient drawdown, by comparison, during incubation 2 . Depending on diatom community structure and associated silicate uptake affinities (Martin Jézéquel et al., 2000), low levels of initial silicate $(<0.7 \mu \mathrm{M})$ may have limited diatom growth throughout the incubation. Similar to Inc. 1, the blank slide treatment appeared to perform slightly better than other treatments, though 95\% confidence intervals of growth rates through day 8 (not shown) similarly indicate no treatments are significantly different at this sampling resolution. We thus defer to the results of the small bottles to ascertain biotic responses to mineral treatments.

\subsection{Small Volume Incubation Results}

\subsubsection{Abiotic ${ }^{57} \mathrm{Fe}-$ Transfer Experiments}

Mercury (Hg) poisoned incubation controls (Fig. 4A-D) were originally designed to test for unintentional physical transfer of immobilized mineral particles from the slide into the suspended particulate pool. Unexpectedly, in Hg-killed $250 \mathrm{~mL}$ incubation bottles, transfer of ${ }^{57} \mathrm{Fe}$ from the immobilized minerals to suspended particulates as ${ }^{57} \mathrm{Fe}_{\mathrm{xs}}(>0.2 \mu \mathrm{m})$ was observed at $\mathrm{T}_{\mathrm{F}}$ in a light-dependent manner in both experiments (Fig. 4C,D). Bottles that were closer to the light source (Row 1) exhibited greater transfer than identical treatments further away (Row 2). Ferrihydrite and fayalite were found to have similar levels of ${ }^{57} \mathrm{Fe}_{\mathrm{xs}}$ transfer at 
similar mineral loadings in Incubation 1 (Inc. 1: Ferri HI vs. Fay HI). Ferrihydrite had been synthesized and freeze-dried 6 months before incubation but had not yet aged to $6 \mathrm{~L}$ ferrihydrite, so it is surprising that a poorly crystalline Fe oxyhydroxide (ferrihydrite) was found to have similar lability to a more crystalline Fe-silicate (fayalite). In incubation 2 , we observed greater transfer of ${ }^{57} \mathrm{Fe}$ from fayalite compared to ferrihydrite chips (Fig 4C,D: Fay LO vs. Ferri LO). Rapid, low temperature dissolution of Si from primary, silicate-bearing minerals (Oelkers et al., 2011) has been observed in artificial seawater systems, and Tréguer and De La Roche (Tréguer and La Rocha, 2013) note that primary minerals, such as fayalite, are often observed to dissolve more rapidly than weathered minerals. Coexamination of silica and Fe solubility from these minerals into seawater from coastal vs. open ocean could be performed to explore our observed abiotic differences in Fe transfer, and furthermore whether stoichiometrically congruent (2Fe:1Si) dissolution of fayalite $\left(\mathrm{Fe}_{2} \mathrm{SiO}_{4}\right)$ is occurring.

Comparing incubations, we observed that incubation 1 generally exhibited greater mobilization of ${ }^{57} \mathrm{Fe}$ from minerals (cf. Fig. 4C-D a factor of 1.3 in Ferri HIRow1, and a factor of 2.4 in Ferri Hi-Row2) despite similar levels of particulate organic matter, as judged from leachable particulate P (Fig. 4A-B). Differential standing stocks of specific and non-specific Fe-ligands that aided in ligandpromoted dissolution of mineral bound Fe could be invoked to explain this disparity, though absolute dissolution rate experiments would be required to determine this with certainty.

While we interpret the transfer of ${ }^{57} \mathrm{Fe}$ from the mineral chips to the water column to be a result of mineral Fe-dissolution, an alternative explanation for ${ }^{57} \mathrm{Fe}$ transfer is the loss of poorly-immobilized minerals from the chips directly into suspension. To distinguish between these two explanations, we conducted a second, sequential total digestion $\left(\mathrm{HNO}_{3} / \mathrm{HF} / \mathrm{HCl}\right.$ acid mixture, $4 \mathrm{~N}$ each, $135^{\circ} \mathrm{C}$, $2 \mathrm{hrs}$ ) of the combined leachate, centrifugation pellet, and filter from all abiotic bottles and multiple biotic samples to examine for extra release of mineral-bound ${ }^{57} \mathrm{Fe}$ from mineral particles. Fayalite particles should be largely inaccessible to the pH 2 leach even in the presence of a reductant (Berger et al., 2008) though mineral 
ferrihydrite, even aged and freeze-dried as treated, may be expected to be comparatively more accessible to the leach.

Sequential total (+HF) digests of poisoned controls indicated the weak leach had accessed 56-67\% of total (leachable plus refractory) particulate P, and 19-27\% (fayalite treatments) or $32-40 \%$ (ferrihydrite treatments) of particulate ${ }^{57} \mathrm{Fexs}$. The correlation between leachable and refractory ${ }^{57} \mathrm{Fe}$ is presented in Figure 5 . The correlation between leached values and totals on the lower end [Figure 5, left] is expected, as the leach (25\% acetic acid, $0.02 \mathrm{M}$ hydroxylamine, brief heating, $2 \mathrm{hrs}$ at RT without agitation), only accessed a portion of the organic material present, leaving $>40 \%$ (poisoned controls) or $25 \%$ (non-poisoned samples) of particulate $P$ on the filters. Aging of both organic matter and inorganic phases between sample collection and analyses (18 mos.) is likely responsible for incomplete organic recoveries, as the freezing protocol described by the original bioavailable leach (Berger et al., 2008) was not implemented. Several samples with significantly elevated refractory ${ }^{57} \mathrm{Fe}$ pools were not positively correlated with increased leachable values [Fig. 5, right, circled], which we interpret as direct mineral loss from the chip during handling. Leach values associated with $>10 \mathrm{ng}$ refractory ${ }^{57} \mathrm{Fe}$ recoveries are noted $(\dagger)$ in subsequent figures, as some portion of the leachable signal may represent refractory source mineral in those cases. We therefore attribute most of the refractory ${ }^{57} \mathrm{Fe}_{\mathrm{xs}}$ signal to additional authigenic ${ }^{57} \mathrm{Fe}$-oxides and biogenic ${ }^{57} \mathrm{Fe}$ bound to organic phases inaccessible to the weak leach rather than to direct mineral loss from the chip, and infer that the leach is primarily accessing nonmineral ${ }^{57} \mathrm{Fe}$.

\subsubsection{Biotic Experimental Results}

Similar to the light-dependent ${ }^{57} \mathrm{Fe}$ transfer observed in poisoned controls, a light/row-dependent production of Chl-a was especially pronounced in incubation 1 [Fig. 6A]. In 5/6 treatments, bottles closer to the light source (Row 1) produced more Chl-a than bottles further away, a result that confounded the intention of replicate bottle analyses in examining treatment significances, yet indicated the importance of slight light effects at these illumination levels. Our observation of 
slightly lower Chl production in bottles incubated with blank slides (which include the epoxy film, but no mineral) compared to unamended (slide-absent, whole seawater only) control bottles may be attributed to slide-related "bottle effects" previously described. For the purposes of the discussion here, we focus primarily on responses in mineral chip treatments compared to the blank chip treatment to isolate the effect of the mineral addition. To compensate for observed light effects within treatments, we subtract the row-specific Chl in blank-chip treatments from unamended and mineral treatments [Fig. 6F], and report treatment means and population standard deviations [Fig. 6G] for the blank-subtracted values. We observe that in all ${ }^{+57} \mathrm{Fe}$-mineral treatments, including fayalite, $\mathrm{Chl}$ response was significantly elevated compared to blank slides, and that HI mineral doses resulted in higher mean Chl values compared to LO mineral doses.

Leachable P results appear more variable than $\mathrm{Chl}$, even after subtraction of the appropriate row-blank values $(6 \mathrm{H})$. A significant leachable $\mathrm{P}$ response above blank values is nevertheless noted in both Ferri HI and Fay LO treatments. Sampleby-sample production of biomass (leachable P) in excess of the blank, more-so than Chl (not shown), appeared positively correlated with leachable ${ }^{57} \mathrm{Fe}_{\text {xs }}$ (Fig 6L). We plot leachable P (excess over blank chip treatment) versus leachable ${ }^{57} \mathrm{Fe}_{\mathrm{xs}}$ in Figure $6 \mathrm{~L}$. Samples with negligible leachable ${ }^{57} \mathrm{Fe}_{\mathrm{xs}}$ are colored red, including one bottle with positive biomass accumulation (Ferri LO-2, possibly ${ }^{56} \mathrm{Fe}$ contaminated), and one bottle that crashed (Fay HI-1 and which also possessed significant ${ }^{57} \mathrm{Fe}_{\mathrm{xs}}$ refractory value $(\dagger)$, indicating possible mineral loss from chip). A strong linear trend is noted even when all values are fitted (red line, left equation), though exclusion of red points (blue linear fit, right equation) greatly improves the $\mathrm{R}^{2}$ without changing the trend. Excess biomass generation over the blank value appears to be in direct correlation to additional ${ }^{57} \mathrm{Fe}$ uptake from ${ }^{57} \mathrm{Fe}$-labelled minerals. Furthermore, ${ }^{57} \mathrm{Fe}: \mathrm{P}$ mole ratios for this excess biomass $0.9-7.6 \mathrm{mmol}$ ${ }^{57} \mathrm{Fe}$ :mol P; Fig. 6L, annotations) were comparable to biogenic Fe:P ratios observed in marine diatoms and autotrophic flagellates from the Southern Ocean (Twining and Baines, 2013) (order: 1-2mmol Fe:mol P). 
Compared to Fe-transfer in abiotic treatments (Fig 6D), the three uncontaminated biotic treatments (Fig. 6E; Ferri HI-1 and -2, Fay HI-2) demonstrated greater transfer of ${ }^{57} \mathrm{Fe}_{\mathrm{xs}}$ by factors of 1.6-3.1. The nature of this excess transfer has two possible explanations: assuming the abiotic solubilization mechanisms observed in poisoned controls are also occurring in biotic experiments, increased preservation of ${ }^{57} \mathrm{Fe}_{\mathrm{xs}}$ in leachable, biotically-bound forms of organic matter could alone explain increased (leach-apparent) transfer of ${ }^{57} \mathrm{Fe}$. Increased absolute solubilization of minerals in biotic cultures is also feasible, perhaps via direct biotic processes or indirectly through the production of ligands that may or may not be photo-active. We cannot distinguish between these scenarios using this experimental setup.

Incubation 2 [Figure 7A-J] displayed less intense growth trends overall with $\Delta \mathrm{Chl}$ vs. blank chip treatment $<0.4 \mu \mathrm{g} / \mathrm{L}$ for all ${ }^{57} \mathrm{Fe}$ mineral amendments. We were thus unable to observe consistent light-/row-dependent Chl-responses to ${ }^{57} \mathrm{Fe}$ minerals [Figure 7A] as in Incubation 1. Row-blank subtraction [Fig. 7F] and associated treatment means [Fig. 7G] for $\mathrm{Chl}$ indicated slight but significant $\mathrm{Chl}$ responses to ferrihydrite but not fayalite amendments, though no dose-dependent responses were observed. Excess leachable P over the blank treatment (Fig. 7H, I) displayed more variable trends than Chl (as in Inc. 1), and was not correlated with ${ }^{57} \mathrm{Fe}_{\mathrm{xs}}$ transfer [not shown]. We suspect-but cannot display definitively in the absence of silicate-amended treatments-that low starting silica concentrations $(<0.5 \mu \mathrm{M})$ inhibited strong diatom growth responses in this incubation despite the presence of mineral Fe that, in Incubation 1, led to increased growth (Chl, P) and strong mineral responses. Many diatom species possess half-saturation constants for silicate uptake that are $>0.5 \mu \mathrm{M}$ (Martin Jézéquel et al., 2000), in support of this claim.

Notably, a slide prepared with ground, un-labeled (natural) mineral biotitean $\mathrm{Fe}^{2+}$ sheet silicate/mica often found in particle assemblages near active continental margins (Lam et al., 2012) and also noted as a component in particle assemblages near Crozet [not shown] —was associated with greatly elevated growth in this incubation ("Biotite" sample). We hypothesize that silicate, rather than Fe, 
sourced from the mineral may have been responsible for the strong additional growth in this bottle, as small diatom species have been shown to access both pure and diatomaceous earth-sourced silica for growth under limiting conditions (Capellacci et al., 2012).

In a final small experiment [Fig. 8] at the beginning of Incubation 1, deep LSF particulates from $200 \mathrm{~m}$ [Table 3] were resuspended in incubation seawater and then added to $250 \mathrm{~mL}$ incubation bottles (where $+1 \mathrm{~mL} \approx+0.25 \mathrm{~L}$-equivalent LSF particles) containing mineral slides. Row 1 bottles without particle addition (light green) are shown for incubation context. Particle amendments demonstrated bottle-by-bottle excess Chl over blank chip controls in all doses $\geq 4 \mathrm{~mL}$, and excess Chl over the mineral chip alone with both $+8 \mathrm{~mL}$ particle amendments (into LO mineral-dosed bottles), demonstrating the strongest Chl increases observed in small bottle incubations. We do not show phosphorus/biomass results due to the addition of significant $P$ from large particles and no means to assess remineralization of this added P. ${ }^{57} \mathrm{Fe}$ results are somewhat ambiguous, with $+4 \mathrm{~mL}$ treatments (which performed similarly to the Row 1 mineral incubation bottles, light green) displaying the most leachable ${ }^{57} \mathrm{Fe}$ transfer, and highly productive $+8 \mathrm{~mL}$ bottles showing a relative decrease in leachable ${ }^{57} \mathrm{Fe}$ transfer compared to $+4 \mathrm{~mL}$ treatments. This may be similar to the effect observed in high-biomass $1 \mathrm{~L}$ timecourse bottles (Fig. 30-P) in which elevated growth leads to a general decrease in leach-accessible ${ }^{57} \mathrm{Fe}$.

\section{DISCUSSION}

Many $\mathrm{dFe}$ amendment incubation studies have demonstrated the interplay between marine biotic community structures, micro and macro-nutrient (co)limitations, and light. A central role for iron in phytoplankton bloom development and decline is well established, but the specific mechanisms associated with its use are as complex as the diverse organisms and marine niches (set by light, nutrients, grazing, etc.) that utilize it (Moore et al., 2006). Much of the oceanic Fe pool is particulate, however, and pFe sources (aeolian, benthic, lateral) are both ubiquitous and under-characterized in the context of whole community incubation 
experiments. Our primary experimental goal was to ascertain whether in situ particulate mineral-Fe bioavailability and utilization can potentially stimulate growth in whole community incubations on a two-week timescale. We were secondarily interested in differential availability of the two different mineral forms we synthesized, and the links between growth responses and ${ }^{57} \mathrm{Fe}$ transfer. The major interaction we demonstrate here-that mineral-sourced Fe can become bioavailable in natural systems through both biotic and abiotic mechanismshighlights an increasingly complex interplay between marine communities and their iron sources.

We observed a modest but positive enhancement of growth in mineralamended incubations, with ferrihydrite (a poorly crystalline Fe oxyhydroxide) exhibiting extra Chl production in both near-shore (Stn 27-Crozet) and off-shore (Stn 43) incubations. Fayalite (a crystalline Fe-silicate) was observed to enhance growth in the near-shore incubation only, but on a similar scale as ferrihydriterelated growth effects despite its more crystalline structure. These results alone suggest an important, if subtle, role for suspended Fe-oxyhydroxide and crystalline Fe-minerals as sources of biologically-available Fe pools in natural waters in longer term exposures. The underlying mechanisms, though not examined directly, may be informed by our Hg-poisoned controls in which light-sensitive transfer of ${ }^{57} \mathrm{Fe}$ from immobilized minerals into suspended $>0.2 \mu \mathrm{m}$, leach-accessible particles was observed. Even in the absence of living cellular machinery associated with biological Fe-acquisition, the Hg-poisoned controls demonstrate that oxyhydroxideand silicate mineral-bound $\mathrm{pFe}$ can be solubilized in a light-sensitive manner in natural seawater (and any associated organic materials released during Hgpoisoning). Further, this dissolution is not a simple function of the crystallinity of the source mineral. Wherever $\mathrm{pFe}$, sunlight, and organic matter co-occur in natural seawater, this process likely generates (and continuously regenerates (Hurst and Bruland, 2007)) fine, authigenic Fe-oxyhydroxide particulate phases, although we did not directly investigate the speciation of the ${ }^{57} \mathrm{Fe}_{\mathrm{xs}}$. A light induced, potentially ligand-promoted, abiotic Fe-cycle thus envisioned likely involves transformation of 
mineral Fe through dissolved and colloidal forms, thereby releasing and sustaining bioavailable pools of Fe.

We hypothesize that biotic processes, either active (e.g. Fe-specific ligand production, mineral-bound bacterial communities that promote solubilization) or passive (e.g. increased specific or non-specific Fe-ligands in active DOC pools) are increasing mineral dissolution rates, although our experiments cannot confirm this directly. The mechanism for the transfer of Fe from the mineral phase to the suspended particle pool remains an interesting question, and one that should be further examined in seawater using ${ }^{57} \mathrm{Fe}$-enriched minerals.

Our selection of two sites, one near-shore and the other in the open ocean, (compared side-by-side in Figure 9) with the former demonstrating stronger transfer and utilization of mineral-bound ${ }^{57} \mathrm{Fe}$ forms, leaves open the possibility that biotic communities associated with the higher ambient $\mathrm{pFe}$ concentrations at Incubation 1 (Figure 2) increased mineral solubilization rates. This would imply that the Crozet biotic community, which is known to respond rapidly to dFe amendment (Moore et al., 2007a; 2007b) may have been better adapted to respond to $\mathrm{pFe}$ addition as well, due to more frequent exposure to $\mathrm{pFe}$ inputs from nearby island sources. Presence of such $\mathrm{pFe}$ adaptation (whether organism-specific or a whole community response) could take the form of increased utilization of $\mathrm{Fe}(\mathrm{II})$ silicates, as suggested by increased ${ }^{57} \mathrm{Fe}_{\mathrm{xs}}$ transfer in fayalite treatments at Inc. 1 (cf. Figure 9E vs. 9F). Fe(II) silicates, including fayalite itself, along with biotite, chlorite, and basalt glasses, were commonly observed in Fe-mineral assemblages at $200 \mathrm{~m}$ near the Crozet platform, in both suspended and LSF particles (Lam and Ohnemus, in prep). Indeed, redox-sensitive chemical species mapping techniques (Lam et al., 2012) showed that up to $40 \%$ of pFe at the Crozet station was present as $\mathrm{Fe}(\mathrm{II})$. Extremely low total $\mathrm{pFe}$ abundances throughout the open ocean station (Figure 2: Incubation 2) could similarly select for biotic communities that are not adapted to respond to inputs of Fe(II) silicates, and only moderately adapted to low-light pFe(III) addition via ferrihydrite.

The particle addition experiment, using LSF particles from beneath the Crozet lithocline, also demonstrated an increased Chl response in surface waters. 
While we do not know what component of the added particles stimulated growth, an alleviation of Fe limitation is consistent with the oceanographic context. This displays directly the effect that large particles and any associated minerals and/or recyclable biogenic Fe, can have on surface productivity (cf. Planquette et al. 2009, 2011). There was increased ${ }^{57} \mathrm{Fe}$ transfer from mineral chips in the $4 \mathrm{~mL}$ particle addition to the LO ferrihydrite and fayalite chips, but not in the more highly productive $8 \mathrm{~mL}$ particle addition treatments. This indicates that Fe-usage from all particle sources, including the immobilized minerals, was enhanced at moderate, but not the highest, levels of increased productivity. Why high biomass systems result in lower concentrations of leach-accessible Fe pools is curious, and we do not know if these observations have implications for open marine environments. If highly productive marine systems result in poorly leach-accessible/nonbioavailable Fe pools, this could be an important constraint on environmental Fe cycling.

We demonstrated that organisms in Incubation 1 responded to mineralsourced Fe addition with increased $\mathrm{Chl}$ and biomass, and did so in a physiologicallyconsistent manner by producing excess biomass at Fe:P mole ratios consistent with Southern Ocean diatoms and autotrophic flagellates (Twining et al., 2004). The lower observed ${ }^{57} \mathrm{Fe}$ transfer in incubation 2 could be equally explained by silica limitation that prevented increased diatom biomass production in response to $\mathrm{pFe}$ addition, or by a community that was poorly adapted to respond to mineral pFe addition and thus failed to increase solubilization/transfer of mineral $\mathrm{Fe}$, regardless of whether it was Fe-limited. Future experiments designed to differentiate between increased biotic utilization and increased mineral solubility/community adaptations could address these ambiguities.

This study demonstrates, for the first time, that mineral Fe can be a source of bioavailable iron, and that some regions appear to be better able to use mineral $\mathrm{Fe}$ than others. More work is needed on determining the prevalence of mineral $\mathrm{Fe}$ bioavailability. Particle-sourced Fe-bioavailability cycles and mechanisms should be examined further using stable-labeled minerals in natural marine systems, as they 
present a means to explore the otherwise subtle, but possibly ubiquitous naturallyoccurring $\mathrm{pFe} / \mathrm{dFe}$ cycles in seawater. 


\section{REFERENCES}

Auro, M. E., Robinson, L. F., Burke, A., Bradtmiller, L. I., Fleisher, M. Q. and Anderson, R. F.: Improvements to 232-thorium, 230-thorium, and 231-protactinium analysis in seawater arising from GEOTRACES intercalibration, Limnol. Oceangr. Methods, 10, 464-474, doi:10.4319/lom.2012.10.464, 2012.

Balch, W. M., Poulton, A. J., Drapeau, D. T., Bowler, B. C., Windecker, L. A. and Booth, E. S.: Zonal and meridional patterns of phytoplankton biomass and carbon fixation in the Equatorial Pacific Ocean, between $110 \mathrm{~W}$ and $140 \mathrm{~W}$, Deep-Sea Research Part II, 58(3), 400-416, doi:10.1016/j.dsr2.2010.08.004, 2011.

Barbeau, K., Moffett, J., Caron, D. and Croot, P.: Role of protozoan grazing in relieving iron limitation of phytoplankton,, 1996.

Berger, C. J. M., Lippiatt, S. M., Lawrence, M. G. and Bruland, K. W.: Application of a chemical leach technique for estimating labile particulate aluminum, iron, and manganese in the Columbia River plume and coastal waters off Oregon and Washington, J. Geophys. Res, 113, C00B01, doi:10.1029/2007JC004703, 2008.

Birkefeld, A., Schulin, R. and Nowack, B.: A new in situ method to analyze mineral particle reactions in soils, Environmental Science \& Technology, 39(9), 3302-3307, doi:10.1021/es048008m, 2005.

Borer, P. M., Sulzberger, B., Reichard, P. and Kraemer, S. M.: Effect of siderophores on the light-induced dissolution of colloidal iron (III)(hydr) oxides, Marine Chemistry, 93(2), 179-193, doi:10.1016/j.marchem.2004.08.006, 2005.

Boyd, P. W., Jickells, T., Law, C. S., Blain, S., Boyle, E. A., Buesseler, K. O., Coale, K. H., Cullen, J. J., de Baar, H. J. W., Follows, M., Harvey, M., Lancelot, C., Levasseur, M., Owens, N. P. J., Pollard, R., Rivkin, R. B., Sarmiento, J., Schoemann, V., Smetacek, V., Takeda, S., Tsuda, A., Turner, S. and Watson, A. J.: Mesoscale Iron Enrichment Experiments 1993-2005: Synthesis and Future Directions, Science, 315(5812), 612617, doi:10.1126/science.1131669, 2007.

Capellacci, S., Battocchi, C., Casabianca, S., Giovine, M., Bavestrello, G. and Penna, A.: Bioavailability of different chemical forms of dissolved silica can affect marine diatom growth, Marine Ecology, 34(1), 103-111, doi:10.1111/j.14390485.2012.00529.x, 2012.

Chever, F., Sarthou, G. and Bucciarelli, E.: An iron budget during the natural iron fertilisation experiment KEOPS (Kerguelen Islands, Southern Ocean), ..., 2010.

Coale, K. H., Michael Gordon, R. and Wang, X.: The distribution and behavior of dissolved and particulate iron and zinc in the Ross Sea and Antarctic circumpolar current along $170^{\circ} \mathrm{W}$, Deep Sea Research Part I: Oceanographic Research Papers, 52(2), 295-318, doi:10.1016/j.dsr.2004.09.008, 2005. 
Committee, 2. G. S. A. I.: Sampling and Sample-handling Protocols for GEOTRACES Cruises,, 1-238 [online] Available from:

http://www.geotraces.org/libraries/documents/Intercalibration/Cookbook.pdf, 2010.

Davey, M. and Geider, R. J.: Impact of iron limitation on the photosynthetic apparatus of the diatom Chaetoceros muelleri (Bacillariophyceae), Journal of Phycology, 37(6), 987-1000, 2001.

Fiala, M. and Oriol, L.: Light-temperature interactions on the growth of Antarctic diatoms, Polar Biology, 10(8), 629-636, 1990.

Hassler, C. S., Schoemann, V., Nichols, C. M., Butler, E. C. and Boyd, P. W.: Saccharides enhance iron bioavailability to Southern Ocean phytoplankton, Proceedings of the National Academy of Sciences, 108(3), 1076-1081, doi:10.1073/pnas.1010963108/-/DCSupplemental/pnas.201010963SI.pdf, 2011.

Hurst, M. and Bruland, K.: An investigation into the exchange of iron and zinc between soluble, colloidal, and particulate size-fractions in shelf waters using lowabundance isotopes as tracers in shipboard incubation experiments, Marine Chemistry, 103(3-4), 211-226, 2007.

Hutchins, D. A., DiTullio, G. R. and Bruland, K. W.: Iron and regenerated production: Evidence for biological iron recycling in two marine environments, Limnology and Oceanography, 38(6), 1242-1255, 1993.

Johnson, K., Gordon, R. and Coale, K.: What controls dissolved iron concentrations in the world ocean? Marine Chemistry, 57(3-4), 137-161, 1997.

Kustka, A., Shaked, Y., Milligan, A. and King, D.: Extracellular production of superoxide by marine diatoms: Contrasting effects on iron redox chemistry and bioavailability, Limnology and ..., 2005.

Lam, P. J. and Bishop, J. K. B.: The continental margin is a key source of iron to the HNLC North Pacific Ocean, Geophys. Res. Lett, 35(7), doi:10.1029/2008GL033294, 2008.

Lam, P. J. and Morris, P. J.: In situ marine sample collection system and methods, Pat. Pending, (13/864,655), n.d.

Lam, P. J., Ohnemus, D. C. and Marcus, M. A.: The speciation of marine particulate iron adjacent to active and passive continental margins, Geochimica et Cosmochimica Acta, 80, 108-124, 2012.

Landing, W. and Bruland, K.: The contrasting biogeochemistry of iron and manganese in the Pacific Ocean, Geochimica et Cosmochimica Acta, 51(1), 29-43, 1987. 
Mahowald, N. M., Engelstaedter, S., Luo, C., Sealy, A., Artaxo, P., Benitez-Nelson, C., Bonnet, S., Chen, Y., Chuang, P. Y., Cohen, D. D., Dulac, F., Herut, B., Johansen, A. M., Kubilay, N., Losno, R., Maenhaut, W., Paytan, A., Prospero, J. M., Shank, L. M. and Siefert, R. L.: Atmospheric Iron Deposition: Global Distribution, Variability, and Human Perturbations*, Annu. Rev. Marine. Sci., 1(1), 245-278, doi:10.1146/annurev.marine.010908.163727, 2009.

Maldonado, M. T., Strzepek, R. F., Sander, S. and Boyd, P. W.: Acquisition of iron bound to strong organic complexes, with different Fe binding groups and photochemical reactivities, by plankton communities in Fe-limited subantarctic waters, Global Biogeochem. Cycles, 19(4), doi:10.1029/2005GB002481, 2005.

Martin Jézéquel, V., Hildebrand, M. and Brzezinski, M. A.: Silicon metabolism in diatoms: implications for growth, Journal of Phycology, 36(5), 821-840, 2000.

Martin, J.: Iron deficiency limits phytoplankton growth in the north-east Pacific subarctic,, 1988.

McKay, R. M. L., Villareal, T. A. and LA ROCHE, J.: Vertical migration by Rhizosolenia spp.(Bacillariophyceae): Implications for Fe acquisition, Journal of Phycology, 36(4), 669-674, 2000.

Moore, C. M., Hickman, A. E., Poulton, A. J., Seeyave, S. and Lucas, M. I.: Iron-light interactions during the CROZet natural iron bloom and EXport experiment (CROZEX): II-Taxonomic responses and elemental stoichiometry, Deep Sea Research Part II: Topical Studies in Oceanography, 54(18-20), 2066-2084, doi:10.1016/j.dsr2.2007.06.015, 2007a.

Moore, C. M., Mills, M. M., Milne, A., Langlois, R., Achterberg, E. P., Lochte, K., Geider, R. J. and La Roche, J.: Iron limits primary productivity during spring bloom development in the central North Atlantic, Global Change Biol, 12(4), 626-634, doi:10.1111/j.1365-2486.2006.01122.x, 2006.

Moore, C. M., Seeyave, S., Hickman, A. E., Allen, J. T., Lucas, M. I., Planquette, H., Pollard, R. T. and Poulton, A. J.: Iron-light interactions during the CROZet natural iron bloom and EXport experiment (CROZEX) I: Phytoplankton growth and photophysiology, Deep Sea Research Part II: Topical Studies in Oceanography, 54(18-20), 2045-2065, doi:10.1016/j.dsr2.2007.06.011, 2007b.

Morel, F. M., Kustka, A. and Shaked, Y.: The role of unchelated Fe in the iron nutrition of phytoplankton, Limnology and Oceanography, 400-404, 2008.

Nodwell, L. and Price, N.: Direct use of inorganic colloidal iron by marine mixotrophic phytoplankton, Limnology and Oceanography, 2001.

O'Neill, H. S.: Quartz-fayalite-iron and quartz-fayalite-magnetite equilibria and the free energy of formation of fayalite ( $\mathrm{Fe} 2 \mathrm{SiO} 4$ ) and magnetite (Fe 304 ), American 
Mineralogist, 72(1-2), 67-75, 1987.

Oelkers, E. H., Gislason, S. R., Eiriksdottir, E. S., Jones, M., Pearce, C. R. and Jeandel, C.: Applied Geochemistry, Applied Geochemistry, 26(S), S365-S369, doi:10.1016/j.apgeochem.2011.03.062, 2011.

Orcutt, B. N., Sylvan, J. B., Knab, N. J. and Edwards, K. J.: Microbial ecology of the dark ocean above, at, and below the seafloor, Microbiology and Molecular Biology Reviews, 75(2), 361-422, doi:10.1128/MMBR.00039-10, 2011.

Planquette, H., Fones, G. R., Statham, P. J. and Morris, P. J.: Origin of iron and aluminium in large particles $(>53 \mu \mathrm{m})$ in the Crozet region, Southern Ocean, Marine Chemistry, 115(1-2), 31-42, doi:10.1016/j.marchem.2009.06.002, 2009.

Pollard, R., Sanders, R., Lucas, M. and Statham, P.: The Crozet Natural Iron Bloom and Export Experiment (CROZEX), Deep Sea Research Part II: Topical Studies in Oceanography, 54(18-20), 1905-1914, doi:10.1016/j.dsr2.2007.07.023, 2007.

Price, N. M.: The elemental stoichiometry and composition of an iron-limited diatom, Limnology and Oceanography, 50(4), 1159-1171, 2005.

Price, N. M., Harrison, G., Hering, J. G., Hudson, R. J., Nirel, P. M., Palenik, B. and Morel, F. M.: Preparation and chemistry of the artificial algal culture medium Aquil, Biological oceanography, 6(5-6), 443-461, 1988.

Raiswell, R., Vu, H. P., Brinza, L. and Benning, L. G.: Chemical Geology, Chemical Geology, 278(1-2), 70-79, doi:10.1016/j.chemgeo.2010.09.002, 2010.

Rich, H. and Morel, F.: Availability of well-defined iron colloids to the marine diatom Thalassiosira weissflogii, Limnology and Oceanography, 35(3), 652-662, 1990.

Rubin, M., Berman-Frank, I. and Shaked, Y.: Dust- and mineral-iron utilization by the marine dinitrogen-fixer Trichodesmium, Nature Publishing Group, 4(8), 529-534, doi:10.1038/ngeo1181, 2011.

Schwertmann, U. and Cornell, R. M.: Iron oxides in the laboratory,, 2008.

Shaked, Y. and Lis, H.: Disassembling iron availability to phytoplankton, Frontiers in microbiology, 3, doi:10.3389/fmicb.2012.00123/abstract, 2012.

Shi, D., Xu, Y., Hopkinson, B. M. and Morel, F. M.: Effect of ocean acidification on iron availability to marine phytoplankton, Science, 327(5966), 676-679, doi:10.1126/science.1183517, 2010.

Toner, B. M., Santelli, C. M., Marcus, M. A., Wirth, R., Chan, C. S., Mccollom, T., Bach, W. and Edwards, K. J.: Biogenic iron oxyhydroxide formation at mid-ocean ridge hydrothermal vents: Juan de Fuca Ridge, Geochimica et Cosmochimica Acta, 73(2), 
388-403, doi:10.1016/j.gca.2008.09.035, 2009.

Tréguer, P. J. P. and La Rocha, De, C. L. C.: The world ocean silica cycle, ..., 5, 477-501, doi:10.1146/annurev-marine-121211-172346, 2013.

Twining, B. S. B. and Baines, S. B. S.: The trace metal composition of marine phytoplankton, ..., 5, 191-215, doi:10.1146/annurev-marine-121211-172322, 2013.

Twining, B., Baines, S. and Fisher, N.: Element stoichiometries of individual plankton cells collected during the Southern Ocean Iron Experiment (SOFeX), Limnology and Oceanography, 49(6), 2115-2128, 2004.

Wells, M. L., Zorkin, N. G. and Lewis, A. G.: The role of colloid chemistry in providing a source of iron to phytoplankton, Journal of Marine Research, 41(4), 731-746, 1983. 


\section{Figure 1: Cruise map and incubation locations}

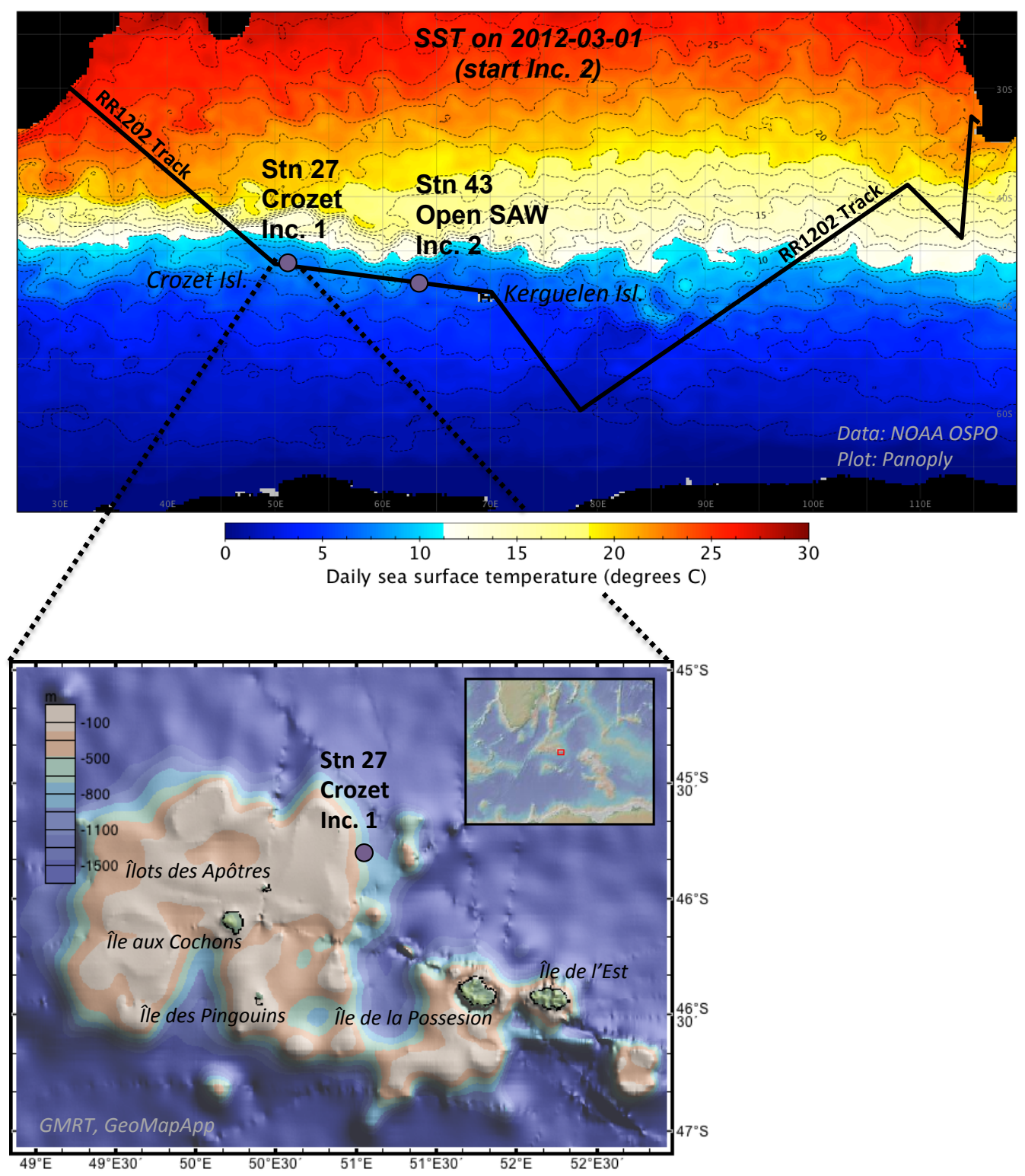

Figure 1: (Upper): Oceanographic stations (purple circles, annotations) along $R / V$ Roger Revelle cruise RR1202 (black line) in the southern Indian Ocean at which incubation source waters were collected. Colors (scale) indicate sea surface temperature (SST) at the start of Incubation 2. (Lower): Zoomed bathymetric view of the Crozet platform displaying the location of Incubation 1 source water collection at the platform shelf break (689m bottom depth). SAW: subantarctic water. 


\section{Figure 2A: Incubation station profiles, particulates}
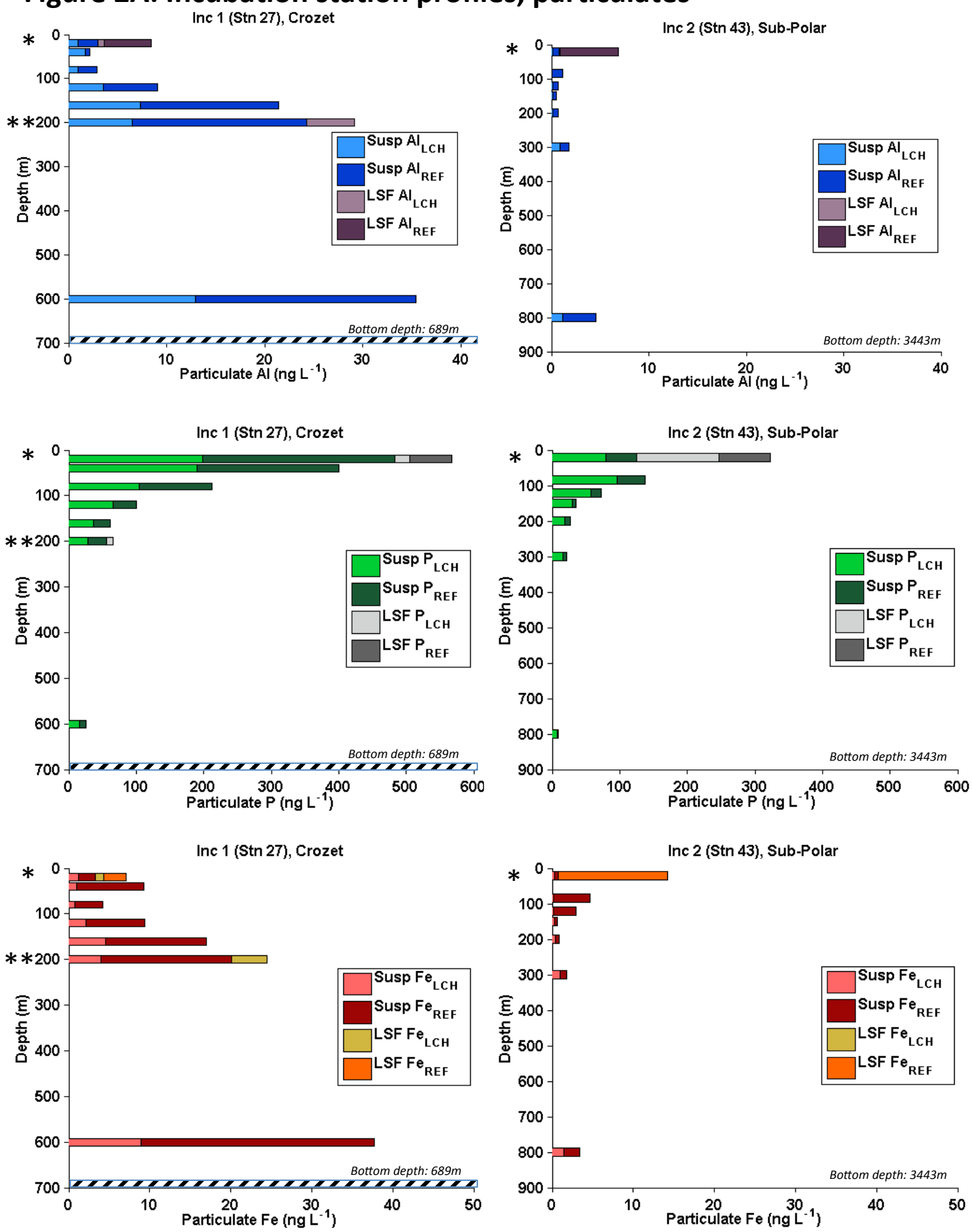


\section{Figure 2B: Incubation station profiles, fluorescence}

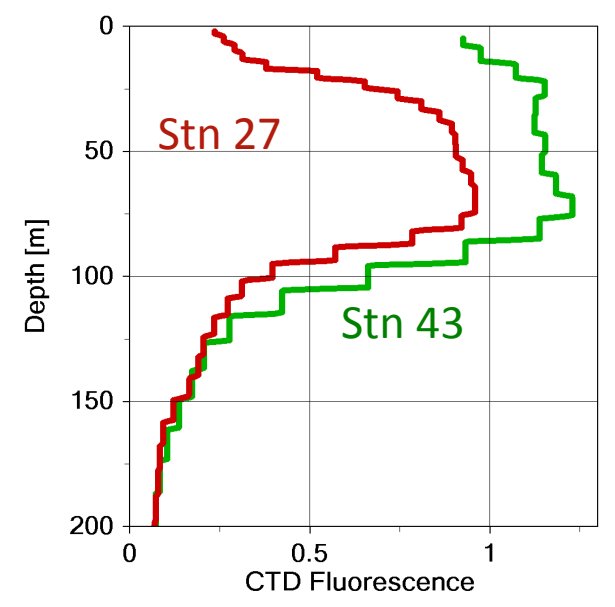

Figure 2: (A): Size-fractionated water column profiles of McLane pump-collected particule $\mathrm{Al}$ (blue), P (green) and Fe (red) at incubation source stations (left column: Incubation 1/ Stn 27; right column: Incubation 2/Stn 43). Suspended (susp, 0.8-51 $\mu$ m, Supor filters) and large size fraction ( $L S F,>51 \mu \mathrm{m}$ polyester screens) particles are separated into leachable ( $L C H$ : modified bioavailable $\mathrm{HAc}_{\mathrm{T}+\mathrm{R}}$ leach from Berger et al. 2008) and refractory (REF: $\mathrm{HF}$ / $\mathrm{HNO}_{3} / \mathrm{HCl}$ ) pools. LSF values (Lch, Ref) shown for incubation source depths (*). LSF values (Lch only) for particle addition source depth (**). (B) Fluorescence profiles from the ship's CTD (arbitrary units) in the upper $200 \mathrm{~m}$ at incubation stations, demonstrating the broad fluorescence maxima between 20-80m commonly observed during the transect. Mixed layer depths, defined as potential density anomaly $>0.05$ vs. $0 \mathrm{~m}$, were $83 \mathrm{~m}$ at Stn 27 and $86 \mathrm{~m}$ at $\operatorname{Stn} 43$. 


\section{Figure 3: Time-course (1L) bottles}
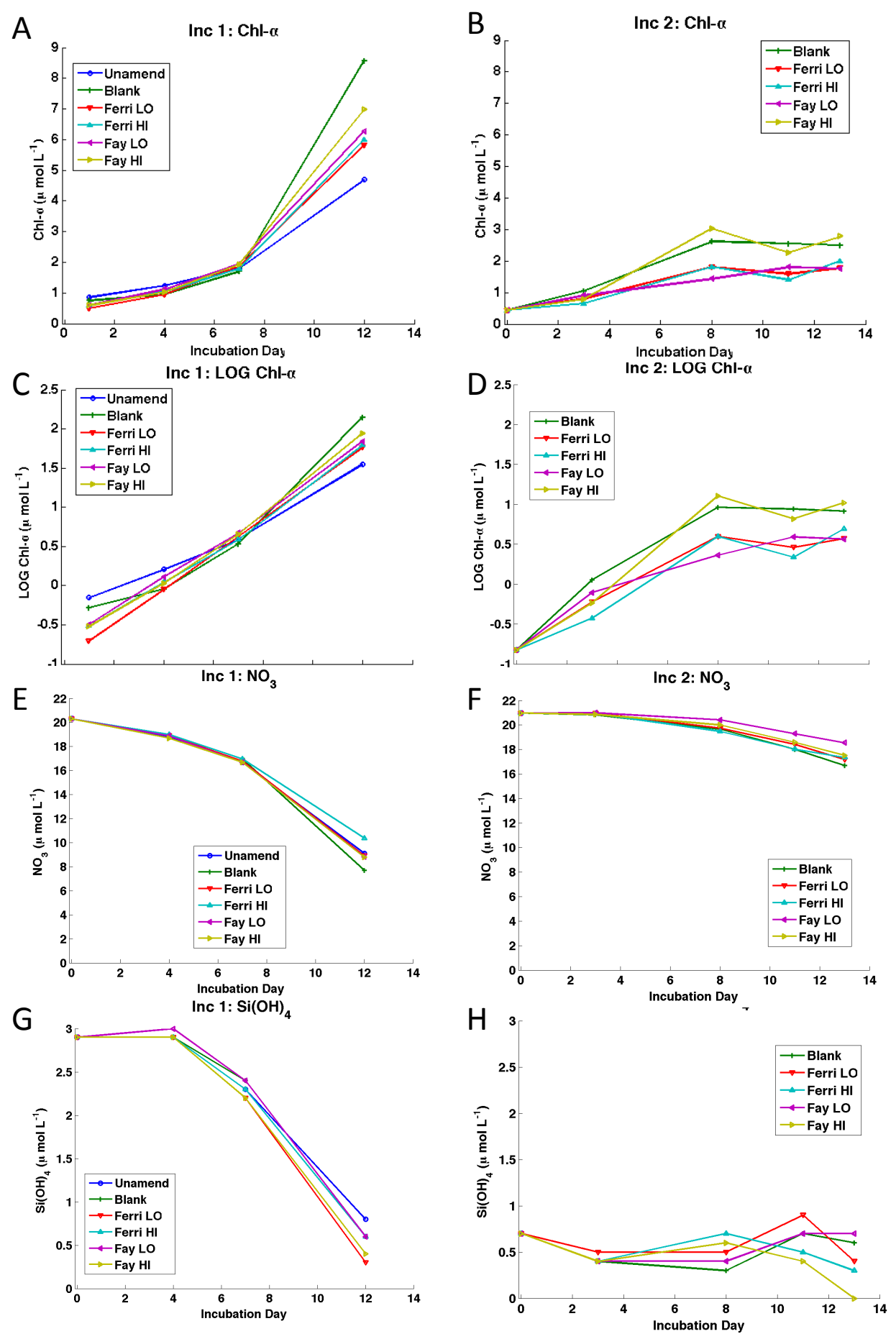
Figure 3, cont'd
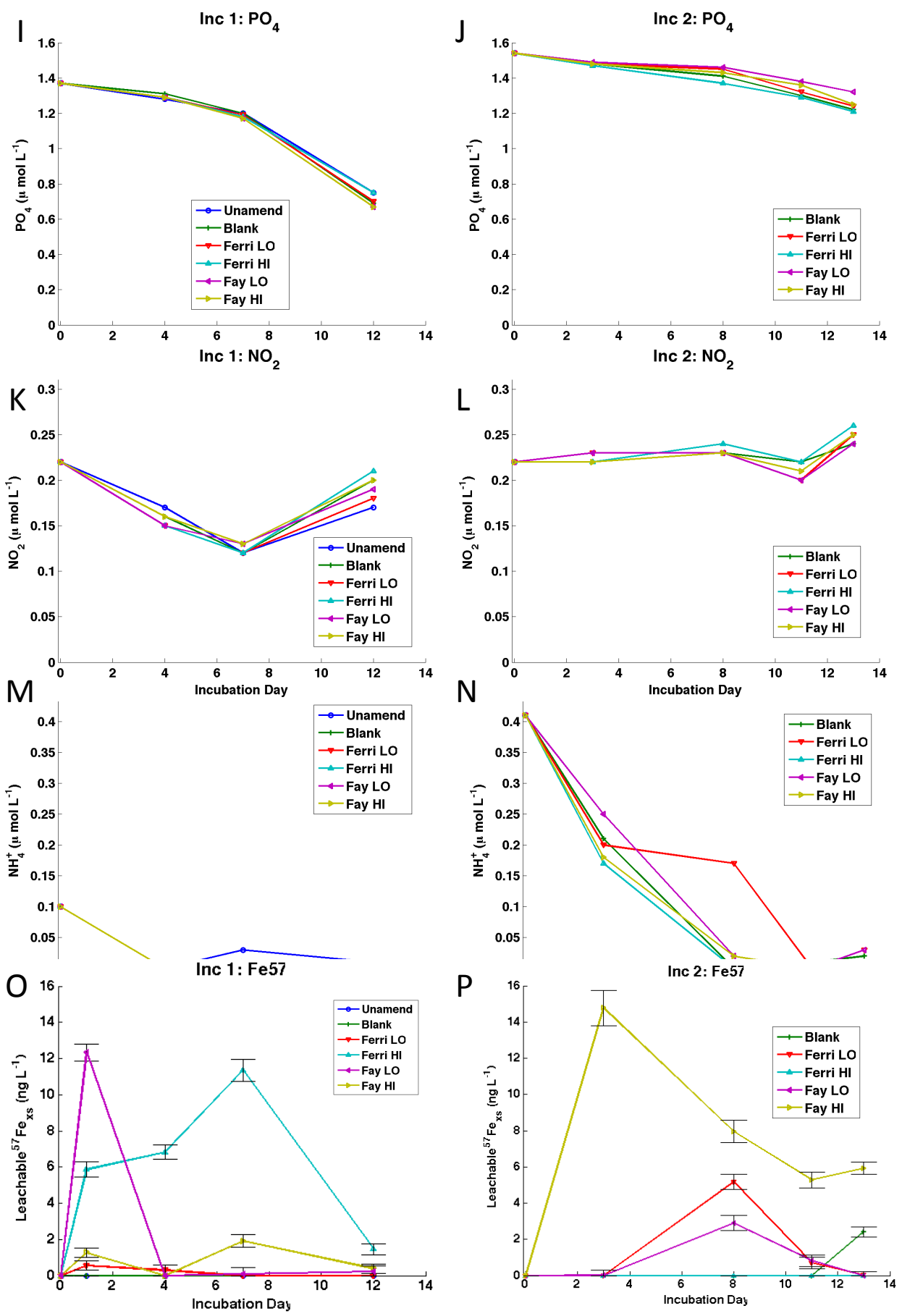
Fig. 3: (A-B) Chlorophyll, (C-D) log Chlorophyll, (E-M) nutrient, and (N-O) suspended leachable ${ }^{57} \mathrm{Fe}_{\mathrm{xs}}$ concentrations from one-liter time-course incubation bottles (n=1 per treatment). Left column: incubation 1; right column: incubation 2. Error bars for ${ }^{57} \mathrm{Fe}_{\mathrm{xs}}$ are $\pm 1 \sigma$ analytical uncertainties (described further in Fig. 6-7 caption). Within each incubation, log-Chl linear fitted growth curves [not shown] were not significantly different (95\% confidence interval of slopes) between all treatments. More intense macronutrient drawdown and greater final chlorophyll concentrations were observed in incubation 1 than incubation 2, where low initial silicate values may have prevented a strong diatom growth response to mineral amendments. Leachable ${ }^{57} \mathrm{Fe}_{\mathrm{xs}}$ values are difficult to interpret due to both changing ratios of mineral:seawater and poorly constrained removal of time-varying biogenic and authigenic leachable pools via subsampling. Decreases in the absolute amounts of leachable ${ }^{57} \mathrm{Fe}_{\mathrm{xs}}$, especially near the end of higher growth incubation 1 and despite increasing mineral:seawater ratios, may indicate aging of leachable biogenic and authigenic Fe pools, if not also the source mineral surfaces, as the incubation progressed. 
Figure 4: Abiotic intercomparison

\section{Incubation 1 (Crozet)}

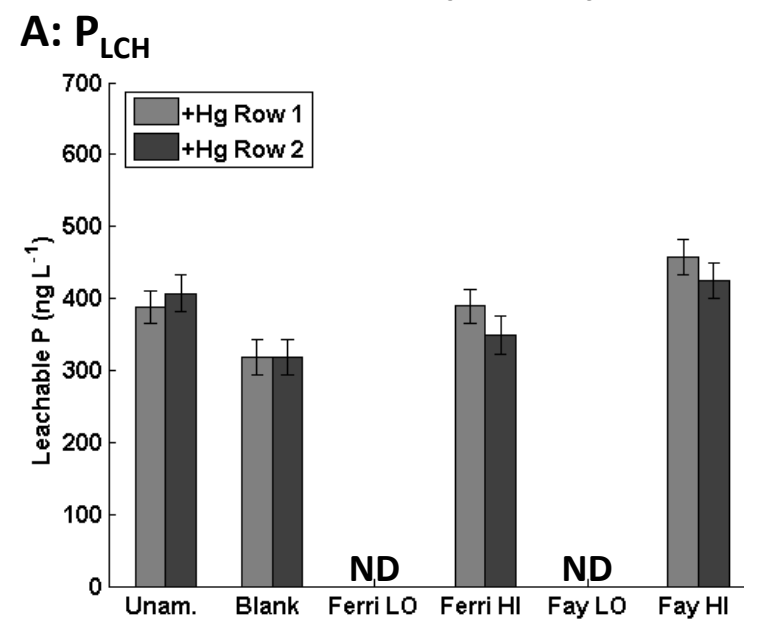

\section{Incubation 2 (Open Ocean)}
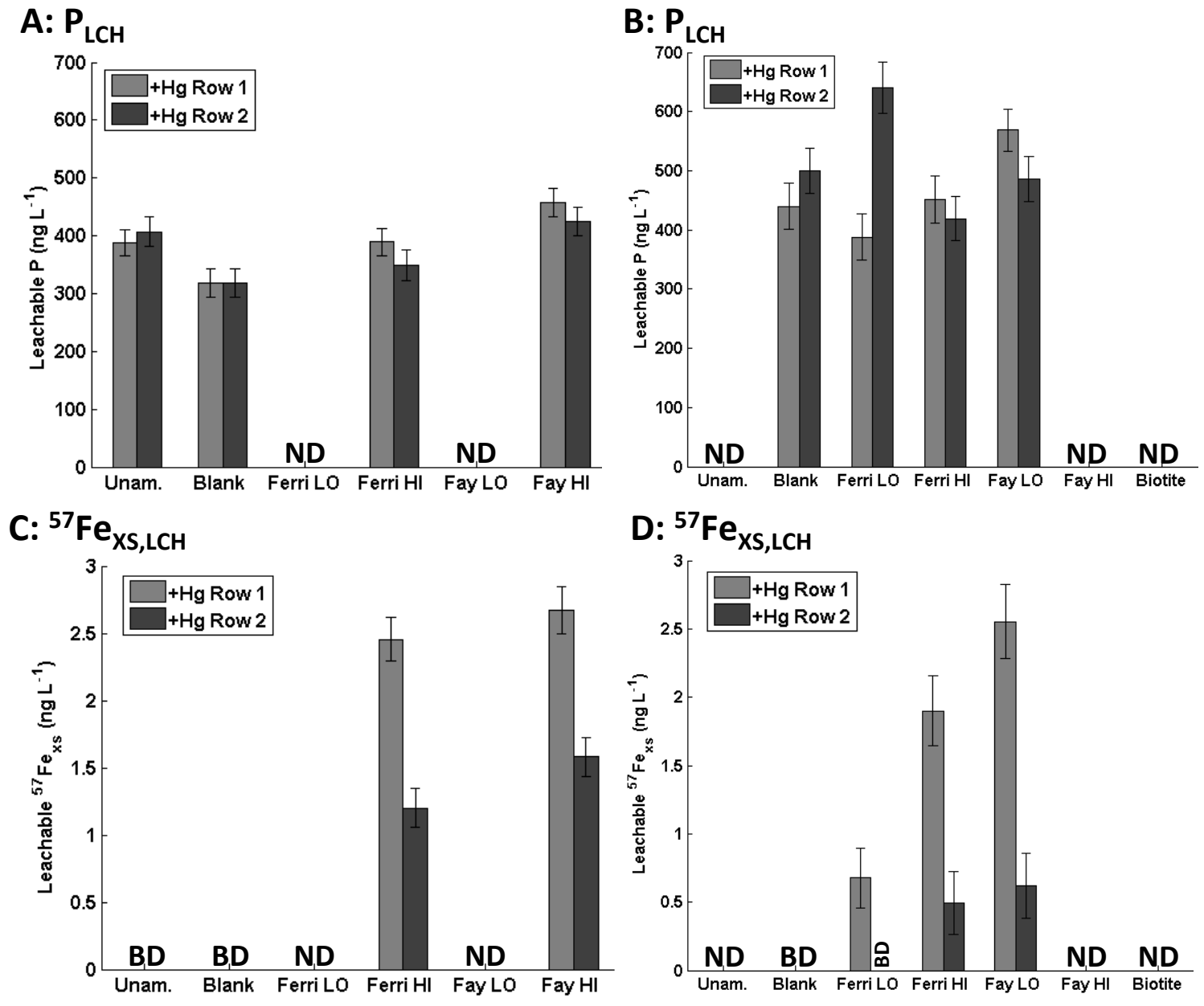

Fig. 4: Abiotic experiments in Hg-poisoned 250mL bottles indicated light-dependent (rowdependent) transfer of ${ }^{57} \mathrm{Fe}_{\mathrm{xs}}$ (lower panels) from immobilized minerals into suspended $>0.2 \mu \mathrm{m}$ particulate phases with more transfer in higher light bottles (Row 1) than bottles further away from the light source (Row 2). Incubation 1 (left), demonstrated similar levels of transfer for both minerals (Ferri HI $\approx$ Fayalite HI). Incubation 2 (right, no Row 3 as in biotic experiments) displayed greater abiotic transfer of ${ }^{57} \mathrm{Fe}$ from mineral fayalite (Fay LO > Ferri HI in row 1). Across incubations, Ferri HI treatments indicated slightly greater abiotic ${ }^{57} \mathrm{Fe}$ transfer in Incubation 1 seawater despite similar levels of leachable particulate biogenic material (particulate $P$, upper panels). Error bars are propagated analytical uncertainties $( \pm 1 \sigma)$. ND: not determined; BD: below detection. 


\section{Figure 5: Leachable vs. refractory ${ }^{57} \mathrm{Fe}_{\mathrm{xs}}$}

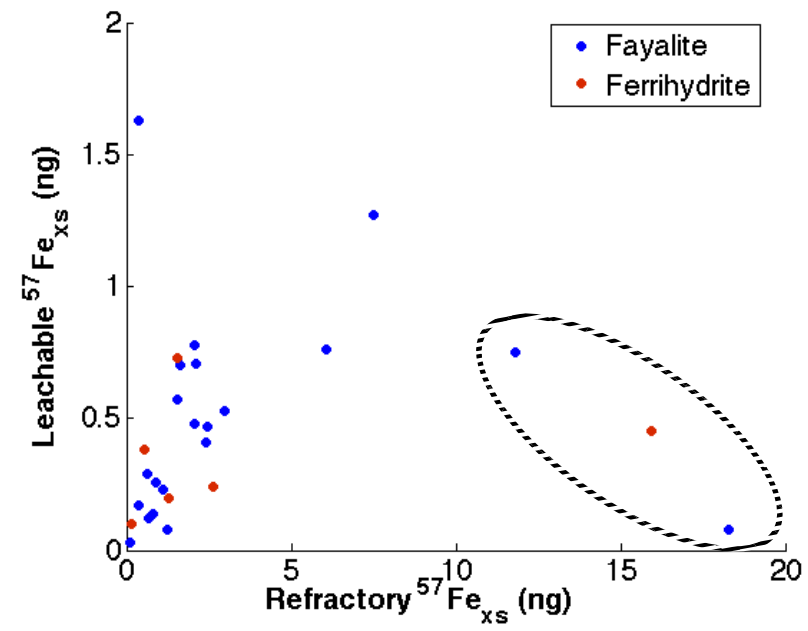

Figure 5: To determine if slide-immobilized mineral particles had physically transferred into leachable suspended phases, sequentially digested refractory (HF/ $\mathrm{HNO}_{3} / \mathrm{HCl}, 4 \mathrm{~N}$ each, $135^{\circ} \mathrm{C}$ for $4 \mathrm{hrs}$ ) ${ }^{57} \mathrm{Fe}_{\mathrm{xs}}$ values (x-axis) were compared to leachable (acetic acid $+0.02 \mathrm{M}$ hyrdroxylamine, $2 \mathrm{hr} \mathrm{RT}, 10 \mathrm{~min} 90^{\circ} \mathrm{C}$ heating step) ${ }^{57} \mathrm{Fe}_{\mathrm{xs}}$ values (yaxis) from all abiotic bottles and multiple biotic experimental bottles. Correlation at lower leachable values (left, most data points) is attributed to incomplete leach accessiblity of both biogenic P phases and some authigenic (in situ precipitated) Fe phases in suspension. Fayalite (blue points) and ferrihydrite (red points) treatments showed broadly overlapping trends. In several cases (circled values, right) mineral loss from chips into suspended particle phase or contamination during filtration appears to have resulted in elevated refractory values, but these were not associated with higher leachable values. 


\section{Figure 6: Incubation 1}

Abiotic

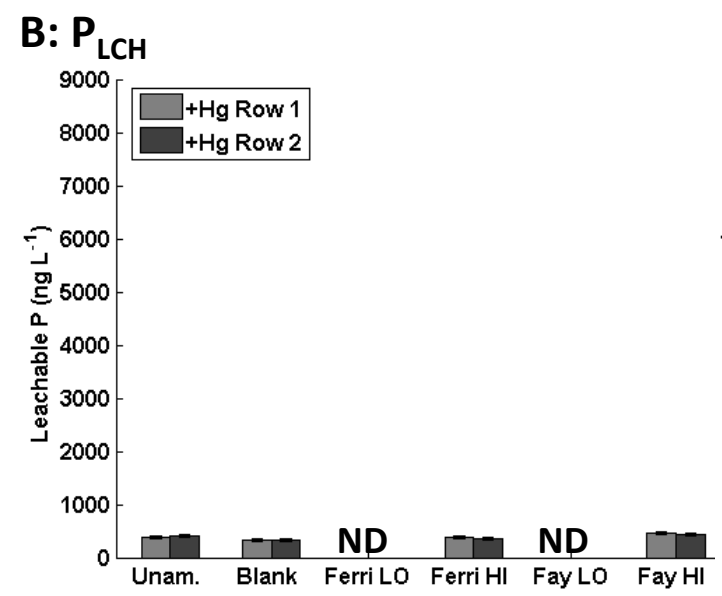

D: ${ }^{57} \mathrm{Fe}_{\mathrm{XS}, \mathrm{LCH}}$

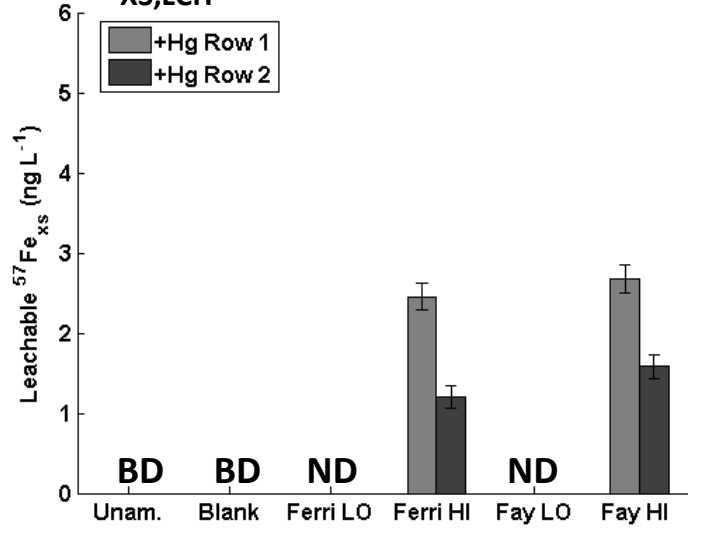

\section{Biotic}
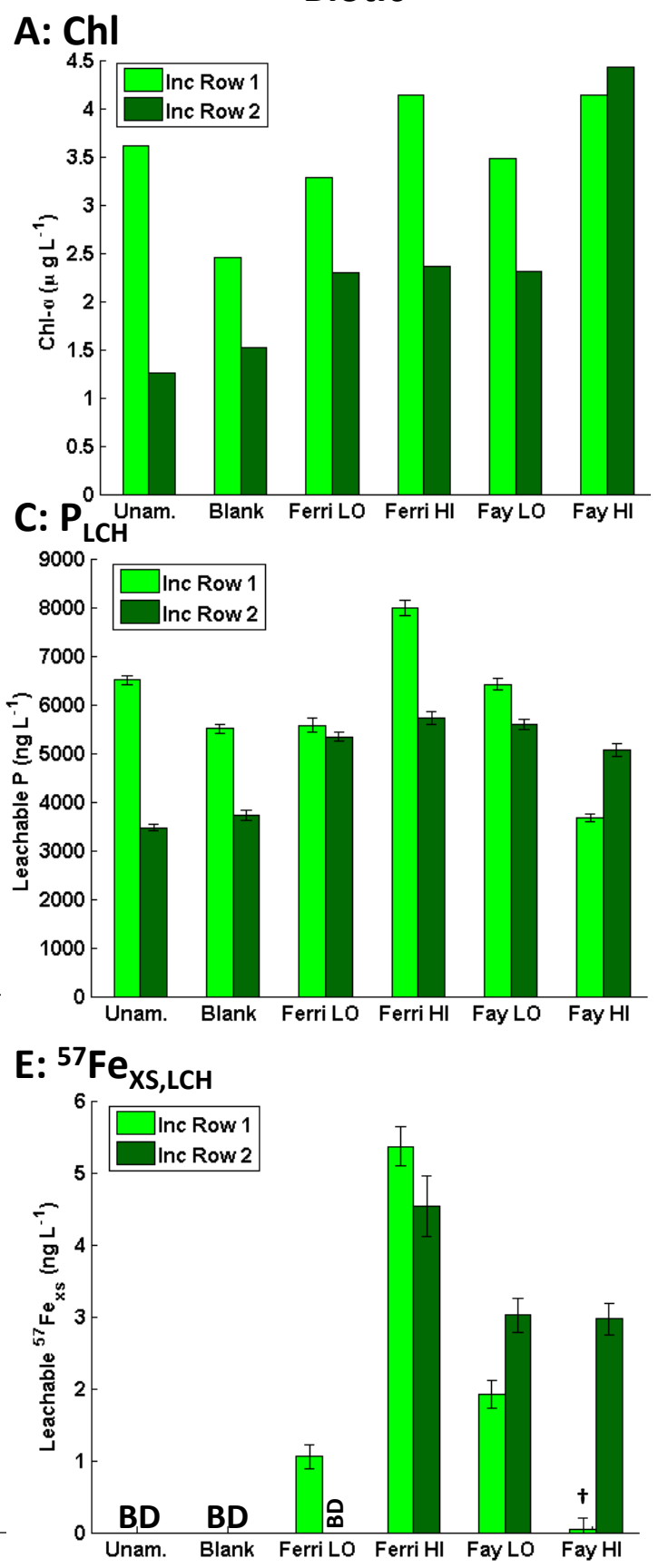
Figure 6: Incubation 1

$\mathbf{F}$

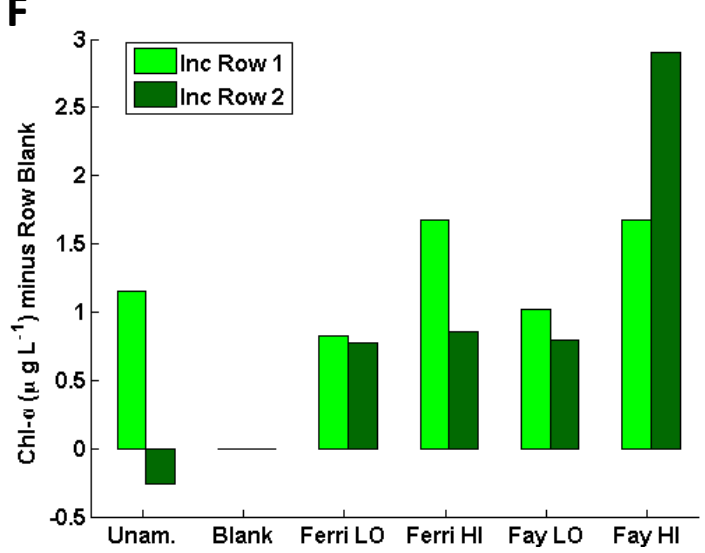

ChI minus BI

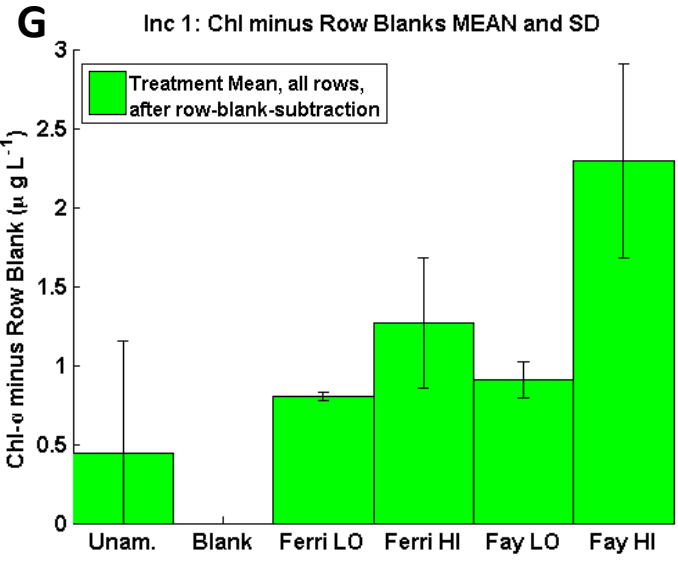

$\mathbf{P}_{\text {LCH }}$ minus $\mathrm{Bl}$
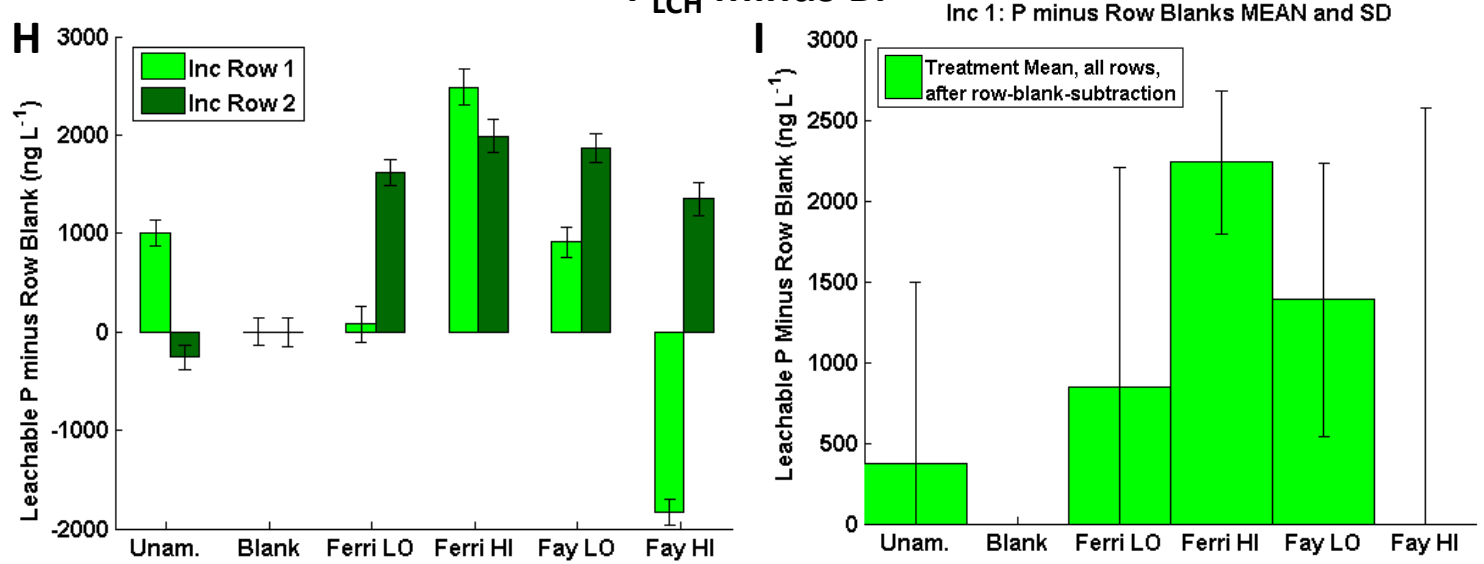

${ }^{57} \mathrm{Fe}_{\mathrm{XS}, \mathrm{LCH}}$

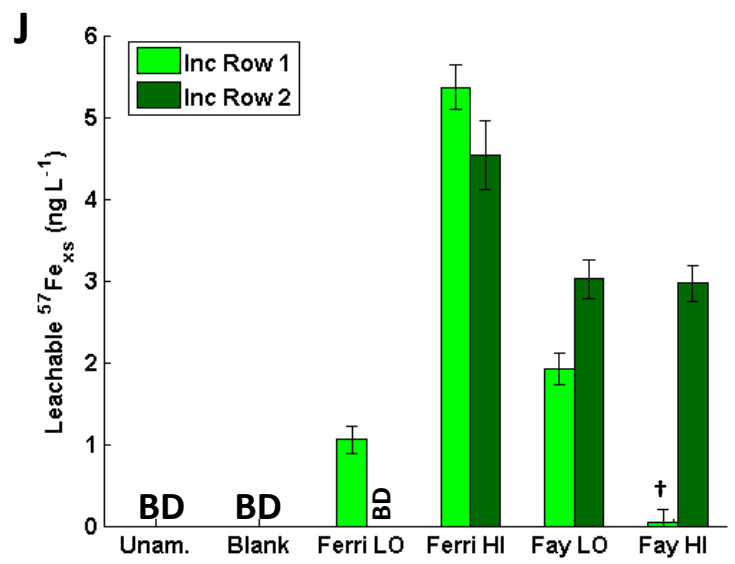




\section{Figure 6: Incubation 1}

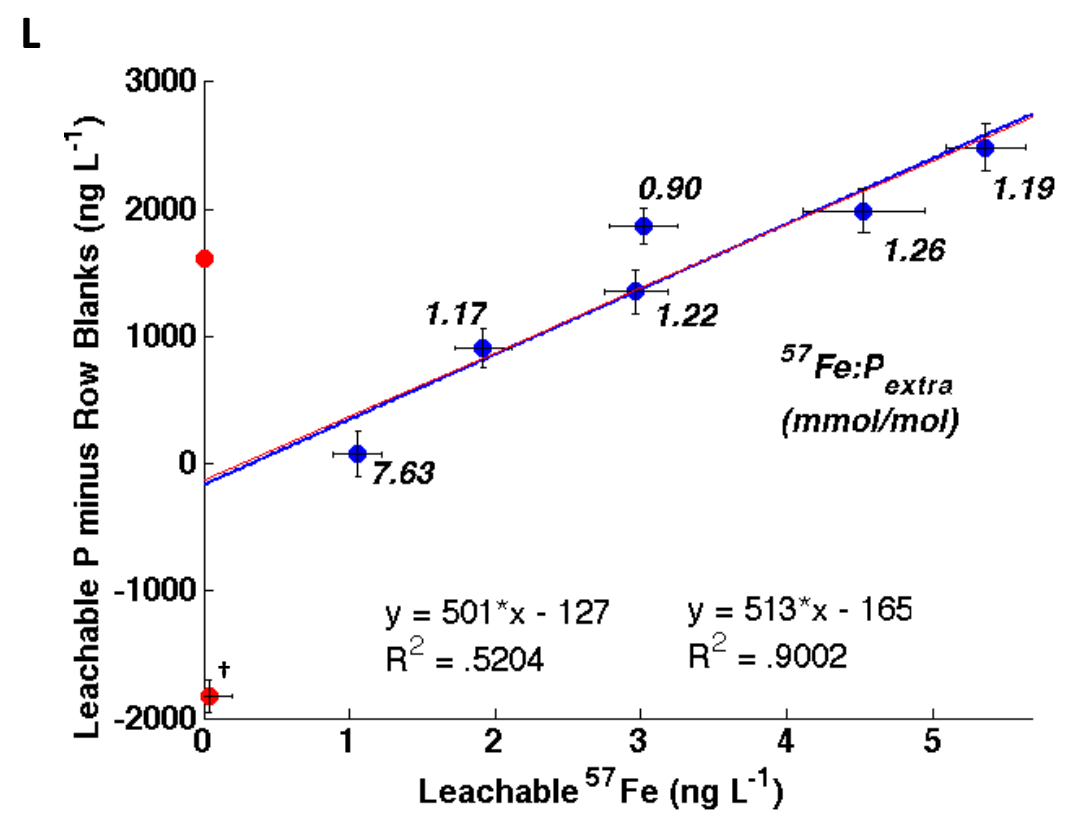

Figures 6 and 7: Measured and row-blank-subtracted chlorophyll (A, F), and leachable P (C, H), along with measured leachable ${ }^{57} \mathrm{Fe}_{\mathrm{xs}}$ (E same as J) from individual bottle treatments in biotic incubations. Row 1 bottles (higher light; light green) were located closest to the incubator light bank, while Rows 2 (lower light) and 3 (Inc. 2 only, darker greens) were further away as described in methods. Abiotic experiments (B, D) in the left column are the same as Figure 5, but plotted on the same scale as biotic experiments for comparison. Error bars for individual bottles represent propagated analytical uncertainties $( \pm 1 \sigma)$ which include filtered volume, instrumental, blank subtraction, and standardization uncertainties (and, for ${ }^{57} \mathrm{Fe}_{\mathrm{xs}}$, subtraction of natural ${ }^{56} \mathrm{Fe} /{ }^{57} \mathrm{Fe}$ signal). Also shown are treatment means of all row-blank-subtracted $\mathrm{Chl}(\mathrm{G})$, row-blank-subtracted leachable $\mathrm{P}(\mathrm{I})$, and ${ }^{57} \mathrm{Fe}_{\mathrm{xs}}$ values $(\mathrm{K})$ with population standard deviations (G, I and K: error bars). BD: below detection. ND: not determined. $\uparrow:>10$ ng refractory ${ }^{57} \mathrm{Fe}_{\mathrm{xs}}$ indicating chance of mineral contamination (excluded from treatment means). $\uparrow \uparrow$ : notably contaminated with ${ }^{56} \mathrm{Fe}$.

L (Figure 6 only): A linear correlation (red line, left equation) was observed between leachable ${ }^{57} \mathrm{Fe}_{\mathrm{xs}}$ and row-blank-subtracted P (excess biomass over blank) for all biotic samples. Exclusion of a bottle suspected of ${ }^{56} \mathrm{Fe}$-contamination and a "crashed" bottle with extremely poor production (red points), improves the quality of the fit without significantly changing the trend (right equation, blue line). ${ }^{57} \mathrm{Fe}: \mathrm{P}$ mole ratios for samples used in the latter fit are shown as numeric annotations. Error bars: analytical uncertainty $( \pm 1 \sigma)$ including blank subtraction. 
Figure 7: Incubation 2
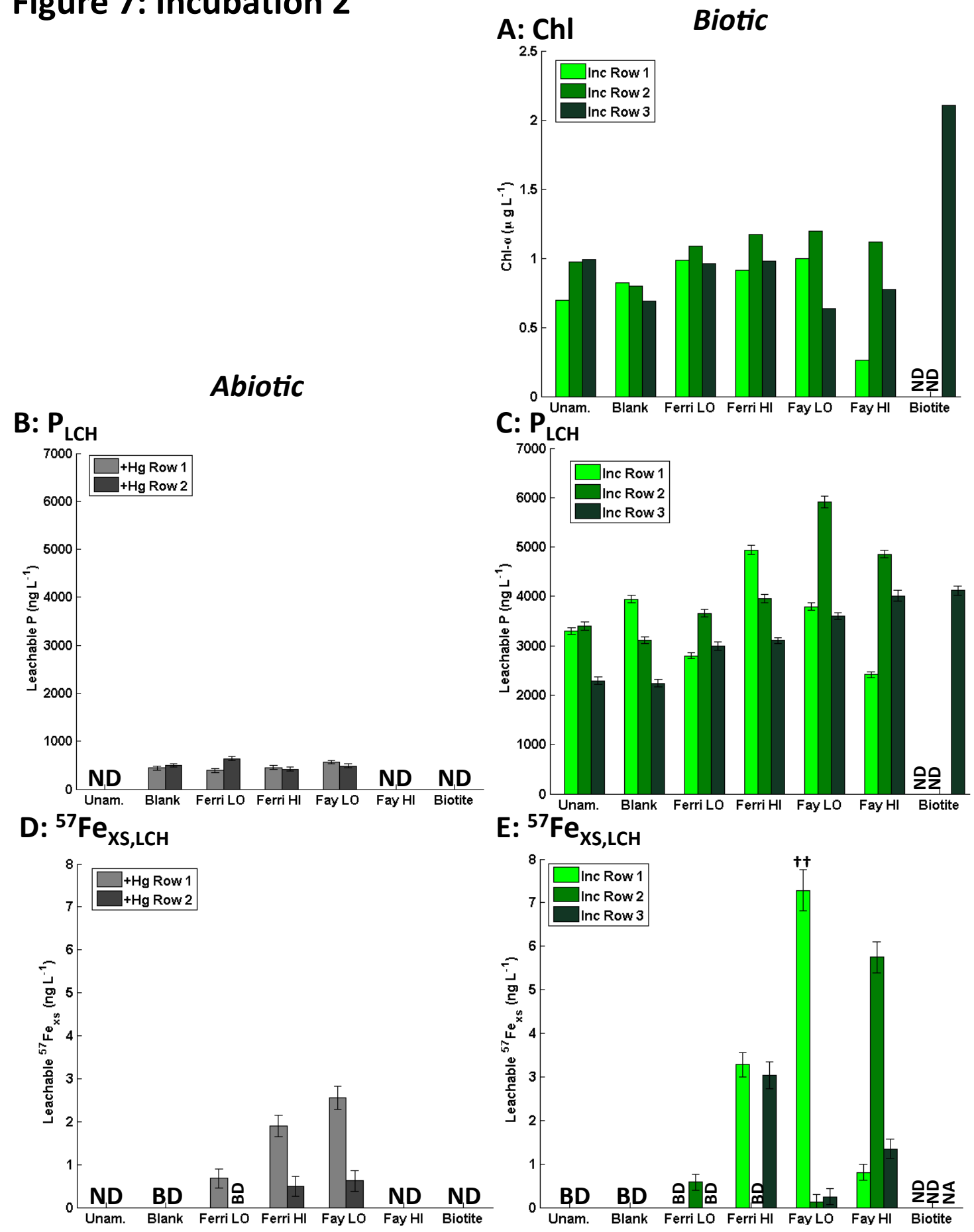


\section{Figure 7: Incubation 2}
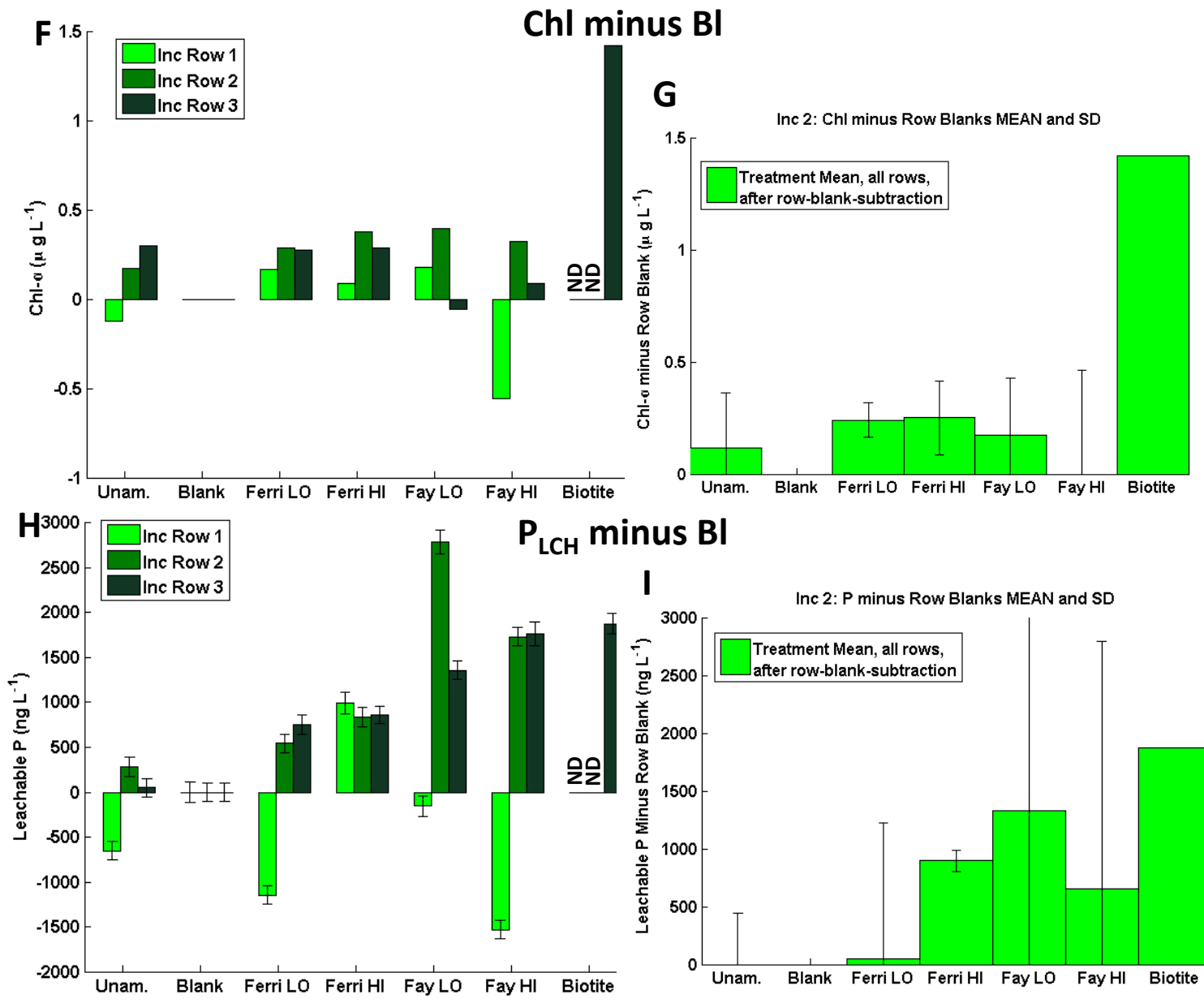

us BI

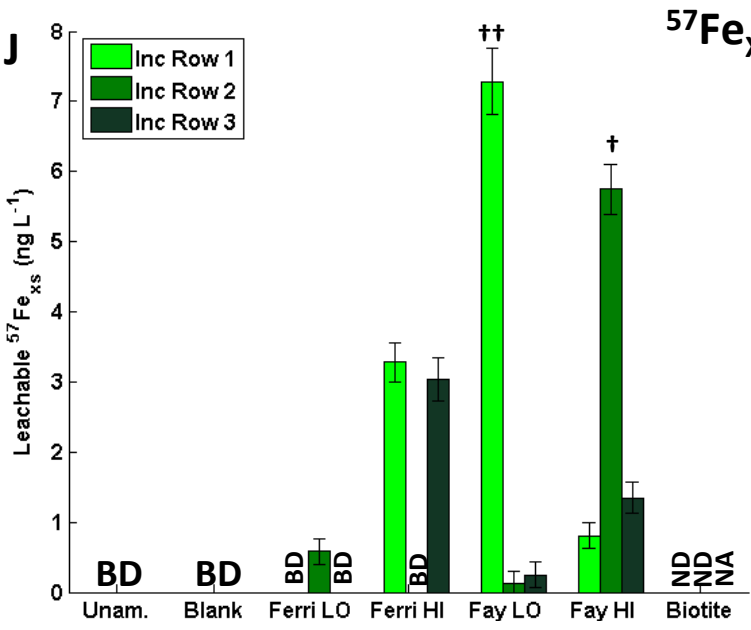

I Inc 2: P minus Row Blanks MEAN and SD

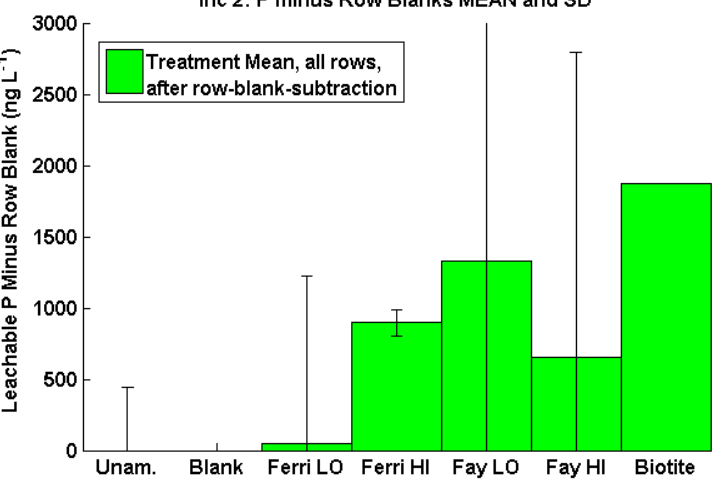

$\mathrm{Fe}_{\mathrm{XS}, \mathrm{LCH}}$

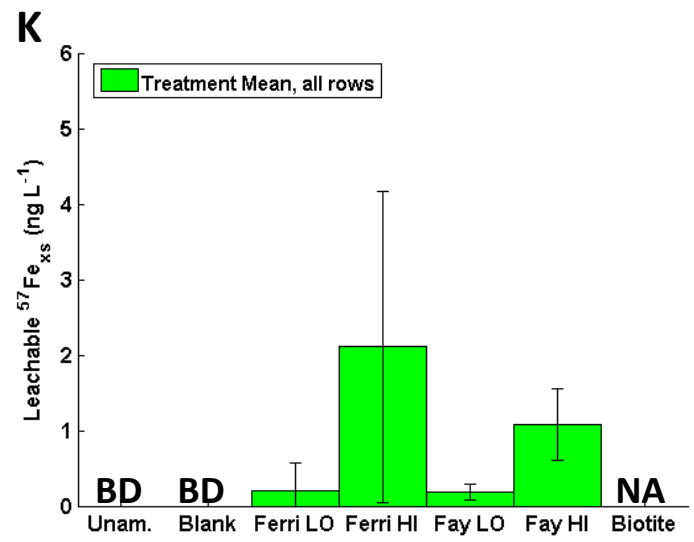




\section{Figure 8: Incubation $1+$ LSF Particles (200m)}

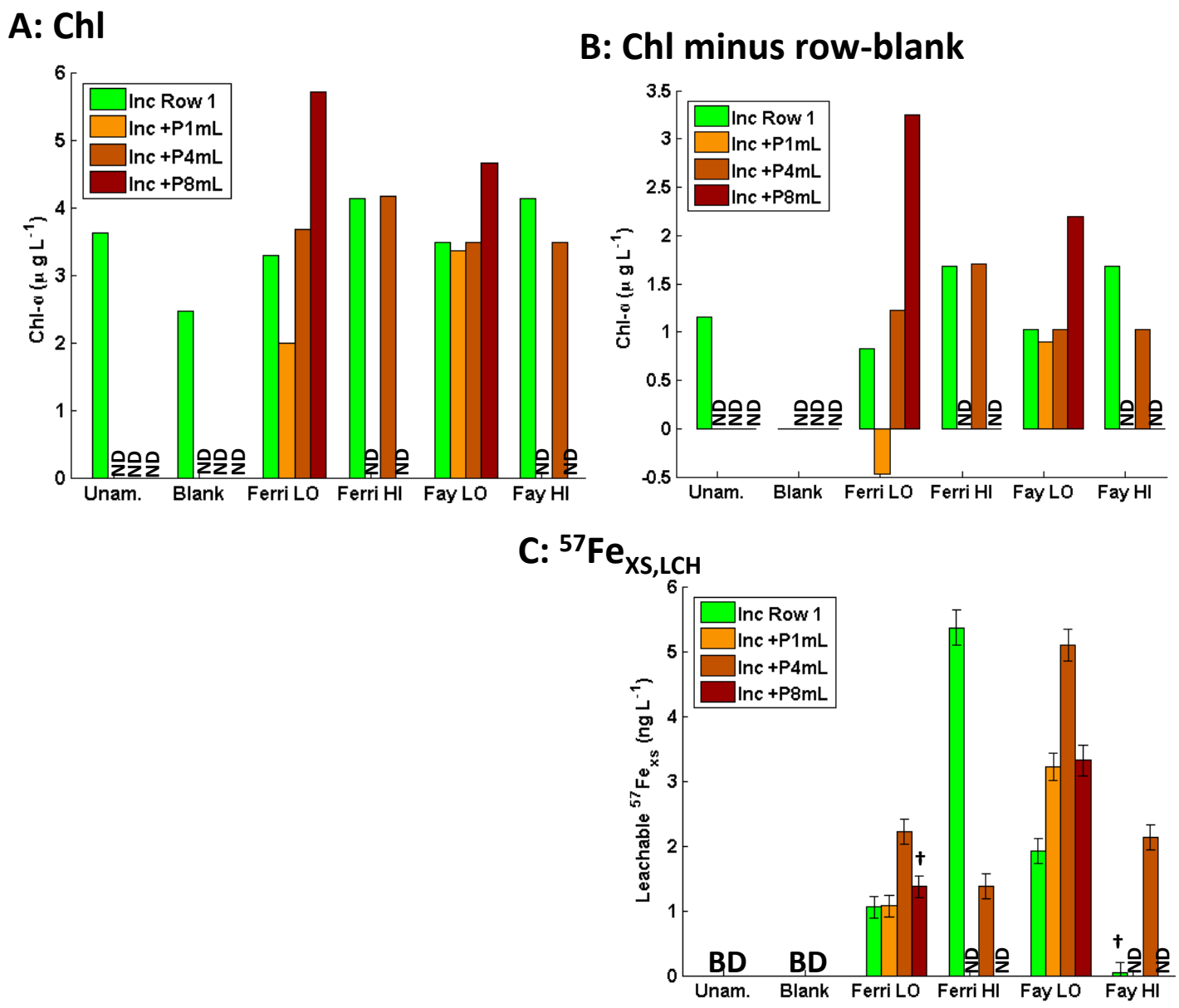

Figure 8: Measured and row-blank-subtracted chlorophyll (A, B), and measured leachable ${ }^{57} \mathrm{Fe}_{\mathrm{xs}}$ (C) from individual bottle treatments in Incubation 1 that were amended with resuspended deep (200m) LSF particles collected by McLane pumps. Each $1 \mathrm{~mL}$ of addition corresponds to $+1 \mathrm{~L}$-equivalent LSF particles [Table 3]. All particle-amended bottles were located in Row 1, so Row 1 non-particle-amended bottles (light green, same as in Fig. 6) are presented for comparison. Additions with $\geq 4 \mathrm{~mL}$ all showed Chl-increases greater than row blanks, and $+8 \mathrm{~mL}$ additions were associated with the strongest increases in Chl levels (dark red bars). Leachable ${ }^{57} \mathrm{Fe}_{\mathrm{xs}}$ showed greatest transfer from minerals in $+4 \mathrm{~mL}$ additions, with $+8 \mathrm{~mL}$ additions associated with less transfer, perhaps due to increased scavenging of leachable Fe by amended particles or by increased biomass that resulted from the amendment. Error bars, abbreviations and symbols are as in Figs. 6-7. 
Figure 9: Biotic Intercomparison

Incubation 1

\section{A: Chl}

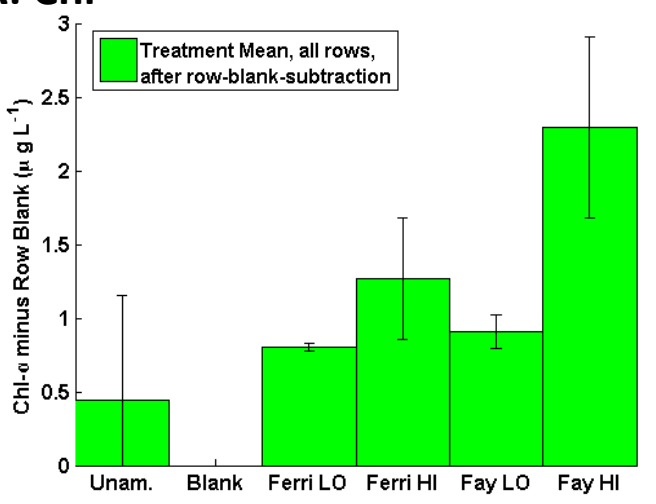

C: $\mathbf{P}_{\mathrm{xs}, \mathrm{LCH}}$
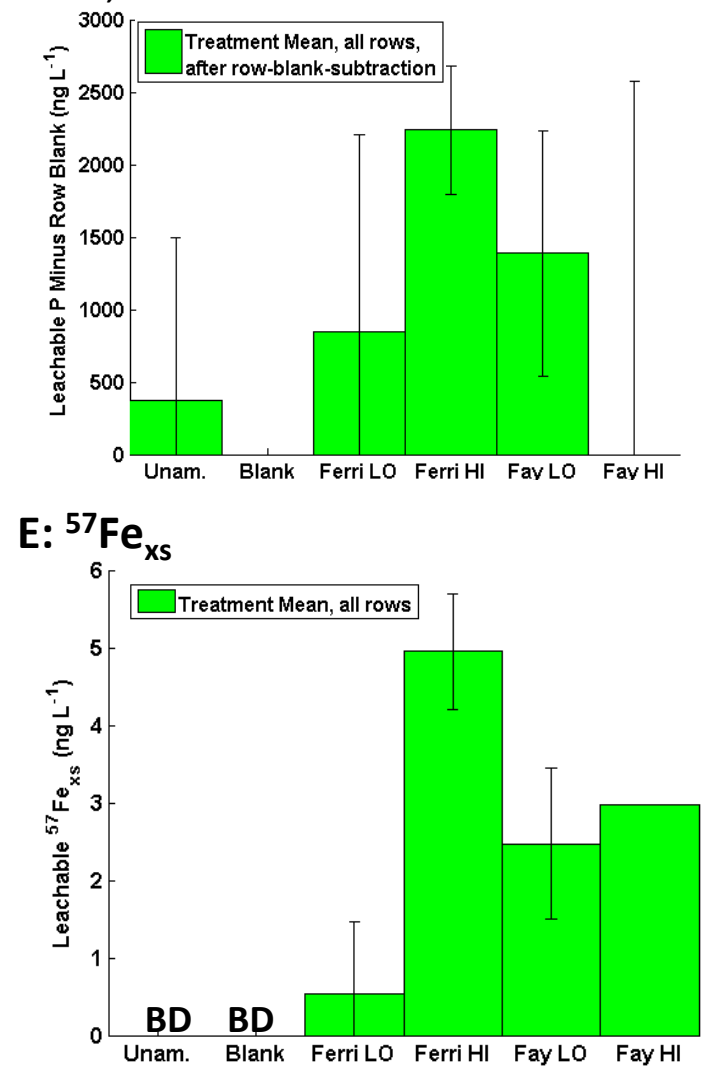

Incubation 2

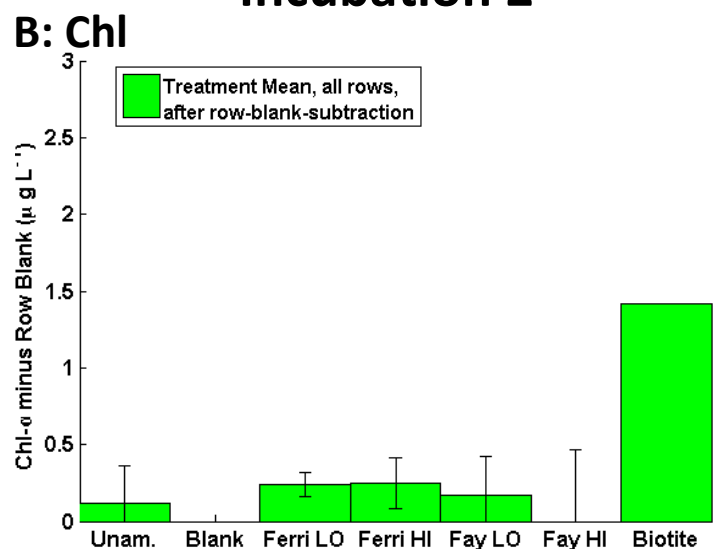

D: $\mathbf{P}_{\mathrm{xs}, \mathrm{LCH}}$
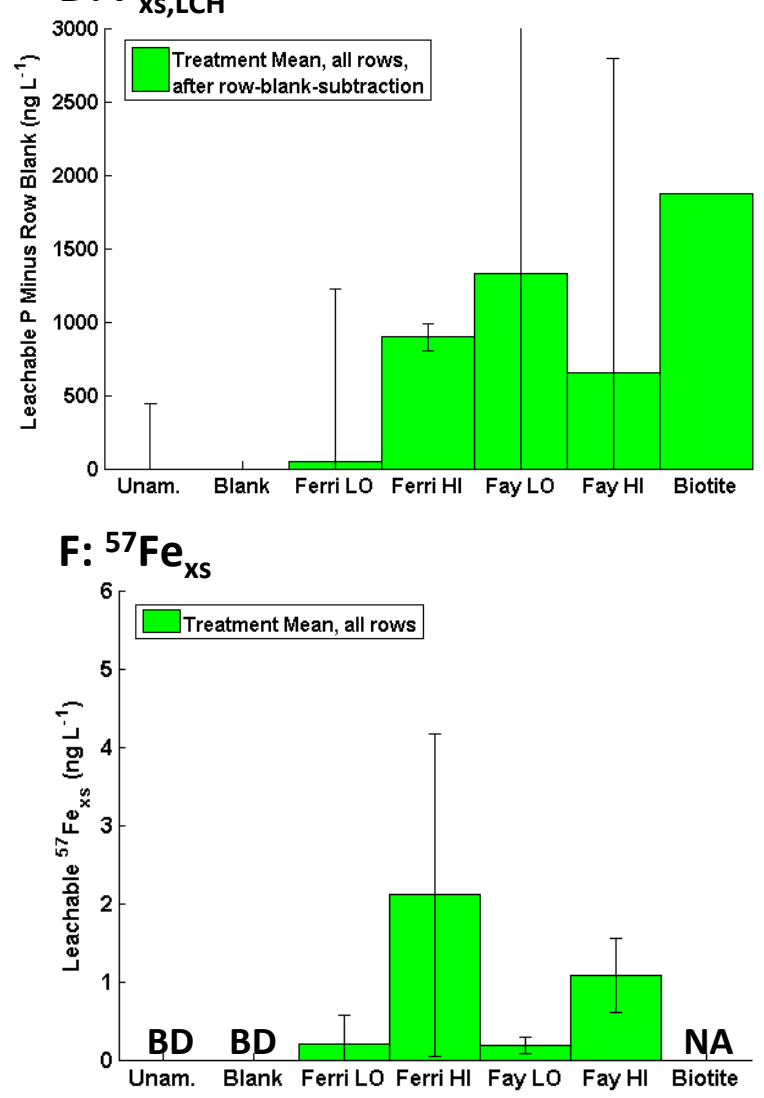

Figure 8: Side-by-side comparison of mean treatment responses from biotic experiments (left: inc. 1; right: inc 2). Abbreviations as in Figs 6-7. 
Table 1: Mineral loadings

\begin{tabular}{|c|r|r|r|r|r|}
\hline & \multicolumn{3}{|c|}{ Total Mineral On Chip } & \multicolumn{2}{|c|}{ If $1 \%$ Surf. Avail. } \\
\cline { 2 - 7 } Dose $\begin{array}{r}\text { Bottle } \\
\text { Vol. }\end{array}$ & ug mineral & ug/L & $\begin{array}{r}\text { Approx. } \\
\text { ug Fe/L }\end{array}$ & ng Fe/L & nmol Fe/L \\
\hline LO $250 \mathrm{~mL}$ & 110 & 440 & 242 & 2420 & 42.5 \\
$1000 \mathrm{~mL}$ & 110 & 110 & 60.5 & 605 & 10.6 \\
HI $250 \mathrm{~mL}$ & 294 & 1176 & 647 & 6468 & 114 \\
$1000 \mathrm{~mL}$ & 294 & 294 & 162 & 1617 & 28.4 \\
\hline
\end{tabular}

Table 2: Incubation treatments and replicates

\begin{tabular}{|c|c|c|c|c|c|c|c|c|c|c|c|c|c|c|}
\hline \multirow[b]{2}{*}{ Dosing: } & \multirow{2}{*}{$\begin{array}{c}\text { Unamen. } \\
\mathrm{N} / \mathrm{A}\end{array}$} & \multirow{2}{*}{\begin{tabular}{|c|} 
Blank \\
N/A
\end{tabular}} & \multicolumn{2}{|c|}{ Ferrihydrite (Fh) } & \multicolumn{2}{|c|}{ Fayalite (Fy) } & \multirow{2}{*}{$\begin{array}{c}\text { Biotite } \\
\text { N/A }\end{array}$} & \multicolumn{2}{|c|}{ +Particles } & \multicolumn{2}{|c|}{ Hg-Killed } & \multirow{2}{*}{ Fh-Lo } & \multirow{2}{*}{$\mathrm{Fh}-\mathrm{Hi}$} & \multirow{2}{*}{ Fy-Lo Fy-Hi } \\
\hline & & & Lo & $\mathrm{Hi}$ & Lo & $\mathrm{Hi}$ & & $+1+4$ & $+8 \mathrm{~mL}$ & Unam & Blk & & & \\
\hline Inc $1,250 \mathrm{~mL}$ & 2 & 2 & 2 & 2 & 2 & 2 & & 24 & 2 & 2 & 2 & & 2 & 2 \\
\hline Inc $2,250 \mathrm{~mL}$ & 3 & 3 & 3 & 3 & 3 & 3 & 1 & & & & 2 & 2 & 2 & 2 \\
\hline Inc $1,1000 \mathrm{~mL}$ & 1 & 1 & 1 & 1 & 1 & 1 & & & & & & & & \\
\hline Inc $2,1000 \mathrm{~mL}$ & & 1 & 1 & 1 & 1 & 1 & & & & & & & & \\
\hline
\end{tabular}

\section{Table 3: Incubation source water particulates}

\begin{tabular}{|c|c|c|c|c|c|c|c|c|c|c|c|}
\hline \multicolumn{12}{|c|}{ Al (ng/L) } \\
\hline \multirow[b]{2}{*}{ Stn } & \multirow[b]{2}{*}{ Depth $(\mathrm{m})$} & \multicolumn{3}{|c|}{ Susp } & \multicolumn{3}{|c|}{ LSF } & \multicolumn{4}{|c|}{ Total pAl } \\
\hline & & Lch & Ref & \%Lch & Lch & Ref & \%Lch & Lch & Ref & $L+R$ & \%Lch \\
\hline 27 (Inc 1) & 20 & 1.00 & 2.00 & $33 \%$ & 0.60 & 4.84 & $11 \%$ & 1.60 & 6.85 & 8.45 & $19 \%$ \\
\hline 43 (Inc 2) & 20 & 0.10 & 0.71 & $12 \%$ & 0.04 & 6.05 & $1 \%$ & 0.14 & 6.75 & 6.89 & $2 \%$ \\
\hline $27(\operatorname{Inc} 1+P)$ & 200 & 6.54 & 17.7 & $27 \%$ & 4.92 & $N D$ & $N D$ & 11.5 & $N D$ & $N D$ & ND \\
\hline Spike & $+1 \mathrm{~mL}$ & $N A$ & $N A$ & $N A$ & 1.27 & $"$ & $"$ & 1.27 & $"$ & $"$ & " \\
\hline Spike & $+4 \mathrm{~mL}$ & $"$ & $"$ & $"$ & 5.06 & $"$ & $"$ & 5.1 & " & $"$ & " \\
\hline Spike & $+8 \mathrm{~mL}$ & $"$ & $"$ & $"$ & 10.1 & $"$ & $"$ & 10.1 & $"$ & $"$ & " \\
\hline
\end{tabular}

\begin{tabular}{|c|c|c|c|c|c|c|c|c|c|c|c|}
\hline \multicolumn{12}{|c|}{$P(n g / L)$} \\
\hline \multirow[b]{2}{*}{ Stn } & \multirow[b]{2}{*}{ Depth $(\mathrm{m})$} & \multicolumn{3}{|c|}{ Susp } & \multicolumn{3}{|c|}{ LSF } & \multicolumn{4}{|c|}{ Total pP } \\
\hline & & Lch & Ref & \%Lch & Lch & Ref & $\%$ Lch & Lch & Ref & $\mathrm{L}+\mathrm{R}$ & \%Lch \\
\hline 27 (Inc 1) & 20 & 198 & 285 & $41 \%$ & 22.4 & 61.5 & $27 \%$ & 220 & 347 & 567 & $39 \%$ \\
\hline 43 (Inc 2) & 20 & 79.0 & 45.8 & $63 \%$ & 122 & 76.6 & $61 \%$ & 201 & 122 & 323 & $62 \%$ \\
\hline 27 (Inc 1+P) & 200 & 28.0 & 28.4 & $50 \%$ & 9.80 & $N D$ & ND & 37.8 & ND & ND & $N D$ \\
\hline Spike & $+1 \mathrm{~mL}$ & $N A$ & $N A$ & $N A$ & 2.52 & $"$ & $"$ & 2.52 & $"$ & $"$ & " \\
\hline Spike & $+4 \mathrm{~mL}$ & $"$ & " & $"$ & 10.1 & $"$ & $"$ & 10.1 & $"$ & $"$ & " \\
\hline Spike & $+8 \mathrm{~mL}$ & $"$ & $"$ & $"$ & 20.1 & $"$ & $"$ & 20.1 & $"$ & $"$ & $"$ \\
\hline
\end{tabular}

\begin{tabular}{|c|c|c|c|c|c|c|c|c|c|c|c|}
\hline \multicolumn{12}{|c|}{$\mathrm{Fe}(\mathrm{ng} / \mathrm{L})$} \\
\hline \multirow[b]{2}{*}{ Stn } & \multirow[b]{2}{*}{ Depth $(\mathrm{m})$} & \multicolumn{3}{|c|}{ Susp } & \multicolumn{3}{|c|}{ LSF } & \multicolumn{4}{|c|}{ Total pFe } \\
\hline & & Lch & Ref & \%Lch & Lch & Ref & \%Lch & Lch & Ref & $L+R$ & \%Lch \\
\hline 27 (Inc 1) & 20 & 1.24 & 2.05 & $38 \%$ & 1.00 & 2.83 & $26 \%$ & 2.24 & 4.88 & 7.12 & $31 \%$ \\
\hline 43 (Inc 2) & 20 & 0.30 & 0.45 & $40 \%$ & $\mathrm{BD}$ & 13.5 & $0 \%$ & 0.30 & 13.9 & 14.2 & $2 \%$ \\
\hline $27(\operatorname{Inc} 1+P)$ & 200 & 3.94 & 16.2 & $20 \%$ & 4.33 & $N D$ & ND & 8.28 & $N D$ & $N D$ & $N D$ \\
\hline Spike & $+1 \mathrm{~mL}$ & $N A$ & $N A$ & $N A$ & 1.11 & $"$ & $"$ & 1.11 & " & " & " \\
\hline Spike & $+4 \mathrm{~mL}$ & $"$ & $"$ & $"$ & 4.45 & $"$ & $"$ & 4.5 & $"$ & $"$ & " \\
\hline Spike & $+8 \mathrm{~mL}$ & $"$ & $"$ & $"$ & 8.91 & $"$ & $"$ & 8.9 & $"$ & $"$ & " \\
\hline
\end{tabular}


Table 1: Mineral loadings on immobilized chips for LO and HI mineral dosings in the two incubation bottle sizes, along with corresponding particulate Fe concentrations. $55 \%$ wt. Fe is assumed for both ferrihydrite and fayalite minerals (though ferrihydrite can be up to $63 \%$ Fe by weight depending on hydration and molecular formula used). Variable particle sizes, differential mineral particle embedding in slides (10-20\% fully embedded within epoxy, with exposed mineral particles anywhere between 10-50\% exposed), and unconstrained mineral surface area make "surface available" Fe extremely poorly constrained, though effective $\mathrm{pFe}$ concentrations assuming $1 \%$ environmental exposure of particles are presented.

Table 2: Incubation treatments and the number of bottle replicates for each incubation described in the text. Blank cells indicate no replicate was performed. Unamen: unamended whole seawater only, no slide. Blank: epoxy-coated slide in whole seawater. Dosings: LO or HI (ca. 110 or $294 \mu \mathrm{g}$ mineral, respectively, as described in the main text). Biotite slide (Inc. 2, biotite) was loaded at a LO dosing. +Particles: LSF filtered particles from $200 \mathrm{~m}$ depth (McLane pumps) were resuspended in a small amount of incubation seawater and added to Incubation 1 bottles such that $+1 \mathrm{~mL} \approx 0.25 \mathrm{~L}$ equivalent of LSF particles (Table 3, Fig. 8). Hg-Killed bottles with slides (dosing) were all conducted in dupilicate.

Table 3: Leachable (Lch) refractory (Ref) and total (Lch + Ref; L+R) particulate concentrations on McLane pump particulate samples (suspended: SUSP; large size fraction: LSF) for incubation source water depths and particulate addition experiment source water depths. Percent leachable (\%Lch) also shown when available. ND: not determined. NA: not applicable. 


\section{Chapter 5: Conclusions}

This thesis primarily sought to expand our knowledge of particulate trace metal distributions in the oceans and to probe the interactions between lithogenic and biotic particles that occur in seawater. We began by analyzing our ability to quantify particulate trace element abundances using modern methods. An intercalibration study between several US laboratories demonstrated inter-lab $1 \sigma$ uncertainties of $\leq 21 \%$ for most elements, improving to $\leq 9 \%$ when considering only intralab variability for many commonly analyzed particulate elements. Greater uncertainties were observed for elements with lower sample:blank loading ratios (e.g. $\mathrm{Zn}, \mathrm{Pb}$ ). The intercomparison processes also inspired offline, self-analysis of laboratory and analytical procedures and highlighted directions for future improvement: both invaluable tools in a small analytical field. We also introduced a new chemical digest procedure that performs complete digestion of polyethersulfone filters, thus allowing high-throughout, consistent-sample-matrix analysis of particulate total digests. This method is a useful tool when conducting particulate analyses on filters that are otherwise challenging or time-consuming to digest.

These techniques were utilized in our acquisition of a large particulate trace metal dataset from the US GEOTRACES North Atlantic Zonal Transect. These data, of which the lithogenic elements were the primary focus, demonstrate the large-scale influence of African dust sources to the North Atlantic, the intensity and variable nature of both reducing and non-reducing benthic nepheloid layers, wide-spread mid-basin influences of hydrothermal systems, and lateral transport of lithogenic particles near continental boundaries. We calculated lithogenic particle residence times relative to dust inputs of $20-60 \mathrm{~d}$ in the upper $200 \mathrm{~m}$ and $0.5-1.5$ years in the upper $1000 \mathrm{~m}$, and observed water column lithogenic inventories that decrease less rapidly than dust inputs away from the primary African source, suggesting increased removal (faster sinking speeds) in dustier environments. Synchrotron XRF-mapping of marine aggregates demonstrated surprisingly high partitioning of

fine lithogenic dust particles into large aggregates in the mixed layer: an interaction that, combined with relatively fast aggregate settling speeds, may exclude fine 
lithogenics from accumulating within deep chlorophyll maxima beneath the mixed layer. These size-fractionation patterns demonstrate how biotic aggregation and disaggregation processes physically link surface lithogenic metal inputs and surface biotic communities and drive vertical lithogenic distribution patterns.

Lithogenic-biotic interactions were the basis for a one-dimensional, multibox model of lithogenic size-fractionated particle distributions. Using only external dust inputs, vertical sinking rates, and reasonable estimates biotic aggregation/disaggregation rates, we demonstrated model pTi profiles and sizefractionation that are similar to field data. Mixed-layer sensitivities to surface aggregation rates, the behavior of deep disaggregation-to-aggregation ratios, and lithogenic-inventory constraints on sinking speeds suggest that measurement and modeling of lithogenic particles may help constrain parameters that also affect carbon export terms. Time-varying inputs of dust fluxes into the model allows examination of water column particulate maxima propagations that are not possible with single time-point measurements, and which vary in intensity and amplitude depending on model parameters. Future quantification of actual water-column responses to time-varying dust forcing may thus allow indirect examination of bulk water column aggregation/disaggregation/sinking rates through fairly simple lithogenic particle measurements.

My final data chapter examined the bioavailability of particulate mineral forms of iron using the stable isotopic tracer ${ }^{57} \mathrm{Fe}$. We presented evidence for transfer of ${ }^{57} \mathrm{Fe}$ from amorphous ferrihydrite and crystalline fayalite into suspended particles in manners that suggest the importance of both abiotic (light-ligandmineral solubilization and continual Fe-recycling) and biotic (community uptake and solubilization) processes. We observed increased Chl production and ${ }^{57} \mathrm{Fe}$ transfer from ferrihydrite in all incubations and from fayalite in island-influenced biotic community, indicating that mineral forms of particulate iron are made bioavailable on a relatively short time-scale after addition. Therefore, in the many places where particulate Fe, ligands, and light are present in seawater, organisms may be using and accessing mineral iron. Our observation of strong lithogenic particle gradients beneath the euphotic zones across the North Atlantic (Chapter 3) 
and near the Crozet platform (Chapter 4) are both potential sites of such particulate solubilization and utilization. Our results indicate a more central role for mineral forms of particulate Fe as a source of bioavailable iron than previously thought. 